\title{
Social dilemmas and transportation decisions
}

\author{
Citation for published version (APA):
}

van Vugt, M. (1996). Social dilemmas and transportation decisions. [Doctoral Thesis, Maastricht University]. https://doi.org/10.26481/dis.19960216mv

Document status and date:

Published: 01/01/1996

DOI:

10.26481/dis. $19960216 \mathrm{mv}$

Document Version:

Publisher's PDF, also known as Version of record

\section{Please check the document version of this publication:}

- A submitted manuscript is the version of the article upon submission and before peer-review. There can be important differences between the submitted version and the official published version of record.

People interested in the research are advised to contact the author for the final version of the publication, or visit the DOI to the publisher's website.

- The final author version and the galley proof are versions of the publication after peer review.

- The final published version features the final layout of the paper including the volume, issue and page numbers.

Link to publication

\footnotetext{
General rights rights.

- You may freely distribute the URL identifying the publication in the public portal. please follow below link for the End User Agreement:

www.umlib.nl/taverne-license

Take down policy

If you believe that this document breaches copyright please contact us at:

repository@maastrichtuniversity.nl

providing details and we will investigate your claim.
}

Copyright and moral rights for the publications made accessible in the public portal are retained by the authors and/or other copyright owners and it is a condition of accessing publications that users recognise and abide by the legal requirements associated with these

- Users may download and print one copy of any publication from the public portal for the purpose of private study or research.

- You may not further distribute the material or use it for any profit-making activity or commercial gain

If the publication is distributed under the terms of Article $25 \mathrm{fa}$ of the Dutch Copyright Act, indicated by the "Taverne" license above, 
SOCIAL DILEMMAS

AND

TRANSPORTATION DECISIONS 


\section{SOCIAL DILEMMAS \\ AND \\ TRANSPORTATION DECISIONS}

\section{Proefschrift}

ter verkrijging van de graad van doctor aan de Rijksuniversiteit Limburg te Maastricht, op gezag van de Rector Magnificus, Prof. mr. M. J. Cohen, volgens het besluit van het College van Decanen, in het openbaar te verdedigen, op vrijdag 16 februari 1996 om 16.00 uur

door

Mark van Vugt

geboren te Amsterdam op 9 mei 1967 
Promotor:

Prof. dr. G. J. Kok

Co-promotores:

Dr. R. M. Meertens

Dr. P. A. M. van Lange (Vrije Universiteit Amsterdam)

Beoordelingscommissie:

Prof. dr. J. C. S. Kleinjans (voorzitter)

Prof. dr. W. B. G. Liebrand (Rijksuniversiteit Groningen)

Prof. dr. H. L. G. J. Merckelbach

Prof. dr. C. J. H. Midden (Technische Universiteit Eindhoven)

Prof. dr. A. van Witteloostuijn

Van Vugt, Mark

Social dilemmas and transportation decisions

ISBN: $08-54-32-57-43$

Printed by University of Southampton Design and Print Centre with a grant from the Dutch Railways [Nederlandse Spoorwegen]. 
to Leo and in memory of Corrie 


\section{Acknowledgements}

This booklet is the end product of my $\mathrm{PhD}$ project at the University of Limburg in the Netherlands, where I worked from September 1991 until September 1995 in the Department of Health Education. During this period many people have contributed in very different ways to the fulfilment of this rather unstructured task. Although their names are not listed on the cover page, it should be clear that without them this thesis could not have been written.

First, I would like to thank Ree Meertens and Paul van Lange for supervising the project. Their advice and ideas concerning the development, planning, and description of the studies were invaluable. Beyond these activities, I am particularly grateful to Ree for giving me the support and freedom to work out my own plans. As for my intellectual development and training in social psychology, I am greatly indebted to Paul who gave me productive lessons in "conceptualizing" my thinking and writing. Having two such supervisors, there was not much doubt about the successful completion of the project.

Second, I wish to thank Rob Ruiter for collaborating with me on the fourth experiment. I very much enjoyed working together and found his enthusiasm inspiring. Moreover, this experience made me aware of my personal role transition from being a student to becoming a teacher, which I found to be a rather pleasant change.

As with all scientific work, this research was embedded in an international network of colleagues exchanging ideas in regular conferences. The social dilemma and social value orientation conferences that $I$ attended were very helpful in discussing my research with more trained colleagues and formed the basis for my visits to the United States. Of the people I met there, I would especially like to thank Charles Samuelson for arranging my stay at Texas A \& M University, and Jeff Joireman for his precise, but kind, feedback on my English.

Financially, the project was made possible by the Dutch Ministry of Traffic \& Waterways, and several smaller grants from the Dutch Scientific Organization. These institutions are thanked for putting their trust in the enterprise and I hope their trust was justified.

How could a four year project be finished successfully without the social and emotional support of family and friends? Henk van der Molen, Hans Brug, and Thijs Lenderink were there for the midweek relaxation sessions, having diner and watching football on television in what could be described as an "ouwe jongens krentenbrood" ["brotherhood"] atmosphere.

Although we were together only at the weekends, Hannie van Hooff was my closest support throughout the thesis period. Together we shared the pains and pleasures of our separate and mutual projects.

I would like to dedicate this book to Leo and Corrie, because as long as I can remember they have been there to support and care for me, first as parents and later as friends. Although Corrie's death inevitably puts a dark shade over this project, by honoring this book to her I hope to make her loss a bit more bearable.

Southampton (UK), December 1995 


\section{Contents}

Chapter 1 Overview of dissertation

1.1 Analysis of commuting patterns

1.2 Theoretical approaches to analyze and modify commuting patterns

1.3 Social dilemma as research paradigm

$\begin{array}{ll}1.4 \text { Mechanisms and principles underlying cooperation in social dilemmas } & 10\end{array}$

1.5 A social dilemma approach to commuting decisions

1.6 Main assumptions, goals, and findings of the research

1.7 General discussion

Chapter 2 Transforming the commuting situation:

Dependence on car versus public transportation

2.1 Introduction

2.2 Method

2.3 Results

2.4 Discussion

Chapter 3 Transforming the commuting situation:

The influence of social value orientations

3.1 Introduction

3.2 Method 60

3.3 Results $\quad 65$

$\begin{array}{ll}3.4 \text { Discussion } & 70\end{array}$

Chapter 4 Self-interested and pro-social motives underlying commuting decisions

4.1 Introduction

$\begin{array}{ll}4.2 \text { Method } & 78\end{array}$

4.3 Results $\quad 82$

4.4 Discussion $\quad 88$

Chapter 5 Pro-social goals and expectations in the commuting situation

5.1 Introduction

$\begin{array}{ll}5.2 \text { Method } & 101\end{array}$

5.3 Results 106

$\begin{array}{ll}5.4 \text { Discussion } & 115\end{array}$

Chapter 6 Structural solutions in the commuting situation:

A field experiment on the first carpool lane in Europe

6.1 Introduction

6.2 Method

6.3 Results

6.4 Discussion 
Summary

Samenvatting

References

Appendices

Curriculum Vitae 


\section{Chapter 1 \\ Overview of Dissertation}

"A commitment to securing resources and opportunities for future generations ... is an appropriate way of expressing our belief that the society and culture that matter to us are important enough to survive into the future."

-- MacLean (1983, p. 194)

\subsection{Analysis of Commuting Patterns}

\section{Origins and consequences of excessive car use}

Arriving at the end of the twentieth century, the world is being challenged by numerous serious problems it has never faced before. One of the more critical and widespread concerns is the pollution and destruction of our natural environment, at both local and global scales. In recent years, scientists have come to realize that human activities are primarily responsible for these environmental changes, and that these problems can only be mastered by modifying the behavioral patterns of humans (Kempton, Darley, \& Stern; 1992; Stern, 1992). Systematic analyses of the behavioral origins of environmental problems reveal that many are related to transportation patterns, and primarily to excessive car use (e.g., Geller, Winett, \& Everett, 1982; Lowe, 1990; Stern, 1992). For example, at a global level cars account for more than 13 percent of the carbon dioxide emissions, the major source of the so-called green house effect (Lowe, 1990). More locally, in the Netherlands automobiles are held responsible for about $50 \%$ of the smog pollution, which is the main precursor to acid rain (i.e., the suspected cause of the poisoning of forests, lakes and streams). Moreover, along with the massive car fleet come problems related to space, waste, noise and odor annoyance, traffic safety and congestion (Cavalini, Hendrickx, \& Rooijers, 1993; Vlek \& Michon, 1992). It is expected that this situation will further deteriorate due to a world wide growth in automobile use -- for example, Dutch traffic experts have estimated that in 2010 the number of car kilometers in the Netherlands will have amplified with $70 \%$ compared to the present level, which will have devastating effects on the environmental quality and accessibility (Dutch Ministry of Traffic \& Waterways, 1990).

In light of these issues, many efforts have been undertaken, over the past two decades, to decrease private car use and increase alternative forms of transportation, such as public transportation, carpooling, and biking (for overviews, see Geller et al., 1982; Lowe, 1990; Newman \& Kenworthy, 1989). So far, however, these attempts that primarily consisted of educational campaigns and financial arrangements have not been very effective. It seems that, even under the current conditions, a vast majority of citizens are not very motivated to diminish their car 
use. Why may this be? Intuitively, two explanations may come to mind. It may be that in making transportation decisions, people evaluate the costs and benefits of various travel options, and conclude that, despite the negative effects of cars on the levels of environmental pollution and traffic congestion, it is much more profitable for them to travel by car than, for example, by public transportation or carpool. This explanation seems plausible in light of prior travel mode research, revealing that many of the more important travel concerns (e.g., flexibility, comfort, speed, and privacy) are perceived to be more strongly associated with cars than with other means of transportation (e.g., Flannelly \& McLeod, 1989; Van Vugt, Van Lange, Meertens, \& Joireman, 1995). Moreover, it may be that individuals do assign great importance to the environmental consequences of their car use, but are faced with many obstacles preventing them from abandoning their cars. Indeed, opinion surveys tell us that citizens are strongly concerned about the quality of the environment (Dunlap \& Scarce, 1991); however, this does not seem to be reflected in their preferences and decisions (Snyder, 1993). For example, car owners in the Netherlands hold moderately strong pro-environmental attitudes, and sincerely believe that car use should be decreased in light of future environmental problems. Yet, environmental awareness is only weakly, if all, related to the individual willingness to reduce car use (Doosje \& Siero, 1990).

What do these findings tell us about the origins of excessive car use, and possible ways to discourage it? First, they indicate that the structure of the decision situation encourages people to use their cars. That is, the individual decision-maker is much better served by choosing for the car, because the positive outcomes (e.g., flexibility, comfort, efficient travel time) accrue to him- or herself, whereas the negative outcomes (e.g., contributions to pollution of environment, traffic congestion) are shared by many other individuals. Yet, when many other people also decide to commute by car, the consequences in terms of pollution and congestion will be worse, so that most people would be much better off commuting by public transportation, thereby minimizing these problems. This situation, in which people are mutually dependent and the individual decision to follow his or her self-interest (i.e., to commute by car) yields a negative impact on the well-being of others represents a social dilemma (Dawes, 1980; Komorita \& Parks, 1994; Messick \& Brewer, 1983; for a formal definition, see paragraph 1.3). Second and related, these findings tell us that people may hold appropriate environmental beliefs and values, but that these may not be strong enough motivators to actually change behavior. Accordingly, to comprehend why people, in spite of the major collective problems associated with their behavior, are still not very motivated to diminish car use we have to better understand (a) the structure of interdependence underlying the commuting situation (i.e., the way people's commuting decisions affect their personal and others' outcomes), and (b) the various motivations and perceptions underlying individuals' commuting decisions. 


\section{Research overview}

The present dissertation extends and complements prior transportation research by examining the decision to commute by car versus public transportation or carpooling from a social dilemma viewpoint. Providing a conceptual framework consisting of interdependence theory (Kelley \& Thibaut, 1978; Rusbult \& Van Lange, in press) and insights derived from the extant social dilemma literature (for recent overviews, see e.g., Liebrand, Messick, \& Wilke, 1992; Komorita \& Parks, 1994; Schulz, Albers, \& Mueller, 1994), this approach assumes that commuting patterns are shaped by the individual construals and perceptions of the decision situation. It is further assumed that these construals will vary as a function of the salience of self-interest versus collective interest, which may be determined by (a) the features of the interdependence structure, and (b) the motivational forces stimulating people to pursue their self-interest or the collective interest.

Based on these assumptions, several studies will be reported regarding the influence of socio-demographic variables (i.e., personal dependence on car versus public transportation), interpersonal dispositions (i.e., social value orientations, trust), expectations about others' decisions, and the perceived collective consequences (i.e., environmental pollution and congestion) on attitudes, preferences, and decisions associated with car versus public transportation. The central focus of these studies is primarily on transportation decisions in the commuting context, while disregarding transportation decisions for recreational or business purposes, because commuting traffic forms the greatest contributor to levels of environmental pollution and traffic congestion (cf. Cavalini et al., 1993; Lowe, 1990). Moreover, at least in the Netherlands the commuting situation frequently proffers viable alternatives for the car, such as public transportation and carpooling, so that commuters have different options beyond commuting by car. The body of research presented in this dissertation consists of experiments, in which samples of daily commuters are faced with simulated commuting situations, containing information about the degree of environmental pollution and traffic congestion. Finally, a field-experiment is reported which examines commuters' reactions to a structural intervention in their personal commuting situation -- the implementation of the first carpool lane in Europe.

Before describing the social dilemma approach in greater detail, this overview chapter will provide a brief evaluation of traditional approaches to analyze and modify transportation patterns. This will be a starting point for the discussion of the main theoretical principles underlying a social dilemma approach to commuting decisions. Thereafter, the major research goals and empirical findings of the experiments will be discussed. The chapter will conclude with a general discussion of the reported findings, including some important theoretical and practical implications, and suggestions for future research. 


\subsection{Theoretical Approaches to Analyze and Modify Commuting Patterns}

\section{Prior models in transportation research}

A brief sketch of the transportation literature reveals that past efforts to modify commuting patterns have typically involved financial (e.g., monetary rewards), and educational strategies (e.g., small- and large-scale information campaigns), and were mostly related to the issue of energy conservation. These programs have been based on two different psychological models of human decision-making (cf. Costanzo, Archer, Aronson, \& Pettigrew, 1986). The first is the reinforcement model, which has its roots in reinforcement theory (Platt, 1973; Skinner, 1953), and is widely used in economy (e.g., Olson, 1965) and applied behavioral analysis (e.g., Geller et al., 1982). This approach assumes that individual commuters will change their transportation behavior if this serves their (economic) self-interest. Thus, people are willing to abandon their cars and start using alternative means of transportation, if car use is sufficiently punished and/or the use of alternative transportation means sufficiently rewarded. Interventions based on this approach have been, to some extent, successful in decreasing car use and promoting alternative travel modes. For example, in a systematic evaluation of various interventions in the domain of commuting traffic, Geller et al. (1982) report from 13 to 23 percent reductions in car mileage after providing monetary rewards.

The second approach to studying commuting decisions is the attitude model, which is derived from prior research and theorizing about the concept of attitudes. This approach has its origin in social psychology, and is based on the assumption that people's behaviors are, at least in part, shaped by their attitudes (i.e., evaluations of a set of aspects relevant to the behavioral options; e.g., theory of reasoned action, theory of planned behavior; Ajzen, 1987; Ajzen \& Fishbein, 1980). Following this approach, interventions that pursue to reduce car use should be aimed at producing less favorable attitudes towards cars and more favorable attitudes toward alternative travel modes. This approach has inspired the widespread use of strategies providing information about the negative consequences of excessive car use, primarily through large-scaled information campaigns. Although many of these campaigns have not been systematically evaluated, prior research has shown that such campaigns typically produce greater problem awareness and recognition, yet little or no behavioral effects (McGuire, 1985; Roberts \& Maccoby, 1985).

\section{New approach to understanding commuting decisions}

The present dissertation advances the social dilemma model as a complimentary approach to the study of commuting decisions. This approach is inspired by interdependence theory and prior research on social dilemmas. A social dilemma approach extends and complements traditional approaches by placing greater emphasis on the importance of the structure of the decision situation commuters are 
faced with. That is, it is more explicitly recognized that commuting decisions are made in a situation of interdependence, in which an individual commuter may negatively influence other commuters' outcomes (i.e., in terms of traffic congestion and environmental pollution). Accentuating the interdependent nature of the decision context may yield several advantages compared to traditional models that consider the individual commuter to be a relatively independent decision-maker.

First, the social dilemma approach may provide a better basis for understanding the relation between the individual commuter's own decision and his or her expectations about the decisions of other commuters. While the attitude model acknowledges that the attitudes and preferences of others may guide the individual decision by providing a social norm (Ajzen \& Fishbein, 1980), they are not assumed to directly affect the personal outcomes. Yet, in the commuting context, it is clear that if more people commute by car, the pollution and congestion effects will worsen, and this may negatively affect the well-being for all. As a result, the individual decision-maker -- even though he or she may be strongly environmentally concerned -- may not be very willing to contribute to a better environment, because his or her situation will not improve unless a substantial number of other people will contribute. Thus, the interdependence structure of the decision situation may help to understand why people, despite holding appropriate beliefs and values, may not be willing to act in an environment-preserving manner.

Second, by emphasizing the role of the interdependence structure underlying the commuting situation, the social dilemma approach may be better able to explain, relative to the reinforcement model, why people sometimes deviate from their "rational self-interest" in deciding for a certain travel option. As noted by Edney $(1980$, p. 134) in his extensive review of prior theorizing about social dilemmas:

"[In reinforcement theory] little or no weight is given to individual's feelings, interpretations, or cognitive processes beyond cost-benefit judgments. It also assumes that all individuals are basically alike taking little account of variables like personality, social orientation, or responsibility and therefore tends to assume that all people behave predictably in response to the same rewards and costs. The theory also avoids dealing with concepts like conscience, and it similarly circumvents questions of altruism and ethics."

Unlike the assumption of reinforcement model that people mostly follow their immediate self-interest, the social dilemma approach proposes that individual preferences and decisions are frequently shaped by broader motivations, such as their considerations about issues of fairness and justice, and their willingness to set an "example" to other people. While these considerations may be found, to some extent, in all people, the social dilemma model also acknowledges that there may be important personality differences in the orientation toward self-interest or collective interest (e.g., social value orientation; Messick \& McClintock, 1968). Perhaps, these factors may help to understand such issues as why some commuters are -- 
whereas others are not -- willing to leave their car at home during a heavy smog phase, why some people commute by public transportation, despite the fact that it is much quicker to take their car, and why a majority of people are willing to pay more than $\$ 100$ per year for toxic waste clean-up (Kempton et al., 1992).

Finally, by accentuating the importance of the interdependence structure the emphasis in attempts to reduce car use is shifted from individually-based solutions (e.g., providing monetary incentives, educational campaigns) to structurally-based solutions -- strategies that alter the interdependence structure between individuals (cf. Messick \& Brewer, 1983; Rusbult \& Van Lange, in press). Structural solutions to transportation patterns may either restrict or eliminate the individual freedom to choose, by (a) developing laws and regulations (e.g., Clean Air Act, eco-taxes), or (b) providing physical arrangements (e.g., closing inner cities for car traffic). Moreover, they may be aimed at increasing the interdependence between individuals by (c) decentralizing the authority for handling the problems related to car use (e.g., providing companies with greater responsibility for developing car-reducing strategies). Although structural strategies may be sometimes experienced as too drastic, inefficient, or infringing on the individual freedom (cf. Samuelson, 1993), their implementation may enforce changes in commuting patterns among large numbers of people who would not be so eager to commute by public transportation on a voluntary basis (cf. Rusbult \& Van Lange, in press).

\subsection{Social Dilemma as Research Paradigm}

\section{Definition of social dilemma}

In a social dilemma each individual decision-maker has generally two choice options, one serving his or her self-interest (i.e., the noncooperative option), and the other serving the collective interest (i.e., the cooperative option). The personal outcomes associated with these options can be framed as "internalities", the outcomes for others "externalities", and these outcomes may either be positive or negative. Accordingly, positive internalities represent beneficial outcomes for the individual, whereas positive externalities represent beneficial outcomes for others. Likewise, the negative internalities and externalities can be described. A social dilemma is formally defined as a situation, in which (a) the individual decision to noncooperate yields negative externalities for all; (b) there is at least one configuration of outcomes, in which a noncooperative decision provides greater positive internalities than a cooperative decision; and (c) the absolute sum of negative externalities is greater than the sum of positive internalities; the latter indicates that the outcomes of both the noncooperative and cooperative decision decline the more people choose to noncooperate, until a level is reached at which cooperation by most individuals provides better outcomes than noncooperation by most individuals (Liebrand \& Van Lange, 1989). 
A classic example of a social dilemma is provided by Hardin (1968) in his analysis of the "Tragedy of the Commons." The parable describes a situation in which a number of herdsmen graze their herds of sheep on a common pasturage. Each herdsman is aware that it yields greater positive internalities to increase the size of his herd, because this provides him with more wool and meat. Yet, in doing so there are negative externalities for all herdsmen, because of the damage done to the common pasturage. Because the positive outcomes accrue to the individual herdsman, whereas the negative outcomes are shared by all, it is most beneficial for each herdsmen to increase the herd, and as this happens, the quality of the commons deteriorate. The capacity of the commons is exceeded and as this process continues -- which is likely to happen, because no individual herdsman would find it attractive to unilaterally decrease his herd size -- the commons will collapse and the herds will be destroyed. Accordingly, each herdsman would ultimately be much better off if most or all herdsmen had decided to cooperate by moderating their herds.

The particular form of interdependence described by this parable relates to a wide range of smaller and larger social conflicts in society, including company strikes, overpopulation, voting for elections, tax evasion, environmental pollution, and traffic congestion (e.g., Hamburger, 1979; Komorita \& Parks; 1994). For example, and relevant to the present dissertation, the decision to commute by car (i.e., the presumed non-cooperative option) generally provides greater positive internalities in terms of flexibility, comfort, and privacy than the decision to commute by public transportation (i.e., the presumed cooperative option). Yet, each commuter by car yields negative externalities to all people, because their car use adds to environmental pollution and traffic congestion. Moreover, the more people decide to commute by car the lower the internalities of both car and public transportation, and if many people decide to commute by car, then they are (ultimately) worse off at the aggregate level than if all or most succeed in commuting by public transportation, which minimizes the levels of environmental pollution and traffic congestion (formally, the sum of externalities is, in absolute terms, greater than the sum of internalities).

\section{Brief history of social dilemma research: Contribution and criticism}

Social dilemmas have been studied extensively for more than five decades, starting with the pioneering work of Von Neumann and Morgenstern (1947) on game theory. These scientists were primarily interested in finding rational solutions for a variety of "games" that represented economic transactions between individuals; their concern was not so much to describe how individuals would actually behave in these games or dilemmas (e.g., when will people shift to cooperation?). In the sixties and seventies this research gap was filled by social scientists in various disciplines (e.g., psychologists, sociologists, political scientists, and economists), who produced an impressive number of experiments on the determinants of cooperative behavior (for recent reviews, see e.g., Komorita \& Parks, 1994; Van 
Lange, Liebrand, Messick, \& Wilke, 1992). These studies primarily focused on one game type, the two-person Prisoner's Dilemma Game', and revealed a number of situational, and (inter)personal factors systematically associated with cooperation in these dyadic settings. Despite their contributions to the body of knowledge about social dilemmas, some serious doubts have been raised about the theoretical basis and external validity of these studies (Nemeth, 1972; Pruitt \& Kimmel, 1977). First, it seemed that a great deal of the research was not so much driven by theories, but by the ease with which various factors could be examined in experimental settings. As noted by Komorita \& Parks (1994, p. 32):

"One of the first experimental studies of the Prisoner's Dilemma Game was conducted by Morton Deutsch in 1958, and for the next ten to fifteen years an enormous number of PDG studies were conducted by a variety of social scientists. However, there was surprisingly little theoretical progress to explain cooperative behavior during this period."

Thus, the congregation of published studies had not accumulated in a strong theoretical framework from which testable hypotheses about the origins of cooperation could be derived. Second, because these studies primarily used rather abstract experimental games as research settings, they were blamed for an insufficient concern with the generalizability of their results to real-life problems (i.e., the issue of ecological validity). In light of these criticisms, Pruitt and Kimmel (1977, p. 370) formulated a prescription for future social dilemma research, namely:

\section{"theory building in the context of a concern about real-life applications."}

Two decades after these authors' critical review, social dilemma researchers have definitely made some progress in increasing the construct and ecological validity of their findings. Regarding the first issue, prior work has identified some general factors that have been shown to promote cooperation in various kinds of social dilemmas (i.e., two-person, multi-person situations), including (a) variations in monetary pay-off structure, (b) group size, (c) communication, (d) expectations about others' cooperation, and (e) individual difference variables (cf. Van Lange et al., 1992). Moreover, research findings have been more strongly embedded in theories about cooperation and interdependence, most notably interdependence

'The Prisoner's Dilemma refers to a story about two prisoners accused of being partners in crime. Each prisoner is approached separately by the district attorney with the proposal to testify against his partner. As a result, he will be free and the other will get a long-term sentence. Yet, if both testify against each other (i.e., the non-cooperative option), they will both suffer an intermediate sentence, and if no one testifies (i.e., the cooperative option) both will receive a short sentence. Thus, in more formal terms, the internalities (i.e., reducing own prison sentence) are in conflict with the externalities (i.e., increasing other's sentence). 
theory (Kelley \& Thibaut, 1978), goal/expectation hypothesis (Pruitt \& Kimmel, 1977), and -- the extended version -- the structural goal/expectation theory (Yamagishi, 1986). By softening the assumption that people are always pursuing their rational self-interest, these theories were better able to explain the development of cooperation than original social dilemmas theories (e.g., game theory, rational choice theory; cf. Luce \& Raiffa, 1957; Olson, 1965; Von Neumann \& Morgenstern, 1947). However, it should be noted that, despite their analytical power, it is yet unclear whether these theories have considerable explanatory power (i.e., are the predictions derived from these theories correct?).

Regarding the second issue, the lack of external validity, it is pleasing to note that contemporary researchers have shown greater interest in applying their findings to real-life social dilemmas. The ecological validity of social dilemma research has been enhanced by studying the emergence of cooperation (a) in larger groups than the original dyads (e.g., Dawes, McTavish, \& Shaklee, 1977; Liebrand, 1984; Yamagishi, 1986), (b) in different types of dilemma structures, besides the prisoner's dilemma game (e.g., chicken, trust and volunteer's dilemma; Diekmann, 1985; Liebrand, 1983; Liebrand, Wilke, Vogel, \& Wolters, 1986), (c) in various presentations of the same dilemma (public good or "give some" dilemmas vs. resource or "take some" dilemmas; e.g., Kerr, 1989; Messick, Wilke, Brewer, Kramer, Zemke, \& Lui, 1983; Samuelson, 1993), (d) in multi-trial versus singletrial dilemmas (e.g., Liebrand, 1984), (e) asymmetric versus symmetric dilemmas (Van Dijk \& Wilke, 1993, 1995), and, finally, (f) in intergroup versus one group settings (e.g., Bornstein, 1992; Insko, Schopler, Hoyle, Dardis, \& Graetz, 1990). Moreover, some researchers have used experimental laboratory games with a central focus on a particular real-life problem (e.g., energy saving; environmental pollution; e.g., Jerdee \& Rosen, 1974; Stern, 1976; Kramer, McClintock, \& Messick, 1986). Finally, some have systematically compared strategies promoting cooperation in experimental games with cooperative strategies used in field settings (e.g., energy conservation, organizational behavior; Rutte, 1990; Samuelson, 1990; for more examples, see Volume 5 of Social Behaviour, 1990). However, it should be noted that one of the major challenges of social dilemma research, that is, to study social dilemmas as they are functioning in the real world (cf. Komorita \& Parks, 1994), has not yet been realized (for an exception, see Erev, Bornstein, \& Galili, 1993).

The present dissertation extends and complements prior social dilemma research in two important ways. First and foremost, the current research focuses on attitudes and decisions in a large-scale social dilemma existing in real-life, the decision to commute by car or public transportation (carpooling). This makes it possible to examine whether the mechanisms underlying cooperation in small-scale laboratory studies are also relevant in pervasive real-world dilemmas with infinite numbers of people. Second, the research has a strong basis in interdependence theory (Kelley \& Thibaut, 1978), a theory that is originally developed for analyzing and explaining cooperation in dyadic interpersonal relationships. Hence, this dissertation will extend traditional social dilemma research on dyads by examining 
the emergence of cooperation in larger groups. Thus, by providing a social dilemma approach to commuting decisions, the current work attempts to strengthen both the practical and theoretical basis of prior social dilemma research.

\subsection{Mechanisms and Principles Underlying Cooperation in Social Dilemmas}

\section{Rational self-interest and cooperation}

Traditionally, the main assumption underlying game theory constitutes rational selfinterest, arguing that people in interdependent settings will tend to maximize their personal outcomes (Luce \& Raiffa, 1957; Olson, 1965). Accordingly, in situations, such as social dilemmas, where the individual interests are partly conflicting, mutual cooperation is very difficult to achieve. Yet, numerous studies have demonstrated the emergence of cooperation under various circumstances, and game theory was not really able to account for these findings (cf. Hamburger, 1979). For example, cooperation is systematically promoted, when the personal costs and the collective benefits of cooperation are greater, the group is smaller, communication is allowed, and group identity is enhanced (for overviews, see Komorita \& Parks, 1994; Messick \& Brewer, 1983; Van Lange et al., 1992). This rather incomplete list of factors is relevant to understanding the main situational variables affecting cooperation in social dilemmas. However, what it does not address is whether these factors, in combination, may produce greater (or weaker) cooperation than each factor separately (i.e., interaction effects). Indeed, social dilemma researchers have recently advocated the development of theories to studying the combined effect of factors promoting cooperation in (real-life) social dilemmas (e.g., Liebrand, 1992; Samuelson, 1990). Moreover, although reviews of social dilemma research have made some theoretical progress in identifying and classifying real-world social dilemmas (i.e., on the basis of their temporal and spatial properties; cf. Messick \& Brewer, 1983; Vlek \& Keren, 1992), a comprehensive taxonomy is lacking so far. Finally, reviews of prior research do not really speak to the perceptual and motivational processes by which people may relinquish their immediate self-interest for the benefit of others.

\section{Interdependence theory: A brief overview}

A theory that may be relevant to analyzing the fundamental properties of interdependence and the development of cooperation in social dilemmas is interdependence theory (e.g., Kelley \& Thibaut, 1978; Rusbult \& Van Lange, in press). Interdependence theory, which has its origins in field theory (Lewin, 1948) and theories of social exchange (Homans, 1961; Thibaut \& Kelley, 1959), stands as the most comprehensive theoretical framework for understanding how interdependent people may influence each others' preferences, behaviors, and 
outcomes. The options and outcomes of interdependence patterns between individuals are formally represented in an outcome matrix, which is:

"...simply a rich and efficient conceptual tool for identifying and formally representing the essential features of interaction phenomenon" (Rusbult \& Van Lange, in press; pp. 7-8).

In its simplest form, the outcomes are depicted in a $2 \times 2$ matrix, in which there are two people and two options (e.g., the noncooperative and cooperative option). Each of the four cells in this matrix represents the joint occurrence of the respective decisions and the associated outcomes for both individuals. Relevant to our research, the $2 \times 2$ matrix presentation does also describe interdependence patterns with larger numbers of people (i.e., social dilemmas) by drawing a distinction between the individual and the collective outcomes. That is, the collective outcome is viewed as the product of the preferences and behaviors of all individuals (cf. Hamburger, 1979; Rusbult \& Van Lange, in press).

What does interdependence theory contribute to our understanding of social dilemmas? First, interdependence theory yields a logical analysis of $2 \times 2$ outcome matrices, in which the total domain of interdependence patterns, including social dilemmas, can be described and distinguished on the basis of differences in four fundamental properties of interdependence: (a) degree of dependence (e.g., what is the impact of an individual decision on the collective outcome?), (b) mutuality of dependence (e.g., does each individual's cooperative decision contributes equally to the collective outcome?), (c) correspondence of outcomes (e.g., is there correspondence or conflict between own and others' outcomes?), and (d) basis for dependence (e.g., is there a coordination or exchange problem?).

These properties are relevant to differentiating social dilemmas from other kinds of interdependence structures. Conceptualized in terms of interdependence theory, a social dilemma is a situation in which actors are, at least to some extent, mutually dependent and their outcomes are moderately correspondent (i.e., in purely cooperative situations outcomes are highly correspondent, whereas in purely competitive situations they are highly noncorrespondent; cf. Liebrand, 1992). Yet, the relative values and strengths of these components determine the precise nature of the dilemma. For example, in large-scale dilemmas the degree of dependence between individuals is generally lower, and this may negatively affect the occurrence of cooperation, because people may realistically believe that their contribution to maintaining the collective resource is futile ("personal efficacy"; Kerr, 1989). As another example, the basis of dependence in small task groups may be better described by coordination (i.e., temporal organization of different work activities) or by exchange (i.e., division of same work activities).

A second important contribution of interdependence theory is that it assumes that people's decisions in interdependence settings are not simply shaped by their immediate self-interest, but also by their broader motives and goals. Using the 
outcome matrix as a conceptual tool, interdependence theory draws a distinction between given matrix preferences, reflecting people's immediate self-interested concerns, and effective matrix preferences, which is a redefined set of preferences, reflecting people's broader concerns, such as their long-term goals, strategic considerations, and considerations for others' well-being. The psychological process, in which people relinquish their direct self-interest to respond to the broader issues of interdependence is called transformation of motivation. As an example, an environmentalist may behave in ways that yield relatively poor personal outcomes (e.g., riding a bike, separating household garbage, and saving household energy), but by doing so he or she promotes the (ultimate) well-being of society. As another example, a soccer-player may forego his immediate self-interest by correcting the mistakes of a team-mate, because this may yield desirable outcomes in the near future (i.e., to win the match).

On a conceptual level, Kelley and Thibaut (1978) distinguish between three types of transformations, (a) transpositional transformations, whereby individuals use temporal rules to coordinate their actions and those of others (e.g., to get up before or after your partner to organize morning activities), (b) sequential transformations, whereby individuals adopt strategies that prescribe successive choices over a course of interactions (e.g., behavioral strategies like Tit-for-Tat or Win-Stay Loose-Change; Messick \& Liebrand, 1995), and (c) outcome transformations, whereby individuals take into account both their own outcomes and those of others (e.g., pro-environmental decisions). Whereas the first and second types of transformations are most relevant for describing interdependence patterns between two individuals (e.g., intimate relationships), the latter type of transformations are relevant to a much broader domain of interdependence situations, including large-scale problems, such as environmental pollution and traffic congestion. Accordingly, we will further focus on these latter type of transformations.

What are the basic motivational factors that may help to understand why people forego their immediate self-interest and cooperate in social dilemmas? Among other factors, people may transform the situation into a pro-social one on the basis of prevailing social norms, perceptual processes, and individual differences in interpersonal orientations. For example, there is evidence that pro-social transformations are instigated by norms of justice and fairness (i.e., adoption of equity or equality rules; e.g., Van Dijk \& Wilke, 1993, 1995). Moreover, pro-social concerns are elicited by perceptions about the presumed cooperative intentions of others (e.g., Dawes et al., 1977), the relevance of one's contribution (e.g., Kerr, 1989), the way outcomes are framed (i.e., as gains or losses; cf. Kahneman \& Tversky, 1979), and the extent to which the collective consequences are uncertain (Suleiman \& Rapoport, 1989; Wit \& Wilke, 1995).

While these factors may enhance pro-social behaviors among all individuals to some extent, there are also important personality differences in the ways individuals evaluate and deal with social dilemmas, and these are particularly 
important to the research presented in this dissertation. The extant literature on outcome transformations concentrates on one such interpersonal disposition, socalled social value orientations (i.e., the ways individuals evaluate their personal and others' outcomes; Kuhlman \& Marshello, 1975; Messick \& McClintock, 1968). Prior social dilemma research has provided evidence in support of at least three orientations (e.g., Kuhlman \& Marshello, 1975; Messick \& McClintock, 1968; McClintock \& Liebrand, 1988): cooperation (i.e., tendency to maximize joint welfare), individualism (i.e. tendency to maximize own welfare, regardless of others' welfare), and competition (i.e., tendency to maximize relative advantage of own versus others' welfare). These orientations have been found to systematically affect decisions in social dilemmas, with cooperators or "pro-social" individuals exhibiting greater cooperation than "pro-self" individuals -- competitors and individualists combined (e.g., Kramer et al., 1986; Van Lange \& Liebrand, 1991). Moreover, these social value orientations also shape cognitive processes in that competitive people perceive interdependent situations and interdependent others as more competitive than do noncompetitive people (e.g., Kelley \& Stahelski, 1970; Van Lange \& Kuhlman, 1994). In addition, there may be other dispositions relevant to understanding outcome transformations, such as individual differences in interpersonal orientation (Swap \& Rubin, 1983), and trust (Yamagishi, 1986).

\subsection{A Social Dilemma Approach to Commuting Decisions}

\section{Transformations of the commuting situation}

What transformations do commuters make of the commuting situation and what are the properties of interdependence underlying the perceived interdependence structure (i.e., effective matrix)? Consistent with many other scientists (e.g., Hamburger, 1979; Hardin, 1968; Liebrand, 1983; Orbell \& Dawes, 1981; Stern, 1992), from the perspective of environmental pollution, the decision to commute by car or public transportation can be described as a pervasive social dilemma. However, such a sketchy analysis is a bit troublesome. As noted by various social dilemma researchers, it is important to keep in mind that the application of an interdependence structure to a real-life problem is appropriate to the extent that it describes the problem accurately:

"... anything that is said about a game in the abstract can be considered as possible relevant to a real-world situation insofar as the game properly abstracts the situation" (Hamburger, 1979; p. 83).

In this light, it may be problematic to a priori conceptualize the commuting situation as a social dilemma, first, because their is often disagreement about what interdependence structure accurately describes the situation. For example, over the past decades the Arms Race between the US and Soviet Union has been described 
in terms of different kinds of dilemma structures (e.g., as prisoner's, chicken, and security dilemma; cf. Komorita \& Parks, 1994). Second, based on interdependence theory there are strong theoretical grounds to assume that actors may transform the same decision situation in fundamentally different ways. Thus, for a proper analysis of the commuting situation, we need to examine more carefully how commuters may transform the decision situation, and what the fundamental characteristics of the perceived interdependence structure are.

One of the main assumptions underlying interdependence theory is that people respond to an interdependent situation, not only on the basis of their immediate self-interest (i.e., given matrix preferences) but also on the basis of their broader motivations (i.e., effective matrix preferences). It is further assumed that the ultimate preferences may be shaped on the basis of how people evaluate their own and others' outcomes (i.e., outcome transformations). Accordingly, it is proposed that the decision to commute by car or public transportation is not only shaped by "primitive" individual concerns, such as convenience, comfort, and flexibility, but also by broader concerns, such as the consequences for the environment. Moreover, because these problems are created by the behaviors of many interdependent others, it is assumed that different transformations of the commuting situation will be importantly affected by expectations about what travel mode most other commuters will choose.

For example, commuters who are concerned with the issue of environmental pollution, but would still prefer to use their car for reasons of convenience, may have the following four preferences in the commuting situation. They may prefer best the situation in which they themselves commute by car, whereas most others commute by public transportation. In this situation, they can follow their selfinterest, while the collective well-being (i.e., a clean and healthy environment) is preserved by others. Their close-to-best preference is perhaps the situation in which all people (including themselves) commute by public transportation, and environmental problems are minimized. Third, a weaker preference may be exhibited for the situation in which all people would commute by car. An individual can follow his or her most favorite travel option, but the ultimate environmental consequences are disastrous. Yet, they might prefer that situation better than the one in which they commute by public transportation, and contribute to a better environment, whereas most others commute by car and pollute the environment (i.e., the "sucker's" pay-off).

The perceived interdependence structure underlying an environmental interpretation shows similarities to the $N$-person Prisoner's Dilemma (Dawes, 1980; Messick \& Brewer, 1983). This interdependence structure is described by the property that each individual prefers the noncooperative option (i.e., commuting by car) above the cooperative option (i.e., commuting by public transportation). Yet, if all or most people decide to noncooperate, they are all worse off than if all or most decide to cooperate (see Hardin's [1968] story of the "Tragedy of the Commons"). Below, the set of preferences for the individual commuter, transforming the 
situation into an environmental problem, is presented in a $2 \times 2$ outcome matrix. The ranking of these preferences for the individual commuter reflects the structure of an N-person Prisoner's Dilemma (cf. Kelley \& Thibaut, 1978; Liebrand, 1983).

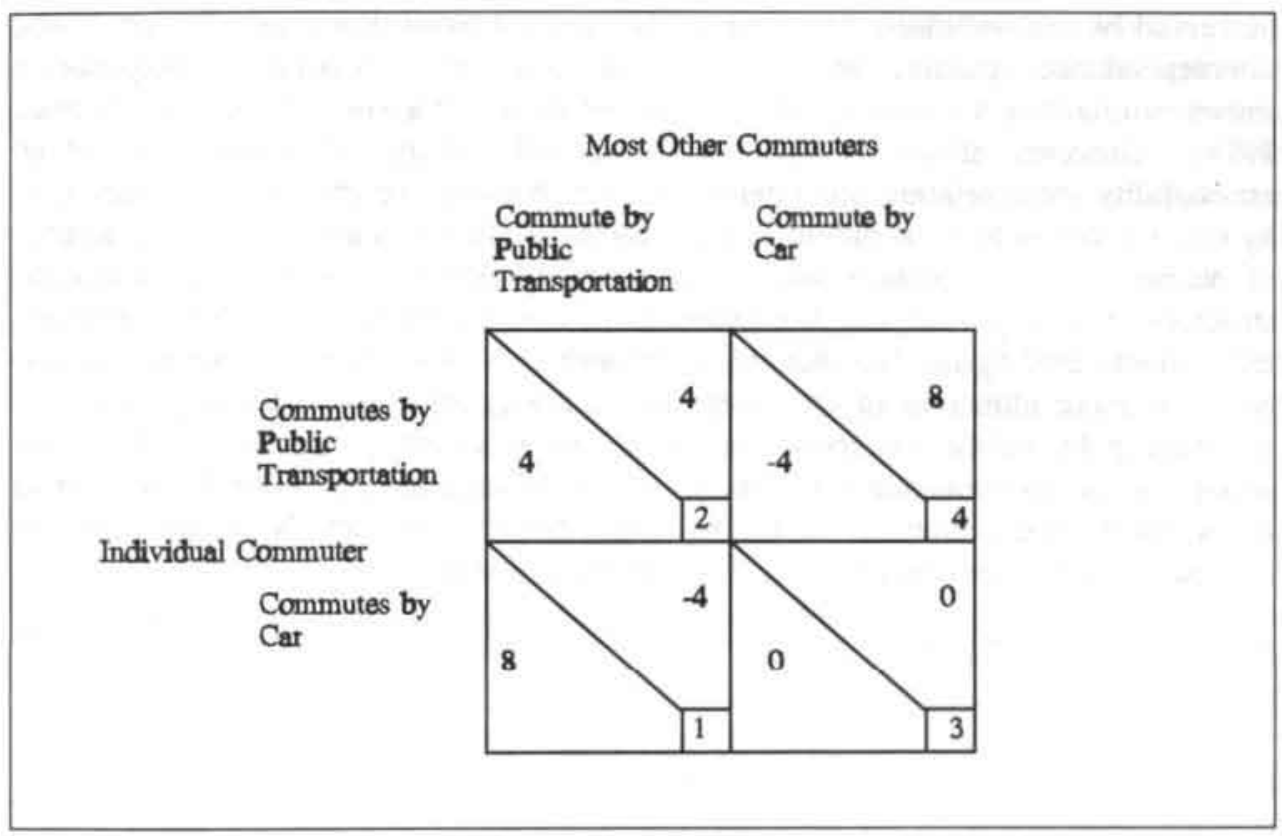

Figure 1. Individual preferences in the commuting situation interpreted as an environmental problem with the structure of an $\mathrm{N}$-person Prisoner's Dilemma.

Note. The number within the little squares reflects the preference ranking for the individual commuter, with 1 (= strongest preference) and 4 (= weakest preference).

As a second example, commuters may be particularly concerned with issues, such as the efficiency and travel time of the commuting options. From this point of view, commuters may have the following four preferences. First, they may prefer most the situation in which they commute by car, whereas most others commute by public transportation, because there will be no traffic congestion on their route. Second, they may exhibit their close-to-best preference for a situation in which they commute by public transportation when others commute by car, so as to avoid traffic congestion. Third, they may exhibit a weaker preference for the situation in which they themselves, and most others commute by public transportation. The weakest preference may be for the situation in which all commute by car, and 
congestion problems are most severe so that each commuter will suffer from serious time delays.

Thus, the commuter who focuses on expected congestion problems, may perceive an interdependence structure that is fundamentally different from the one perceived by the commuter who focuses on environmental problems. The perceived interdependence structure underlying a congestion or accessibility interpretation shows similarities to the $N$-person Battle of Sexes Dilemma (Kelley \& Thibaut, 1978). However, if we assume that the second and third best-preference of an accessibility interpretation are interchangeable, because, relative to the travel time by car, the travel time of public transportation is much less affected by the number of people using this option, the perceived interdependence structure parallels the structure of an $\mathrm{N}$-person Chicken Dilemma (Liebrand, 1983). Both these structures are characterized by the fact that the noncooperative option (i.e., commuting by car) becomes more attractive to the extent that more people choose to cooperate (i.e., commuting by public transportation), and less attractive to the extent that more people choose to noncooperate. The set of individual preferences consistent with an accessibility interpretation (reflecting the structure of an N-person Chicken Dilemma) is presented below in a $2 \times 2$ outcome matrix.

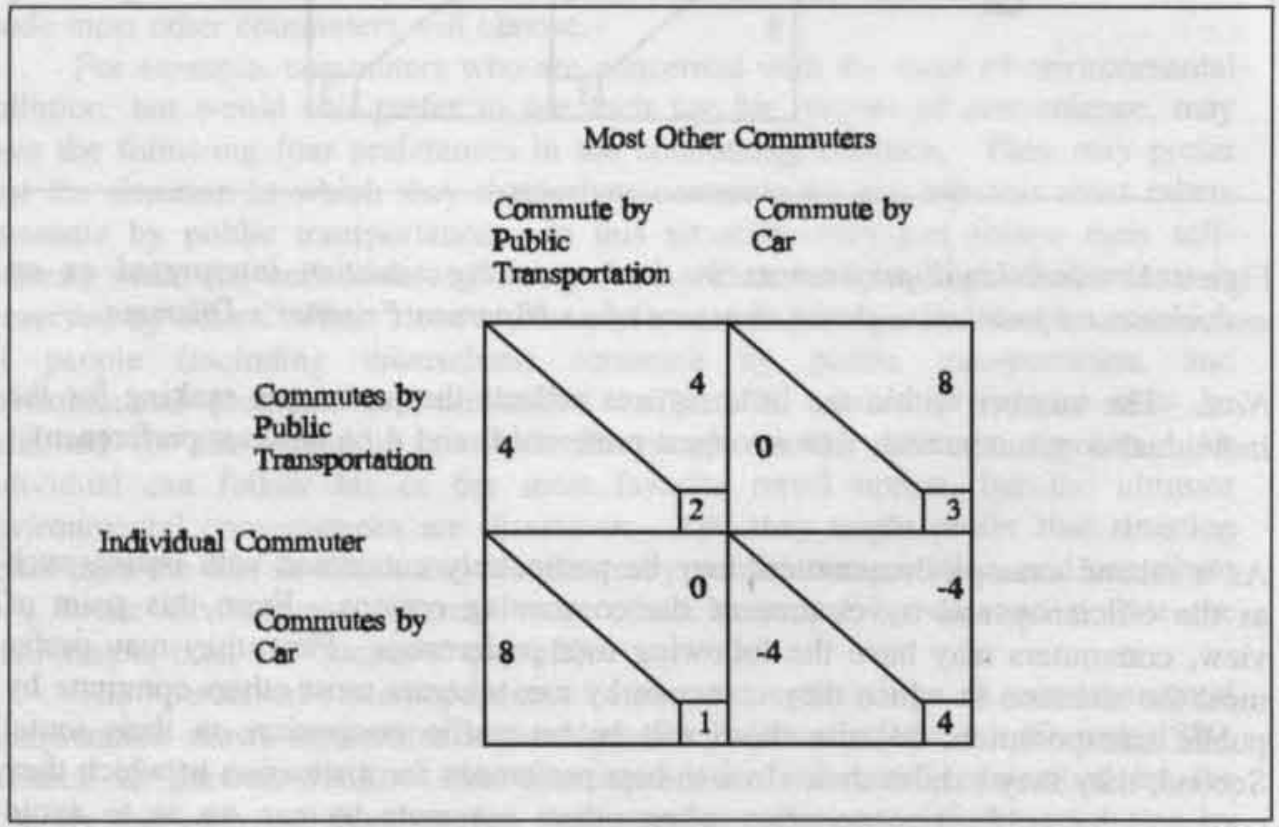

Figure 2. Individual preferences in the commuting situation interpreted as an accessibility problem with the structure of an $\mathrm{N}$-person Chicken Dilemma.

Note. The number within the little squares reflects the preference ranking for the individual commuter, with 1 (= strongest preference) and 4 (= weakest preference). 


\section{Differences in properties of the interdependence structure}

What are the main differences between the interdependence structures of an environmental and accessibility interpretation of the commuting situation? Conceptualized in terms of interdependence theory, these interdependence structures are, first, characterized by differences in degree of dependence. Viewing the commuting situation as a trade-off between convenience and environment, the individual commuter should feel relatively independent from other commuters, because their convenience is not likely to be affected by other commuters, while their contribution to environmental problem is negligible. However, focusing on the problem of traffic congestion commuters are more likely to feel interdependent, because the outcomes in terms of travel time are more strongly affected by others' decisions.

Second, in deciding to commute by car or public transportation commuters are, at first glance, mutually dependent, because by deciding to commute by car they have an equal impact on each others' outcomes in terms of pollution and congestion. Yet, a closer look reveals that when focusing on the issue of environmental pollution, there is, at least, some asymmetry in dependence in that commuters may affect the outcomes of people outside the commuting situation who may suffer from the negative side-effects of excessive car use (e.g., smog pollution, getting involved in traffic accidents). This nonmutuality has some interesting societal implications, in that, for reasons of fairness, car owners are expected to contribute relatively more to the well-being of others and society (through higher taxes, and fines) than, for example, bike owners (cf. Wit, Wilke, \& Oppewal, 1992).

Third, the outcomes of the individual commuter are at intermediate levels of correspondence in both the environmental and accessibility interpretation. That is, even though there is a personal incentive to commute by car for each individual, there is also an incentive to commute by public transportation, so as to avoid traffic congestion, but also to avoid heavy pollution. Thus, the interests of commuters are partly in conflict - in the sense that each would prefer to take the car - but also partly overlapping - in the sense that nobody would prefer a situation in which all commuters take their car. This makes the decision to commute by car or public transportation not always obvious, because it is relatively ambiguous with respect to what decision is most appropriate (cf. Liebrand, 1992).

Finally, the basis for dependence (i.e., whether people must coordinate or exchange their decisions?) importantly differs between the interdependence structures of an environmental or accessibility problem. Focusing on the problem of environmental pollution the situation can be described as a problem with high levels of "fate control" (cf. Kelley \& Thibaut, 1978), in which people's well-being is directly affected and threatened by others' decisions. Thus, solutions to this problem require an "exchange" of outcomes, in that all people should give up some of their self-interest for a better environment. In contrast, focusing on the problem of traffic congestion, the situation is characterized by high levels of "behavioral control" (cf. Kelley \& Thibaut, 1978). That is, the commuting population should 
attempt to coordinate their behaviors so as to seek for the optimal level of cars to drive on the route without creating traffic jams, or, the optimal number and distribution of passengers in trains or buses, so as to provide everyone with a seat.

\section{Other possible transformations of the commuting situation}

These are two relevant examples of how people may interpret the commuting situation -- as environmental or accessibility problem. However, in reality, the perceived interdependence structure may be more ambiguous (e.g., people may interpret the situation as a combination of these problems), or related to a totally different set of problems. For example, in the United States many people commute by car, although some or most people would rather prefer to commute by bike (Stern, 1992). However, because there are, compared to the situation in the Netherlands, fewer structural arrangements for bikers (e.g., separate bike lanes), people may feel unsafe commuting by bike, particularly when they expect many to commute by car. This may lead to a situation in which most continue commuting by car, where they might rather prefer to commute by bike. This safety interpretation of the commuting situation shows similarities to the structure of an $\mathrm{N}$ person Trust Dilemma (Liebrand, 1983). This structure is characterized by the fact that individuals are much better off if all or most cooperate (i.e., to commute by bike) than noncooperate (i.e., to commute by car). Yet, the more people choose to noncooperate, the less attractive it is for the individual to cooperate. Below, the outcome matrix of a safety interpretation with a structure similar to an $\mathrm{N}$-person Trust Dilemma is depicted in a $2 \times 2$ matrix.

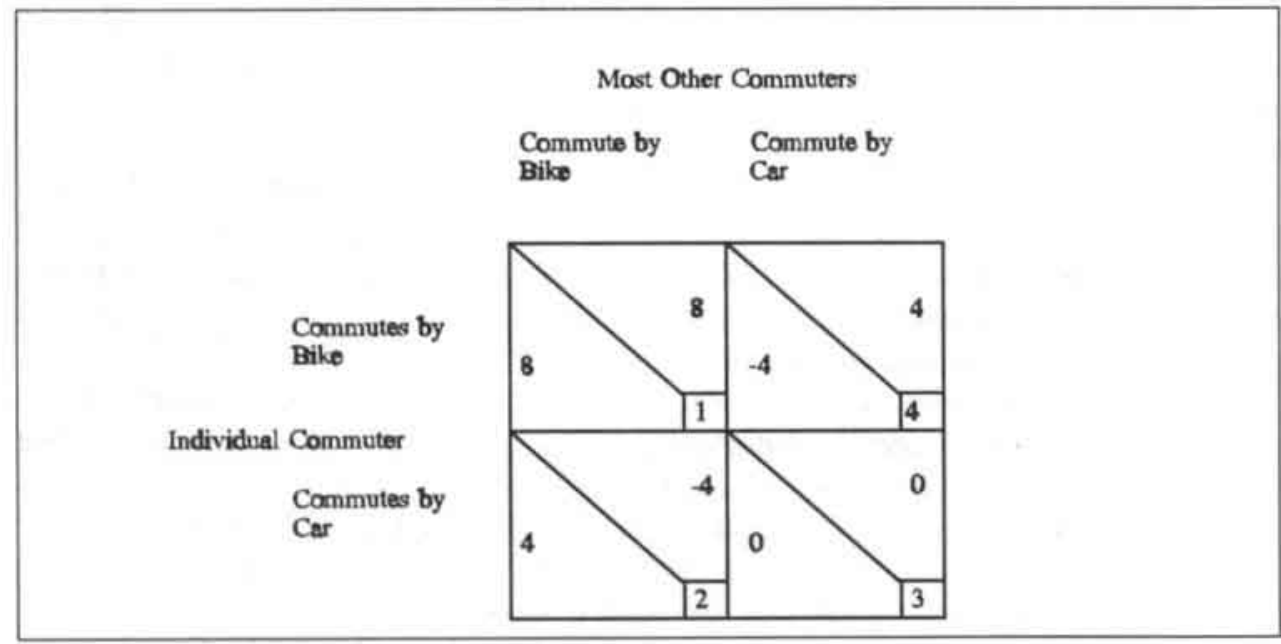

Figure 3. Individual preferences in the commuting situation interpreted as a safety problem with the structure of an $N$-person Trust Dilemma.

Note. The number within the little squares reflects the preference ranking for the individual commuter, with 1 (= strongest preference) and 4 (= weakest preference). 


\subsection{Main Assumptions, Goals, and Findings of the Research}

\section{Introduction to research}

Following a social dilemma approach, the main assumption of the dissertation is that the decision to commute by car or public transportation is shaped by (a) the properties of the interdependence structure underlying the commuting situation (i.e., social dilemma features), and (b) the different transformations people make of it (i.e., interpretations as environmental or accessibility problem). These transformations may be instigated by various socio-demographic and interpersonal variables, which determine the salience of self-interest versus collective interest. Furthermore, it is assumed that these different transformations will come about through the individual expectations about the decisions of interdependent others, and the expected seriousness of the problems associated with car use.

Based on these assumptions five experiments were conducted, testing several hypotheses regarding the importance of various motivational and perceptual factors in shaping commuters' preferences. Moreover, in an exploratory vein, it was inspected whether these factors would affect the individual approval of structural solutions to this real-life social dilemma. To examine these issues, we utilized several different research methodologies, including scenario studies, and a field experiment. In the scenario studies, performed through survey and laboratory simulations, research participants were confronted with a hypothetical commuting situation, in which numerous commuters were (supposedly) involved, and information was systematically varied about the environmental and travel time consequences of their commuting decisions (for an example, see Appendix I). For the benefit of the external validity, the research participants were primarily selected from the population of individuals commuting by car on either a regular or permanent basis. In addition, a field study was performed, evaluating a structural solution to a real-life commuting situation -- the implementation of the first carpool lane in Europe. These five studies are reported extensively in Chapters 2 to 6 of the dissertation. Below, we will briefly discuss the main research goals and findings.

\section{Experiment 1}

Transforming the commuting situation:

\section{Dependence on car versus public transportation}

The purpose of the first experiment was twofold. First, this research addressed the question whether people would make different transformations of the same commuting situation on the basis of their dependence on either car or public transportation (i.e., how much a person would "need" each of these travel options). Second, a more general purpose was to examine whether the standard commuting situation would provide a useful paradigm to analyze transformations and decisions in large-scale real-world social dilemma, such as the commuting situation. To examine these issues, people from two distinct populations in the Netherlands, one 
being more strongly dependent on cars -- daily commuters -- and the other on public transportation -- students (i.e., in the Netherlands, students have free access to public transportation) -- were asked to make a single choice for commuting by car or public transportation. In advance, information was provided about the presumed decisions of a majority of other commuters, and the expected environmental and travel time consequences. Based on interdependence theory (Kelley \& Thibaut, 1978), it was assumed that people's decision would be affected by the perceived interdependence structure underlying the decision situation.

Consistent with predictions, it was found that commuters primarily perceived the situation as an accessibility problem -- with a structure similar to an $\mathrm{N}$-person Chicken Dilemma -- whereas students perceived it primarily as an environmental problem -- with a structure similar to an $\mathrm{N}$-person Prisoner's Dilemma. That is, relative to students, commuters exhibited a greater preference for commuting by public transportation when a majority was expected to commute by car, and a weaker public transportation preference when a majority was expected to commute by public transportation. These different transformations were not or barely influenced by the way the decision situation was framed (i.e., as environmental, accessibility, or combined problem), leading to the conclusion that commuters and students were apparently quite convinced that the choice for car versus public transportation reflected an accessibility or environmental problem, respectively. Moreover, the arguments they gave for their commuting preferences were consistent with these interpretations, in that most commuters reported reasons related to efficiency and travel time, whereas most students reported environmental concerns. From a more general perspective, these findings delineated that the standard commuting situation provides a suitable framework for analyzing commuting patterns, by eliciting rather naturalistic reactions from research participants (for further details, see Chapter 2).

\section{Experiment 2 \\ Transforming the commuting situation: \\ The influence of social value orientations}

The second experiment extended and complemented the previous study in three important ways. First, the decision situation was replicated in a laboratory setting, where commuters would presumably feel more strongly interdependent, because they received feedback about the behavior of other commuters, who supposedly participated in the same commuting situation. Second, the single-choice commuting situation was enlarged to a multi-choice situation, and decisions for car or public transportation were made during the period of a working week (i.e., five days). Third and most importantly, following the impact of a socio-demographic factor on commuting preferences (i.e., dependence on car versus public transportation), this experiment addressed the impact of a personality factor, social value orientations, which was more directly related to the salience of self-interest versus collective interest. It was predicted that, because of their concern with the collective well- 
being, pro-social commuters would primarily view the decision situation as an environmental problem, whereas pro-self commuters, being more concerned with their personal well-being, would primarily view the situation as an accessibility problem.

Consistent with predictions, it was found that pro-social commuters and proself commuters, who were classified on the basis of the Ring Measure of Social Value (Liebrand, 1984; see for more details, Chapter 3), differed in their commuting preference, with pro-socials exhibiting a greater preference for public transportation. Moreover, pro-socials exhibited a greater preference for public transportation when they expected the majority to commute by public transportation, which provides some evidence for an environmental interpretation of the commuting situation (with an interdependence structure similar to an N-person Prisoner's Dilemma). Conversely, pro-selfs exhibited greater preference for public transportation when they expected the majority to commute by car, and this was consistent with an accessibility interpretation (with an interdependence structure similar to an $\mathrm{N}$-person Chicken Dilemma). Further evidence for the role of social value orientations was obtained by analyzing commuters' responses to an environmental threat in their personal commuting situation. All of the pro-social versus only $70 \%$ of the pro-self commuters indicated that they would immediately leave their car at home in case of a smog alarm.

A final result of the experiment was that travel mode attributes reflecting collective concerns (i.e., pollution, public health) were judged to be more strongly related to public transportation preferences, whereas travel mode attributes reflecting individual concerns (i.e., flexibility, convenience) were considered to be more strongly related to preferences for car. This provided some evidence that the commuting situation indeed reflected the structure of a social dilemma - a situation with opposing individual and collective interests (for further details, see Chapter 3 ).

\section{Experiment 3}

\section{Self-interested and pro-social motivations underlying commuting decisions}

The third experiment addressed the impact of two factors related to self-interested outcomes (i.e., travel time, travel time variability), and two factors related to collective outcomes (i.e., social value orientations, impact of cars on environmental pollution) on preferences for commuting by car versus public transportation. The aim of the research was, first, to determine the influence of variabilities in travel time, which would cause uncertainty about the precise travel times of car or public transportation. Extending rational decision models (e.g., game theory, rational choice theory), it was hypothesized that public transportation preferences were enhanced not only by the belief that public transportation would provide a more favorable travel time than the car, but also at least an equally reliable travel time (i.e., equal or smaller variability). This hypothesis was strongly supported, and it appeared that the effects of time variability on public transportation preferences 
could be attributed, in part, to a loss of perceived control over the travel time by car (cf. Averill, 1973; Bandura, 1986).

Second, the study examined possible interaction effects between pairs of selfinterested and collective concerns in predicting commuting preferences. In addition to the main effect for time variability on public transportation preferences, main effects were found for average travel time, level of environmental pollution, and social value orientations. Interestingly, the results revealed that out of three concerns for commuting by public transportation (i.e., shorter travel time, smaller travel time variability, and greater impact of cars on pollution), any combination of two concerns increased public transportation preferences more strongly than the sum of their separate effects. This seems to indicate that individuals might apply a nonadditive, multiplicative rule in forming their commuting preference.

The third goal of the experiment was to replicate and complement the prior findings regarding the impact of social value orientations -- in the current experiment these were assessed by employing the three-choice Decomposed Games method (Messick \& McClintock, 1968; for more details about this procedure, see Chapter 4 and Appendix II). Consistent with the previous study, it was found that, relative to pro-self commuters, pro-social commuters were more concerned about the environment, and exhibited greater preferences for public transportation. However, no evidence was obtained for the predictions that pro-social commuters would be more sensitive to information about collective outcomes (i.e., pollution) and pro-self commuters to information about self-interested outcomes (i.e., travel time). Regarding the first issue, the preferences of pro-self commuters parallelled those of pro-social commuters when the environmental effects of car use were quite substantial. A plausible explanation would be that when the collective interest is in danger, cooperation may also serve the ultimate self-interest of pro-selfs. Another explanation would be that information about the detrimental effects of cars on the environment may create such a powerful social norm to cooperate that personality differences become less salient (cf. Snyder \& Ickes, 1985). Finally, that pro-self and pro-social commuters did not differ in their sensitivity to information about travel time is perhaps understandable from a theoretical model of social value orientation, suggesting that pro-socials assign greater weight than pro-selfs to collective outcomes, but these groups assign equal weights to outcomes for self (Wyer, 1969).

\section{Experiment 4 \\ Pro-social goals and expectations in the commuting situation}

The fourth experiment extended and complemented the prior experiments in several ways. First, in line with the goal/expectation hypothesis (Pruitt \& Kimmel, 1977), it was argued that public transportation preferences would be greater to the extent that people were more strongly concerned about the collective interest (i.e., prosocial orientation), and expected many other people to cooperate as well (i.e., hightrusting individuals). Accordingly, the main prediction was that pro-social 
commuters with high levels of trust -- as measured by Yamagishi's (1986) Trust scale -- would have greater preferences for public transportation than either lowtrusting pro-social commuters, or pro-self commuters, regardless of their level of trust. The predicted interaction of social value orientation and trust was indeed found. Interestingly enough, greater public transportation preferences were also obtained for pro-self commuters with low trust than high trust, which may well be explained by the fact that pro-selfs primarily viewed the decision situation as an accessibility problem (with a structure similar to an $\mathrm{N}$-person Chicken Dilemma), in which it is more profitable take public transportation to the extent that fewer others are expected to do the same.

Second, hypotheses regarding the sensitivity of social value orientations to information about the travel time and environmental pollution conditions were tested again in this experiment. As opposed to the findings of the previous experiment, it was found that, relative to pro-social commuters, pro-self commuters exhibited more pronounced preferences for public transportation when there was a high probability of traffic congestion. However, no evidence was obtained for an interaction between social value orientation and the salience of environmental pollution.

A third goal was to replicate the earlier reported multiplicative effect of two different concerns to commute by public transportation (see experiment 3 ). Despite the fact that a more favorable travel time by public transportation and a greater impact of cars on environmental pollution independently increased public transportation preferences, their combination had no surplus effect.

A final, explorative goal was to examine commuters' approvals and evaluations of a series of structural solutions to the commuting situation. On the basis of structural-goal/expectation theory (Yamagishi, 1986), it was argued that public transportation use could be stimulated effectively only when the individual freedom to commute by car was either eliminated or restricted. First, a factor analysis of these solutions revealed that commuters perceived a distinction between, on the one hand, freedom-restricting solutions (e.g., obligation to commute by car, reduction of parking places), and, on the other hand, freedom-preserving solutions (e.g., information about disadvantages of commuting by car, environmental campaign). Second, commuters exhibited a greater preference for freedompreserving solutions, and did not at all prefer freedom-restricting solutions. These preferences were not or hardly affected by the individual social value orientation or trust. Yet, in evaluating different types of change, pro-social commuters seemed to be more concerned than pro-self commuters with the collective effects of these interventions, and low-trusters seemed to be more concerned than high-trusters with the consequences of these interventions for their individual interest (for further details, see Chapter 5). 


\section{Experiment 5}

\section{Structural solutions in the commuting situation:}

\section{A field experiment on the first carpool lane in Europe}

The fifth experiment complemented the previous experiment by addressing the impact of a structural solution in a real-life commuting situation -- the implementation of the first carpool lane in Europe. The main research question was how commuters would respond psychologically to this intervention in their own commuting situation. The lane was built on one of the most congested highways in the Netherlands - the route from Amersfoort to Amsterdam -- and was exclusively reserved for cars carrying at least three people. To examine the effects of the carpool lane, a quasi-experimental research design was developed, including two kinds of commuters (i.e., solo drivers, carpoolers), two different routes (i.e., carpool lane route, control route), and two measurement times (i.e., one month preceding and following the opening of the lane). Although it was expected that this lane would enhance the perception about a more favorable travel time of carpooling, the main hypothesis was that this intervention would evoke a process of selfjustification among solo drivers who were faced with this lane. This would arise from feelings of relative deprivation among those solo drivers who would not be able to carpool, and/or from feelings of dissonance among those who were largely unwilling to carpool. The results revealed that, relative to judgments made by solo drivers before opening of the lane, judgments made after opening were more negative about carpooling. Specifically, it was found that solo drivers on the route providing the carpool lane decreased the importance of an attribute inherently linked to carpooling (i.e., low travel costs), and increased the importance of an attribute inherently linked to solo driving (i.e., flexibility). Moreover, whereas carpoolers on the carpool lane became increasingly positive about carpooling, solo drivers on both the carpool lane route and control route exhibited a much weaker preference for carpooling after establishment of the lane.

A second research question addressed the impact of collective efficacy judgments (i.e., the belief that society is able and willing to promote carpooling; cf. Bandura, 1986; Kerr, 1989) on the prediction of carpool intentions among solo drivers. Based on a social dilemma frame work, it was expected that, in addition to the well-established behavioral determinants -- attitudes, social norms, and selfefficacy (cf. theory of planned behavior; Ajzen, 1987), collective efficacy would have an independent effect on predicting carpool intentions. Indeed, some preliminary evidence was obtained that the weak carpool intention of solo drivers could be attributed, in part, to a low perception of the collective efficacy of carpooling.

As a final result, consistent with a social dilemma interpretation of the decision situation, it was found that attitudes serving the collective interest (i.e., good for environment) were considered to be more strongly related to preferences for carpooling, whereas attitudes serving self-interest (e.g., flexibility, comfort) were 
considered to be more strongly related to preferences for driving solo (for further details, see Chapter 6).

\subsection{General Discussion}

\section{Main conclusions}

This dissertation utilized a social dilemma approach to examine attitudes and decisions in a real-world social dilemma, to commute by car versus public transportation or carpooling. Starting with an evaluation of traditional approaches to analyze and modify transportation patterns (i.e., reinforcement and attitude model), the possible merits of a social dilemma approach were discussed. This model, which is based on interdependence theory (Kelley \& Thibaut, 1978) and the extant literature on social dilemmas, provided a conceptual framework in which to understand how commuting preferences are shaped by the interdependence structure of the decision situation (i.e., the social dilemma features), and the transformations commuters made of the decision situation. Several experiments were conducted to examine determinants of commuters' decisions. The major findings of these studies can be summarized into four more general conclusions. The first conclusion is that the decision situation of commuters was indeed perceived as a social dilemma, a situation in which individual and collective interests are at odds. Second, consistent with a social dilemma approach, commuting preferences are not only shaped by the immediate, self-interested outcomes of commuters (i.e., the given matrix preferences), but also by their broader motives and concerns in the commuting situation (i.e., the effective matrix preferences). For example, depending on the salience of self-interest or collective interest commuters perceived the decision situation as either an environmental problem (with a structure similar to an Nperson Prisoner's Dilemma) or as an accessibility problem (with a structure similar to an N-person Chicken Dilemma). The third conclusion must be that, despite some optimism about the effectiveness of structural solutions in solving real-world social dilemmas (e.g., Messick \& Brewer, 1983; Rusbult \& Van Lange, in press), their implementation may have unintended negative side-effects, because they may be perceived as a threat to the individual self-determination. Fourth, the findings of all five experiments indicated that preferences for public transportation were often much better explained by the combined impact of two personality variables, two situational variables, or one personality and one situational variable, than by the sum of their separate effects. This seems to suggest that cooperation in a real-world social dilemma may be best studied from an integrative approach that takes into account both the personal and the situational determinants of behavior (cf. Kihlstrom, 1987).

In the next sections, these more important contributions of the research will be discussed in greater detail, together with their theoretical and practical implications. In addition, we will outline some of the strengths and limitations of 
the present research, and suggest ideas for future work. The overview chapter will be closed with an evaluation of various research paradigms to study social dilemmas in the real-world.

\section{Conclusion 1:}

\section{The commuting situation as social dilemma}

This dissertation extended prior research on transportation patterns by emphasizing the importance of the interdependence structure of the decision situation. Although the aim of the research was not so much to provide a theoretical analysis of the fundamental interdependence properties of the commuting situation, there was some evidence indicating that the decision situation was interpreted as a social dilemma by the commuters. First, it was demonstrated that travel attributes serving the individual self-interest (i.e., flexibility, comfort, and travel time) were judged to be more strongly associated with commuting (alone) by car, whereas travel attributes serving the collective interest (i.e., environment and public health) were considered to be more strongly associated with public transportation and carpooling (see Chapters 3 and 6). Moreover, consistent with a social dilemma interpretation, it was found that commuters considered these self-interested concerns to be more important determinants of their decision than collective concerns (see Chapter 6).

Some indirect evidence for a social dilemma interpretation was provided by the finding that factors associated with enhancing cooperation in experimentalgaming studies also enhanced cooperation in this real-life dilemma. For example, preferences for public transportation systematically varied with the reported travel time and pollution consequences, factors affecting the salience of self-interest and collective interest, respectively (see Chapters 4 and 5). Indeed, prior social dilemma research consistently revealed that cooperation is enhanced when the basis for collective rationality becomes more salient (e.g., Kelley \& Grzelak, 1972; Komorita, Sweeney, \& Kravitz, 1980). In addition, parallel to prior social dilemma research (e.g., Kuhlman \& Marshello, 1975; Sattler \& Kerr, 1991; Van Lange \& Kuhlman, 1994; Yamagishi, 1986, 1988), commuting preferences were also shaped by individual differences in social value orientations and trust (see Chapters 3, 4, and 5). Moreover, social value orientations also predicted the individual reaction to a potential environmental disaster in the commuting situation (i.e., smog alert; see Chapter 3). These findings underscore the importance of interpersonal dispositions in how people respond to a large-scale dilemma in the real-world. Also, they complement prior research by emphasizing the relevance of personality differences related to egoism and altruism in understanding the issue of environmental pollution and how such collective problems may become disastrous. This is particularly important in light of Stern's (1992, p. 284) remark in his extensive review of psychological research to environmental pollution that:

"Personality variables rarely show systematic relationships to environmentally relevant behavior, with the exception of locus of control and related variables." 
Nevertheless, despite the convergent support for a social dilemma interpretation of the commuting situation, it should be noted that the commuting scenarios in the present studies were particularly designed to highlight the contrast between individual and collective concerns, and this may have contributed to the effects of personality and situational variables related to self-interest versus collective interest (so-called precipitating situations; cf. Snyder \& Ickes, 1985). In this regard, it is also important to note that, whereas the scenario studies revealed consistent evidence for the role of personality differences (i.e., in social value orientations), no dispositional differences were found in how people responded to the implementation of the carpool lane (see Chapter 6). Among other explanations, this may indicate that, in reality, there may be important situational variables evaporating the impact of relevant (inter)personal factors on the development of cooperation (e.g., no or limited access to public transportation facilities, difficulties with finding carpool partners, or coordinating work schedules). Thus, it seems appropriate to replicate the above findings concerning the influence of various social dilemma factors with a more direct focus on actual commuting decisions.

\section{Conclusion 2:}

\section{Evidence for transformations of the commuting situation}

Contrary to the reinforcement model (e.g., Olson, 1965; Skinner, 1953), the social dilemma model assumed that commuters would not only respond to the commuting situation on the basis of their immediate self-interest (i.e., the given matrix preferences), but might relinquish their self-interest on the basis of their broader motives in the decision situation (i.e., the effective matrix preferences). There was converging evidence in support of these transformation processes. A first factor associated with transformation of motivation (Kelley \& Thibaut, 1978; Rusbult \& Van Lange, in press) was uncertainty about the travel times associated with commuting by car versus public transportation (see Chapter 4). Our research revealed that commuting preferences were not only shaped by beliefs regarding differences in average travel time, but also by beliefs regarding differences in variability of travel time. Commuters strongly preferred public transportation above their car when it would yield at least an equal time variability, regardless of what the average travel time would be. Thus, inconsistent with game-theoretical notions (Olson, 1965), individuals did not respond to the concrete and immediate outcomes in the commuting situation (i.e., a short travel time), but also to the perceived uncertainty of these outcomes (cf. "certainty-effect"; Kahneman \& Tversky, 1979). This finding underlines the individual desire to reduce uncertainty as a major psychological motive at work in social dilemmas, situations in which individuals are frequently faced with uncertainties about the outcomes of their own and others' decisions (cf. "social and environmental uncertainty"; Suleiman \& Rapoport, 1989; Wit \& Wilke, 1995).

Second, transformation of motivation was set in motion by an individual's dependence on either car or public transportation. Individuals being strongly 
dependent on either their car (i.e., Dutch commuters) or public transportation (i.e., Dutch students) interpreted the same commuting situation very differently, respectively more in terms of accessibility problems or environmental problems. Moreover, the most frequently reported arguments that these groups gave for their commuting preference were quite consistent with either an accessibility or environmental interpretation (see Chapter 2).

Finally, a third factor related to transformation of motivation was social value orientation. It was found that commuters who were primarily concerned with their immediate self-interest -- pro-self people -- viewed the decision situation more strongly in terms of travel time and congestion problems, whereas commuters primarily concerned with collective well-being -- pro-social people -- viewed it more strongly in terms of environmental pollution (see Chapter 3 ). Consistent with these interpretations, relative to pro-selfs, pro-socials assigned greater importance to the environmental consequences of their commuting decisions (see Chapters 3 and 4). Congruent with a social dilemma model, these differential transformations were expected to emerge through the individual expectations about the commuting behaviors of others. Indeed, when a majority of commuters was expected to commute by public transportation, pro-social commuters would opt for public transportation as well, whereas pro-self commuters would opt for the car. Thus, these two value orientations perceived two fundamentally different interdependence structures underlying the decision situation, for pro-socials one that was more closely related to an N-person Prisoner's Dilemma -- representing a deliberation between own convenience and the environment -- and for pro-selfs one that was more closely related to an $\mathrm{N}$-person Chicken Dilemma -- representing a concern for efficiency and travel time (see Chapter 3). Additional evidence for these different transformations was obtained by comparing commuting preferences among social value orientations with different trust levels (see Chapter 5). Consistent with an environmental interpretation, it was found that pro-social commuters with high levels of trust exhibited greater preferences for public transportation than either lowtrusting pro-socials or pro-selfs, regardless of their level of trust (cf. goal/expectation-hypothesis; Pruitt \& Kimmel, 1977).

To summarize, these findings quite convincingly demonstrated that people had very different motivations underlying their commuting preferences, and that at least some people were motivated to relinquish their immediate self-interest (i.e., to commute by car) on the basis of their broader concerns in the commuting situation (i.e., to avoid uncertainty and traffic congestion, to act in a responsible and environment-preserving manner). These transformation processes gave rise to various interpretations of the commuting situation (i.e., as accessibility or environmental problem), and these were closely related to their commuting preferences. Admittedly, our research did not directly measure the concept of transformation of motivation. Yet, recent research has provided some more direct evidence for these transformation processes in the commuting situation by showing that the effective matrix preferences of commuters are indeed more strongly related 
to their commuting decisions than the given matrix preferences (Joireman, Van Lange, Kuhlman, Van Vugt, \& Shelley, in press).

\section{Conclusion 3:}

\section{Negative side-effects of structural solutions in the commuting situation}

By focusing on the structural aspects of the decision situation, a social dilemma approach suggests the relevance of structurally-based solutions. These solutions are aimed at changing the interdependence structure of the decision situation, by altering either the reward structure, the physical environment, or the individual freedom to choose (e.g., Messick \& Brewer, 1983; Samuelson \& Messick, 1986; Vlek \& Michon, 1992; Yamagishi, 1986). It was expected that structural solutions would be particularly useful for promoting cooperation in social dilemmas with large numbers of actors, because the expectations about others' voluntary cooperation may tend to be rather low (cf. structural-goal/expectation theory; Yamagishi, 1986). Nevertheless, the current research revealed that commuters did not at all approve of structural solutions to diminish car use, particularly those that limited the individual freedom of choice. First, it was found that, relative to freedom-preserving solutions (e.g., information about disadvantages of cars), freedom-restricting solutions (e.g., reducing parking space, the obligation to commute by public transportation) were perceived by commuters as far less effective, and as a greater threat to the individual freedom, the collective and the individual interest. Accordingly, commuters did not particularly favor structurallybased solutions to the commuting situation, despite the salience of environmental and congestion problems associated with excessive car use (see Chapter 5). Second, evidence was obtained that after the implementation of a structural solution in a real-life commuting situation -- the carpool priority lane -- the attitudes and preferences toward carpooling among solo drivers were much more negative than before. This could be attributed to a process of self-justification, a psychological revaluation of the travel options so as to maintain a positive impression of the chosen option (cf. Aronson, 1988).

What may account for the negative reactions to structural solutions and how can these be avoided? A first explanation may be that commuters have very limited possibilities to commute by public transportation or carpool. That is, a considerable number of people may simply be unable to abandon car use, because there are various obstacles associated with using alternative travel modes (e.g., irregular working schedules, limited public transportation facilities). Indeed, in the carpool study the reported self-efficacy to carpool among solo drivers was extremely low. Second, commuters may be skeptical about the effectiveness of these and other solutions to decrease car use (e.g., will a sufficient number of people actually stop using their cars?) and may therefore show no willingness to decrease their own car use. This interpretation was supported by the finding that perceptions of collective efficacy (cf. Bandura, 1986; Kerr, 1989) significantly predicted solo drivers' weak 
intention to carpool, beyond traditional psychological variables such as attitudes, social norms, and self-efficacy (theory of planned behavior; Ajzen, 1987).

Third, structural solutions may be perceived by the public as too drastic and too much infringing on the individual freedom (Samuelson, 1993). Accordingly, commuters may respond negatively to these interventions because they may fear for their autonomy (i.e., car use is viewed by many as a basic right).

\section{Conclusion 4: \\ Evidence for multiplicative effects of factors promoting cooperation in the commuting situation}

As noted in the introduction of this overview, there is a growing concern in social dilemma research with how various factors may interact in explaining and promoting pro-social behavior (e.g., Knight, Johnson, Carlo, \& Eisenberg, 1994; Liebrand, 1992; Samuelson, 1990). Examining these interactions may be particularly important in real-life social dilemmas, because, relative to laboratory situations, naturalistic settings are often more ambiguous and unstructured, and do not provide strong situational cues to respond in certain ways (Snyder \& Ickes, 1985). Accordingly, behavior may be shaped by the various interpretations of the decision situation, and these may be a function of both personality and situational variables. In this dissertation many interaction effects have been observed, including person $\mathrm{x}$ situation, person $\mathrm{x}$ person, and situation $\mathrm{x}$ situation interactions. They indicate that cooperation in this large-scale dilemma (i.e., to commute car or by public transportation) can be much better understood from an integrative perspective, that recognizes the relevant situational and personal determinants, and their interactions in shaping pro-social behavior (cf. Kihlstrom, 1987; Mischel, 1968).

First, consistent evidence was found for the idea that personality and situational variables, in combination, may better explain public transportation preferences than the sum of their separate effects (cf. Bem \& Allen, 1974; Kenrick \& Funder, 1988). The effect of social value orientation on commuting preferences was strongly moderated by situational determinants, such as expectations about the decisions of others, and the salience of traffic congestion, and environmental pollution. For example, pro-social commuters were more willing to commute by public transportation when they expected others to take public transportation as well (see Chapter 3). In contrast, pro-self commuters were more likely to commute by public transportation when they expected others to commute by car, and also when they expected heavy traffic congestion (see Chapters 3 and 5).

Second, a novel finding of the present dissertation was that the combination of two dispositional variables, social value orientations and trust, importantly shaped public transportation preferences, with high-trusting pro-socials exhibiting greater public transportation preferences than both low-trusting pro-socials and proselfs, irrespective of their level of trust (cf. goal/expectation hypothesis; Pruitt \& Kimmel, 1977). This finding denotes that the prediction of pro-social behaviors can 
be enhanced by the use of multiple dispositional predictors. In fact, focusing on the influence of one single personality trait may often lead to the erroneous conclusion that there is no relationship between personality and behavior. In the context of environmental pollution, this may help to understand why prior research has revealed only weak correlations between single personality variables and environmental behavior (Stern, 1992).

Finally, interaction effects were also obtained for pairs of situational variables. One of the studies revealed that when two out of three situational barriers to commute by public transportation (i.e., longer travel time, greater variability in travel time, low environmental impact of cars) were simultaneously removed, their combined effect was more pronounced than the sum of their separate effects. Hence, commuters tend to use a compensatory, multiplicative rule, instead of an addition-of-utilities rule to determine their preferences (see Chapter 4). Yet, another study showed that when a self-interested and pro-social motive to commute by public transportation were highlighted at the same time (i.e., shorter travel time, and heavy pollution of cars), their combination did not have a stronger impact than the sum of the separate effects (see Chapter 5). A plausible explanation for this discrepancy may be that for people to choose public transportation, their cognitive set of relevant evaluative dimensions should contain at least as much benefits associated with public transportation as with cars.

\section{Practical implications}

Information about the reliability of alternative travel modes. Commuters in the research sample exhibited a preference not only for a short, but also for a reliable travel time. It is not likely that public transportation nor any other travel mode can really compete, at this moment, with the car in terms of their average travel times. However, given that car commuters are increasingly experiencing heavy traffic congestion and difficulties with finding parking space, it may be that traveling by public transportation frequently provides a more reliable travel time than by car. Similarly, for short distances, commuting by bike may often yield a more predictable travel time than the car. If this is true, it may be promising to focus in campaigns on this advantage of commuting by public transportation and bike.

Information about the environment. Because some commuters perceive the commuting situation more as an environmental problem (with the underlying structure of a Prisoner's Dilemma), whereas others perceive it as an accessibility problem (with the underlying structure of a Chicken Dilemma) they may respond very differently to campaigns stressing the significance of the environment and the environment-preserving efforts of other people. Whereas such messages might influence the decisions of people who are generally concerned with the collective interest (e.g., pro-social value orientations) and/or those who expect many others to voluntarily give up their self-interest (i.e., high-trusting people), they may not at all affect the decisions of individuals who are primarily concerned with their self- 
interest (e.g., pro-self value orientations). Perhaps this may help to understand why environmental campaigns have not been terribly successful in changing people's transportation decisions (Baerwald, 1985; Kostyniuk, 1982). Rather than providing information about the environment, perhaps more promising are campaigns stressing the individual gains of environment-preserving behaviors, because they might influence people with various orientations. For example, in the commuting context, people may be persuaded to use public transportation by stressing its advantages in terms of a greater travel comfort, and a shorter and more reliable travel time. It goes without saying that such messages are only effective to the extent that they are realistic, which may require some structural changes in the availability and quality of public transportation.

Solving both environmental and congestion problems? It is good to realize that even if some interventions would succeed in reducing the car use of considerable numbers of people, the long-term effects are uncertain. That is, individuals who perhaps commuted by train so as to avoid congestion problems, may be driven back into their cars when they expect more people to commute by train, and therefore fewer problems related to traffic jams and finding parking space. Thus, remedies to change transportation patterns should take into careful consideration the different social dilemmas that people perceive to underlie the transportation situation, because these interpretations might determine the ultimate success of car-reducing interventions.

Accentuating two benefits at the same time. Some of the findings suggest that people may be persuaded to leave their cars when several benefits of alternative travel options are highlighted simultaneously (e.g., providing information about the travel time and environmental benefits of alternatives). Indeed, interventions focusing on one single benefit may not be a strong enough motivator to change people's behaviors, and they may easily evoke a process of self-justification among commuters as was observed in the field-study on the carpool lane. However, this is perhaps less likely to happen when people are all of a sudden faced with multiple advantages associated with alternative commuting options, because this would make it harder to find a good excuse for why they are still using their car. Accordingly, it seems worthwhile to implement two or more interventions at the same time, for example, the provision of a carpool lane together with the provision of tax-benefits for carpoolers.

Decentralization. The research findings revealed that commuters preferred individually-based solutions (e.g., information, communication strategies) much better than structurally-based solutions (e.g., punishments, physical interventions), and justified their car use when confronted with a structural intervention in their own commuting situation. In view of this, future attempts to decrease car use and promote alternative travel modes must take into account the following. First, it seems important to know what mechanisms people use to justify their car use. For example, people seem to frequently underestimate the travel time of commuting by car, while overestimating the travel time by public transportation. Such unrealistic 
optimistic beliefs about car use may be tackled by providing them with more realistic travel time information. Second, before implementing any structural change, it must be examined whether a sufficient number of people believe they are actually capable of performing the desired behaviors. Third, it is important to know whether people feel that the environmental and congestion problems can be resolved by their mutual efforts (i.e., perceived collective efficacy), that their personal contribution does matter, and that considerable others are also willing to contribute. Of course, particularly in large-scale social dilemmas, like environmental pollution, people may tend to hold rather pessimistic beliefs about these factors.

These considerations should encourage a more decentralized approach to changing transportation patterns. That is, instead of communicating to citizens directly, coordinating governments should make use of intermediate authorities, such as companies or other institutions, and stimulate them to develop their own projects to reduce car use (e.g., implementation of vanpool or carpool systems). Advantages of this approach are, first, that these institutions are perhaps better able to match the individual needs and wishes of commuters. For example, for companies in inner cities it may be more easy to stimulate bike use among their employees, whereas for companies in industrial parks perhaps carpool programs are more suitable. Second, commuters may feel a stronger commitment to these institutions than to the national government, and are therefore more willing to accept drastic interventions from them than from the superimposed government (see the carpool lane experiment). Finally, people may feel more responsible for and be more optimistic about the management of the problems related to car use when these problems are presented more locally (e.g., how can we diminish congestion and pollution in our area?). Thus, decentralization may enhance both the feelings of commitment, personal responsibility, self-efficacy and collective efficacy among commuters, which, in turn, may increase their willingness to contribute (cf. Kerr, 1989). An example of decentralization in the Netherlands is the recently implemented traffic management program (cf. Van Lange, 1995) in which companies and institutions, in collaboration with the national government, develop plans to reduce private car use among their employees. Similar forms of decentralization have been undertaken in the domains of energy conservation and health education, and these provide good evidence that local activities can be very helpful in promoting the desired environmental and health behaviours (e.g., through community or social network approaches; e.g., Weenig, Schmidt, \& Midden, 1990; Van Assema, 1993).

\section{Strengths, limitations, and suggestions for future research}

Before closing this overview, it seems appropriate to evaluate some strengths and limitations of the current work. One potential limitation concerns the fact that in all but one experiment (see Chapter 6), scenario paradigms were used to measure commuters' decisions. Consequently, this paradigm does not rule out tendencies of social desirability and self-presentation, and this may account for the relatively high 
overall preference for public transportation that was found in these scenario studies, and particularly in conditions where serious environmental pollution -- a socially desirable attribute - was reported. However, these tendencies are presumably not responsible for the main effects of travel time, and travel time variability, because these outcomes are primarily related to self-interest. Moreover, these biases are less likely to account for the effects of social value orientations, because the measurements of social value orientations are free of inclinations toward social desirability (Platow, 1992; Van Vugt \& Samuelson, 1995), nor do they account for the various interaction effects that were found between social value orientations and other factors (i.e., expectations about others' decisions, levels of pollution and congestion). In this regard, it should also be noted that various features of the scenario studies (e.g., using real commuters and realistic outcomes, creating the impression that many commuters participated in the decision situation) have enhanced the ecological validity of the current findings. Finally, some additional findings related to commuters' actual behavior (e.g., judgments of travel attributes, reports of reactions to smog alerts) were quite consistent with the findings obtained in the hypothetical commuting situations, hence providing additional evidence for the validity of our research paradigm.

This is not to deny, however, that factors promoting public transportation in these situations may be overshadowed, in reality, by more powerful social and situational constraints (cf. Weiner, 1980). Indeed, the fact that social value orientations did not predict commuting decisions in the field study on the carpool lane may well be explained by such constraining factors (e.g., irregular work schedules, difficulties finding carpool partners). Thus, it would be fruitful to replicate the current findings with a more direct focus on behavior. The results of our research may serve as a starting point for further designing and implementing more expensive and time-consuming field studies in the context of transportation and other environmentally relevant behaviors.

A second limitation pertaining to social value orientations is the fact that the research samples in the current work consisted for 50 to $80 \%$ of pro-social commuters. Although these percentages are not uncommon in social dilemma research (for a recent review, see Van Lange \& Messick, in press), tendencies of self-selection may have been responsible for the sample compositions. Indeed, previous research has demonstrated that pro-social individuals are more willing to participate as volunteers in experiments than individualists or competitors (McClintock \& Allison, 1989). Accordingly, the possibility of a selection bias may provide an alternative explanation for the high overall preference for public transportation obtained in the present research. From a practical viewpoint, the possibility of such self-selection processes may have important implications for the effects of voluntary-based environmental programs, because it seems to indicate that such activities may primarily attract a group of pro-social people, and may not sufficiently reach people with pro-self orientations, who are presumably most responsible for environmental pollution. 
A third limitation is that the current studies did not directly measure the motivational and cognitive states underlying commuters' preferences. First, the feelings of deprivation and dissonance that were presumed to underlie selfjustification effects were not actually measured (see Chapter 6). More importantly, the transformation processes (e.g., accessibility vs. environmental interpretations) that were assumed to take place among commuters with different social value orientations and levels of car versus public transportation dependence were not directly assessed, but were inferred from their decisions (see Chapters 2 and 3 ). Yet, some indirect evidence for these transformation processes was obtained in that students, when asked to verbalize the reasons for their commuting preference, reported arguments related to a concern with the environment, whereas commuters reported concerns with efficiency and travel time (see Chapter 2).

Despite the fact that it is not easy to unequivocally demonstrate these transformation processes (cf. Rusbult \& Van Lange, in press), we believe future research should be aimed at examining the concept of transformation of motivation more directly. A potentially useful technique is to have commuters rank their preference for combinations of outcomes for self and others in the commuting situation (e.g., how much do you prefer the situation in which you commute by car, and most others commute by public transportation? etc.) -- which correspond to the cells in the $2 \times 2$ outcome matrix. This ranking procedure may reveal important information about what interdependence structure commuters perceive to underlie the decision situation. For example, the results of a recent experiment using this procedure revealed that pro-social commuters exhibited greater preferences for the situation in which most people, including themselves, would commute by public transportation, whereas pro-self commuters exhibited greater preferences for the situation in which they would commute by car, and most others by public transportation (Ruiter, Van Vugt, Meertens, \& Van Lange, 1995). Moreover, some recent findings were obtained (Joireman et al., in press) showing that commuters' effective matrix preferences (i.e., their general evaluation of the commuting situation) were more strongly related to their decision to commute by car or public transportation than the given matrix preferences (i.e., evaluation on the basis of only travel time or convenience considerations).

Some strengths of the current work are also worth discussing. First, this dissertation is one of the primary attempts to study attitudes and decisions in a large-scale real-world problem, environmental pollution, from an explicit social dilemma framework. Although many researchers have suggested that environmental pollution can be described as a pervasive social dilemma (e.g., Dawes, 1980; Hardin, 1968; Komorita \& Parks, 1994; Samuelson, 1990), so far no empirical evidence has been provided in support of this claim. We may only hope that the current research will be followed by more studies examining environmental pollution and other important real-world problems on the basis of insights derived from the social dilemma literature. 
A second strength of the current work is that it has provided some of the first evidence of how people actually respond to a structural solution in a real-world social dilemma. Prior research has concentrated primarily on whether people would opt for structural solutions, and how they would evaluate these solutions (e.g., Messick et al., 1983; Samuelson, 1993). Despite some optimism among social dilemma researchers and policy makers about the effectiveness of structural solutions (e.g., Messick \& Brewer, 1983; Rusbult \& Van Lange, in press), these interventions may have negative side-effects, because people may perceive it as a threat to their autonomy and self-determination (cf. Samuelson, 1993). Further research is needed to examine how structural solutions in the real-world are perceived, how people respond to these solutions, and how negative reactions can be avoided. This may require an intensive collaboration of psychologists -- who have been relatively mute on the topic of structural change -- with other social scientists, such as sociologists and political scientists that have a more established tradition in studying the effects of institutional and structural change (e.g., Edney, 1980; Orbell \& Wilson, 1978; Ostrom, 1990).

Finally, traditional approaches to examine transportation patterns tend to view people as relatively independent decision makers (i.e., the reinforcement and attitude model). Although these approaches are parsimonious for describing decisionmaking in individual settings, their perspectives may be somewhat limited for analyzing decisions in interdependent situations, because they do not offer a clear basis for assuming that behaviors may be shaped by the social context in which they are made. The present work advanced a framework based on interdependence theory to understand the interdependent nature of commuting decisions. It is interesting to note that this theory has been primarily designed to study social interactions in interpersonal dyadic relationships (Kelley \& Thibaut, 1978). The current work revealed that it may also be helpful in analyzing decisions in interdependence settings involving many other people, such as the decision to commute by car or public transportation, by providing relevant concepts, such as transformation of motivation, degree of and basis for dependence (e.g., coordination vs. exchange), and correspondence of outcomes. This is not to deny, however, that there may also be other useful theoretical approaches that may explain decisions in such situations equally well. For example, the norm-activation model of altruism (Schwartz, 1977), has been particularly successful in predicting a range of environmental behaviors, such as recycling, energy conservation, and the purchase of lead-free gasoline (for an overview, see Stern, 1992).

\section{Some final remarks and considerations for possible research strategies}

This dissertation offered an extension of social dilemma research that had been mainly performed under highly-controlled laboratory conditions -- using experimental games as decision tasks -- by focusing on decisions and preferences in a real-life social dilemma, the commuting situation. It seems appropriate to say a 
bit more about the differences between more fundamental versus applied approaches to study social dilemmas, in terms of their main assumptions and features. Moreover, some new directions in social dilemma research have been advanced recently, and they are discussed as well.

A systematic comparison of the present research with prior experimental research on social dilemmas reveals, first, that the scale of the problem under investigation strongly varies. While most laboratory studies have created social dilemmas within groups consisting of two to nine people (for an exception, see Kerr, 1989), real-life social dilemmas, at least the ones with the greatest social and societal implications, occur on much larger scales consisting of infinite numbers of actors. For example, the commuting situation consists of thousands of commuters making daily travel mode decisions at the same time, and even more people are involved when the environmental consequences of these commuting decisions are taken into consideration (e.g., smog pollution, acid rain, global warming). In terms of interdependence theory (Kelley \& Thibaut, 1978), this implies that the degree of mutual dependence between actors is much lower in real-life social dilemmas than in laboratory dilemmas, and this may strongly attenuate cooperation, because the impact of people's decisions on the collective outcome is much smaller, and people feel personally less responsible (Latané \& Wolf, 1981), and efficacious (Kerr, 1989) for preserving the collective good. Moreover, the more actors are involved the greater will be the uncertainty about whether sufficient numbers of people are willing to contribute (cf. "social uncertainty"; Messick, Allison, \& Samuelson, 1988; Suleiman \& Rapoport, 1989; Wit \& Wilke, 1995).

Second, the time horizon of real-life dilemmas is generally much larger. Although many recent gaming studies have extended the time perspective of the research paradigm by using sequential (vs. single-trial) games as decision tasks (i.e., resource and public goods dilemmas; e.g., Kerr, 1989; Messick et al., 1983; Van Dijk \& Wilke, 1993), the consequences of individual behaviors are generally observed within a very restricted time period (i.e., usually within one hour). In contrast, the behavioral consequences in real-life dilemmas are generally spread out over much longer time periods. For example, it may take many years before toxical waste dumpings will affect the soil and ground water conditions, or massive tax evasion will deteriorate public good facilities. Consequently, people in these dilemmas are faced with much greater uncertainty about the collective consequences of their decisions ("environmental uncertainty"; cf. Messick et al., 1988; Suleiman \& Rapoport, 1989; Wit \& Wilke, 1995). This may give rise to greater optimism about the future, because people may think that next generations will be able and willing to find solutions for these problems (e.g., through developing new technologies and devices; cf. Snyder, 1993; Stern, 1992). Consequently, people today may not really see the necessity and urgency of establishing wide-spread cooperation among members of contemporary society.

A third difference between experimental games and real-world dilemmas pertains to the number and feasibility of the behavioral options. First, whereas the 
choices in laboratory games are usually dichotomous (i.e., noncooperative versus cooperative option), and/or unidimensional (i.e., the amount of cooperation), there are generally many more alternatives in real-life dilemmas, each with its own specific features and qualities. For example, in the commuting context the set of options consist of commuting by car alone, carpool, public transportation, motorcycle, bike, walking, staying at home, etcetera. These options differ in numerous respects, not only in terms of how much they add to environmental pollution, but also in terms of comfort, flexibility, speed, and consequences for personal health. Second and more importantly, in real-life not all behavioral options may be equally viable. For example, it may not be feasible for individuals to commute by public transportation or carpool because there may be various situational and personal constraints associated with these options. It is clear that these factors (i.e., number and feasibility of alternatives) may importantly affect the occurrence of cooperation, with greater cooperation to the extent that alternatives are greater in number, better accessible, and higher in quality.

Fourth, the current findings revealed that the interdependence structure many researchers assume to underlie a particular decision situation may not be the one actors will actually respond to. A major strength of laboratory games is that the structure of the decision situation is relatively unambiguous, and easy to understand for most participants, so that research findings can be unequivocally related to experimental conditions (Pruitt \& Kimmel, 1977). Yet, in reality the interdependence structure is not so transparent, and people may perceive different interdependence structures of the same situation on the basis of their dominant values and goals (Kelley \& Thibaut, 1978). Accordingly, one of the lessons of the current dissertation is that researchers must be careful in assuming a priori that a particular real-life problem reflects a specific type of interdependence structure, before examining the relevant properties and transformations of the decision situation (cf. Hamburger, 1979).

Given the constraints associated with traditional experimental gaming research it would be worthwhile to look at some other research strategies and paradigms that are perhaps better able to account for the temporal and spatial features of social dilemmas in the real world. One promising research strategy is the application of computer simulations that allow researchers to examine more closely how cooperation evolves in time and space. For example, by running computer simulations in which pairs of "individuals" played prisoner's dilemma games against each other in different environments, Messick and Liebrand (1995) recently found that, contrary to scientific instinct, larger groups were able to maintain substantial cooperation at stable levels, whereas smaller groups converged to states of either no or full cooperation. A second potentially useful paradigm is Kelley's (1984) transition list approach, which forms an extension of interdependence theory (Kelley \& Thibaut, 1978). Interdependence, according to this approach, is understood not only in terms of the outcomes in the present situation, but also in terms of future interdependent situations that are created as a 
consequence of earlier decisions. This allows one to examine how individual preferences in social dilemmas may change over time. For example, after having experienced repeatedly the negative consequences of traffic jams, a commuter may decide to lower the dependence on other commuters by taking a side-route, altering his or departure time, or commuting by bike or public transportation. As another example, the purchase of a solid bike may increase the opportunities of members in a household to act in environment-preserving ways.

A third productive strategy would be to directly examine social dilemmas asthey-occur-in-the-real-world. This is, of course, the approach that has been started in the present research by focusing on transportation and environmental pollution. A following step may be to extend and apply the social dilemma approach to other domains of environmental behavior (e.g., household recycling, purchase of energysaving devices, adoption of "clean" production technologies in factories), and perhaps also different domains of pro-social behavior (e.g., volunteering, voting, and paying taxes). A more theoretical goal of this research strategy might be to develop a formal model of how individual decision-making in real-world dilemmas may take place, extending prior attitude-behavior models that are not able to fully account for decisions in interdependent settings (cf. theories of reasoned action, and planned behavior; Ajzen 1987; Ajzen \& Fishbein, 1980). The new model should be based on the assumption that cooperation is the outcome of an individual-psychological process, consisting of various behavioral phases that are relatively independent from another (cf. persuasion/communication matrix; McGuire, 1985).

For example, for cooperation to occur it may be that people should: first, be aware that there is a collective interest in danger; second, understand the relation between the collective problem and their own behavior; third, be willing to cooperate; and, fourth, be able to cooperate (cf. Van Lange, Van Vugt, \& Van Veenendaal, in press). The fulfillment of these conditions will probably depend on a variety of (social-)psychological factors, that may have their origins in the interdependence structure of the situation -- a variety of these factors have been examined in the extant social dilemma literature. First, problem awareness is perhaps a function of the personal involvement and knowledge about the problem, and this may depend on the temporal and spatial features of the problem (i.e, the more distant and further away, the less salient). Problem understanding may be dependent on the attributions of the actors (e.g., is the problem caused by human beings or by spontaneous natural variations), which may depend on the degree of dependence (i.e., the lower, the less clear is the link between individual behavior and collective outcome). The willingness to cooperate may be a function of (a) intrinsic (e.g., interpersonal dispositions), and (b) extrinsic motivations (e.g., rewards, punishments, social norms). Finally, the ability to cooperate may be shaped at the individual level by the perceptions of personal efficacy, and at the group level by the perception of collective efficacy, and these are presumably affected by degree of dependence (i.e., the lower the dependence, the less relevant is one's personal contribution and expectation of the group's ability to preserve the 
collective good). In a similar vein, it may also be important to examine what factors may enhance that people will maintain their first-started cooperation (e.g., through feedback mechanisms), how various factors may interact in promoting cooperation (e.g., relation between intrinsic motivations and efficacy), and how various phases may be interconnected (e.g., unwillingness to cooperate may come about in a reduced problem awareness; cf. "self-justification"; Messé \& Sivacek, 1979).

To conclude, we believe that these three research strategies (i.e., computer simulations, transition list approach, and a real-life approach) may importantly complement and extend the existing body of knowledge by their focus on the temporal and spatial aspects of decision-making in social dilemmas. The applied social dilemma approach of the current research has contributed perhaps a bit more to our understanding of how people might perceive and respond to one specific real-life social dilemma. Hopefully, this may be a starting point for developing more projects in an attempt to ultimately solve or reduce one of the more serious and pervasive problems the world is facing today, environmental pollution. 


\section{Chapter 2 \\ Transforming the commuting situation: Dependence on car versus public transportation ${ }^{1}$}

"The car is the carapace, the protective, and aggressive shell of urban and suburban man... It has become an article of dress without which we feel uncertain, unclad, and incomplete in the urban compound."

-- McLuhan (1964, p. 322)

\subsection{Introduction}

\section{Commuting by car or public transportation?}

The choice between commuting by car versus commuting by public transportation may be affected by several variables, such as efficiency, convenience, or financial costs. A comparative survey conducted in major cities revealed that in Amsterdam $58 \%$ commuted by car, $14 \%$ by public transportation and $28 \%$ cycled or walked. In Washington DC, on the other hand, $80 \%$ commuted by car, $14 \%$ by public transportation, and only $6 \%$ cycled or walked, whereas in Tokyo only $16 \%$ commuted by car, $59 \%$ by public transportation, and $25 \%$ cycled or walked (Newman \& Kenworthy, 1989). It is clear that such choices are affected by structural variables, such as the scarcity of parking space, the quality of public transportation, or the likelihood of traffic jams. These variables influence the relative efficiency of cars versus public transportation. In addition to such criteria of accessibility, the choices to commute by car or by public transportation may also be evaluated in terms of how much they pollute the environment. Over the past five years more and more attempts have been made by the Dutch government to promote commuting by public transportation in order to decrease environmental pollution and accessibility problems. But these efforts -- primarily through the use of campaigns -- have not been very fruitful yet. So far, the conclusion seems to be that it is hard for people to change the habit of using the car and to start commuting by public transportation.

The current chapter reports a study on individuals' preferences for car versus public transportation as two different means to commute. In part, this study was conducted in light of the belief that excessive car use may ultimately lead to a

This chapter was published as:

Van Vugt, M., Meertens, R. M., \& Van Lange, P. A. M. (1994). Commuting by car or by public transportation: An interdependence-theoretical analysis. In U. Schulz, W. Albers, \& U Mueller (Eds.), Social dilemmas and cooperation (pp. 291-309). Berlin: Springer-Verlag. 
disastrous situation much the same as the "Tragedy of the Commons" described by Hardin (1968). By employing a hypothetical -- single-trial -- commuting situation, we focus on the different ways in which such decision situations may be construed, and on factors that may promote commuting by public transportation. More specific goals of this study are, first, to examine how individuals may assign different meanings to the identical hypothetical situation, and exhibit different preferences for car versus public transportation on the basis of their dependence on the car versus public transportation. Second, we examine how people respond to information regarding the choices of other individuals.

The choice between car and public transportation is made in situation of interdependence. An individual's own choice not only affects his or her own well-being, but also that of other individuals. For example, it is clear that excessive car use has a negative impact on others' well-being, because excessive car use causes higher levels of pollution, traffic congestion, and noise. The current chapter is based on the assumption that the type of interdependence individuals perceive to underlie this decision situation -- commuting by car versus public transportation -may vary as a function of the salience of self-interest versus collective interest, and how much individuals think they are dependent on the car versus public transportation. As stated most explicitly in Kelley and Thibaut's (1978) interdependence theory, it is unlikely that all or most individuals merely make their choices on the basis of the "objective" decision situation, or the given matrix that represents an individual's immediate outcomes. Indeed, one may assume that any given structure of interdependence undergoes a series of transformations so as to result in an effective matrix that is more directly predictive of behavior in interdependent situations. Such transformations may be dictated by an individual's personal motives, such as a concern for comfort, or individual freedom. On the other hand, such transformations may also be dictated by a concern for the collective welfare, the willingness to contribute to a good future, or a motivation to be a good "example" to other individuals. We propose that such "pro-social" or "pro-society" transformations are greater to the extent that self-interest is less salient, and to the extent that individuals think they are -- or actually are -- less dependent on the car.

\section{The role of the perceived interdependence structure}

In what ways may the decision between car and public transportation be construed, and what are the characteristics of different interdependence structures individuals may perceive? We propose that individuals may interpret this decision situation in at least two distinct ways. First, an individual may interpret the decision situation as a choice between personal convenience and our environment. According to this interpretation (hereafter referred to as an environmental interpretation), the option of going by car is attractive from an individual short-term perspective. Relative to public transportation, traveling by car is considered to have greater benefits in terms of convenience, such as flexibility, independence, and comfort. The option of going 
by public transportation, however, may be relatively more attractive from a collective long-term perspective. Relative to cars, public transportation is cleaner, and therefore less damaging to our environment. The structure of interdependence underlying an environmental interpretation shows similarities to the $\mathrm{N}$-person Prisoner's Dilemma (Hamburger, 1979; Van Lange, Liebrand, Messick, \& Wilke, 1992) or to the social trap (Platt, 1973): The option of going by car (i.e. noncooperative choice) is always more attractive to an individual regardless of other individuals' choices. However, if all individuals opt for the car, then each individual is eventually worse off than if all individuals had opted to go by public transportation (i.e., cooperative choice). The simple fact that this environmental interpretation comes into being when individuals realize the long-term detrimental effects associated with car use, suggests that such individuals essentially make a pro-social or pro-society transformation of the given situation: They will view the decision situation not only in terms of their own immediate payoffs, but also consider the situation in light of long-term effects for all individuals involved. Hence, those who spontaneously consider the decision situation as an environmental problem will be more concerned with the collective interest than those who do not.

A second possible interpretation of the decision between car versus public transportation is more strongly affected by the criterion of accessibility. According to this accessibility interpretation, an individual does not so much view the decision situation in terms of long-term or societal implications, but focuses on the immediate costs or benefits for self: "What is the most efficient or quickest way to travel?" An accessibility interpretation reflects a structure of interdependence that is fundamentally different from the structure of interdependence underlying an environmental interpretation. According to the accessibility interpretation the option of going by car is more attractive to the extent that fewer other individuals go by car, because of a lower probability of traffic jams and/or parking problems. The option of going by public transportation is more attractive to the extent that more other individuals go by car, and traffic jams and parking problems could be avoided. From this point of view, an individual's choice should be strongly influenced by his or her expectations regarding the probable behavior of other individuals. The structure of interdependence underlying an accessibility interpretation resembles the so-called $N$-person Chicken Dilemma (Liebrand, 1983). As opposed to the N-person Prisoner's Dilemma there is no dominant option in the $\mathrm{N}$-person Chicken Dilemma. Individuals are better off by a car choice (i.e., noncooperative choice) than by a public transportation choice (i.e., cooperative choice) when a sufficient number of other individuals do not opt for the car. If a great number of other individuals opt for the car, then the option of public transportation is more attractive. Thus, when individuals construe the decision situation as an accessibility problem, then the expectations regarding other individuals' choices should be an important determinant of their choices. 
To summarize, we propose that the choice to commute by car or by public transportation could be interpreted spontaneously in two different ways; (1) as an environmental problem with the features of a N-person Prisoner's Dilemma, and (2) as an accessibility problem with the features of an N-person Chicken Dilemma. Whereas the environmental interpretation is assumed to be instigated by a salience of collective interest, the accessibility interpretation is instigated by a greater salience of self-interest.

\section{Dependence on car versus dependence on public transportation}

The line of reasoning above provides a conceptual framework that allows us to understand how individuals may construct different interdependence situations. We propose that the interpretation of the decision situation, at least in part, depends on the salience of the individual interest versus collective interest, which in turn is influenced by how much individuals think they are dependent on the car versus public transportation. Put differently, the salience of self-interest [versus collective interest] should be affected by the level of dependence on the car (or public transportation), i.e., "how much one needs the car [versus public transportation]. The level of dependence on the car or public transportation is likely to be influenced by a variety of more specific factors. Examples are the extent to which one is used to the car or public transportation, fully aware of the pros and cons regarding the car or public transportation, and poorly informed about the pros and cons regarding alternative means of transportation. Therefore, we assume that people who tend to use the car on a daily basis - the majority of commuters in the Netherlands (Central Bureau of Statistics, 1991) -- not only feel more dependent on or attached to the car, but also have more experience with the advantages and disadvantages of the car than people who never or very infrequently use the car -most of the students in the Netherlands. The ease with which luggage can be taken, the comfort and individual freedom could be mentioned as favorable aspects of the car. On the other hand, daily commuters also have experience with some aversive aspects of the car, particularly the frustration due to ending up in a traffic jam or due to not finding parking space. To individuals who frequently go by car, these advantageous and disadvantageous aspects may be highly salient, and therefore we assume that commuters are likely to perceive the decision situation as an accessibility problem.

Individuals who less frequently use the car and presumably feel they are less dependent on the car - students - are less likely to construe the decision situation as a problem of accessibility. In the Netherlands, most students are very much dependent on public transportation because they usually do not have enough money to buy a car, and they have free access to public transportation. Most students evaluate the pros and cons of public transportation in the absence of viable alternatives, and are therefore likely to take most of the disadvantages associated with public transportation for granted. They also experience a clear advantage of public transportation over the car: Public transportation is less damaging to the 
environment. The negative implications regarding excessive car use (e.g., pollution, smell) are even more salient, because students frequently use the bike. Therefore, we assume that students are likely to emphasize the environmental aspects regarding the decision situation. Because commuters are more dependent on their cars than students -- who are more dependent on public transportation -- we predict that commuters exhibit a greater tendency to prefer the option of going by car than students who should exhibit a greater tendency to prefer the option of going by public transportation (Hypothesis 1).

\section{The role of expectations regarding other commuters' choices}

We have asserted that commuters are likely to perceive the decision situation primarily as an accessibility problem, and that -- through their personal experience - they are fully aware of the advantages and disadvantages of the car as a means to commute. It is important to note that some (if not most) of the disadvantages (e.g., traffic jams, problems findings parking space), at least in part, are caused by interdependent others. Hence, commuters are likely to construe the decision as an $\mathrm{N}$-person Chicken Dilemma, in which going by car (i.e., the noncooperative option) is only more attractive than going by public transportation (i.e., the cooperative option) to the extent that fewer other individuals choose to go by car. Therefore, if commuters perceive the decision problem primarily as an $\mathrm{N}$-person Chicken Dilemma, then their preferences should be influenced to a great extent by what they think other individuals will choose.

In contrast, we have asserted that students are likely to perceive the decision situation as an environmental problem which resembles the properties of an N-person Prisoner's Dilemma. From a game theoretical point of view, the expectations regarding the behavior of other individuals should not influence own preferences in the situation. Whether the majority of other individuals decides to commute by car or by public transportation, in either case the option for commuting by car is the relatively more attractive one. However, there may be a variety of psychological factors that lead individuals to prefer the same option as what they think other are going to choose (e.g., normative or conformity pressures; cf. Liebrand, Wilke, Vogel, \& Wolters, 1986; Kerr, 1989). But, unlike the perception of an N-person Chicken Dilemma, the perception of an N-person Prisoner's Dilemma should not lead to a stronger motivation to prefer the cooperative option as the actor thinks that fewer other individuals will choose for this cooperative option. Therefore, among students preferences for public transportation should be greater when they think that the majority will choose for commuting by public transportation than when they think that the majority will choose for commuting by car. In contrast, among daily commuters preferences for public transportation should be greater when they think that the majority will choose for commuting by car than when they think that the majority will choose for commuting by public transportation (Hypothesis 2). 
Finally, the perception of the structure of interdependence could also be influenced by the presentation of the "objective" structure of interdependence (cf. McClintock \& Liebrand, 1988). By presenting the decision problem as an accessibility problem an individual's self-interest may become more salient. Conversely, by presenting the decision situation as an environmental problem the collective interest may become more salient. This allows us to test the hypothesis that students have a stronger preference for commuting by public transportation when many other individuals are expected to commute by public transportation and the situation will be presented as an environmental problem. As opposed to students, commuters will have a stronger preference to go by public transportation when many people are expected to go by car and the situation is presented as an accessibility problem (Hypothesis 3 ).

\subsection{Method}

\section{Research participants}

The experiment was conducted using two different samples. The first sample consisted of undergraduate students of the Faculty of Health Sciences at the University of Limburg in Maastricht. A questionnaire was administered as part of social science class. In total, eighty-six students participated: 72 women and 14 men. The second sample consisted of employees of a large insurance company in Utrecht. All of these employees usually commuted by car. Of the 120 questionnaires that were distributed, 88 were returned ( $73 \%$ ), 60 by men and 28 by women.

\section{Overview of the design}

The questionnaire contained a hypothetical commuting situation. There were six different versions of the commuting situation. First, the expectations regarding others' choices were manipulated: One group was led to believe that the majority commutes by car, and the other group was led to believe that the majority commutes by public transportation. Second, the situation was presented in one of three ways: As an environmental problem, an accessibility problem, or as both an environmental and accessibility problem. The experimental design was thus a 2 (Group: Commuters vs. Students) by 2 (Expectation: Majority Car vs. Majority Public Transportation) by 3 (Presentation: Environmental problem, Accessibility problem, vs. Combined problem). The main dependent variable was the preference for car versus public transportation.

\section{The commuting situation}

A description of a hypothetical commuting situation -- with a distance of 30 kilometers between home and work -- was given on paper (see for an example, Appendix I). The research participants were asked to imagine that they were 
commuters for a single day in this situation. They could state their preference either to commute by car or to commute by public transportation.

Manipulation of Expectation. Participants were given information about the travel-mode choices that were supposedly made in earlier research with the same commuting situation. It was suggested that in each of the earlier studies either a majority $(60 \%)$ chose to go by car or a majority $(60 \%)$ chose to go by public transportation.

Manipulation of Presentation. In the presentation of the situation as an Environmental problem it was stated that there would be serious environmental damage when a majority were to go by car in the commuting situation. Specifically, it was stated that "the vegetation at the side of the road will decrease slowly as a consequence of acid rain produced by cars. Moreover, a contribution is made to the greenhouse effect which may threaten mankind in the future". In contrast, it was stated that "regardless of the number of commuters, public transportation will hardly cause any damage to the environment". In the presentation as an Accessibility-problem it was argued that there would be a serious time delay due to congestion when a majority were to go by car. Normally it would take 40 minutes by car. However, when a majority would choose to go by car the travel time would be 70 minutes. The travel time by public transportation was always 50 minutes -- including the time of pre- and post-transportation. In the presentation as a Combined problem both information about potential environmental damage and about a potential delay was given.

\section{Dependent measures}

Students and commuters stated their preferences for the car or public transportation on a seven point bipolar scale, ranging from 1 (strong preference to commute by car) to 7 (strong preference to commute by public transportation). In order to examine more closely how the decision situation was construed, we asked each participant to write down the main reasons for his or her preference. By focusing on spontaneous use of arguments related to environment (e.g., environmental pollution, environmental damage) or accessibility (e.g., travel time, traffic congestion), we counted the number of people that either mentioned environment or accessibility as a major reason for their preference.

\subsection{Results}

\section{Preference for car versus public transportation}

Car versus public transportation preferences were analyzed in a 2 (Group: Students vs. Commuters) by 2 (Expectation: Majority Car vs. Majority Public Transportation) by 3 (Presentation: Environmental problem, Accessibility problem, vs. Combined problem) ANOVA. This analysis revealed a strong main effect for 
Group, $F(1,162)=53.15, p<.001$. As predicted by Hypothesis 1 , Commuters had a stronger preference for car $(M=3.30)$ than did Students $(M=5.26)$. Further testing revealed that each of these means differed significantly from 4 , the midpoint of the preference scale. Commuters preferred commuting by car above the neutral point, $t(87)=3.74, p<.001$, whereas Students did the opposite, $t(85)=6.30, p$ $<.001$.

In addition to the main effect for Group, the analysis revealed an interaction of Group and Expectation, $F(1,162)=10.72, p<.001$. The means associated with this interaction are shown in Table 1.

Table 1

Preferences for Public Transportation as Function of Personal Dependence and Expectation about Others'

Expectation about others' commuting decisions

Majority

car Majority public transport

Group

Students

$5.07^{\mathrm{a}}$

$5.44^{\mathrm{a}}$

Commuters

$3.98^{\mathrm{b}}$

$2.61^{\mathrm{c}}$

Note. The preference scale ranges from 1 (= strong preference for car) to 7 (= strong preference for public transportation); means with a different superscript differ significantly, $p<.05$

As can be seen in Table 1, commuters exhibited a stronger public transportation preference when they are led to believe that the Majority commutes by Car than when they are led to believe that the Majority commutes by Public Transportation. This finding is consistent with the idea that commuters construe this decision situation as an N-person Chicken Dilemma. 
Preferences of students were not significantly influenced by our manipulation of Expectation, although there is a tendency towards greater Public Transportation preferences when they think that the majority chooses to commute by public transportation versus by car. Thus, Hypothesis 2 is supported for the commutersample, but not or marginally at best for the student-sample.

This lack of support for a part of Hypothesis 2 could be due to the fact that many students did not have a driver's license (which is not uncommon in the Netherlands). Therefore, using the student sample, we performed an analysis of variance and added the factor Driver's License (License versus No license) to the design. The analysis revealed a significant interaction of Driver's license and Expectation, $F(1,74)=16.83, p<.03$. The means associated with this interaction are presented in Table 2 .

Table 2

Preferences for Public Transportation as Function of Driver's License and Expectation for Student sample

Expectation about others' commuting decisions

Majority

car

$N$

Driver's license

License

55

$4.39^{a}$

$5.30^{b}$

No License

31
Majority public transport

Note. The preference scale ranges from 1 (= strong preference for car) to 7 (= strong preference for public transportation); means with a different superscript differ significantly, $p<.05$

The means in Table 2 reveal that there is a difference in stated preference between the Expectation-conditions only for students who possess a Driver's License. When students with a License expect a Majority to commute by Public Transportation 
they also have a stronger preference to go by public transportation than when they expect a Majority to go by Car. Thus, Hypothesis 2 is supported for students with a driver's license. This finding illustrates that students (with a driver's license) perceive the decision situation as an -- pro-socially transformed -- N-person Prisoner's Dilemma.

Finally, we were interested in examining the idea that students would exhibit a stronger public transportation preference when the majority was expected to commute by public transportation and the decision problem was presented as an environmental problem, and the idea that commuters would exhibit a weaker car preference when the majority was expected to commute by car and the situation was presented as an accessibility problem (Hypothesis 3). Ideally, support for this hypothesis would be revealed by a significant interaction of Group, Expectation, and Presentation. However, this three-way interaction was not found to be significant, $F(2,162)<1$. To provide a more precise test for each of these predicted interactions separately, we conducted two 2 (Expectation) by 3 (Presentation) ANOVA's, one using the student sample, the other using the commuter sample.

Using the student sample, this analysis did not reveal evidence for an interaction of Expectation and Presentation, $F(2,74)<1$.

Using the commuter sample, a 2 (Expectation) by 3 (Presentation) ANOVA revealed a marginally significant interaction of Expectation and Presentation, $F(2,80)=3.90, p<.06$. The means associated with this interaction effect are presented in Table 3. 
Table 3

Preferences for Public Transportation as Function of Presentation and Expectation for Commuter sample

Expectation about others' commuting decision

Majority
car
Majority

public

transport

Presentation

$\begin{array}{lcc}\text { Environmental problem } & 3.50^{\mathrm{a}} & 2.64^{\mathrm{a}} \\ \text { Accessibility problem } & 4.31^{\mathrm{b}} & 2.60^{\mathrm{a}} \\ \text { Combined problem } & 4.20^{\mathrm{b}} & 2.60^{\mathrm{a}}\end{array}$

Note. The preference scale ranges from 1 (= strong preference for car) to 7 (= strong preference for public transportation); means with a different superscript differ significantly, $p<.05$.

Consistent with Hypothesis 3, commuters' car preference was lowest when the decision situation was presented as an Accessibility problem or a Combined problem and when commuters were led to believe that the majority would commute by car. Interestingly, when commuters were led to believe that the majority would commute by public transportation, then their car preferences were not in the least influenced by the three different presentations.

After the participants in both samples had stated their car versus public transportation preferences, they were asked to write down the reasons for their preferences. A chi-square analysis on the frequencies of these reasons revealed some clear-cut differences between the samples in mentioning environmental and accessibility arguments, $\operatorname{Chi}^{2}(1, N=174)=37.37, p<.001$. Environmental arguments are given by $46 \%$ of the students and by only $9 \%$ of the commuters, whereas travel time and traffic congestion is mentioned as an argument by only $14 \%$ of the students and by $47 \%$ of the commuters. Apart from environmental 
arguments, $40 \%$ of the students gave practical reasons for their preference, like having free access to public transportation. A considerable amount of commuters mentioned convenience and freedom, besides travel time as arguments for their preference $(33 \%)$.

\subsection{Discussion}

\section{Main conclusions}

This study was conducted in light of the belief that excessive car use may ultimately lead to a disastrous situation, or at least a situation most of us rather do not like to think about. We have used Kelley and Thibaut's (1978) interdependence theory to analyze how individuals may construct different interdependence situations on the basis of the same decision situation (i.e., a commuting situation). Because of their felt dependence on cars as a means to commute, we claimed that commuters would primarily perceive this decision situation as an accessibility problem, with a structure very similar to an $\mathrm{N}$-person Chicken Dilemma. Conversely, students who were expected to feel a greater dependence on public transportation were assumed to perceive the decision situation primarily as an environmental problem, with a structure very similar to an N-person Prisoner's Dilemma. The results were quite consistent with these claims.

One major finding of this study is that the participants in the two samples -students and daily commuters -- responded differently to expectations regarding the choices of other individuals. Students -- at least those students with a driver's license -- tended to have a weaker preference for commuting by public transportation when a majority of the others was expected to commute by car than when a majority was expected to commute by public transportation. This finding, in support of Hypothesis 2, is reminiscent of a very robust relationship between expectations and choice observed in experimental research on prisoner's dilemmas, in particular in those studies in which the expectations of others' cooperation were manipulated (e.g., Liebrand et al., 1986; Schroeder, Jensen, Reed, Sullivan, \& Schwab, 1983). The present findings may very well be explained in terms of conformity and normative pressures associated with beliefs regarding others' concern with environmental pollution. It is morally more acceptable to commute by car when one believes that a majority commutes by car than when one believes that a minority commutes by car.

Also consistent with Hypothesis 2, commuters exhibited a weaker preference for commuting by car when they believed that the majority commuted by car than when they believed that the majority commuted by public transportation. This provides some evidence for our claim that commuters are likely to transform the given decision situation into an accessibility problem, with an $\mathrm{N}$-person Chicken Dilemma structure. From this "effective matrix," it indeed is more rational to cooperate when one believes that a greater number of others do not cooperate. 
Moreover, it appeared that in the condition in which the majority prefers to commute by car, commuters exhibited virtually identical preferences for commuting by public transportation when the situation was presented as an accessibility problem only and when the situation was presented as an accessibility plus environmental problem, and both of these conditions yielded stronger public transportation preferences than when the situation was merely presented as an environmental problem. This suggests that commuters were more persuaded by the accessibility interpretation than by the environmental interpretation. Finally, the reasons commuters described for their preferences were consistent with an accessibility interpretation: About half of them $(47 \%)$ spontaneously reported travel time as a reason, whereas only $14 \%$ of the students reported this reason. These findings provide convergent evidence in support of the claim that commuters tend to perceive the decision situation as an accessibility problem, rather than an environmental problem.

The current findings did not reveal unequivocal support for Hypothesis 3, that students' preference for commuting by public transportation would be especially greater when both they expected a majority to commute by public transportation and the situation was presented as an environmental problem. One post-hoc interpretation of this finding is that the type of presentation had little influence on students' perceptions of the decision situation. It seems plausible that students are quite convinced in advance that the choice between car and public transportation is an environmental issue, and the environmental presentation (by the experimenter) does not further strengthen this conviction.

The study revealed some support for the idea that commuters' preferences for commuting by car would be especially low when they believe that the majority commutes by car, and when the presentation includes the accessibility interpretation. The interesting result here is that for commuting purposes public transportation can be better promoted by stressing the limits of the accessibility of cars than by stressing the environmental advantages of public transportation. Throughout the chapter we have analyzed the decision "car versus public transportation" in terms of interdependence theory (Kelley \& Thibaut, 1978), in particular accentuating the role of transformation processes. Although interdependence theory is in essence focused on dyadic relations, and may not be so easily applicable to multi-person situations, the current findings underline the usefulness of an interdependence analysis. Indeed, individuals tend to construct different interdependence situations on the basis of broader goals, whereby students are more likely than commuters to make a pro-social or pro-society transformation of the decision situation, because students are relatively less dependent on cars, and more dependent on public transportation. It should be noted that this analysis does not preclude any other (better) theoretical analysis. However, the experiment was designed not so much to test interdependence theory, but to use interdependence theory as a conceptual framework. 
In the current study we also found strong support for Hypothesis 1: Commuters exhibited a stronger preference for commuting by car than did students who exhibited a stronger preference for commuting by public transportation. This finding was anticipated on the basis of differential levels of experienced dependence on cars versus public transportation. However, as an alternative explanation, one might argue that this finding reflects sex differences -- the vast majority of students were women, whereas the majority of commuters were men. Indeed, the current study cannot rule out the interpretation that women are more in favor of public transportation than men who might be more in favor of cars, and that women and men may respond differently to expectations regarding others' choices. However, in prior social dilemma research sex-differences in choice behavior are rather inconsistent (Van Lange, 1992). Thus, it seems not plausible that the current results are due to the stereotypical idea that women are more cooperative than men. Another stereotype -- that men like car driving better than women -- may provide a more plausible explanation.

\section{Strengths, limitations and implications of the study}

Before closing, we wish to outline a few strengths and limitations of the current research. One limitation is that the study employed a hypothetical decision situation. It may therefore be that tendencies toward social desirability or favorable self-presentation, at least in part, colored the findings obtained. Second, the current study cannot rule out several alternative explanations for the obtained differences between commuters and students. In addition to the interpretation based on sexdifferences, it is also possible that differences in age, income, or other more or less unforeseen differences related to the distinction commuters versus students help to explain the results.

A major strength of the current study is that we concentrated on a real-life dilemma situation, using a sample of individuals (commuters) whose commuting behavior at the moment is of utmost importance to the future quality of the environment. The finding that these individuals are inclined to perceive the decision situation as an accessibility problem with the structure of an N-person Chicken Dilemma helps to understand why campaigns stressing the concern for the environment are in fact less effective than we had hoped. This suggests that, in designing campaigns aimed at reduction of car use, one has to take into account the interpretations people assign to such situations of interdependence. A moral appeal to the collective interest of a clean environment is more likely to change the behavior of an individual who does not feel dependent on the car than the behavior of an individual who feels very much dependent on the car. These latter individuals may be more sensitive to arguments that emphasize the personal benefits associated with public transportation, or the disadvantages associated with commuting by car, such as travel time and perhaps the greater financial costs of the car. 


\section{Chapter 3 \\ Transforming the commuting situation: The influence of social value orientations ${ }^{1}$}

"...the key to motivating individual and collective action -- whether to halt the destruction of the environment, to eliminate the threat of nuclear confrontation, to get involved in neighborhood crime-watch organization, or to form a self-help group to cope with shared problems -- is to be found in the psychological functions that such activism serves."

-- Snyder (1993, p. 259)

\subsection{Introduction}

\section{Availability and quality of commuting options}

It is widely assumed that the car is one of the greatest inventions of human technology. People ascribe to cars highly-rewarding qualities like convenience, efficiency, and individual freedom. Despite these positive qualities, society increasingly faces serious problems caused by the massive use of cars. Currently, many major cities in the world are trying to cope with air pollution, noise, and congestion because they have relied all too heavily on cars as a means of transportation, while ignoring alternatives, such as public transportation, biking, or walking. In a study of 32 of the world's major cities, Newman and Kenworthy (1989) found wide variations in the percentages of people commuting by car. In Washington D.C., for example, $81 \%$ commuted by car, in Amsterdam $58 \%$, whereas in Tokyo only $16 \%$ commuted by car. It is clear that decisions regarding commuting by car versus public transportation are affected by structural variables, such as a scarcity of parking space, the likelihood of traffic jams, or differences in the quality or costs of cars versus the quality or costs of public transportation. In the Netherlands -- where 55\% commute by car (Central Bureau of Statistics, 1991) -- both car and public transportation are often equally viable commuting options, because these options do not tremendously differ in travel time or travel costs.

The current chapter uses interdependence theory (Kelley \& Thibaut, 1978) to analyze the decision to commute by car versus public transportation. Our main assumption is that individuals may construe the decision situation as either an environmental issue or an accessibility problem. Moreover, it is assumed that such

\footnotetext{
This chapter was published as:
}

Van Vugt, M., Meertens, R. M., \& Van Lange, P. A. M. (1995). Car versus public transportation? The role of social value orientations in a real-life social dilemma. Journal of Applied Social Psychology, 25, 258-278. 
construals may vary as a function of the individual's social value orientation (i.e., individual's preferences for particular patterns of outcomes for self and others; Messick \& McClintock, 1968). On the basis of these assumptions some hypotheses will be tested regarding the influence of social value orientations on preferences for car versus public transportation in a commuting situation.

\section{Car versus public transportation: An interdependence analysis}

The decision to commute by car or by public transportation has consequences not only for the commuter him- or herself but also for others. An individual's wellbeing may be strongly affected by the choices of others in at least two different ways. As more people commute by car rather than by public transportation, the individual may experience (a) the negative effects of environmental pollution and/or (b) the costs associated with traffic congestion, provided that he or she commutes by car as well. Similarly, the individual's own choice affects the well-being of others. This interdependent situation is to some extent problematic, because the individual's own well-being may be better served by a choice for the car -- as it may yield greater individual outcomes in terms of convenience, flexibility, and privacy -- whereas the well-being of others is better served by the individual choice for public transportation, which neither contributes to pollution nor to congestion. This particular type of interdependence yielding a conflict between individual and collective interests is better known as a social dilemma (Dawes, 1980; Messick \& Brewer, 1983).

Individuals may construe a situation in which they must decide to go by car or by public transportation in at least two distinct ways (cf. Van Vugt, Meertens, \& Van Lange, 1994). First, the decision to commute by car or by public transportation can be interpreted as a choice between the pursuit of own immediate outcomes (i.e., personal convenience) versus a concern with the collective wellbeing in the long run (i.e., our environment). According to this interpretation, the choice for the car is attractive from an individual short-term perspective. Relative to public transportation, the car generally provides more convenience, flexibility, and privacy. On the other hand, the choice for public transportation is attractive from a collective long-term perspective, because - relative to cars -- public transportation produces fewer waste materials that threaten the quality of our environment. The structure of interdependence underlying this interpretation resembles an N-person Prisoner's Dilemma Game (Dawes, 1980; Hamburger, 1979; Van Lange, Liebrand, \& Kuhlman, 1990), or a social trap (Platt, 1973). According to this interpretation, the option of going by car (i.e., non-cooperative choice) is always more attractive to an individual regardless of other individuals' choices. However, if all individuals opt for the car, then each individual is ultimately worse off than if all individuals had opted to go by public transportation (i.e., cooperative choice).

A second possible interpretation of the decision to commute by car or by public transportation is instigated by considerations of travel time, ride continuity, 
and accessibility. The decision situation is viewed not so much in terms of long-term societal consequences, but rather in terms of the immediate costs and benefits for oneself: "Would it be more efficient or quicker to go by car or public transportation?" The interdependence structure reflecting this accessibility interpretation is fundamentally different from the interdependence structure reflecting a choice between personal convenience and our environment. According to an accessibility interpretation the choice for commuting by car is more attractive as fewer individuals choose to go by car, because of a lower probability of time delays due to traffic jams, and/or parking problems. However, when the number of others commuting by car exceeds a certain limit, the choice for public transportation may yield greater outcomes for oneself because congestion can be avoided. The structure of interdependence underlying an accessibility interpretation resembles the so-called N-person Chicken Dilemma Game (Liebrand, 1983; Liebrand, Wilke, Vogel, \& Wolters, 1986). Individuals are better off by a choice for the car (i.e., non-cooperative choice) than a choice for public transportation (i.e., cooperative choice) when a sufficient number of other individuals do not opt for the car².

\section{Transformation of motivation: The role of social value orientations}

What factors determine whether individuals construe the decision to commute by car or by public transportation as an environmental versus accessibility problem, or as a Prisoner's versus Chicken Dilemma Game, respectively? The fundamental assumption underlying the current chapter is that judgments and decisions regarding commuting by car versus public transportation are shaped by what Kelley and Thibaut (1978) in their interdependence theory have referred to as transformation of motivation. They argue that it is unlikely that all or most individuals make their choices on the basis of the same "objective" decision situation, or the given matrix that represents an individual's immediate outcomes. Indeed, one may assume that any given structure of interdependence undergoes a series of transformations so as to reach an effective matrix that is more directly predictive of behavior in interdependent settings. Such transformations may, on the one hand, be dictated by an individual's self-interested concerns, such as considerations of personal prosperity and well-being. On the other hand, such transformations may also be dictated by broader concerns, such as consideration of collective welfare, willingness to contribute to a good future, or motivation to set a "good example" to other individuals.

${ }^{2}$ Formal descriptions of the Prisoner's and Chicken Dilemma Games are discussed in more detail by Kelley and Thibaut (1978) and Liebrand (1983). It should be noted that the Chicken Dilemma represents an interdependence structure that is very similar to the one obtained by an accessibility interpretation (cf. Liebrand, 1983); however, this is not to deny that other games that similarly - or even more extensively - represent possibilities for coordination (e.g., "Battle of Sexes", as suggested by Harold Kelley [1994; personal communication]) may also serve as a model for an accessibility interpretation in this commuting context. 
One of the factors that may determine these divergent transformations are social value orientations (McClintock, 1972), or differences in the way individuals evaluate outcomes for themselves and others. There is empirical support for at least three distinct orientations (e.g., Kuhlman \& Marshello, 1975; Messick \& McClintock, 1968; McClintock \& Liebrand, 1988): cooperation (i.e., the tendency to maximize joint welfare), individualism (i.e., the tendency to maximize own welfare with no or very little regard for others' welfare), and competition (i.e., the tendency to maximize relative advantage over others' welfare). Accordingly, cooperators or "pro-social" individuals should primarily evaluate interdependent situations in terms of collective welfare, whereas "pro-self" individuals (individualists and competitors) should primarily evaluate such situations in terms of their own well-being.

Over the past decades, this claim has received considerable support, revealing that -- relative to individualists and competitors -- pro-socials are more likely to exercise personal restraint, and to make cooperative choices in a variety of interdependent situations, including social dilemma tasks (e.g., Knight \& Dubro, 1984; Kramer, McClintock, \& Messick, 1986; McClintock \& Liebrand, 1988; Sattler \& Kerr, 1991; Van Lange \& Kuhlman, 1994). Although much of this work has focused primarily on decision making in relatively abstract contexts -- using experimental games as a means to induce and examine interdependent situations (for exceptions, see McClintock \& Allison, 1989) -- the findings highlight the idea that pro-socially oriented individuals assign greater weight and attention to the long-term collective consequences, whereas individualists and competitors primarily focus on their immediate self-interests.

Thus, in the context of commuting decisions it is likely that pro-socials -more than individualists and competitors -- take account of the long-term collective consequences for the environment, evaluating how much car versus public transportation differ in terms of the amount of harm done to the environment. That is, they are assumed to primarily transform the situation into an N-person Prisoner's Dilemma Game. Conversely, individualists and competitors are more likely than pro-socials to consider their short-term self-interest, evaluating how much these options differ in personal convenience, flexibility, and accessibility. Because the individual outcomes associated with travel time by car (versus public transportation) depend largely on the decisions of others, we assume that pro-self individuals will view the situation primarily as an $\mathrm{N}$-person Chicken Dilemma Game.

\section{Research design and hypotheses}

The above provides a conceptual framework in which to understand how individuals with differing social value orientations may construe and behave in a real life social dilemma -- the decision to commute by car versus public transportation. Ideally, one would like to examine such issues in the real world; however, it seems exceedingly difficult to successfully manipulate people's beliefs regarding other people's commuting choices because of various situational and ethical constraints 
(for related reasoning, see Cooper 1976; Weiner 1980). Accordingly, the current research complements prior research on social dilemmas by examining a hypothetical commuting task designed to simulate decisions regarding car versus public transportation as closely as possible by using actual commuters and by presenting "outcomes" in terms of the magnitudes of travel time and environmental pollution. This task was used to test three hypotheses following from our prior discussion and further explicated in the next paragraphs.

Given pro-socials' concern with collective welfare and pro-selfs' concern with own well-being, we predicted, first, that pro-socials would exhibit a stronger preference to commute by public transportation than pro-selfs who would be more likely to prefer commuting by car (Hypothesis 1). Support for this prediction would not only provide evidence in support of the ecological validity of social value orientations, but would also contribute to our understanding of the determinants of environmentally relevant behavior. This seems particularly important in light of Stern's (1992) extensive review of environmental change in which he concluded that "personality variables rarely show systematic relationships to environmentally relevant behavior, with the exception of locus of control and related variables" (p. 284). Furthermore, he asserted that little is known regarding the link between motives or values such as egoism and altruism and environmental behavior ( $\mathrm{pp}$. 279-281).

Second, based on the assumption that pro-socials primarily construe the situation as an environmental issue (resembling an N-person Prisoner's Dilemma), whereas pro-selfs primarily construe it as an accessibility problem (resembling an $\mathrm{N}$-person Chicken Dilemma), we predicted an interaction of social value orientation and expectations about others' commuting choices. In a considerable body of research regarding N-person Prisoner's Dilemmas, it has been demonstrated that cooperative choices can be elicited by cooperation of the majority of others (e.g., Liebrand et al., 1986; Schroeder, Jensen, Reed, Sullivan, \& Schwab, 1983; Yamagishi, 1986). One of the possible explanations for this finding is that the behavior of a majority may give rise to conformity pressures that provide individuals with a standard as to what is the most appropriate thing to do. On the other hand, decisions in Chicken Dilemmas should be extremely sensitive to expectations of others' cooperative behavior, because the individual outcomes are directly affected by the behavior of others. That is to say, non-cooperation yields greater outcomes for self if the majority cooperates, but yields lower outcomes for self if the majority does not cooperate. Taken together, it is predicted that prosocials should exhibit a stronger preference for public transportation when they believe that the majority of others commute by public transportation. Conversely, pro-selfs should be more strongly motivated to commute by public transportation when they believe the majority of others commute by car (Hypothesis 2).

Furthermore, the interaction of social value orientation and expectations about others' choices, predicted in Hypothesis 2, may be more pronounced when 
the possibility of traffic congestion associated with commuting by car is more salient. Accordingly, the current research manipulated the possibility of congestion (no possibility versus a clear possibility of congestion), so as to test the following specific hypothesis. When people believe that the majority commutes by car, then pro-self individuals in particular may be more motivated to commute by public transportation under conditions in which there is clear possibility of time delay (caused by congestion) than under conditions in which this is less of a possibility. For pro-socials we predict that their preferences will take a similar form in these two conditions. (Hypothesis 3).

While these two outcomes -- travel time and environmental pollution -- are assumed to be important, it is not expected that these are the only attributes that individuals take into account in evaluating car or public transportation in real-life commuting decisions. Accordingly, we administered a judgment task in which we asked commuters to rate the two options on a list of travel attributes that are assumed to affect commuting decisions as well. This allows us, first, to examine whether individuals indeed construe commuting decisions as a social dilemma - a deliberation between individual (e.g., travel convenience, travel flexibility, and travel time) versus collective outcomes (e.g., environment, public health). Second, this may provide some evidence in support of the ecological validity of the predicted relationship between social value orientations and commuting decisions. That is to say, relative to individualists and competitors, pro-socials presumably assign greater weight to the collective outcomes and smaller weight to the individual outcomes of their travel decisions. To further investigate this issue, we examined how pro-social and pro-self individuals would respond to a serious environmental threat in their personal commuting situation.

\subsection{Method}

\section{Participants and design}

Thirty-one female and 25 male Dutch adults were recruited by an advertisement in three local newspapers of Maastricht, inviting commuters by car to participate in a study about decision-making in commuting situations. The average age of the commuters was 32 years. All people commuted by car on a daily basis. They were paid 25 Dutch Guilders (about $\$ 14$ in U.S. currency) for their participation. The design was a 2 (Social Value Orientation: Pro-socials vs. Pro-selfs) by 2 (Expectations of Others' Commuting Choices: Majority Car vs. Majority Public Transportation) by 2 (Congestion: Absence of Congestion-possibility vs. Presence of Congestion-possibility). All variables were between-subjects factors. The major dependent variable was the individual's preference for commuting by car or by public transportation. 


\section{Procedure}

The experiment was scheduled in groups of six people. Upon arrival, each individual was individually seated in front of a computer in a separate cubicle. After the general instructions, two tasks followed: (1) the measurement of individuals' social value orientations, and (2) the simulation of a commuting situation. The experiment concluded with a post-experimental questionnaire and a careful debriefing.

The measurement of social value orientation. Each individual's social value orientation was assessed by a series of decomposed games (Messick \& McClintock, 1968), which involve making choices between specific combinations of outcomes for oneself and for a (hypothetical) other. In the current chapter, we employed a computerized version of the Ring Measure of Social Value (e.g., Liebrand, 1984; McClintock \& Liebrand, 1988) -- this and related measurements of social value orientations have been shown to have good internal consistency, test-retest reliability over a period of four to six weeks, and appear to be free of tendencies toward social desirability (e.g., Liebrand, 1984; Kuhlman, Camac, \& Cunha, 1986; Platow, 1992). The Ring Measure of Social Value is described in more detail in Liebrand (1984) and McClintock \& Liebrand (1988).

The task consists of 32 choices between pairs of own/other outcome combinations (defined in terms of amounts of money). These outcome combinations are sampled from a circle within an own-other outcome space, of which the horizontal axis reflects the outcomes for self, and the vertical axis the outcomes for other. Specific own-other outcome combinations are depicted as points in this two-dimensional space. The center of the circle coincides with the $(0,0)$ point in the outcome space, delineating an outcome of zero for Self and zero for Other. The circle in the present study has a radius of 10.00 Dutch florins (one Dutch florin is approximately $\$ 0.60$ ). The task of the research participant is to choose between two own-other outcome combinations that are adjacent to each other on the circle. As an example, in option A Self gets $8.30 \mathrm{Dfl}$ and Other 5.55 Dfl, whereas in option B Self gets $9.25 \mathrm{Dfl}$ and Other gets $3.85 \mathrm{Dfl}$. For each of the 32 pairs of own/other outcome combinations, people were instructed to choose that pair they most preferred.

Adding up the chosen amounts separately for Self and Other provides an estimate of the weights an individual assigns to own and other's outcomes. These weights can be used to measure each individual's value vector. Value vectors between 67.5 and 22.5 degrees (i.e., other's maximum outcome $=90$ degrees, and own maximum outcome $=0$ degrees) were classified as cooperators; those between 22.5 and 337.5 degrees as individualists, and those between 337.5 and 292.5 degrees as competitors. Consistent with previous research, participants were only classified if the length of their vector exceeded one fourth of the maximum length of a value vector. The length of a value vector provides an index of the consistency of the individual choice behavior (cf. McClintock \& Liebrand, 1988); 
the maximum vector length is twice the radius, and random choices between the pairs result in a zero vector length. On the basis of this consistency criterion, out of 56 individuals, six could not be classified, and from the classifiable people, 22 were classified as pro-social, 23 as individualistic and five as competitive. Given the low number of competitors and the fact that our hypotheses were identical for individualists and competitors, we combined individualists and competitors to form a group of essentially pro-self interested individuals. Accordingly, our analyses focused on differences between pro-social and pro-self individuals (for similar procedures, see e.g., Kramer et al., 1986; Van Lange \& Liebrand, 1991).

Simulation of commuting situation. In the second task, we described a commuting situation so as to provide a context in which to examine the individual preferences for commuting by car versus public transportation (for an example, see Appendix I). The situation was designed in an attempt to parallel very closely actual commuting situations in the Netherlands. The distance between work and home was set at 40 kilometers, which could be covered by car or by train. There was a highway near home, and a railway station within a three-minute walking distance from home. Research participants commuted during one week (i.e., for five days, from Monday through Friday). They were led to believe that the experiment was conducted with a total number of 180 people, sitting before computers at ten different locations (i.e., universities), and making commuting choices at the same time -- so as to mimic the fact that commuting situations always involve a considerable number of interdependent others. It was made explicit that people's preferences for commuting by car versus public transportation were stored on their personal computers, which were said to be linked to a mainframe computer recording all individual responses for each day. Once each individual's preference was recorded, the mainframe computer would then provide information regarding the preferred choices of all commuters. In reality, however, there were not 180 individuals involved, and the personal computer simply stored their own preferences.

Once the commuting situation was explained, it was made explicit that there would be serious environmental damage to the extent that more and more individuals would prefer commuting by car. Specifically, we stated that "the more people will commute by car, the more rapidly the vegetation at the side of the road will decrease as a consequence of acid-rain produced by cars; moreover, the greater will be the contribution to the greenhouse effect, which may threaten humanity in the future". In contrast to car use, it was stated that "regardless of the number of commuters, public transportation will not cause any damage to the environment".

Congestion. We manipulated the possibility of traffic congestion so as to examine whether the presence or absence of this possibility would affect car versus public transportation preferences. In the Absence of Congestion-condition it was stated that there would be no time delay associated with going by car, irrespective of the number of people who preferred to go by car. Commuters were told that 
going by car would always take about 40 minutes, regardless of the number of commuters going by car. In the Presence of Congestion-condition a serious time delay would occur when many others would prefer going by car. It was stated: "Normally it will take about 40 minutes to commute by car. However, to the extent that more people go by car the travel time by car could increase to as much as 70 minutes." The travel time by public transportation was always about 50 minutes -including a three-minute walk from home to the railway station, and a two minute walk from the end-station to work.

Expectations of others' commuting choices. Expectations of others' commuting choices were manipulated by providing people with information regarding the number and percentage of others who commuted by car or public transportation. Specifically, from Monday through Friday, individuals received information regarding the choices of all 180 commuters. This information, which was said to be provided by the mainframe computer, was given after each participant had stated his or her daily preference for going by car versus public transportation. In the Majority Car-condition the commuters were led to believe that a majority (range from $65 \%-75 \%$; mean $70 \%$ ) consistently commuted by car. In the Majority Public Transportation-condition they were led to believe that a majority consistently commuted by public transportation (range from 65\%-75\%; mean $70 \%$ ). Thereafter, the consequences of own and others' preferred choices in terms of environmental damage and possible time delays were presented to the research participants. The consequences for the environment and travel time as a function of Expectations and Presence versus Absence of Congestion-possibility are summarized in Table 4 (see next page). This table also shows that, when a Majority commuted by Car in the Presence of Congestion-condition, the daily travel time by car was either 61 or 62 minutes, rather than the 40 minute-travel-time for car in the other conditions. 
Table 4

Environmental and Travel Time Consequences of Decisions by a Majority of Commuters

Environmental

Congestion

consequences

Expectations about others'
Absence of congestion
Presence of congestion
Majority

by car
Serious damage produced by cars

No damage produced by public transportation
40 minutes by car

50 minutes by public transportation
61-62 minutes by car

50 minutes by public transportation
Majority by public transportation
Some damage produced by cars

40 minutes by car

50 minutes by public transportation
40 minutes

by car

50 minutes by public transportation
No damage produced by public transportation

\section{Dependent measures}

Every working day, before commuters received information regarding the choices of others, they stated their own preferences for going by car versus public transportation $(1=$ strong preference for car, $7=$ strong preference for public transportation), as well as their actual choices $(1=\mathrm{car}, 2=\text { public transportation })^{3}$.

Post-experimental questionnaire. One of the goals of this post-experimental questionnaire was to examine the ecological validity of the simulated commuting task and the role of social value orientations in commuting decisions. First, we

${ }^{3}$ Commuters were led to believe that these choices served as input for calculating the percentages of people commuting by car or public transportation. 
asked commuters: "What would you do when you are ready to leave home on a morning and suddenly there is a radio announcement, saying that serious smog will occur when too many commuters will go by car on that day?" $(1=$ commute by car, 2 = commute by alternative means of transportation). Second, individuals rated their concern ( 1 = very unimportant, $7=$ very important $)$ with each of seven travel attributes (travel time, travel costs, travel convenience, environment, public health, weather, travel flexibility).

Information checks. To provide a check for the information about environmental damage and the manipulation of Congestion, the participants were asked to rate the following statements about the decision situation: "If too many people choose to go by car on a day, there will be serious environmental damage" and "If too many people choose to go by car on a day, there will be serious time delay". All commuters $(100 \%)$ confirmed the statement that there would be serious environmental damage if too many people choose to go by car. Also, all individuals in the Presence of Congestion-condition (100\%), compared to $25 \%$ in the Absence of Congestion-condition, believed that there would be serious time delay if too many people choose to go by car, $\mathrm{Chi}^{2}(1, N=50)=30.47, p<.001$. Generally, these checks indicated that the information was understood, although the result that still $25 \%$ of the commuters in the Absence of Congestion-condition believed that there would be time delay clearly is less than ideal (we will address this issue in the Discussion).

After the working week, participants were asked whether most of the 180 people had displayed a preference to go by car or by public transportation during the week $(1=$ strong preference for car, $7=$ strong preference for public transportation). The manipulation check of Expectations is highly significant, $F(1,42)=365.88, p<.001$. Commuters in the Majority Public Transportation-condition thought that the commuters had a stronger preference for going by public transportation $(M=5.73)$ than people in the Majority Car-condition $(M=2.04)$. Finally, the participants were debriefed, thanked and paid for their participation.

\subsection{Results}

\section{Preference for car versus public transportation ${ }^{4}$}

Preferences for commuting by car versus public transportation $(1=$ strong preference for car, 7 = strong preference for public transportation) were first

${ }^{4}$ Preliminary analyses of the data revealed highly significant correlations between daily commuting preferences and commuting choices ( $r$ 's varied from .76 to .82 ). Because of the greater variance in commuting preferences relative to choices, and the fact that the hypotheses for these measures were identical, only the analyses of the first measure are reported here. 
analyzed in a 2 (Social Value Orientation: Pro-socials vs. Pro-selfs) by 2 (Expectations of Others' Commuting Choices: Majority Car vs. Majority Public Transportation) by 2 (Congestion: Absence of Congestion-possibility vs. Presence of Congestion-possibility) by 4 (Day: Tuesday through Friday) ANOVA with repeated measures for the last factor ${ }^{5}$. This analysis revealed, first, a main effect for Social Value Orientation, $F(1,42)=3.79, p<.05$. Consistent with Hypothesis 1, Pro-socials $(M=5.22)$ exhibited a stronger preference for commuting by public transportation than did Pro-selfs $(M=4.17)$.

More importantly, and consistent with Hypothesis 2, we observed an interaction of Social Value Orientation and Expectations, $F(1,42)=4.47, p<.05$. Further tests for simple effects revealed that Pro-socials exhibited a greater preference for commuting by public transportation in the Majority Public Transportation-condition than in the Majority Car-condition. In contrast, Pro-selfs exhibited a greater preference for commuting by public transportation in the Majority Car-condition than in the Majority Public Transportation-condition. These findings (see Table 5) provide evidence in support of Hypothesis 2 that stated that pro-social individuals indeed construed the decision situation as an $\mathrm{N}$-person Prisoner's Dilemma, whereas pro-self individuals construed it as an $\mathrm{N}$-person Chicken Dilemma.

\section{Table 5}

Preferences for Public Transportation as Function of Social Value Orientation and Expectation about Others'

Expectation about others'
commuting decisions

$\begin{array}{ll}\begin{array}{l}\text { Majority } \\ \text { car }\end{array} & \begin{array}{l}\text { Majority } \\ \text { public } \\ \text { transpor- }\end{array} \\ & \text { tation }\end{array}$

Social value orientation
Pro-social commuters

$4.77^{a}$

$5.75^{\mathrm{b}}$

5.22

$4.85^{\mathrm{a}}$

$M$

tation

(1)

5.22

\section{Pro-self commuters}

4.85

Note. The preference scale ranges from 1 (= strong preference for car) to 7 (= strong preference for public transportation); means with a different superscript differ significantly, $p<.05$

5 Preference on Monday was excluded from this analysis because at that point in the experiment commuters had not received information about other commuters' choices. 
In Hypothesis 3, we predicted that pro-selfs would be more in favor of public transportation when (a) they expected a majority to prefer commuting by car, and (b) they believed there was the possibility of time delay. For pro-socials we expected that their preferences for public transportation would be enhanced when a majority preferred public transportation, and that this would take a similar form in the Absence of Congestion and Presence of Congestion-conditions. Ideally, evidence in support of Hypothesis 3 would be revealed by an interaction of Social Value Orientation, Expectations of Others' Commuting Choices, and Possibility of Congestion. However, this interaction was not significant, $F(1,42)<1$. Additionally, we conducted a more precise analysis, testing whether there would be an interaction between Expectations of Others' Choices and Congestion for Pro-self commuters. However, also this two-way interaction was not significant, $F(1,24)<$ 1. Thus, we find no evidence supporting Hypothesis 3 .

Next, we analyzed people's preferences for Monday, examining whether preferences for public transportation versus car would be dependent on social value orientations when information regarding what the majority prefers could not influence such preferences. A 2 (Social Value Orientation: Pro-socials vs. Proselfs) by 2 (Congestion: Absence of Congestion-possibility vs. Presence of Congestion-possibility) ANOVA revealed a marginally significant main effect for Social Value Orientation, $F(1,46)=3.41, p<.08$. As predicted by Hypothesis 1 , Pro-socials $(M=4.95)$ tended to exhibit a stronger preference for commuting by public transportation than did Pro-selfs $(M=4.07)$.

Finally, after the commuting task people were asked how they would respond to a radio announcement saying that serious smog would occur in their own commuting situation when too many people would opt for the car. As one would expect on the basis of Hypothesis 1, more Pro-social (100\%) than Pro-self commuters $(70.6 \%)$ indicated that they would not continue commuting by car, but instead would take an alternative means of transportation, $\mathrm{Chi}^{2}(1, N=50)=5.23, p$ $<.05$. Thus, this result complements the above findings by providing additional evidence in support of the ecological validity of social value orientations in commuting decisions.

\section{Travel concerns related to car versus public transportation}

In the introduction of this chapter we assumed that the decision to commute by car versus public transportation could be defined as a social dilemma, in which a concern with long-term collective welfare should lead to preferences for public transportation, whereas a concern with own immediate well-being should lead to preferences for car. Given these claims, it is important to examine whether individuals' preferences are related to these individual and collective concerns. Accordingly, we asked individuals to rate their concern $(1=$ very unimportant, $7=$ very important) with a list of travel attributes, some of which are more descriptive of cars, whereas others are more descriptive of public transportation. If the task 
indeed has ecological validity, and commuters construe such decisions as a social dilemma, then "individual" concerns should correlate negatively, and "collective" concerns should correlate positively with their preferences for public transportation.

In Table 6, a summary is presented of the correlations between each of these concerns, and the preference for commuting by public transportation. As can be seen in Table 6, the collective concerns such as environment and public health correlated positively with the preference for public transportation. In contrast, individual concerns (e.g., travel convenience and flexibility) correlated negatively with the preference for public transportation. Moreover, the two collective concerns intercorrelated positively (correlation of judgments of environment and public health), and most of the individual concerns were intercorrelated positively (e.g., several significant correlations between judgments of travel costs, travel flexibility, travel time, and travel convenience).

The distinction between individual and collective concerns received further support from the results of a principal component analysis on all of these concerns. After varimax rotation, this analysis revealed two factors with Eigenvalues greater than 1. The first factor explained $37.0 \%$ of the variance, and was described by the items travel convenience, travel flexibility (both with factor loadings of .86), and travel time (factor loading of .54). The second factor explained $27.2 \%$ of the variance, and was described by the items public health and environment (the respective factor loadings were .88 and .71 ). Accordingly, the first factor contained items representing individual concerns, whereas the second factor contained items representing collective concerns.

Thus, the correlational analyses in combination with the principal component analysis illustrate that the decision between car and public transportation entails at least one essential element of a social dilemma -- a deliberation between individual concerns and collective concerns. Moreover, the fact that collective concerns were positively associated, and individual concerns were negatively associated with public transportation preferences, provides support for the ecological validity of the simulated commuting task. 
Table 6

Correlations between Travel Concerns and Preference for Public Transportation

$\begin{array}{lr}\begin{array}{l}\text { Preference Time Costs Conv Envi } \\ \text { public } \\ \text { transportation }\end{array} & \begin{array}{l}\text { Public } \\ \text { Health }\end{array} \\ \end{array}$

Pref. P.T.

Travel Time

Travel Costs

Travel Convenience

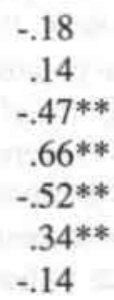

$\begin{array}{ll}\ldots & \ldots \\ .04 & \ldots \\ .32 * & .13 \\ -.20 & .2 \\ .27^{*} & .1 \\ -.24 & .35 * \\ .31 * & .25\end{array}$

$\begin{array}{llll}\ldots & \ldots & \ldots & \ldots \\ \ldots & \ldots & \ldots & \ldots \\ \ldots & \ldots & \ldots & \ldots \\ -.28^{*} & \ldots & \ldots & \ldots \\ .71^{* *} & -.47 * * & \ldots & \ldots \\ -.01 & .55^{* *} & .02 & \ldots \\ .58^{* *} & -.02 & .52 * * .32 *\end{array}$

Note. ${ }^{*} p<.05 ;{ }^{* *} p<.01$

Finally, to explore whether these concerns were related to social value orientations, we performed a MANOVA on individual and collective concerns including the full factorial design. First, the means on collective concerns (i.e., average of environment and public health items; alpha $=.71)$ for Pro-socials $(M=5.73)$ and Pro-selfs $(M=5.13)$ were in line with the prediction in Hypothesis 1 , but the main effect of Social Value Orientation on collective concerns did not reach acceptable levels of statistical significance, $F(1,48)=2.52, p<.11$. Furthermore, the effect of Social Value Orientation on individual concerns (i.e., average of convenience, flexibility, and travel time items; alpha $=.68$ ) was not significant, $F(1,48)<1^{6}$.

6 This analysis also revealed a significant interaction of Social Value Orientation and Expectations on individual concerns, $F(1,42)=6.42, p<.02$. Means indicated that pro-selfs assigned greater importance to individual concerns when the majority was expected to go by public transportation, whereas pro-socials assigned greater importance to individual concerns when the majority was expected to go by car. This is in line with Hypothesis 2 that pro-socials transform the situation into an environmental problem (resembling a Prisoner's Dilemma Game), whereas pro-selfs transform it into an accessibility problem (resembling a Chicken Dilemma Game). 


\subsection{Discussion}

\section{Main conclusions}

This study was conducted in light of the belief that excessive car use may lead to a situation most of us would rather wish to avoid. We have used concepts derived from Kelley and Thibaut's (1978) interdependence theory to analyze how individuals may construe different interdependence structures of the same decision situation (i.e., commuting situation) according to their social value orientations. One of the major findings of the research presented in the current chapter was that pro-socials - relative to pro-selfs -- exhibited greater preferences for commuting by public transportation, and were more concerned with the collective outcomes (i.e., environment) of their decisions. In addition, a greater percentage of pro-socials indicated that they were ready to stop driving their cars in case of a serious environmental threat in their working area. Generally, these results were in accordance with Hypothesis 1. These findings underline the role of social value orientations in how individuals approach and respond to a large scale social dilemma that exists in real life (cf. McClintock \& Allison, 1989). Moreover, these findings complement prior research on environmentally relevant behavior in that personality differences related to such concepts as egoism and altruism seem promising in advancing our understanding of environmental behavior (cf. Stern, 1992).

A further important finding was that pro-socials exhibited a greater preference for commuting by public transportation, when they were led to believe that the majority preferred to commute by public transportation than when they were led to believe that the majority preferred to commute by car. From an environmental point of view one should indeed expect that it is morally less acceptable to take the car when a majority is going by public transportation ("normative pressures"; cf. Liebrand et al., 1986). For pro-selfs we found the reverse effect: They were more strongly inclined to commute by public transportation if they were led to believe that the majority of others would commute by car. These findings are in line with Hypothesis 2, and they support the notion that pro-socials transform the situation into an environmental issue (resembling an $\mathrm{N}$-person Prisoner's Dilemma), whereas pro-selfs transform it into a accessibility problem (resembling an $\mathrm{N}$-person Chicken Dilemma).

However, contrary to Hypothesis 3 this interaction of social value orientation and expectations of others' commuting choices was not further influenced by the possibility of a time delay due to congestion. A post-hoc interpretation for the absence of this finding may be that the manipulation of possibility of congestion was only partially successful (i.e., 25 percent of participants in the Absence of Congestion-condition believed that congestion was still a possibility). Presumably, because the people were daily commuters, they may have had a good deal of experience with traffic jams, and accordingly, they may have paid little attention to information that was inconsistent with such experiences. Thus, it seems likely that 
to a large extent commuters have approached this simulated commuting task based on their own experience, and accordingly may have been less responsive to information regarding congestion.

The finding regarding the individual responses to an environmental threat in their own commuting situation deserves some further attention. All pro-socials versus about 70 percent of pro-selfs indicated that in case of a smog alarm they would immediately leave the car at home and seek alternative means of transportation. This provides further support for the relevance of social value orientations regarding the way in which individuals approach serious environmental problems. Prior laboratory research has revealed that an enhanced level of group identity may be particularly useful in dealing with "emergency" situations (i.e., situations in which the collective resources were almost depleted; Kramer \& Brewer, 1984, Exp. 2). The current findings indicate that, in addition to group identity, personality differences reflected by social value orientations, to some extent, may influence the probability with which such situations become disastrous. It seems therefore important to conduct future research as to explore how pro-selfs, in particular, can be motivated to respond less selfishly to such alarming situations.

\section{Strengths, limitations, and implications of the study}

Before closing, we wish to outline some of the strengths and limitations of the scenario paradigm that was used in the current research. This methodology measures people's reports of how they would commute in a particular situation given the specific environmental and accessibility conditions. Consequently, a potential limitation of this paradigm is that it does not directly exclude tendencies toward favorable self-presentation or other self-enhancing processes which to some extent may account for the fairly strong overall preference for public transportation. However, such tendencies are less likely to account for the effects involving social value orientation because the measurement of this variable has been demonstrated to be independent of tendencies toward favorable self-presentation (e.g., Platow, 1992). Moreover, it seems unlikely that the interaction between social value orientation and expectations of other commuter preferences is a result of a contemplative process in terms of favorable self-presentation. In this regard, it also important to point out that several features of the current study (e.g., using actual commuters, creating a clear impression that many other commuters are involved) enhance the validity of the results obtained. And, several additional findings (e.g., judgments of several travel concerns in real-life; how individuals respond to a smog alarm) are consistent with the notion that the hypothetical commuting situation indeed represented a social dilemma and that this dilemma is likely to be construed and solved differently by pro-social and pro-self individuals. Nevertheless, it would be fruitful to replicate the current, preliminary work by using a paradigm that focuses more strongly on actual behavior as well as on the real consequences of such choices. 
Some implications of the current work are also worth discussing. Although interdependence theory (Kelley \& Thibaut, 1978) has primarily focused on interpersonal, dyadic relationships and interactions, the current study shows that this theory may also serve as a useful conceptual framework in which to understand interdependent situations involving many other individuals. In contrast to more traditional social dilemma theories (e.g., rational choice theory, game theory) that view people as basically self-interested, interdependence theory denotes that human behavior is also shaped by considerations beyond an individual's immediate selfinterest (e.g., pro-social motives).

One of the practical implications of the current findings is that remedies to the massive problem of environmental pollution should primarily focus on changing the behavior of individuals with pro-self orientations. The finding that these individuals are inclined to perceive the commuting situation as an accessibility problem with a structure very similar to an N-person Chicken Dilemma Game helps to understand why campaigns stressing the significance of our environment may, in fact, be less effective than expected. That is to say, a moral appeal to the collective interest of a clean environment may further promote pro-collective behavior by pro-social individuals, but it may have very little impact on the behavior of pro-self individuals. Thus, in designing campaigns aimed at reduction of car use or other environmentally-damaging behaviors, one has to take into account the different interpretations people assign to such situations of interdependence (cf. Snyder, 1993). In light of the current results, it is plausible that pro-self individuals are particularly sensitive to arguments that emphasize the personal benefits of commuting by public transportation, or the personal costs of commuting by car, such as travel time or travel convenience. It goes without saying that such messages are only effective to the extent that they are persuasive, which may require some structural changes in public transportation, such as an extension of networks, an increase in transport-frequency, or an improvement in travel convenience and flexibility. 


\section{Chapter 4 \\ Self-interested and pro-social motives \\ underlying commuting decisions ${ }^{1}$}

"Humanity is conducting a grand experiment on its natural environment and cannot afford to fail. We have only one earth on which to experiment."

-- Stern (1992, p. 271)

\subsection{Introduction}

\section{Environmental pollution as social dilemma}

The functioning of societies is perhaps most strongly challenged by social dilemmas - situations in which private interests are at odds with collective interests (Dawes 1980; Messick \& Brewer, 1983). One of the more problematic social dilemmas that societies are facing today concerns the fact that many personally attractive and convenient behaviors, such as private car use, are detrimental to the environment shared by all members. Although many scientists have described environmental pollution as a pervasive social dilemma (e.g., Hardin, 1968; Orbell \& Dawes, 1981; Samuelson, 1990; Stern, 1992), this analysis has received little empirical attention from social dilemma researchers (i.e., they have tended to focus on experimentally created social dilemmas using experimental games as decision tasks; for some exceptions, see Brechner \& Linder, 1981; Samuelson, 1990). Thus, it is relevant to provide evidence in support of the claim that the extant social dilemma literature can indeed contribute to an understanding of the psychological mechanisms underlying environmental behavior.

The current chapter focuses on a number of motivational factors underlying individual judgements of one particular, but significant environmental behavior -the decision to commute by car versus public transportation. Using extensions of rational choice theory (Olson, 1965) and insights from interdependence theory (Kelley \& Thibaut, 1978), we provide a conceptual framework towards understanding how differences in mean travel time, variability in travel time, and the impact of car use on the environment may affect public transportation preferences in a hypothetical commuting situation. Moreover, we analyze how individual differences in social value orientations -- preferences for patterns of

\footnotetext{
${ }^{1}$ This chapter was published as:

Van Vugt, M., Van Lange, P. A. M., \& Meertens, R. M. (in press). Commuting by car or public transportation? A social dilemma analysis of travel mode judgements. European Journal of Social Psychology.
} 
outcomes to self and others (Messick \& McClintock, 1968) -- are related to these commuting preferences.

\section{Self-interested motives in a social dilemma:}

\section{Minimizing the costs of travel time and travel time variability}

The decision to commute by car or public transportation not only bears an impact on the well-being of the individual commuter, but also on the well-being of others. For example, as more individuals commute by car people may experience the negative consequences of environmental pollution and traffic congestion. This situation is potentially disruptive because the individual interest is generally better served by a choice for the car (i.e., the presumed non-cooperative option), as it may provide better outcomes in terms of travel convenience, flexibility, and travel time. However, it is in the interest of all if more people decide to commute by public transportation (i.e., the presumed cooperative option), which would minimize the contributions to pollution and congestion. This particular type of interdependence with conflicting individual and collective interests can be framed as a social dilemma (e.g., Dawes, 1980; Messick \& Brewer, 1983).

According to some original theories of social dilemmas, such as game theory and rational choice theory (e.g., Luce \& Raiffa, 1957; Olson, 1965), individuals wish to maximize expected subjective utility, preferring options that are expected to yield greatest individual gains or smallest individual losses. In the context of commuter decisions, one relevant attribute that defines utility for most commuters is travel time. Indeed, prior research has revealed consistently that commuter decisions are influenced by time considerations with individuals preferring the option that is least costly in terms of average travel time (e.g., Kropman \& Katteler, 1993; Loos \& Kropman, 1993).

However, we assume that individuals respond not only to differences in average travel time, but also to differences in variability of travel time (i.e., unexpected variations in daily travel times). This variability may result in numerous psychological and social costs, both for the individual commuter who is confronted with a great deal of uncertainty (e.g., "when will I arrive at work?") and for the organization for which he or she works (e.g., meetings might have to be canceled). Despite the prevalence of time variabilities in daily commuting traffic, this factor has been largely neglected in traffic research (for exceptions, see Mahmassani \& Chang, 1985; Van Knippenberg \& Van Knippenberg, 1986). However, the issue of uncertainty has been addressed thoroughly in psychological research on decision making, revealing that people prefer behavioral options providing certain outcomes more than options providing uncertain outcomes (for reviews, see Abelson \& Levi, 1985; Dawes, 1988). Frequently, this tendency is so powerful that it leads to preferences which are largely inconsistent with the basic assumption underlying traditional formulations of rational choice theory - to maximize expected utility - - because people tend to prefer certain outcomes moderate in size more than uncertain outcomes great in size (cf. Kahneman \& 
Tversky, 1979) $)^{2}$. The need for certainty has been attributed to the individual's desire to exercise control over his or her own outcomes. Uncontrollable events may elicit feelings of anger, frustration and stress, and may lead individuals to search for information about how to increase personal control or opt for behavioral alternatives providing more controllable outcomes (Averill, 1973; Bandura, 1986). Similarly, great variations in daily travel times may reduce the sense of personal control associated with a certain type of travel mode and may stimulate the search for alternatives.

Taken together, on the basis of rational choice theory we predict, first, that commuters will exhibit a greater preference for public transportation (versus car) if this option yields a lower average travel time (Hypothesis 1). Second, on the basis of prior research on decision making, we predict an independent effect of travel time variability, such that individuals will exhibit a greater preference for public transportation (versus car) if it provides a smaller variability in travel time (Hypothesis 2a). Third, it is expected that the effect of variability can be explained, at least in part, by a decrease in the perceived controllability of the travel time by car (Hypothesis $2 b$ ).

\section{Minimizing the costs for all of us:}

The role of social value orientations

The above reasoning delineates two motivational processes underlying commuting preferences (i.e., reduction of time loss and reduction of time uncertainty) that follow soundly from prior theorizing and research regarding decision making. While these motivational processes may provide a parsimonious framework for understanding individual judgement and decision making in situations where the social implications are small, we believe that this approach is too limited for understanding social dilemmas. Specifically, these motives alone would suggest that individuals construe social dilemmas primarily or exclusively in terms of their own personal outcomes. However, one of the major findings of prior social dilemma research is that a substantial number of people take into account broader considerations, derived from a general concern with the well-being of the collective (cf. Dawes, 1980; Messick \& Brewer, 1983; Van Lange, Liebrand, Messick, \& Wilke, 1992). Indeed, following Kelley and Thibaut's (1978) interdependence theory, one may assume that individuals transform any given interdependence situation -- "the given matrix" or a situation delineated in terms of the pursuit of immediate self-interest -- according to broader motivations and considerations that individuals bring into the situation. The result of this transformational process is

${ }^{2}$ This tendency is known as the "certainty-effect". As an example, Kahneman and Tversky (1979) asked subjects to choose between two options. Option A described a gain of $\$ 4000$ with a .8 probability, and Option B described a gain of $\$ 3000$ for sure. It appeared that only a small minority $(20 \%)$ preferred the more uncertain Option A, although this option represented the greatest expected utility. 
what Kelley and Thibaut (1978) have termed "the effective matrix," which is assumed to be more predictive of individuals' ultimate preferences and behaviors in settings of interdependence. Of most interest here are the so-called pro-social transformations, which may be inspired by more specific concerns such as the desire to promote collective welfare, to provide a good example for others, or to enhance a good feeling about oneself (e.g., to act responsibly and in line with one's moral values or principles).

An important question then is what determines the willingness of individuals to forego the immediate self-interest, and to pursue the collective welfare? First, transformational processes may be largely shaped by pre-existing individual differences in social value orientations, or the ways in which individuals evaluate outcomes for self and others. This construct has received considerable attention in research on social dilemmas, revealing that those who tend to maximize outcomes for self and others (i.e., pro-socials) choose more cooperatively and expect others to choose more cooperatively than those who tend to maximize own outcomes with little or no regard for others' outcomes (i.e., individualists), or those who tend to maximize own outcomes relative to the outcomes afforded to others (i.e., competitors; e.g., Kuhlman \& Marshello, 1975; McClintock \& Liebrand, 1988; Van Lange \& Kuhlman, 1994). Moreover, there is also some evidence for the ecological validity of social value orientations in that pro-socials exhibit greater willingness to participate voluntarily in psychology experiments, and that they make greater concessions in the context of a negotiation task than do individualists and competitors (De Dreu \& Van Lange, in press; McClintock \& Allison, 1989).

Nevertheless, in light of the ubiquity of interdependent situations in the real world, this evidence is rather limited, and the concept of social value orientation has received virtually no attention in the context of environmentally relevant attitudes and behavior (except Van Vugt, Meertens, \& Van Lange, 1995). This latter issue seems particularly important given Stern's (1992) comprehensive analysis of the psychological determinants of environmental damage, in which he concluded that prior research hardly revealed any systematic relations between personality factors and environmentally relevant judgements and behaviors, and that little is known regarding the personal motives and values -- such as egoism and altruism -underlying environmentally relevant behavior (for an exception, see Stern, Dietz, \& Kalof, 1993). Therefore, we explore whether, relative to individualists and competitors, pro-socials are more likely to take into account the long-term, collective consequences of their decisions in the commuting situation, assigning greater weight to how much harm cars and public transportation would do to the environment, and less likely to consider exclusively their own immediate outcomes (e.g., travel time, travel convenience or travel flexibility). Accordingly, we predict that pro-socials will exhibit a greater preference for commuting by public transportation than individualists and competitors (Hypothesis 3).

Second, we propose that pro-social transformations are also instigated by the extent to which available options differ in their consequences to the collective 
welfare -- how much the travel options differ in their damaging effects on the environment. When cars have only a minor impact on the environment, collective concerns will not be very salient, and commuters presumably will not be strongly motivated to give up their individual interest (i.e., commute by car). However, when the environmental impact of car use is large, individuals may more strongly realize the detrimental effects of car use, yielding a stronger concern with the longterm collective welfare (cf. Jorgenson \& Papciak, 1981; Samuelson, Messick, Rutte, \& Wilke, 1984). Thus, we predict that, across variations of the consequences for self, individuals will exhibit a greater preference for public transportation when they believe that car use has a large rather than a small impact on environmental pollution (Hypothesis 4).

\section{Interaction of self-interested and pro-social motives}

The above framework considers the separate effects of two self-interested concerns (i.e., reduction of travel time and variability), a pro-social concern (i.e., impact of car use on environmental pollution), and a factor associated with the personal evaluation of self-interested and pro-social concerns (i.e., social value orientation). Rather than merely predicting independent effects, we propose that some of these factors may interact to determine commuter judgements and preferences. As noted by some social dilemma researchers, it frequently may be that the combination of two factors yield greater effects than one would expect on the basis of their separate effects (e.g., Liebrand, 1992; Samuelson, 1990; Stern, 1992). This may be so because often it is necessary to simultaneously overcome a number of barriers, any one of which may prevent the emergence of pro-social behavior. In the context of commuting decisions, this assertion seems to be particularly valid because the individual advantages of car use are myriad (e.g., travel convenience, flexibility, travel time, protection against weather), and have to be weighted against a very limited number of individual advantages (e.g., time to read), and a single long-term collective advantage (i.e., environment) associated with public transportation use. Accordingly, it seems reasonable to expect that preferences for public transportation may be strongly enhanced if two important obstacles will be removed at the same time. Therefore, we predict that commuters will exhibit a much stronger preference for public transportation (versus car), if this option provides both (1) a lower average travel time, and (2) at least an equal travel time variability (Hypothesis 5).

In addition, the effects of factors relevant to understanding individual's concern with short-term self-interest (i.e., travel time) and long-term collective interest (i.e., impact of cars on environmental pollution) may be influenced by differences in social value orientations. Given the fact that pro-social individuals are more concerned with the collective consequences, and individualists and competitors with the personal consequences of their decisions, we advance two additional hypotheses. First, consistent with previous research (Kramer, McClintock, \& Messick, 1986) we suggest that when the collective interest is not or not seriously affected by individuals' decisions then pro-socials, individualists, and 
competitors will exhibit similar levels of cooperation; however, when the collective is being threatened pro-social individuals will be more likely to exercise selfrestraint, whereas individualists and competitors are more likely to improve their outcomes when they are still able to do so. Thus, we predict that -- relative to individualists and competitors -- pro-social commuters will be more sensitive to information that cars contribute heavily to environmental pollution. Accordingly, pro-social commuters will exhibit a stronger increase in public transportation preference between the situations where cars have a small versus large impact on environmental pollution than individualists and competitors (Hypothesis 6).

Conversely, individualists and competitors might be more responsive to information about how their commuting decision will affect their self-interest, which will presumably depend on the relative efficiency of public transportation. Accordingly, we predict that individualists and competitors -- relative to prosocials -- will exhibit a sharper increase in public transportation preference from the situation where public transportation yields a longer travel time (versus car) to where public transportation yields a shorter travel time (Hypothesis 7).

While the outcomes in terms of travel time, travel time variability, and environmental pollution are assumed to be important, we do not claim that these are the only attributes or evaluations that commuters take into account. Accordingly, we administered a post-experimental judgement task in which we asked commuters to evaluate the importance of a list of travel attributes (e.g., protection against bad weather) in their real-life commuting decisions. This allows us, first, to examine whether individuals indeed construe the commuting situation as a social dilemma. If so, attributes reflecting individual outcomes (e.g., travel time, travel flexibility, travel convenience) should correlate negatively with public transportation preferences, whereas the opposite should occur for attributes reflecting collective outcomes (i.e., environment). Second, this allows us to examine the assumed relationship between these evaluations and social value orientation: Relative to individualists and competitors, pro-socials should assign greater importance to collective outcomes and less importance to individual outcomes.

\subsection{Method}

\section{Research participants}

Three hundred questionnaires were distributed among employees of a publishing company in Deventer -- a medium-sized city in the middle of the Netherlands. In total, 192 questionnaires were returned (104 by men, 88 by women), yielding an overall response rate of $64 \%$. The average age of the commuters was 35 years and eight months. All individuals were regular car commuters, and more than half of them $(51 \%)$ commuted by car on a daily basis. The rest occasionally (i.e., less than once a week) commuted by bike $(38 \%)$, or by public transportation $(11 \%)$. 


\section{Overview of the design}

By means of different future scenarios of a commuting situation, the following independent variables were manipulated. First, the relative travel time of public transportation versus car was varied: In one condition the travel time by public transportation was shorter than by car, whereas in the other condition the travel time by public transportation was longer. The second factor was relative travel time variability, and consisted of three conditions in which public transportation -relative to car -- either had a smaller time variability, an equal time variability, or a greater time variability. The third factor involved the differential magnitude of the environmental damage produced by cars. It was stated that car use either had a large or small impact on environmental pollution. Finally, we examined social value orientations, which focused on differences between the group of pro-socials versus the group of individualists and competitors combined ("pro-selfs") -- the reason for this two-category distinction will be described below. Thus, the experimental design was a 2 (Time) by 3 (Variability) by 2 (Social Value Orientation) by 2 (Pollution) design. All variables except one were betweensubjects factors and cell sizes varied from nine to 55 commuters (due to a substantial unevenness in the number of pro-social vs. pro-self people). For reasons of statistical power, the factor Variability was manipulated within-subject's and the three variability conditions were presented to commuters in random order to control for possible order effects.

\section{Procedure}

The questionnaires were distributed to car commuters at the entrance of the company on a weekday morning, and completed at the working place in about twenty minutes (those who returned their questionnaires were thanked, and were given a small gift for their participation). The questionnaire consisted of three parts: (1) the assessment of an individual's social value orientation, (2) the description of a commuting situation, and (3) a series of post-experimental questions.

Assessment of social value orientation. As a first task, nine three-choice decomposed games (cf. Messick \& McClintock, 1968) were administered -- this procedure is described in more detail in Appendix II. In each decomposed game a choice is made between combinations of outcomes -- depicted in amounts of money or points -- to self and a hypothetical other person, a measure of social value orientation which has revealed good internal validity (e.g., Liebrand \& Van Run, 1985), as well as test-retest reliability (e.g., Eisenberger, Kuhlman, \& Cotterell, 1992; Kuhlman, Camac, \& Cunha, 1986), and appears to be free of tendencies toward social desirability (Platow, 1992). Paralleling prior work, each game consists of three alternatives, corresponding to one of three social value orientations: cooperation, individualism, or competition. Specifically, in a decomposed game the cooperative option provides the greatest joint outcome, the individualistic option the greatest outcome for self regardless of other's outcome, and the competitive option 
the greatest difference between outcomes for self and other. In line with previous research (McClintock \& Allison, 1989; Platow, McClintock \& Liebrand, 1990), individuals were only classified if at least six of the nine choices were consistent with one social value orientation. Accordingly, out of 192 individuals, 141 were classified as pro-socials, 31 as individualists, and 10 as competitors. Ten people could not be categorized on the basis of the above criterion. Due to the low number of individualists and competitors, and given the fact that there were no different predictions for these groups, we combined individualists and competitors to form a group of essentially self-interested individuals, a group which we have earlier referred to as "pro-selfs" (cf. Kramer et al., 1986; Van Lange \& Liebrand, 1991).

Description of the commuting situation. Next, commuters were asked to read the description of a hypothetical commuting situation, which was designed in an attempt to parallel a commuting situation that presumably can be found within a ten year period from now (an example is provided in the Appendix I). The aim of such future scenarios was to optimize the credibility of the different manipulations that may seem somewhat unrealistic at present. Commuters were asked to imagine that they were living in a suburb 40 kilometers from the company they worked for (approximately 25 miles). They could cover this distance to work either by car or by train. There was a highway near home, and a train station at a three-minute walk. Once the commuting situation was explained, individuals were told that their choices would have consequences for the amount of environmental pollution produced, and for their travel time to work.

Pollution. All participants were first informed that the environment would be in a very bad condition in ten years. Subsequently, approximately half of the people read that within a ten years' period, cars would be responsible for very little of the environmental damage, mainly because of the use of catalytic converters for cars and other environment-preserving measures (Small Impact-condition). In contrast, the other half of the people received information indicating that cars would be one of the main polluters of the environment within ten years, despite several environment-preserving measures (Large Impact-condition). In both conditions, it was stated explicitly that public transportation would hardly cause any environmental damage.

Time. Half of the commuters read a scenario indicating that the average travel time by public transportation was always shorter than by car (Travel Time Public Transportation Shorter-condition; from now on referred to as PTT Shorter). It would take 40 minutes on average to cover the distance to work by public transportation, and 60 minutes to cover it by car. Conversely, the other people read a scenario describing that the average travel time by public transportation was always longer than by car, and the travel times were exactly the opposite (PTT Longer-condition). In all conditions, it was emphasized that the travel time by public transportation included a few-minute walk from home to the station, and from the end station to their company. 
Variability. Each participant received three different scenarios describing the day-to-day variability in travel time by public transportation compared to car. One scenario indicated that the time variability by public transportation was much smaller (with a range from 2 minutes below to 2 minutes above the average time) than by car (16 minutes below and above average time), creating the PTV Smallercondition. The other two scenarios informed individuals that the time variability by public transportation was either equal to car ( 9 minutes below or above average; PTV Equal-condition) or much greater than car (16 minutes vs. 2 minutes below or above average; PTV Greater-condition). These three scenarios were administered to individuals in random order. Each scenario ended with a brief summary of the consequences of commuters' decisions in terms of environmental pollution, travel time, and time variability (see Appendix I).

\section{Dependent measures}

Preference for car versus public transportation. In each of the three commuting versions individuals could indicate their preferences for commuting by car or by public transportation on a bipolar response scale, ranging from 1 ( = very strong preference for car) to 7 ( = very strong preference for public transportation), whereby the midpoint 4 was anchored as "indifferent". Also, after each preference they had to make a choice between the two alternatives $(1=\mathrm{car} ; 2=$ public transportation). Finally, in each version commuters were asked to indicate for car and public transportation separately, how much control they thought they could exercise over their travel time $(1=$ very little control; $7=$ very much control $)$.

Post-experimental questionnaires. Three different types of post-experimental questionnaires were administered. First, commuters judged the perceived control of travel times for car and public transportation in their personal commuting situation ( $1=$ very little control; $7=$ very much control). Second, they rated their concern ( 1 = very unimportant; $7=$ very important) with a list of five travel attributes, which have shown to be important considerations for "real life" commuting decisions (e.g.. Flannelly \& McLeod, 1989; Golob, Horowitz, \& Wachs, 1979): travel convenience, travel time, travel flexibility, protection against weather, and environmental pollution. Third, as to determine how plausible the information in the future scenarios was, individuals rated two statements concerning the credibility of, respectively, the environmental and travel time conditions $(1=$ not at all plausible; $7=$ very plausible $)^{3}$.

\footnotetext{
${ }^{3}$ Analyses revealed no difference in the credibility of travel time information between the PTT Shorter $(M=4.19)$ and PTT Longer-conditions $(M=4.46), F(1,181)=1.96$, n.s. However, commuters in the Large Impact-condition thought that the environmental information was more plausible $(M=4.94)$ than commuters in the Small Impact-condition $(M=3.90), F(1,181)=18.34$, $p<.001$. Thus, individuals were somewhat more inclined to believe that cars would have a major impact on the level of pollution in the near future.
} 


\subsection{Results}

\section{Preferences for car versus public transportation}

Preferences for commuting by car or by public transportation were analyzed in a repeated measurements ANOVA, employing a 2 (Time) by 3 (Variability) by 2 (Social Value Orientation) by 2 (Pollution) design, all independent variables being between-subjects factors, except for Variability ${ }^{4}$. Consistent with Hypothesis 1, this analysis revealed a main effect for Time, $F(1,174)=14.74, p<.001$, indicating that preferences for public transportation were greater when public transportation was associated with shorter $(M=5.32)$ than longer travel times $(M=3.98)$.

More importantly, and consistent with Hypothesis 2a, we found a strong main effect for Variability, $F(2,348)=52.63, p<.001$. Public transportation was preferred most when PTV was Smaller $(M=5.41)$, and least when PTV was Greater $(M=3.85)$, with intermediate preferences when PTV was Equal $(M=4.87)$. All paired comparisons between the conditions yielded significant differences, $p$ $<.05$.

Moreover, a significant main effect for Social Value Orientation, $F(1,174)=$ $4.63, p<.04$, provided support for Hypothesis 3, revealing that Pro-socials exhibited stronger preferences for commuting by public transportation $(M=4.91)$ than Proselfs $(M=4.02)$.

Finally, according to Hypothesis 4, commuters would display a stronger preference for public transportation when the collective costs of cars would be greater. A main effect for Pollution, $F(1,174)=29.96, p<.001$, indeed revealed that preferences for public transportation were greater when Cars had a Large Impact $(M=5.38)$ rather than a Small Impact $(M=3.88)$ on Environmental Pollution. Thus, Hypotheses 1 through 4 received good support by the four significant main effects described above.

On the basis of Hypothesis 5, it was predicted that individuals would be much more in favor of public transportation if two conditions were fulfilled, namely public transportation was (a) more efficient in terms of travel time than car, and (b) more or equally reliable in terms of time variability. Evidence in support of

${ }^{4}$ Preliminary analyses revealed no significant main or interaction effects for the order in which the three variability-conditions were presented; therefore, this factor was dropped from further analysis. Additionally, we compared the main analysis using Variability as within-subject factor with an analysis on the first stated commuting preference using Variability as between-subjects factor. This analysis yielded the same main and interaction effects.

Finally, the continuous variable measuring commuting preference was correlated with the number of public transportation choices across the variability conditions; an extremely high intercorrelation was found, $r=.89, p<.001$. Moreover, we conducted a 2 (Time) by 2 (Pollution) by 2 (Social Value Orientation) ANOVA on the number of public transportation choices and the same effects were found as in the analysis on the mean commuting preference (however, the Social Value Orientation $x$ Pollution interaction changed to marginal significance); therefore (and in order to safe space), only the results on the commuting preference will be reported. 
Hypothesis 5 would be obtained by an interaction Time and Variability, which was found to be marginally significant, $F(2,348)=2.60, p<.08$. This effect was qualified by a significant three-way interaction of Time, Variability, and Pollution, $F(2,348)=6.24, p<.005$ (the associated means are displayed in Figure 4).

To provide a more precise test of the predicted interaction between Time and Variability, we performed for each level of the factor Pollution a 2 (Time) by 3 (Variability) repeated measurements ANOVA. First, when Cars had a Small Impact, this analysis revealed a significant interaction of Time and Variability, $F(2,158)=7.86, p<.001$. Consistent with Hypothesis 5, the difference between a Shorter (line depicted with triangle symbols in Figure 4) and Longer travel time (line depicted with circle symbols) was substantially greater when PTV was Smaller $(M \prime \mathrm{s}=5.63$ vs. 4.02$), t(79)=-3.78, p<.001$, or Equal $(M \prime s=4.71$ vs. 3.52$), t(79)$ $=-2.84, p<.001$, than when PTV was Greater $\left(M^{\prime}\right.$ 's $=2.91$ vs. 2.85$), t(79)<1$. Second, the interaction of Time and Variability failed to be significant when Cars had a Large Impact, $F(2,198)=1.82, p<.20$.

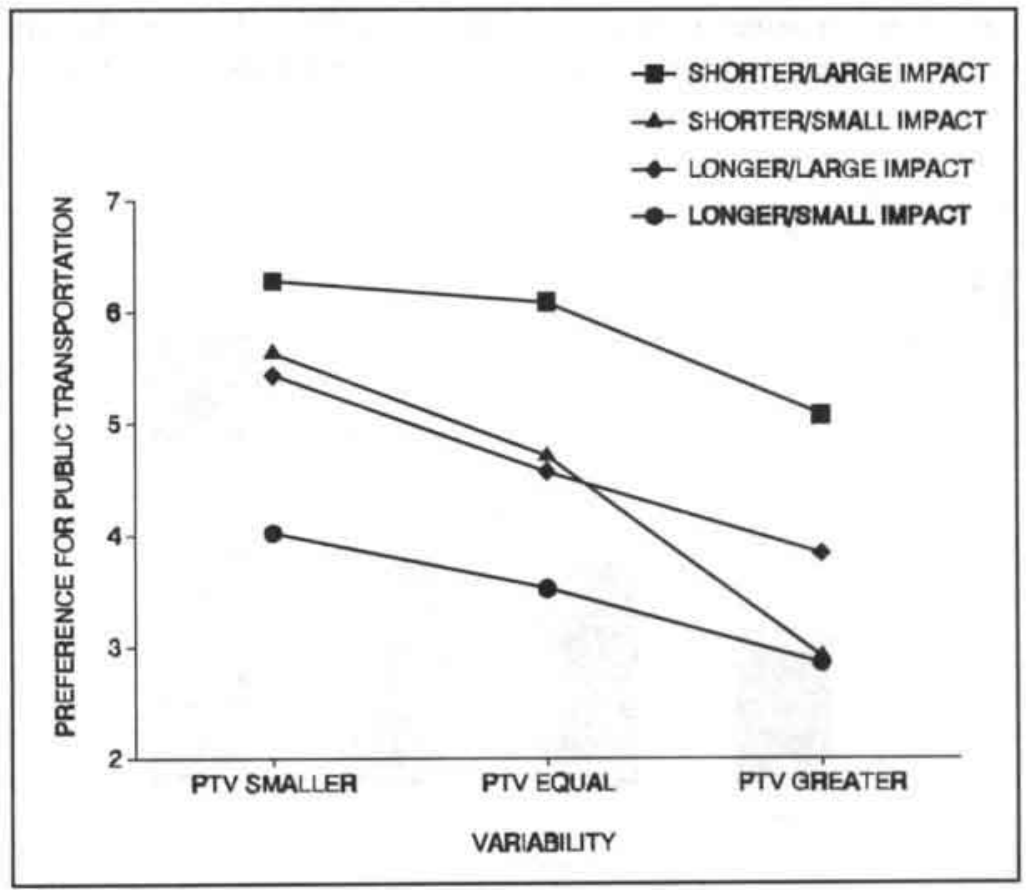

Figure 4. Preference for public transportation as a function of average travel time, time variability, and impact of cars on pollution.

Note. Preference varies from 1 (= very strong preference for car) to 7 (= very strong preference for public transportation), whereby 4 (= indifferent). 
Thus, these analyses provide partial support for Hypothesis 5. That is to say, when cars had a small impact on environmental pollution, commuters indeed displayed a much stronger preference for commuting by public transportation when public transportation afforded (1) a shorter average travel time, and (2) at least an equally reliable travel time. However, when cars had a strong impact on environmental pollution there was no surplus effect of the combination of these conditions.

A post-hoc explanation for this finding may be that any combination of conditions in which two obstacles for taking public transportation were removed, including the situation where cars are extremely (versus mildly) polluting relative to public transportation, enhanced public transportation preferences. To examine this possibility, we combined the (weighted) mean public transportation preference of each condition where two barriers to use public transportation were simultaneously eliminated, and compared them with the means of the other conditions (see Figure 5). Consistent with this post-hoc reasoning, we observed a more pronounced increase in public transportation preference moving from the elimination of just one obstacle $(M=3.60)$ to two obstacles $(M=5.12$; difference of 1.52 scale points) than from the situation in which no obstacle had been removed $(M=2.85)$ to one obstacle $(M=3.60$; difference of 0.75$)$, or from two $(M=5.12)$ to the situation in which all three obstacles had been removed $(M=6.19$; difference of 1.07$)$.

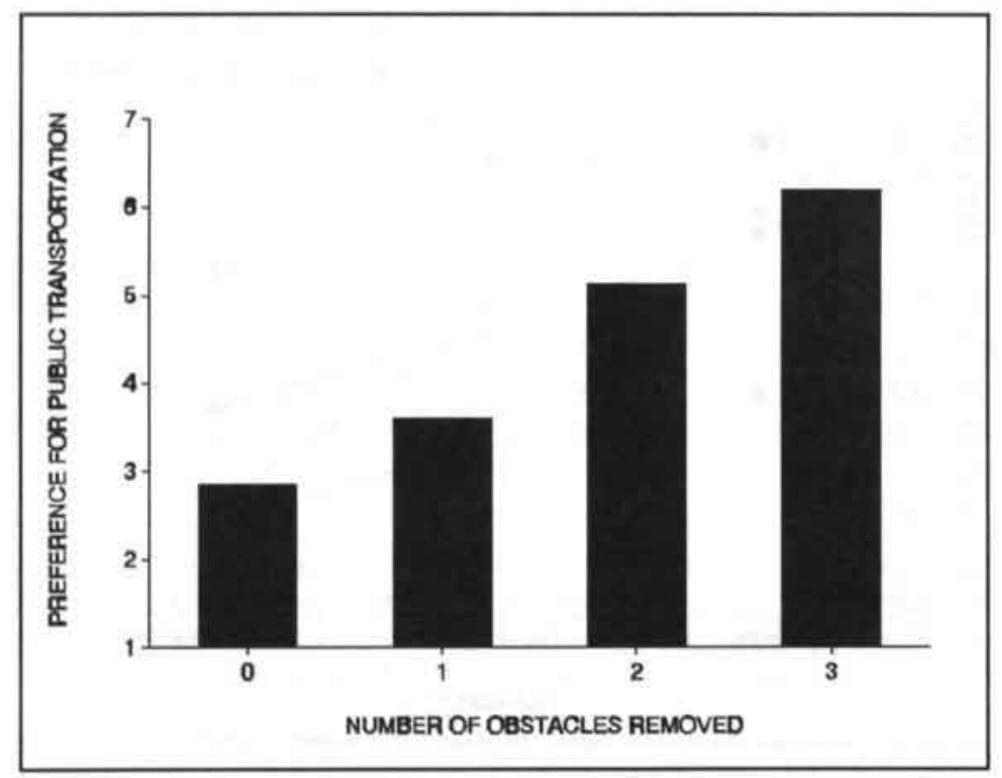

Figure 5. Preference for public transportation as a function of the number of obstacles removed for commuting by public transportation.

Note. Preference varies from 1 (= very strong preference for car) to 7 (= very strong preference for public transportation). 
Furthermore, a closer examination of the absolute commuter preferences in Figure 4 indicated that there were seven conditions (out of twelve in sum) in which public transportation was significantly preferred above the car. These conditions had in common that at least two out of three barriers to use public transportation were eliminated: It had at least an equally reliable travel time, and was much shorter and less environmentally polluting than the car. In every other condition -- where no or just one obstacle to use public transportation was removed -- commuters preferred commuting by car or were indifferent. These results were independent of Social Value Orientation, as was illustrated by the absence of a significant four-way interaction, $F(2,348)<1$.

Hypothesis 6 predicted an interaction between Social Value Orientation and Pollution, such that differences between the Pollution-conditions would be more pronounced for Pro-socials than Pro-selfs. This interaction effect was found to be significant, $F(1,174)=4.74, p<.03$, but in a manner inconsistent with Hypothesis 6 . As can be seen in Figure 6, Pro-selfs showed a much sharper increase between the condition when Cars had a Small $(M=3.07)$ versus Large Impact $(M=5.22$; difference of 2.15 scaling points), $F(1,39)=23.74, p<.01$, than Pro-socials $(M$ 's $=$ 4.20 vs. 5.41 ; difference of 1.21 scaling points), $F(1,139)=17.75, p<.01$. Thus, contrary to our prediction in Hypothesis 6, not pro-social but pro-self commuters appeared to be more sensitive to information that the collective welfare was being threatened.

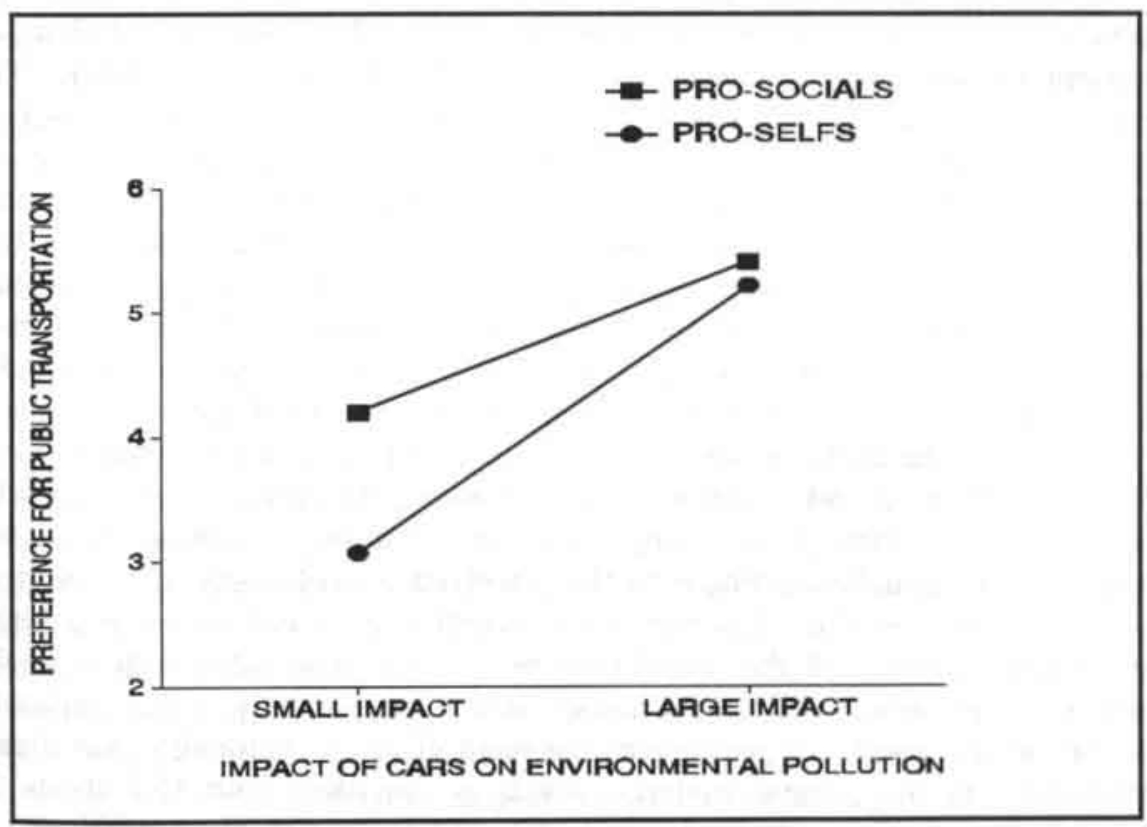

Figure 6. Preference for public transportation as a function of social value orientation and impact of cars on pollution.

Note. Preference varies from 1 (= very strong preference for car) to 7 (= very strong preference for public transportation). 
Finally, Hypothesis 7 tested the prediction that preferences of pro-selfs (relative to pro-socials) would be more strongly affected by differences in travel time. However, the interaction of Social value Orientation and Time was not significant, $F(1,174)<1$. Thus, no evidence was found that pro-self commuters were more responsive to information about the efficiency of public transportation.

\section{Perceived controllability of travel time}

In Hypothesis $2 b$ it was predicted that the impact of variability on public transportation preferences could, at least in part, be attributed to a loss of perceived controllability of travel time by car. To examine this, we transformed the perceived controllability of car versus public transportation travel times into a difference score, so as to parallel the relative measure of transportation preference. For each version, an individual's controllability score of travel time by public transportation was subtracted from the controllability score of travel time by car, so that a positive score (score above 0 ) indicated a higher perceived controllability of the travel time by car and a negative score (score below 0) indicated a higher perceived controllability of the travel time by public transportation. Our analysis proceeded in several steps. First, we determined the average score of the three controllability ratings and found that across all conditions the perceived controllability of travel time by car was higher than by public transportation $(M=+.58), t(181)=4.40, p$ $<.001$.

Second, the relative controllability scores were analyzed in a 2 (Time) by 3 (Variability) by 2 (Social Value Orientation) by 2 (Pollution) design, all independent variables being between-subjects factors, except for Variability. This analysis revealed a strong main effect for Variability, $F(2,348)=42.32, p<.001$. If the effect of Variability on commuter preferences could, at least in part, be attributed to differences in perceived controllability of travel time, then the relative controllability score of car travel time would be higher (lower) when the time variability by public transportation would be greater (smaller). Indeed, the relative perceived controllability of driving time by car was highest in the PTV Greatercondition $(M=+1.59)$, and lowest in the PTV Smaller-condition $(M=-.37)$, whereas the mean score fell in between $(M=+.53)$ in the PTV Equal-condition.

Third, we analyzed commuter preferences in a repeated measurements ANCOVA containing all factors, and included the relative controllability judgements of car versus public transportation travel times as a covariate. These preferences were strongly influenced by the perceived controllability of travel times, $F(1,173)=35.38, p<.001$. The regression weight of -.36 indicates that a higher perceived controllability of the travel time by car was associated with a weaker preference for commuting by public transportation. Importantly, compared to the initial analysis on commuter preferences the main effect of Variability was clearly less prominent in the present analysis, which is consistent with Hypothesis $2 \mathrm{~b}$. Although the main effect remained significant, $F(2,347)=31.72, p<.001$, the $\mathrm{F}$ value decreased considerably after controlling for the covariate (without and with 
covariate: $F^{\prime}$ s $=52.63$ vs. 31.72 ; a decline of approximately $40 \%$ ). The adjusted means for this main effect indeed demonstrated less clear-cut differences between the Variability conditions than the corresponding unadjusted means (presented within parentheses): Variability Smaller: $M=5.07$ (5.41) vs. Equal: $M=4.85$ (4.87) vs. Greater: $M=4.21$ (3.85). The other main and interaction effects were relatively unaffected by the covariance analysis. Thus, the influence of greater time variability by car (versus public transportation) on the public transportation preference is partly (but not entirely) attributable to the loss of perceived controllability of travel time commuting by car.

Finally, after the commuting task, commuters were asked to rate -- both for car and public transportation - the following question: "How much control do you think you can exercise over the travel time [by car/public transportation] in your daily commuting situation?" ( 1 = very little control, 7 = very much control). Again, we transformed both scores into a relative score, and compared the judgement of people who commuted by car on a daily basis $(N=162)$ with that of a group of commuters $(N=20)$ who occasionally (i.e., less than once a week) commuted by public transportation. Consistent with the previous analyses, it was found that commuters who sometimes used public transportation had a considerably lower perception of controllability of car travel time $(M=+.74)$ than daily car commuters $(M=+1.89), F(1,109)=4.80, p<.04$.

\section{Ratings of travel attributes of car versus public transportation}

One of the assumptions of the present study was that the commuting context would, at least to some extent, reflect a conflict between individual (i.e., commuting by car) and collective interests (i.e., commuting by public transportation). Moreover, we argued that the deliberation between these interests may in part be determined by an individual's social value orientation. Thus, at the end of the experiment commuters were asked to rate the importance of a list of travel attributes in their daily-life commuting decisions $(1=$ very unimportant, $7=$ very important). These travel attributes varied to the extent that they served either the individual (i.e., travel flexibility, travel convenience, protection against weather, and travel time) or the collective interest (i.e., environmental pollution).

If the commuting situation under investigation indeed reflected the structure of a social dilemma then the self-interested attributes would be negatively and the collective attribute would be positively correlated with public transportation preferences. Accordingly, we performed a correlational analysis between these travel concerns and the preference for commuting by public transportation (the average score over three commuting versions). As expected, the concern for environmental pollution had a high, positive correlation with the preference for commuting by public transportation $(r=.53, p<.01)$, whereas travel flexibility $(r$ $=-.52, p<.01)$ and protection against the weather were negatively correlated with 
public transportation preference $(r=-.25, p<.01)^{5}$. Moreover, all individual concerns (travel flexibility, travel convenience, travel time, and protection against the weather) had high intercorrelations. These findings were corroborated by a series of regression analyses, revealing that both the collective benefit -environment - and one of the individual benefits -- travel flexibility -- made independent, significant contributions toward predicting overall preferences for public transportation (the average preferences across the different levels of Variability).

Second, we hypothesized that pro-socials would attach more importance to the long-term collective outcomes of their decisions, whereas pro-selfs would attach more importance to the short-term self-interested outcomes. In a MANOVA we compared the ratings of pro-social and pro-self individuals on the two most influential travel attributes, environmental pollution and travel flexibility. This analysis revealed a significant multivariate effect, indicating an overall difference in ratings between Pro-social and Pro-self individuals, $F(2,179)=3.32, p<.04$. The associated means per attribute demonstrate that Pro-socials assigned greater value to environmental pollution $(M=5.74)$ than Pro-selfs $(M=5.22), F(1,180)=5.68, p$ $<.02$. Conversely, Pro-selfs tended to assign greater value to travel flexibility $(M=$ 5.61) than Pro-socials $(M=5.22)$, but this effect failed to reach acceptable levels of significance, $F(1,180)=1.68, p<.20$. Taken together, these results provide partial support for the claim that pro-social commuters are more concerned with the longterm collective outcomes of their commuting decisions and pro-self commuters are more concerned with their short-term outcomes.

\subsection{Discussion}

\section{Main conclusions}

The major purpose of this chapter was to examine the motivational factors underlying individuals' judgements of the decision to commute by car or public transportation. A social dilemma analysis was advanced so as to demonstrate that preferences for public transportation might be promoted by both self-interested and pro-social motives. The current findings provided strong evidence in support of Hypotheses 1 and $2 \mathrm{a}$, in that individuals preferred options yielding shorter travel times as well as smaller variabilities in travel time. Moreover, preferences for public transportation were also affected by broader, pro-social considerations. In line with Hypothesis 3, pro-social individuals exhibited greater preferences for commuting by public transportation than did pro-self individuals. In addition, consistent with Hypothesis 4, preferences for public transportation were greater when individuals were confident that excessive car use was detrimental to the

${ }^{5}$ A comparison between the ratings given by daily car versus occasional public transportation commuters revealed no systematic differences. 
environment. Moreover, we observed that the elimination of two obstacles to use public transportation promoted preferences for public transportation more strongly than the sum of their separate influences, which is in partial agreement with Hypothesis 5. Finally, contrary to Hypothesis 6 pro-self individuals were more sensitive than pro-social individuals to information about the detrimental effects of car use on the environment. Also, contrary to Hypothesis 7 both groups were about equally responsive to information about the efficiency of public transportation. Below, we will briefly discuss these and some other findings, evaluating their theoretical and practical implications.

First, the current findings revealed strong evidence that commuter preferences are shaped not only by beliefs regarding differences in average travel time, but also by knowledge concerning the differences in variability of travel time. Assuming that time is an important resource or outcome, these findings in combination extend original claims underlying rational choice theory (Olson, 1965) by indicating that individuals assign meaning not only to outcomes per se, but also to the variability in these outcomes. Consistent with prior laboratory research, this latter result illustrates that individuals prefer options yielding certain outcomes above ones yielding uncertain outcomes (i.e., uncertainty caused by variability in travel times), independent of other features of outcomes (e.g., average travel time). From a more empirical perspective, this finding extends prior research on decision making, which to our knowledge has confirmed this "certainty"-effect (Kahneman \& Tversky, 1979) primarily in individual decision tasks. Thus, the current finding underlines the need for minimizing the costs of uncertainty as a major psychological motive at work in social dilemmas, situations in which people frequently have to make decisions under a great deal of uncertainty regarding the state of the collective resource and strategies of other people ("environmental and social uncertainty"; cf. Suleiman \& Rapoport, 1989).

Beyond this (and in support of Hypothesis $2 b$ ), the current results revealed that differences in perceived controllability partially accounted for the effect of variability in travel time on commuter preferences. Once the influence of perceived controllability was statistically controlled for, variability in travel time accounted for a considerably smaller (although still quite substantial) amount of variance in preferences for public transportation. Also, we found that a greater perceived controllability was associated with a lower preference for commuting by public transportation, indicating that an individual's desire to exercise control over his or her outcomes is an important psychological drive underlying commuter preferences. Accordingly, while perceived variability in travel time seems quite unpleasant, it is even more aversive when individuals think they cannot somehow influence or control this variability. This may help to understand why many individuals fail to commute by public transportation, because these modes of transportation are associated with some variability in travel time which they cannot control themselves. In contrast, commuting by car may also be associated with variability in travel time (i.e., caused by traffic congestion), but people may think that they are 
better able to control this type of unpredictability (e.g., by listening to radio announcements about traffic jams, by taking "short-cuts"). However, in light of increasing traffic jams, it may be possible to encourage the use of public transportation if commuters could be convinced that public transportation is relatively more reliable than their cars. This implication nicely complements prior research revealing that traffic congestion is associated with a perceived lack of control among car drivers, which in turn may cause high levels of stress (Schaeffer, Street, Singer, \& Baum, 1988; Stokols, Novaco, Stokols, \& Campbell, 1978).

A second finding was that commuter preferences were influenced by individuals' social value orientations, with pro-socials exhibiting greater overall preferences for public transportation than pro-selfs (i.e., individualists and competitors). This finding extends prior work which simulated environmentally relevant decision problems in laboratory settings (Kramer et al., 1986; Van Vugt et al., 1995). Along with this prior research, the current findings provide some support for the claim that social value orientations influence behavior in real-life social dilemmas - a claim often made by researchers interested in this individual differences-variable, but rarely ever tested directly. More generally, these findings are important because they provide evidence in support of: (a) the assertion that individuals' preferences in a real word social dilemma are also governed by prosocial motivations (i.e., not all people focus on the "given matrix" representing outcomes for self only; Kelley \& Thibaut, 1978), (b) the ecological validity of the concept of social value orientation (i.e., most prior research has examined social value orientations in the context of experimental games), and (c) the claim that environmentally relevant judgements and behaviors are shaped by personality variables (i.e., the extant literature suggests that such relationships tend to be weak or absent; cf. Stern, 1992).

However, in the current chapter no evidence was obtained for the predictions that pro-social commuters, relative to pro-self commuters, would be more sensitive to information about the collective outcomes (i.e., environmental pollution) and less sensitive to information about the personal outcomes (i.e., travel time) of their commuting decisions. First, that pro-socials and pro-selfs showed a similar increase in preference for public transportation when this option became more efficient in travel time is understandable from a theoretical model of social value orientations, which suggests that all individuals assign an equal, positive value to outcomes for self, but that pro-socials and pro-selfs differ in the values they assign to outcomes for others -- with pro-socials assigning positive values to outcomes for others, and pro-selfs being either indifferent (i.e., individualists) or even assigning negative values (i.e., competitors) to outcomes for others (cf. McClintock \& Liebrand, 1988; Wyer, 1969). From this perspective, it is understandable that pro-socials and proselfs were equally responsive to information concerning their self-interest (i.e., travel time). Consistent with this explanation is the finding in the post-experimental judgement task that pro-socials attached more importance to the environment than 
did pro-selfs, but that both groups did not significantly differ in the importance they attached to self-interested concerns (i.e., travel flexibility).

Second, and also contrary to our prediction was the finding that pro-self (rather than pro-social) commuters were more strongly affected by information about the detrimental effects of car use, so that their public transportation preferences paralleled those of pro-social commuters when car use had a great impact on the environment. How do we account for this finding? One post-hoc interpretation is that pro-self individuals shift from the pursuit of immediate selfinterest toward one of greater collective interest when the social dilemma is critical, and the consequences of their choices in terms of pollution are severe. Pro-selfs may do so because they start to believe that, given the necessity of such pro-social choices (a) most others would do same, and (b) their ultimate self-interest is better served by such choices. A second interpretation derives from the general notion that personality differences tend to be more pronounced as the situational norms and demands are weaker (cf. Snyder \& Ickes, 1985). Indeed, it may well be that the differences underlying pro-social and pro-self individuals are overshadowed by powerful social norms dictating the appropriateness and moral correctness of commuting by public transportation. It goes without saying that such norms are more prominent when cars are believed to be very polluting as opposed to mildly polluting. The overall finding that preferences for public transportation were much greater when individuals believed that car use had a large (rather than a small) impact on the environment is consistent with the previous hypothesis. Moreover, this finding complements prior research on social dilemmas by indicating that individuals exhibit greater cooperation as the basis for collective rationality (i.e., concern for collective outcomes) becomes more salient (for a recent review, see Van Lange et al., 1992), and by supporting the notion that individual commuters do not only consider the immediate individual outcomes of their choices (i.e., travel time), but also consider the long-term collective consequences. Setting theoretical issues aside, this finding may be relevant for educational purposes because there appears to be a growing consensus among environmental experts that excessive car use is among the main causes of environmental pollution, and that technological improvements of cars (such as more advanced car catalysts) may not be sufficient to reduce these problems significantly (cf. Stern, 1992).

A third finding concerns the idea that when two barriers to use public transportation are simultaneously removed, their combined effect is more pronounced than the sum of their separate effects. This notion, which formed the basis for Hypothesis 5, received a fair amount of support. That is, we found some support for the hypothesis that preferences for public transportation are a multiplicative function of average travel time and variability in travel time -- these benefits can be construed as two conditions that must be met for a substantial increase in public transportation preferences to occur. However, our findings seemed to indicate that this multiplicative effect was obtained for any combination of obstacles being eliminated (i.e., any pair of anti-car or pro-public transportation 
judgements: favorable travel time, smaller or at least equal variability, and much greater impact of cars on level of pollution). This indicates, first, that commuters may apply a compensatory decision rule in thinking about commuting by car versus public transportation in which individual and collective outcomes are commensurable - that is, individuals translate even two disparate attributes onto a common scale of utility (cf. Abelson \& Levi, 1985). Second, in addition to simply applying the addition-of-utilities rule, individuals may also apply a non-additive, multiplicative rule in forming preferences. As outlined earlier, it seems likely that commuters use a multiplicative rule because presumably a combination of obstacles have to be removed before public transportation can really compete with the multiple benefits associated with cars.

One more specific finding deserves brief attention. The current work provides good support for the claim that the decision situation indeed represents a social dilemma. Concerns reflecting self-benefit (e.g., travel flexibility and protection against weather) were associated with stronger preferences for commuting by car, whereas concerns reflecting collective benefit (i.e., environmental pollution) were associated with stronger preferences for commuting by public transportation (of course, our experimental instructions may have somewhat influenced the latter relationship). Moreover, the finding that commuters who assigned greater value to the environment exhibited stronger preferences for public transportation (i.e., pro-socials) adds further credence to this claim. In this regard, it should also be noted that interdependence theory (Kelley \& Thibaut, 1978) has provided a useful framework for studying decisions in this real-life social dilemma by assuming that interdependent behavior is not only shaped by purely self-interested concerns -- a claim often made by traditional theories of social dilemmas (e.g., game and rational choice theory) -- but also by the broader implications of behavior, such as concern for the collective well-being.

\section{Limitations and suggestions for future research}

Before closing, we wish to outline some limitations of the research presented in the current chapter. First, an unintended limitation of the present study is that the sample of commuters consisted predominantly of people with pro-social orientations (approximately $80 \%$ ), which may be due to a process of self-selection -- thirty-six percent of the original sample did not return their questionnaires. Indeed, previous research has demonstrated that, relative to pro-socials, pro-self individuals are less willing to participate as subjects in experiments (McClintock \& Allison, 1989). Consequently, the current findings regarding the overall preference for public transportation, and the main effect for pollution may have been positively biased. In contrast, the effects for travel time and variability (i.e., two self-interested concerns) may have been somewhat underestimated. From a somewhat different perspective, the possibility of such selection-biases may also have a practical implication because it suggests that programs aimed at altering people's 
environmental behaviors may attract a group of primary pro-social individuals rather than individuals with pro-self orientations.

The other limitations are related to the scenario paradigm that was used in the present study. This methodology measures commuters' reports of how they would behave in a situation given certain travel time and environmental conditions. Consequently, one potential confinement of this methodology is that it does not rule out response tendencies such as self-presentation or social desirability, which may account for the overall strong public transportation preference that was found among a sample of daily and regular car commuters. However, such tendencies are less likely to account for the effects involving travel time and variability, because these are primarily self-interested concerns. Moreover, the measurement of social value orientation appears to be free of social desirability tendencies (e.g., Platow, 1992). In this regard, it should also be noted that several features of the current chapter (e.g., using actual commuters, realistic outcomes) to some extent contributed to the ecological validity of the current findings. Moreover, other measures included in this work (i.e., ratings of travel attributes) suggest that the commuting situation was indeed perceived as a social dilemma. A third but related limitation is that the factors promoting use of public transportation in the present study may in reality be overshadowed by powerful social and situational constraints (e.g., car as status symbol, low accessibility of public transportation). Thus, it would be fruitful to replicate the current work with a more direct focus on behavior.

Nevertheless, we believe that the scenario paradigm is a constructive, albeit preliminary, research strategy for developing causal models of human decision making in real-life social dilemmas. That is, the current findings may help researchers to further design and implement more costly and time-consuming field studies in the context of one of the most pervasive dilemmas society is facing today, environmental pollution. 



\section{Chapter 5 \\ Pro-social goals and expectations in the commuting situation}

"Individuals trust some more than others, trust some not at all, and trust some for some purposes but not for others."

-- Johnson (1975, p. 132)

\subsection{Introduction}

\section{Research questions}

Arriving at the end of the twentieth century, the world is being challenged by many social dilemmas -- situations in which personal or smaller group interests clash with society's interest at large (e.g., Dawes, 1980; Komorita \& Parks, 1995). One of the more serious and widespread social dilemmas concerns the local and global pollution of our environment, caused by the massive use of personally convenient devices, such as heaters, refrigerators, and cars (Kempton, Darley, \& Stern, 1992; Stern, 1992). For example, if fewer people decide to commute by car, and more people start commuting by public transportation, society would be much better off regarding the degree of environmental pollution (e.g., Lowe, 1990). Over the past two decades, many efforts have been undertaken to discourage car use and promote alternative travel modes -- primarily through financial arrangements and large-scale education campaigns -- but these have not been terribly successful (e.g., Baerwald, 1985; Geller, Winett, \& Everett, 1982; Kostyniuk, 1982). So far, it seems that not many people are motivated to voluntarily decrease commuting by car, maybe because they do not wish to give up the personal benefits of car use (e.g., flexibility, privacy, comfort), or do not expect many others will relinquish these benefits for a better environment.

How are preferences for commuting by car or public transportation shaped? If we assume that a considerable number of people will not commute by public transportation, because they may be pessimistic about other people's intentions or reluctant to forego their self-interest, might there be any systematic personality differences underlying commuting preferences? Moreover, if voluntary-based changes are difficult to accomplish, what structural solutions might be successful in reducing car use in the commuting situation, and how do commuters evaluate them? In a broad conceptual framework, using several social dilemma theories (i.e., goal/expectation theory; Pruitt \& Kimmel, 1977; interdependence theory; Kelley \& Thibaut, 1978; structural goal/expectation theory; Yamagishi, 1986), the work presented in the current chapter attempts to provide some preliminary answers to these questions. Specifically, it is hypothesized that pro-environmental decisions (i.e., commuting by public transportation) are influenced by a set of two interpersonal dispositions, determining (a) the weights individuals assign to selfinterest versus collective interest (i.e., social value orientation), and (b) the 
expectations about others' cooperative intentions (i.e., trust); moreover, we expect these personality variables to systematically affect their evaluations of structural solutions to this real-life social dilemma. Our hypotheses are tested in a standard commuting situation with a sample of regular car commuters, whose social value orientations and trust levels are measured in advance.

\section{Commuting situation as social dilemma}

The decision to commute by car or public transportation is essentially a problem of interdependence. That is, the multiple benefits of commuting by car (e.g., flexibility, convenience, efficiency) accrue to the individual him- or herself, whereas the multiple costs (e.g., pollution, congestion) are shared by all members of society. Accordingly, the interdependence structure underlying the commuting situation stimulates individuals to pursue their short-term self-interest to commute by car at the cost of the long-term well-being of society at large (i.e., the presumed noncooperative option). Indeed, society would be much better served if more people decided to commute by public transportation (i.e., the presumed cooperative option), because this would minimize problems related to environmental pollution and traffic congestion. This decision situation where individual and collective interests tend to be at odds can be framed as a social dilemma (e.g., Komorita \& Parks, 1995; Messick \& Brewer, 1983; Van Lange, Liebrand, Messick, \& Wilke, 1992).

How can public transportation be stimulated given that commuting by car is personally beneficial for most people? One of the more promising theories explaining cooperation in social dilemmas, the goal/expectation theory (Pruitt \& Kimmel, 1977), formulates two conditions that must be fulfilled to establish collective decisions. First, individuals must achieve the goal of mutual cooperation. That is, they have to realize that enduring noncooperation by many people will eventually lead to a disastrous situation for all. However, these pro-social motivations are not sufficient to elicit cooperation, and they must be accompanied by the expectation that a considerable number of other people are also willing to cooperate, because otherwise the individual contribution will be wasted. Although goal/expectation theory has been primarily formulated to explain cooperation in two-person social dilemmas, it may be relevant for the present study, because it delineates that public transportation preferences may be shaped by the combined effect of the individual goals and expectations in the commuting situation.

\section{Pro-social goals in the commuting situation: \\ The role of social value orientations}

Why would commuters shift from considering primarily their short-term selfinterested outcomes -- to commute in a convenient and efficient manners -- to considering the long-term collective outcomes of their decision? Following interdependence theory (Kelley \& Thibaut, 1978), we assume that people in interdependent settings do not merely respond to the objective decision situation 
(i.e., the given matrix), which is largely determined by an individual's immediate hedonistic outcomes. That is, in an interdependent situation individual preferences and behaviors frequently reflect not only the pursuit of immediate self-interest, but also their broader goals and values, such as a concern with the collective wellbeing, an intention to be good to other people, and serve as an "example" to others. This process, whereby people relinquish their immediate self-interest and take into account broader concerns, is referred to as transformation of motivation (Kelley \& Thibaut, 1978; Rusbult \& Van Lange, in press), and leads to a new set of preferences (i.e., the effective matrix) that is presumably more predictive of individual decision-making in social dilemmas. Among other possibilities, transformation of motivation may be guided by interpersonal dispositions, referring to more or less stable personal orientations or response patterns in interdependent situations (cf. Rusbult \& Van Lange, in press).

An interpersonal disposition that may activate the transformation from shortterm personal to long-term collective goals in the commuting situation is social value orientation, reflecting individual preferences for distributions of outcomes to self and others (Messick \& McClintock, 1968). Past work on social value orientations generally distinguishes between three types (e.g., Kuhlman \& Marshello, 1975): cooperation (assignment of equal, positive weights to outcomes for self and others), individualism (assignment of positive weights to outcomes for self, and indifference regarding outcomes of others), and competition (assignment of positive weights to outcomes for self, but negative weights to outcomes for others). These social value orientations have been demonstrated to systematically affect choice patterns in social dilemmas, with cooperative or "pro-social" individuals exercising greater restraint, and exhibiting greater cooperation than individualists and competitors -- together referred to as "pro-selfs" (e.g., Kramer, McClintock, \& Messick, 1986; Liebrand, Wilke, Vogel, \& Wolters, 1986; Parks, 1994; Sattler \& Kerr, 1991). Whereas prior work focused, for the most part, on the impact of social value orientations in experimentally induced social dilemmas, studies of real-world social dilemmas -- such as bargaining, volunteering in research, or sacrificing in intimate relationships (De Dreu \& Van Lange, in press; McClintock \& Allison, 1989; Van Lange \& Agnew, 1995) -- have obtained some evidence in support of the ecological validity of social value orientations.

Recently, it has been observed that social value orientations may also shape the ways in which commuters evaluate their commuting situation (Van Vugt, Meertens, \& Van Lange, 1995). That is, individuals with pro-social orientations tend to view the commuting situation more as an environmental problem, in which they pursue to minimize the environmental costs of their behavior. Conversely, individuals with pro-self orientations tend to interpret the decision situation more as an accessibility problem, in which they seek to minimize the costs of their travel time. How might such interpretations affect people's commuting decisions?

First, it is expected that these different interpretations are shaped by structural features of the commuting situation, determining the salience of collective interest 
and self-interest. Accordingly, we predict that public transportation preferences will be enhanced when commuters expect that cars produce major (vs. minor) environmental damage (Hypothesis 1a), and when commuters expect heavy (vs. virtually no) congestion commuting by car (Hypothesis $\mathrm{Ib}$ ).

More importantly, we expect that people with distinct social value orientations will respond differently to these conditions. Given pro-socials' orientation toward the long-term collective consequences and pro-selfs' orientation toward the shortterm self-interested consequences of their decisions, the following hypotheses are advanced. First, we predict that pro-social commuters will exhibit an overall greater preference for public transportation than pro-self commuters (Hypothesis $2 a$ ). Moreover, we expect that differences between social value orientations will be more pronounced when either the long-term collective interest (i.e., environment) or short-term individual interest (i.e., travel time) is at stake. That is, pro-socials will perhaps be more sensitive to information about the detrimental environmental effects of car use, whereas pro-selfs will be more sensitive to information regarding the relative efficiency of cars. Accordingly, relative to pro-self commuters, prosocial commuters are expected to exhibit a stronger increase in public transportation preference when car use causes major (vs. minor) environmental damage (Hypothesis $2 b$ ). Conversely, relative to pro-social commuters, pro-self commuters are expected to exhibit a sharper increase in public transportation preference when heavy (versus no) traffic congestion is foreseen, and commuting by car is relatively less efficient than public transportation (Hypothesis $2 c$ ).

\section{Pro-social expectations in the commuting situation: Individual differences in trust}

While commuters with pro-social orientations may be more inclined to consider the environmental effects of car use, it may not be sufficient to provoke a change toward public transportation. As noted by goal/expectation theory (Pruitt \& Kimmel, 1977), individuals should also expect cooperation from interdependent others. An interpersonal disposition relevant to understanding these expectations, is someone's level of general or depersonalized trust (cf. Deutsch, 1958; Edney, 1980; Yamagishi, 1986). Over the past decade a number of studies have addressed the impact of trust on cooperative decisions in different social dilemma formats (i.e., resource dilemmas, public good dilemmas). That work has revealed that hightrusting individuals are more likely to exercise restraint in shared resources and invest in collective goods than low-trusting individuals (e.g., Brann \& Foddy, 1987; Messick, Wilke, Brewer, Kramer, Zemke, \& Lui, 1983; Parks, 1994; Yamagishi, 1986, 1988, 1992; Yamagishi \& Sato, 1986). Although this evidence is compelling, we should note that all of these studies have been conducted in laboratory settings with groups of students of maximally eight people. Thus, it remains to be seen whether trust can be predictive of decisions in large-scale dilemmas, such as the problem of environmental pollution, where expectations about others' cooperation are systematically lower than in small-scale dilemmas (cf. Kerr, 1989; Kerr \& 
Bruun, 1983; Olson, 1965; Yamagishi, 1992). However, in light of the size of these problems, and the lack of reliable information about what others will do, someone's general trust in others may be an important "cue to action."

How may an individual's trust level affect the predicted relationship between social value orientation and decisions in the commuting situation? First, for individuals with pro-self orientations their trust level should have very little effect on their preferences for commuting by car or public transportation. That is, given their lack of concern with the long-term collective interest of a clean environment they are not very likely to decide for commuting by public transportation, whether or not they expect others to act in a pro-environmental fashion. Second, for individuals with pro-social orientations, their trust level should, at least in theory, have no impact on their commuting decisions either, because from a social dilemma perspective, it is always personally more attractive to commute by car than by public transportation, irrespective of the number of others who commute by public transportation. Nevertheless, past work on social dilemmas has revealed that expectations about others' pro-social behaviors may influence the perceived social desirability of cooperation, leading to stronger social and normative pressures to cooperate (e.g., Dawes, McTavish, \& Shaklee, 1977; Liebrand et al., 1986). Moreover, the expectancy of others' cooperation may enhance the perceptions of manageability or efficacy of the social dilemma (cf. Kerr, 1989, 1992), which may further increase the willingness to cooperate of people who are generally concerned with the collective interest (i.e., pro-social orientations).

On the basis of the above reasoning, three additional hypotheses are advanced. First, based on the assumption that high expectations about other commuters' cooperation may encourage people to also give up their self-interest for the sake of the environment, we predict that high-trusting commuters will exhibit greater preference for public transportation than low-trusting commuters (Hypothesis 3a). Moreover, based on goal/expectation theory it is expected that pro-social commuters with high levels of trust should display greater public transportation preferences than pro-social commuters with low trust levels, and pro-self commuters with either low and high trust levels (Hypothesis $3 b$ ). Finally, we predict that public transportation preferences among pro-socials with high levels of trust will be most pronounced when cars are causing major (vs. minor) environmental damage, whereas the preferences of the three remaining commuter groups will not be affected by the differential impact of cars on environmental pollution; their public transportation preference is expected to be similar, regardless of whether car use is expected to cause major or minor environmental damage (Hypothesis 3c).

\section{Approval of solutions in the commuting situation}

The above provides a framework in which to understand how commuters may be willing to forego their self-interest, when they (a) share pro-social goals, and (b) are optimistic about the number of people that will cooperate. Yet, particularly in social dilemmas involving many actors, such as environmental pollution, it may not 
be very realistic to believe -- not even among high-trusting individuals -- that a considerable number of people is willing to voluntarily forego their self-interest. That is, compared to small-scale social dilemmas, in large-scale social dilemmas people are less identifiable, and experience lower levels of personal responsibility and efficacy (cf. Kerr, 1989, 1992; Latané \& Wolf, 1981); therefore, they will be less motivated to cooperate in such situations. Hence, cooperation in social dilemmas involving many people must be assured and enhanced in some other ways than by voluntarily-based cooperation, and this may be accomplished by changing the structure of interdependence underlying the decision situation (structural goal/expectation theory; cf. Yamagishi, 1986). Structural changes involve the "coordinated, collective action among members to either eliminate or transform the incentive structure of the social dilemma" (Samuelson, 1993; p. 299), and they are generally aimed at increasing the negative outcomes of noncooperation and positive outcomes of cooperation. Over the past decade, several types of structural change have been examined in social dilemmas (e.g., providing selective incentives, appointing a leader, implementing a sanctioning system, decentralization, applying equity or equality rules) and these have been generally effective in promoting systematic cooperation (Kelley \& Grzelak, 1972; Komorita, Sweeney, \& Kravitz, 1980; Rutte \& Wilke, 1984, 1985; Samuelson, 1991, 1993; Samuelson, Messick, Rutte, \& Wilke, 1984; Van Dijk \& Wilke, 1993, 1995; Yamagishi, 1986, 1988, 1992). However, these studies were conducted in laboratory settings, in which four to eight people were facing a social dilemma, and could exhibit their preference for one kind of structural solution (for an exception, see Samuelson, 1993). This raises at least two important questions about the validity of these findings for real-world social dilemmas.

First, while prior theorizing about solutions to social dilemmas (e.g., Komorita \& Parks, 1994; Messick \& Brewer, 1983; Yamagishi, 1986) has suggested the distinction between structural solutions (i.e., solutions that alter or eliminate the interdependence structure) and nonstructural solutions (i.e., solutions that alter the subjective interpretation of the situation by providing information, education, and communication), so far no empirical work has addressed the validity of this taxonomy. That is, do actors actually perceive and classify different solutions based on whether these strategies affect the structure of the social dilemma they are facing? Or, do people categorize these solutions differently, such as in terms of whether these exert their influence through (a) promoting cooperation or decreasing noncooperation, (b) affecting the personal freedom, or (c) large-scale versus smallscale interventions. Accordingly, an explorative goal of the current work is to examine how commuters classify a series of solutions aimed at decreasing car use and stimulating public transportation.

Second, despite some optimism about the effectiveness of structural solutions to social dilemmas (Messick \& Brewer, 1983), in real-life these solutions may be judged as too drastic, inefficient, unfair, or incompatible with personal freedom (cf. Klandermans, 1992; Rusbult \& Van Lange, in press; Samuelson, 1993). 
Accordingly, commuters may not be very prone to accept and comply with these solutions in their commuting situation. Thus, it is important to provide more insights in (a) the major evaluative dimensions underlying judgments of structural solutions, and (b) the types of structural solutions that are most strongly approved of by commuters. In the current chapter, we explore to what extent these solutions are judged to be (a) effective, and to what extent they are perceived as preserving (b) the individual freedom, (c) self-interest, and (d) collective interest (cf. Samuelson \& Messick, in press). Moreover, we examine whether these evaluations are systematically related to individual differences in social value orientation and trust. First, we anticipate differences between pro-social and pro-self commuters on the dimensions of self-interest and collective interest. Given that pro-social commuters assign greater importance than pro-selfs to outcomes for others, we advance the hypothesis that pro-socials (vs. pro-selfs) will attach more importance to whether these solutions serve the collective interest (Hypothesis 4a). In contrast, pro-self commuters who assign greater weight to outcomes for self, will attach more importance to whether these solutions serve their self-interest (Hypothesis $4 b$ ). Second, because of their greater optimism about others' cooperation, we predict that high-trusters will assign greater importance to the collective interest in evaluating structural solutions (Hypothesis 5a), whereas low-trusters assign greater importance to their self-interest (Hypothesis $5 b$ ).

\subsection{Method}

\section{Participants and design}

One hundred-and-forty daily commuters in the Netherlands participated in the current study. Among them were 105 males and 34 females -- one commuter failed to indicate gender -- with an average age of 36.5 years (minimum and maximum age, respectively 19 and 62 years). The participants were people commuting by car on either a daily $(52 \%)$ or regular basis $(48 \%)$-- the latter group also occasionally (i.e., less than once a week) commuted by bike, train or bus. The hypotheses of the present study were tested in a 2 (Social Value Orientation: Pro-social vs. Pro-self individuals) by 2 (Trust: High vs. Low-Trust individuals) by 2 (Traffic Congestion: Expectancy of No vs. Heavy Traffic Congestion) by 2 (Pollution: Expectancy of Minor vs. Major Environmental Damage due to car use) factorial design consisting of all between-subjects factors. The Social Value Orientation and Trust groups were formed on the basis of their individual answers to two personality questionnaires, administered prior to the description of the commuting situation. The different levels of Congestion and Pollution were manipulated through varying information about the environmental and travel time consequences of commuting decisions, and commuters were randomly assigned to each of these experimental conditions. Our main dependent variables were (a) the individual preferences for commuting by car or public transportation (i.e., train), and (b) commuters' 
approvals, and (c) evaluations of a series of interventions in the commuting situation.

\section{Procedure}

Commuters were recruited at two gas stations in a large industrialized area in the middle of the Netherlands (near the city of 's Hertogenbosch) during the morning and evening rush-hour traffic. Most commuters were employees of companies located in that particular business district. After they expressed their willingness to participate in the research, they received a survey, which could be filled in either at work or home in approximately 25 minutes, as well as a stamped self-addressed return envelope. Out of a total of 300 distributed questionnaires 140 were returned, yielding a response rate of approximately forty-seven percent. Those who returned their surveys received a letter of thanks including a debriefing form and two small gifts (a marker pen and a road map of the Netherlands containing information about carpooling).

The questionnaire consisted of three parts. The first part contained personality questionnaires, measuring the individual's (a) social value orientation, and (b) level of trust. In the second and third part the description of the commuting situation was presented to the commuters, followed by a series of questions referring to that particular commuting situation (e.g., preferences for car versus public transportation, approvals and evaluations of interventions in the commuting situation).

\section{Personality questionnaires}

First, we administered a series of three-choice Decomposed Games (e.g., Kuhlman \& Marshello, 1975; Messick \& McClintock, 1968) to assess an individual's social value orientation (for more details about this procedure, see Appendix II). Decomposed games entail decisions between specific outcomes for self and an (imaginary) other. This technique has good internal consistency (e.g., Liebrand \& Van Run, 1985; Parks, 1994), test-retest reliability over a considerable time period (Eisenberger, Kuhlman, \& Cotterell, 1992; Kuhlman, Camac, \& Cunha, 1986), and is not related to measures of social desirability (Platow, 1992). Moreover, there is some evidence for the ecological validity of this measurement (e.g., Bem \& Lord, 1979; McClintock \& Allison, 1989; Van Lange \& Agnew, 1995).

The decomposed games utilized in the present study were adopted from previous research (e.g., McClintock \& Allison, 1989; Van Lange \& Kuhlman, 1994). They consist of nine decisions between distributions of imaginary monetary outcomes to self and an (anonymous) other. Each decision situation contains three allocation options. One of these options proposes an equal distribution of outcomes and represents the value orientation of cooperation. Another option proposes a distribution which maximizes own outcomes irrespective of other's outcomes, which is indicative of the value orientation of individualism. A third option advances a distribution which maximizes the difference between own outcomes and other's outcomes, and is representative of the value orientation of competition. An example 
of a decomposed game is the choice between (A) fl. 4.80 for Self and fl. 4.80 for Other; (B) fl. 5.40 for Self and fl. 2.80 for Other; (C) fl. 4.80 for Self and fl. 0.80 for Other (one Dutch florin is approximately \$0.65). Option A represents the cooperative option, because the sum of outcomes for Self and Other $(4.80+4.80=$ $9.60)$ is larger than for option B $(5.40+2.80=8.20)$ and $C(4.80+0.80=5.60)$. In addition, option B represents the individual option, because the outcome for Self (5.40) is larger than for either option A (4.80) or C (4.80). Finally, option C represents the competitive option, because the difference between the outcome for Self and Other $(4.80-0.80=4.00)$ is larger compared to option A $(4.80-4.80=0)$ and $\mathrm{B}(5.40-2.80=2.60)$.

Individuals were classified as either cooperators, individualists, or competitors if at least six out of nine decisions were consistent with a particular value orientation (for a similar procedure, see Van Lange \& Kuhlman, 1994). Accordingly, out of a total number of 140 individuals 95 were classified as cooperators $(68 \%), 33$ as individualists $(24 \%)$ and four as competitors $(3 \%)$. On the basis of the above consistency criterion, eight commuters $(6 \%)$ could not be classified. In line with previous research on social value orientations, we combined the individualists and competitors to form a group of basically self-interested or "pro-self" individuals, and contrasted them in our analyses with the group of cooperative or "pro-social" individuals (for a similar procedure, see Van Lange \& Liebrand, 1991; Van Vugt et al., 1995).

Second, we administered a short questionnaire assessing an individual's general level of trust. The Trust-questionnaire contained a list of five items and was based on the original Trust-scale developed by Yamagishi (1986) and Yamagishi and Sato (1986). Prior research has demonstrated that the Trust-scale has good internal consistency, test-retest reliability, and construct validity (e.g., Parks, 1994; Yamagishi, 1986, 1988, 1992; Yamagishi \& Sato, 1986); however, none of these studies have directly addressed the ecological validity of the scale. The items are presented in the form of statements, and for each of them individuals can indicate how much they agree or disagree $(1=$ very strongly disagree, $7=$ strongly agree). In the present study the following statements were utilized: (a) Nowadays you have to be careful, otherwise people will exploit you; (b) if there would be fewer police men, it would be much more dangerous on the streets; (c) one should not trust other people, unless one knows them well; (d) many things in life often fail, because a lot of people pursue their self-interest; (e) you have to be careful with strangers, until you know you can trust them. We performed a reliability analysis on these items, and found that the Trust-scale had an acceptable reliability coefficient of .70 . The individual level of trust was simply measured by averaging the scores on these four items, so that a high average score reflects a low level of trust and a low average score a high level of trust. In line with prior research (e.g., Yamagishi, 1986), we classified the subjects through a median split to form a group of Low-trusters (with an average score above 4.70) and a group of High-trusters (with an average score below 4.70). 
To assess whether social value orientation and trust were independent personality constructs, we performed a 2 (Social Value Orientation) by 2 (Trust) crosstabs analysis. This analysis revealed no systematic differences in the proportion of pro-socials and pro-selfs among the high-trust commuters (respective percentages for pro-socials and pro-selfs were $74.2 \%$ vs. $25.8 \%$ ) as compared to low-trust commuters (respective percentages of pro-social and pro-self commuters were $69.7 \%$ vs. $30.3 \%)$, $\mathrm{Chi}^{2}(1, N=131)<1$. Hence, we may conclude that social value orientation and trust appeared to be unrelated personality factors in the current study (cf. Parks, 1994).

\section{Commuting situation}

The second part of the survey contained a description of a commuting situation, and commuters were asked to read the information carefully. The situation was designed in an attempt to parallel very closely the actual commuting situation of the commuters in the sample (for an example, see Appendix I). People were asked to imagine that they were employees of a company named Comptel, which employed about 2000 workers -- all of them commuted to work on a daily basis. The distance between home and the company was fixed at 40 kilometers (approximately 25 miles), which could be covered either by car or by public transportation (i.e., train). There was a highway and a railway (including a train station) at a very close distance from home, both leading directly to the industrial area where Comptel was located. Before commuters made their decisions to commute by car or by public transportation, it was explicitly stated that all 2000 employees (a) had access to both types of transportation, (b) were commuting in the morning rush hour, and (c) used the same highway or railway route. Thereafter, they received information about the presumed effects of their and others' commuting decisions on the levels of traffic congestion and environmental pollution. In an attempt to increase the plausibility of the information the commuting situation was set in the near future (at ten years from now).

Level of traffic congestion. It was explained that under normal circumstances commuting by car would be much faster than by public transportation (respective travel times were 40 versus 50 minutes). However, contrary to commuting by train, the travel time by car could increase enormously as a consequence of traffic congestion on the route. In the Expectancy of No Congestion-condition we stated that the amount of traffic jams had been reduced considerably in the past few years. Accordingly, there was virtually no chance that people would end up in a traffic jam, and so most of the times the travel time by car would be normal (i.e., 40 minutes). In the Expectancy of Heavy Congestion-condition, it was stressed that over the past few years there had been an enormous rise in the amount of traffic jams on the route. Accordingly, there was a great likelihood that people would end up in a traffic jam and this could increase the travel time by car to as much as 70 minutes. Finally, in both conditions it was made clear that public transportation would always provide a stable travel time of 50 minutes. 
Degree of pollution. All commuters were given information that the environment was seriously polluted within ten years from now: "Scientists have determined that the hole in the ozone layer has expanded and the earth temperature has risen. Moreover, on many locations there are reports of serious smog and acid rain effects that form a threat to the environment and public health." In addition, it was phrased in the Expectancy of Minor Environmental Damage-condition that "the contribution of car use on the level of environmental pollution has dropped significantly." Conversely, in the Expectancy of Major Environmental Damagecondition, we stated that "car use contributes heavily to the level of environmental pollution." Moreover, in both conditions we stressed that public transportation hardly contributes to the level of environmental pollution.

\section{Dependent measures}

After reading the description of the commuting context, we administered a series of questions that were related to commuters' (a) preferences for commuting by car or public transportation, and their (b) approvals, and (c) evaluations of interventions in the commuting situation.

Commuting preferences. Commuters were asked to rate their preference for commuting by car or public transportation on a seven point scale, ranging from (1) strong preference for car, to (7) strong preference for train.

Approval of interventions in the commuting situation. In addition, we examined the appraisals of a list of specific changes in the commuting situation aimed at modifying the commuting behavior of the employees of Comptel. First, we examined their judgment of maintaining the commuting situation without imposing any regulations on commuters' decisions $(1=$ strongly opposing, $7=$ strongly approving). Second, participants were asked to indicate their approval of a series of ten specific interventions (Interventions A to J), ( 1 = strongly opposing, 7 = strongly approving). These interventions were deliberately selected from an extensive list of Dutch policy measures proposed for reducing the environmental and congestion problems associated with commuter traffic (Dutch Ministry of Traffic \& Waterways, 1990; Vlek \& Michon, 1992). Specifically, the following interventions were proposed: (A) Reduction of parking places at the company; (B) distribution of parking places per unit of the company; (C) no reimbursement of travel expenses for commuting by car; (D) obligation to commute by car for employees that do not need their car during work time; (E) company provides information about disadvantages of commuting by car and advantages of commuting by train; (F) construction of additional driving lane on highway to company; (G) rewards for people commuting to work by public transportation; $(\mathrm{H})$ appointment of a transport coordinator (i.e., person who actively promotes alternative transport modes) per unit of the company; (I) dutch government starts educational campaign stressing the environmental effects of car use; $(\mathrm{J})$ increase of public transportation facilities (i.e., extra trains on route to company). As can be seen, the above list covers a wide range of interventions, including financial (iluterventions $\mathrm{C}$ and $\mathrm{G}$ ), 
infra-structural (interventions A, F, J), freedom-limiting (intervention D), and decentralizing strategies (interventions B and $\mathrm{H}$ ) -- all of them are thought of as structural solutions to social dilemmas (cf. Messick \& Brewer, 1983; Samuelson \& Messick, in press). In addition, we included a pair of interventions that are thought of as nonstructural solutions (interventions E and I).

Evaluations of interventions in the commuting situation. Commuters also rated the maintenance option and the ten more specific interventions on each of the following evaluative dimensions that are assumed to be important attributes for evaluating changes in the context of social dilemmas (e.g., Samuelson, 1993; Samuelson \& Messick, in press): (a) effectiveness ("How effective do you think this intervention is for reducing car use in the commuting situation?"): $1=$ very ineffective, 7 = very effective; (b) collective interest ("To what extent do you think this intervention will affect the collective interest?"): $1=$ strongly threaten collective interest, 7 = strongly preserve collective interest; (c) self-interest ("To what extent do you think this intervention will affect your self-interest?"): 1 = strongly threaten self interest, $7=$ strongly preserve self-interest; (d) individual freedom ("To what extent do you think this intervention will affect your personal freedom?"): 1 = strongly threaten individual freedom, 7 = strongly preserve individual freedom. Finally, commuters rank ordered these four evaluative dimensions in terms of their importance for judging solutions in the commuting situation ( 1 = most important dimension, 4 = least important dimension).

Plausibility of information. In the final section of the questionnaire commuters answered two questions concerning the plausibility of the information provided in the scenarios regarding (a) the congestion and (b) pollution conditions ( $1=$ very unrealistic, $7=$ very realistic). Univariate analyses, including a 2 (Social Value Orientation) by 2 (Trust) by 2 (Congestion) by 2 (Pollution) factorial design, revealed a systematic difference for information about the level of traffic congestion, in that commuters in the No Congestion-condition $(M=3.95)$ found the information less realistic -- however, clearly not unrealistic -- than commuters in the Heavy Congestion-condition $(M=5.00)$. No systematic differences were obtained for the plausibility of information regarding the degree of environmental pollution, so we may conclude that, on the whole, the different scenarios were quite convincing.

\subsection{Results}

\section{Preference for commuting by car versus public transportation}

In order to test the general predictions regarding the influence of pollution, and congestion (Hypotheses 1a, 1b), social value orientation (i.e., Hypotheses 2a, 2b, and $2 \mathrm{c}$ ), trust (i.e., Hypothesis $3 \mathrm{a}$ ), and the combination of these interpersonal dispositions on commuters' preferences (i.e., Hypothesis 3b, 3c), we performed a 2 (Social Value Orientation) by 2 (Trust) by 2 (Congestion) by 2 (Pollution) ANOVA 
on public transportation preference, all factors being between-subjects factors. Using a significance level for alpha of .05 , this analysis revealed a variety of significant main and interaction effects that are addressed below.

First, consistent with Hypotheses $1 \mathrm{a}$ and $1 \mathrm{~b}$, there were main effects for Pollution, $F(1,116)=4.79, p<.05$, and Congestion, $F(1,116)=20.29, p<.001$, indicating that in the heavy congestion $(M=5.98)$ and major damage-conditions $(M$ $=5.62$ ) commuters displayed greater preferences for public transportation than in the no congestion $(M=4.55)$ and minor damage-conditions $(M=4.85)$.

Second, contrary to Hypothesis 2a, the main effect of Social Value Orientation was not significant, $F(1,116)=2.36, p=.13$, although the means were in the predicted direction, with pro-socials $(M=5.37)$ exhibiting a greater preference for commuting by public transportation than pro-selfs $(M=4.73)$.

Third, in Hypothesis $2 \mathrm{~b}$ it was predicted that the degree of environmental damage would have a greater impact on the public transportation preference of prosocial than pro-self commuters. However, there was no support for a Social Value Orientation and Pollution interaction effect, $F(1,116)<1$. 
Fourth, a significant interaction was found between Social Value Orientation and Congestion, $F(1,116)=3.94, p<.05$. In Hypothesis $2 \mathrm{c}$, it was predicted that pro-self commuters would be more sensitive to possible time delays resulting from congestion than pro-social commuters. The concomitant means (displayed in Figure 7) demonstrate, first, that the weakest overall public transportation preference was found among pro-self commuters when no congestion was expected $(M=3.77)$. Moreover, consistent with Hypothesis 2c, it can be seen that for pro-selfs there was a much greater increase in public transportation preference from the no $(M=3.77)$ to the heavy congestion-condition ( $M=6.13$; difference of 2.36 scale points), $t(35)$ $=15.05, p<.001$, than for pro-socials $(M=4.88$ vs. 5.93 ; difference of 1.05 scale points), $t(93)=6.87, p<.01$. Thus, the expected delay in travel time had indeed a stronger impact on the commuting decisions of pro-self commuters.

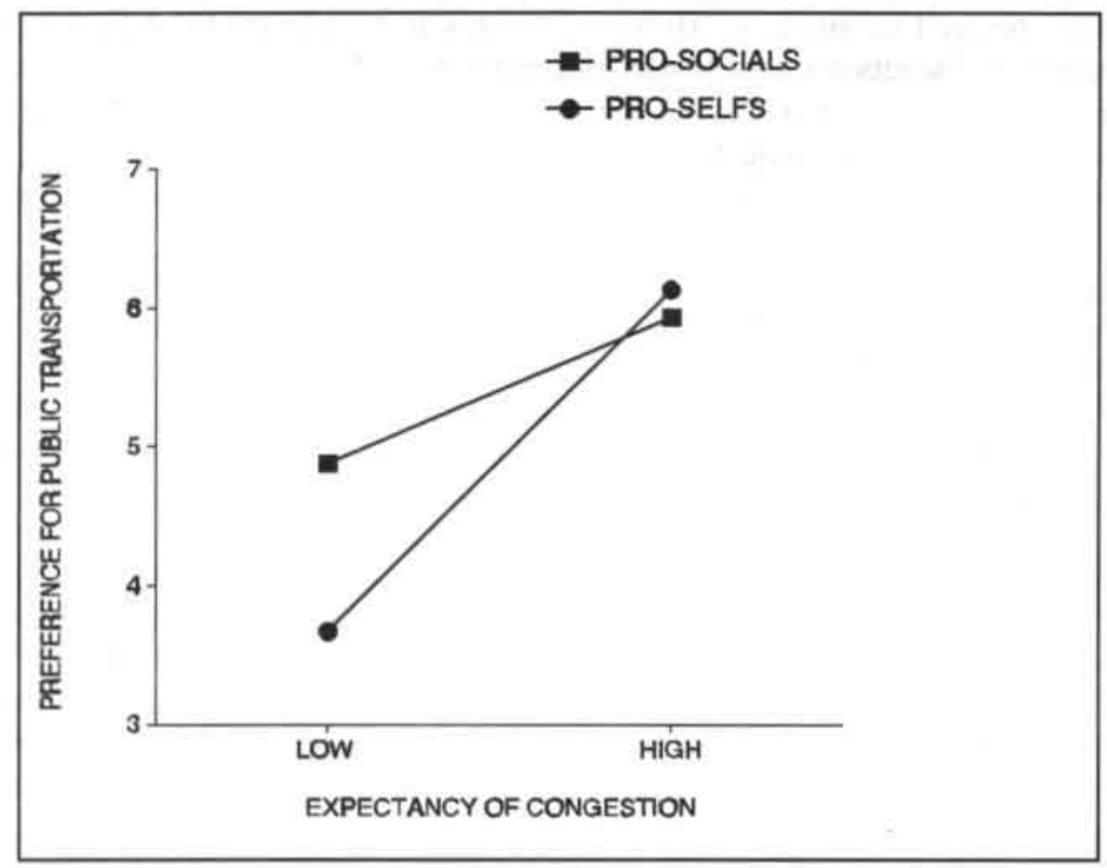

Figure 7. Preference for public transportation as a function of social value orientation and expectancy of congestion.

Note. Preference varies from 1 (= very strong preference for car) to 7 (= very strong preference for public transportation). 
Fifth, a significant main effect of Trust emerged, $F(1,116)=5.13, p<.05$. As predicted in Hypothesis 3a, high-trusters displayed a greater public transportation preference $(M=5.55)$ than low-trusters $(M=4.83)$.

Sixth, on the basis of goal-expectation theory we expected that pro-social commuters with a high level of trust would prefer public transportation more strongly than either pro-socials with low levels of trust, or pro-selfs, irrespective of their level of trust (i.e., Hypothesis $3 b$ ). Our analysis revealed indeed a significant interaction of Social Value and Trust, $F(1,116)=4.12, p<.05$. In order to test this prediction more precisely, we compared the means of pro-social commuters with high levels of trust versus the means of the three remaining commuter groups. Consistent with Hypothesis $3 \mathrm{~b}$, this contrast was significant, $F(1,124)=12.30, p$ $<.001$, and the means showed that, relative to the other commuter groups ( $M=$ $4.72 ; N=83$ ), pro-social high-trusting commuters exhibited a greater preference for public transportation $(M=5.98 ; N=49)$. A closer examination of the means for each separate Social Value $x$ Trust category (as shown in Table 7) revealed that, consistent with our prediction, within the group of pro-social commuters, hightrusting individuals $(M=5.98)$ preferred public transportation more strongly than low-trusting individuals $(M=4.72), t(93)=3.21, p<.01$. Surprisingly, however, within the group of pro-self commuters the means were reversed, and high-trusters exhibited a weaker preference for public transportation $(M=4.29)$ than low-trusters $(M=5.10), t(35)=1.69, p<.05$ (we will address this issue in the discussion).

Table 7

Preferences for Public Transportation as Function of Social Value Orientation and Trust

Trust

$\begin{array}{lll} & \text { Low } & \text { High } \\ \text { Social value orientation } & \text { trust } & \text { trust }\end{array}$

Pro-social commuters

$4.72^{\mathrm{a}}$

$5.98^{\mathrm{b}}$

Pro-self commuters

$M$

4.83

5.55

Note. The preference scale ranges from 1 (= strong preference for car) to 7 (= strong preference for public transportation); means with a different superscript differ significantly, $p<.05$ 
Seventh, it was predicted in Hypothesis $3 \mathrm{c}$ that the public transportation preference of pro-social high-trusting commuters would be further enhanced by information about the major environmental damage resulting from car use. Yet, no evidence for a three-way interaction of Social Value Orientation, Trust, and Pollution emerged, $F(1,116)<1$.

Finally, besides the predicted main effects for Congestion and Pollution, there was an unexpected significant interaction effect between these independent variables, $F(1,116)=8.84, p<.01$. A closer examination of this interaction pattern revealed that in the condition of minor environmental damage, preferences for public transportation were more pronounced from the no $(M=3.83)$ to the heavy congestion-condition ( $M=6.19$; difference of 2.33 scale points) than in the condition of major environmental damage $\left(M^{\prime} \mathrm{s}=5.52\right.$ vs. 5.74 ; difference of 0.22$)$. In a similar vein, in the absence of traffic congestion, the public transportation preference increased from the minor $(M=3.83)$ to the major environmental damage-condition ( $M=5.52$; difference of 1.69 scale points), whereas the means of the two environmental conditions were almost identical in case of heavy congestion ( $M$ 's $=6.19$ vs. 5.74 ; difference of minus 0.45 scale points). Taken together, these findings suggest that information about the seriousness of either the environmental or congestion problem increases public transportation preference to the same level as information accentuating the seriousness of both problems.

\section{Importance rankings of evaluative dimensions}

In order to test the predictions that, in evaluating solutions to this real-world dilemma, people with distinct social value orientations (i.e., Hypothesis 4) and trust levels (i.e., Hypothesis 5) would differ in the importance assigned to self-interest versus collective interest in evaluating solutions, we performed analyses on the importance rankings of the four dimensions (i.e., effectiveness, collective interest, self-interest, and freedom; $1=$ most important, $4=$ least important). First, a chisquare analysis was performed on the first ranked choice to examine the assumption of equiprobability (i.e., all four dimensions are ranked first by an equal number of commuters). This assumption was not valid, $\operatorname{Chi}^{2}(3, N=126)=30.12, p<.001$, and the percentages indicated that most commuters $(39.7 \%)$ considered effectiveness to be the first important dimension in evaluating solutions, which was closely followed by individual freedom $(34.1 \%)$. The dimensions collective interest $(15.9 \%)$ and self-interest $(10.3 \%)$ were considered to be most important by a much smaller number of commuters'.

1 Although all groups agreed that effectiveness and freedom were the most important evaluative dimensions for judging solutions, the rank ordering of dimensions varied somewhat between people with different social value orientations and trust levels, and these variations were in line with our hypotheses. Specifically, for pro-socials and high-trusters the dimension of collective interest was more important than self-interest, whereas for pro-selfs and low-trusters the ordering was reverse, with self-interest being rated as a more important dimension than collective interest. 
To test Hypotheses 4 and 5, importance rankings for all dimensions were analyzed in four 2 (Social Value Orientation) by 2 (Trust) by 2 (Congestion) by 2 (Pollution) ANOVAs ${ }^{2}$. These analyses yielded a significant main effect for Social Value Orientation on collective interest, $F(1,108)=5.95, p<.05$, revealing that, in support of Hypothesis $4 \mathrm{a}$, pro-socials $(M=2.53)$ were more concerned than proselfs $(M=3.00)$ about whether these solutions would affect the collective interest. In contrast, relative to pro-socials $(M=3.11)$, pro-selfs $(M=2.67)$ were more concerned with whether these solutions would preserve the self-interest; however, this effect was not significant, $F(1,108)=2.90, p<.10$. Moreover, consistent with Hypothesis $5 \mathrm{~b}$, differences between levels of trust were obtained for self-interest, $F(1,108)=4.38, p<.05$, in that low-trusters $(M=2.77)$ assigned greater value to the preservation of their self-interest than did high-trusters $(M=3.23)$; however, no differences emerged on the dimension collective interest, $F(1,108)<1$. These effects were not further influenced by the congestion and pollution conditions.

To summarize, Hypotheses 4 and 5 addressing the impact of interpersonal dispositions on the evaluation of solutions to the commuting situation received partial support, in that for social value orientation differences were found on the dimension of collective interest, but not on the dimension of self-interest, whereas for trust differences were found on the dimension of self-interest but not on collective interest.

\section{Approval of interventions in the commuting situation}

A more exploratory purpose of the present study was to examine how commuters would classify the series of interventions in the commuting situation. Moreover, we explored to what extent the approval ratings of these solutions would be related to (a) their position on the evaluative dimensions (i.e., effectiveness, collective interest, self-interest, freedom), and (b) the interpersonal dispositions of commuters.

Classification of interventions. First, we performed a principal component analysis on the approval ratings for the list of interventions A to $\mathrm{J}(1=$ strongly opposing, 7 = strongly approving), so as to examine the validity of the theoretical distinction between structural and nonstructural solutions; thus, ideally a two-factor solution would appear. Indeed, using a varimax rotation of factors with eigenvalues greater than 1.0, two factors emerged, accounting for $37.5 \%$ and $15 \%$ of the variance, respectively. As can be seen in Table 8 , the first factor was predominantly produced by interventions $\mathrm{A}, \mathrm{B}, \mathrm{C}, \mathrm{D}$, and $\mathrm{F}$ (the latter with a strongly negative factor loading), whereas interventions E, G, I and J loaded more strongly on the second factor. At first glance, the first factor seemed to represent the structural dimension of change in social dilemmas, including freedom-limiting,

${ }^{2}$ Parametric tests were used here on ordinal data because of their better power and flexibility for analyzing factorial designs (see e.g., Gardner, 1975; McNemar, 1969; Samuelson, 1993). For example, in an overview of various ratings scales and statistics, Gardner (1975) concluded that parametric tests, such as ANOVA and t-test, yield valid conclusions for data at subinterval levels. 
decentralizing, monetary, and infrastructural strategies, whereas the second factor may represent the nonstructural dimension, which consists of more individuallybased solutions. However, a closer inspection of the factor loadings revealed that the second factor, besides the pair of nonstructural interventions (interventions E and I), also included a monetary (intervention G), and infrastructural strategy (intervention J) -- a pair of presumed structural interventions -- but these have in common that they focus primarily on promoting the attractiveness of public transportation (i.e., by providing rewards or better public transportation facilities), while sustaining the individual freedom to commute by car. Accordingly, the outcomes of the factor analysis suggest that commuters classify changes in the commuting situation not so much on whether they affect the objective structure of the situation, but on whether they restrict the psychological and physical freedom to commute by car. Thus, it is perhaps more reasonable to draw a distinction between freedom-restricting versus freedom-preserving solutions to the commuting situation ${ }^{3}$.

\section{Table 8}

\section{Factor Loadings for Approvals of Interventions in the Commuting Situation}

Intervention
Factor I

Freedom-

restricting

Factor II

Freedompreserving
A. Reduction of parking places
B. Distribution of parking places
C. No reimbursement of travel expenses by car
D. Obligation to commute by $\mathrm{pt}$
E. Information by company about car disadvantages
F. Construction additional driving lane
G. Rewards for commuting by pt
H. Appointment transport coordinator
I. Campaign by government stressing environment $\quad-.03$
J. Increase public transportation facilities

Note. Approval of intervention ( $1=$ strongly opposing, $7=$ strongly approving) served as input for the factor analysis; in between parentheses are the factor assignments for each intervention.

${ }^{3}$ This solution of the factor analysis was corroborated by reliability analyses performed on the average ratings of the classes of freedom-restricting (intervention F was inversely coded) and freedom-preserving interventions. These analyses yielded acceptable Cronbach's alphas of .79 and .69 , respectively. Moreover, additional correlational analyses revealed that both freedom-restricting $(r=-.26, p<.01)$ and freedom-preserving solutions $(r=-.33, p<.01)$ were negatively related to the maintenance option (i.e., maintaining the present commuting situation), and positively related to the stated preference for public transportation (respective $r$ 's $=.53$ and $.39, p^{\prime} s<.01$ ). 
Mean approval and evaluation ratings. Second, we examined the mean approval ratings and ratings on the evaluative dimensions for each of the three classes of solutions (i.e., maintenance, freedom-restricting, and freedom-preserving solutions), which are presented in Table 9. An inspection of this table reveals that the maintenance option received the poorest ratings in terms of both approval and evaluations. Thus, commuters seemed to be strongly supportive of solutions in the commuting situation. However, of the two groups of solutions, freedom-restricting solutions were clearly less preferred than freedom-preserving solutions. Moreover, compared to freedom-preserving solutions, freedom-restricting solutions were inferior on all evaluative dimensions, but particularly in terms of the protection of individual freedom $\left(M^{\prime} \mathrm{s}=4.74\right.$ vs. 2.62 ; difference of 2.12$)$, which provides some more evidence for the result of the factor analysis, indicating a distinction between solutions in terms of their effect on individual freedom.

Table 9

Mean Approval and Evaluation Ratings for Maintenance and Solutions

Judgmental dimensions

Solutions

Approval Effectiveness Collective int. Self-interest Freedom

Maintenance

3.14

2.89

3.05

3.45

3.97

Freedom-

restricting (A)

4.14

4.17

3.94

2.62

Freedom-

preserving (B)

5.42

5.03

5.33

5.06

4.74

Difference B-A

1.80

0.89

1.16

1.12

Note. Approval scale varies from 1 (= strongly opposing) through 7 (= strongly approving); effectiveness scale varies from 1 (= very ineffective) through 7 (= very effective); the remaining scales vary from 1 (= strongly threaten ...) through 7 (= strongly preserve ...). 
Approval of solutions and factorial design. Third, we analyzed whether approvals of change were related to interpersonal (i.e., social value orientations, trust) and situational variables (i.e., levels of pollution and congestion), by performing an ANOVA on the approval ratings with a 2 (Social Value Orientation) by 2 (Trust) by 2 (Pollution) by 2 (Congestion) by 3 (Solution) factorial design. The factor Solution served as a within-subject variable, consisting of three levels (Maintenance vs. Freedom-restricting vs. Freedom-preserving solutions). This analysis yielded, first, a significant main effect of Solution, $F(2,228)=54.37, p$ $<.001$, indicating that freedom-preserving solutions $(M=5.42)$ were indeed much more approved of than both freedom-restricting solutions $(M=3.62), t(132)=$ $14.20, p<.001$, and maintaining the present situation $(M=3.14), t(130)=10.61, p$ $<.001$. Planned comparisons further revealed that freedom-restricting solutions were more strongly approved of than the maintenance option, $t(130)=2.11, p<.05$.

In addition, this analysis yielded one main effect of Trust, $F(1,114)=4.28, p$ $<.05$, and three two-way interactions of Trust and Pollution, $F(1,114)=4.50, p$ $<.05$, Social Value Orientation and Pollution, $F(1,114)=3.59, p<.05$, and Congestion and Pollution, $F(1,114)=4.06, p<.05$. Accordingly, we performed three univariate ANOVA's for each level of solution separately, including a full factorial design. First, a significant univariate effect of Trust was obtained for the approval of freedom-restricting solutions, $F(1,114)=6.81, p<.01$, with high-trusters exhibiting greater approval of these solutions $(M=3.92)$ than low-trusters $(M=$ 3.31). Second, a significant Trust and Pollution interaction emerged for the approval of maintaining the commuting situation, $F(1,114)=8.10, p<.01$. Means associated with this interaction revealed that differences between minor and major pollution-conditions were less pronounced for low-trusters $(M / s=2.90$ vs. 3.19 ; difference of 0.29$)$ than high-trusters $(M \mathrm{~s}=3.69$ vs. 2.77 ; difference of 0.92$)$, with high-trusters showing a greater support for maintenance when minor pollution was expected.

Third, contrary to what the multivariate analysis suggested there were no significant univariate two-way interactions of Social Value Orientation and Pollution. 
Finally, a significant interaction was found for Congestion and Pollution on the approval of freedom-restricting solutions, $F(1,114)=7.52, p<.01$, indicating that the strongest approval of solution was found in case of major environmental damage and no congestion $(M=4.34)$. Yet, when both environmental damage and congestion were expected to be severe, the mean approval rating $(M=3.34)$ equaled those of the conditions in which only the congestion problem $(M=3.69)$, or neither of the problems were present $(M=3.24)^{4}$.

\subsection{Discussion}

\section{Main conclusions}

The current chapter provided a social dilemma approach to commuting decisions, arguing that public transportation preferences (i.e., the presumed cooperative option) may be enhanced by the independent, and multiplicative effects of two interpersonal dispositions related to the individual (a) goals (i.e., social value orientation), and (b) expectation about others (i.e., trust) in the commuting situation. The research findings were generally consistent with our hypotheses. First, consistent with Hypotheses $1 \mathrm{a}$ and $1 \mathrm{~b}$, public transportation preferences were greater when public transportation was more rational from both an individual (i.e., more favorable travel time) and collective viewpoint (i.e., less pollution). Second, as predicted were proself commuters more sensitive to information affecting their personal outcomes in the commuting situation (i.e., heavy congestion while commuting by car; Hypothesis 2c). Moreover, consistent with Hypotheses $3 \mathrm{a}$ and $3 \mathrm{~b}$, trust in the cooperation of others increased public transportation preferences and, most importantly, this was merely found among people with pro-social value orientations (cf. goal/expectation theory, Pruitt \& Kimmel, 1977). Fourth, in partial agreement with our hypotheses, in evaluating several types of solutions in the commuting situation, pro-social commuters assigned greater importance than pro-selfs to the dimension of collective interest (Hypothesis 4a), and low-trusting commuters

${ }^{4}$ For each social value orientation and level of trust separate regression analyses were performed in which the two approval of solution scores were regressed onto the judgments on the four evaluative dimensions via the step-wise entry method. These analyses revealed, first, that for freedom-preserving solutions the ordering of dimensions was fairly stable across the interpersonal orientations categories, with collective interest being the most important predictor, followed by effectiveness and self-interest (i.e., only for pro-socials the dimension of self-interest was not entered in the regression equation), while the attribute freedom did not contribute significantly to predicting approval of freedom-preserving solution. The overall explained variances were quite high, and varied between 71 and 80 percent. More interesting were the results of the step wise regression analyses for freedom-restricting solutions. In line with our prediction (i.e., Hypothesis 4 ), it was found that for pro-selfs the self-interest dimension first entered the equation, with freedom as second, whereas the other dimensions did not come in. Conversely, for pro-socials collective interest was entered first, followed by freedom, self-interest, and effectiveness. Consistent with the prediction in Hypothesis 5, for low-trusters the dimension of self-interest was entered first, followed by effectiveness, and freedom, whereas for high-trusters the ordering was somewhat different with collective interest being first entered, followed by self-interest, freedom, and effectiveness. Similar to the findings for the other solution type, the total variance accounted for was considerable (between 62 and 83 percent). 
assigned greater importance than high-trusting commuters to the dimension of selfinterest (Hypothesis 5b). Finally, contrary to Hypotheses $2 \mathrm{~b}$ and $3 \mathrm{c}$, the public transportation preference of pro-social commuters, regardless of their trust level, did not grow further when cars were expected to produce major environmental damage. Below, these and other findings will be briefly considered, together with their theoretical and practical implications.

First, the current research revealed some evidence that commuting preferences were influenced by individual differences in social value orientations. Although pro-self commuters did not exhibit an overall weaker preference for public transportation, relative to pro-social commuters, their willingness to commute by public transportation was much lower when the expectation of traffic jams was minimal. However, when traffic congestion was expected to be severe their public transportation preferences parallelled those of pro-social commuters. Thus, this result demonstrates that pro-self commuters were much more concerned with their immediate and self-interested outcomes in the commuting situation, seeking for the travel option yielding a more efficient travel time. This finding is important, because it provides evidence for the claim that social value orientations are relevant for understanding decisions in real-life social dilemmas -- a claim often made by social dilemma researchers, but rarely ever tested directly (for exceptions, see McClintock \& Allison, 1989; Van Lange \& Agnew, 1995; Van Vugt et al., 1995).

A second finding was that commuter preferences were not only shaped by individual differences in social value orientations, but also by differences in levels of trust, in that high-trusting commuters exhibited overall greater preferences for public transportation than low-trusting commuters. This result provides some additional evidence in support of the claim that decisions in real-life social dilemmas, such as environmental pollution, are shaped by individual difference variables, determining the individual (a) goals (i.e., social value orientation) and (b) expectations about interdependent others (i.e., trust). Interestingly, a preliminary analysis revealed that these interpersonal dispositions were unrelated. This is somewhat inconsistent with claims made in earlier social dilemma research that these social motivations might be correlated, with pro-self people being generally less trusting than pro-social people (e.g., Kelley \& Grzelak, 1972; Kuhlman, Camac, \& Cunha, 1986; Yamagishi, 1992). Yet, it may be that particularly people with competitive rather than people with individualistic orientations may be somewhat more pessimistic about others' cooperation. Due to the low number of competitors in the present research, this interpretation could not be tested. Accordingly, future research should examine more closely the link between social value orientations and trust.

More important was the finding that these two interpersonal dispositions had a combined effect on commuting preferences. Consistent with goal/expectation theory (Pruitt \& Kimmel, 1977), the strongest public transportation preferences were found among people with both (a) pro-social goals (i.e., pro-social orientations), and (b) pro-social expectations about others' (i.e., high levels of trust). From a 
theoretical viewpoint this finding is relevant, because it delineates that goal/expectation theory, which was primarily developed to explain cooperation in two-person experimental games is also applicable to real-life social dilemmas with numerous actors. This is even more important in light of Pruitt and Kimmel's (1977) extensive review of social dilemma literature from which they concluded that there should be more emphasis on "theory building in the context of real-life applications" (p. 370). Moreover, in a more general sense the current work contributes to research on the role of personality in the domain of pro-social behaviors. The present study is among the first to demonstrate that two interpersonal dispositions, in combination, may have a stronger impact on pro-social decisions (i.e., to commute by public transportation) than the sum of their separate effects (cf. Joireman, Van Lange, Kuhlman, Van Vugt, \& Shelley, 1995; Knight, Johnson, Carlo, \& Eisenberg, 1994). By focusing on a single dispositional variable, researchers may all too often underestimate or ignore the impact of personality traits on pro-social behaviors. For example, examining the independent relation between social value orientations and commuting preferences in the present work would have led to the erroneous conclusion that personality does not affect pro-social decisions. Thus, in light of future psychological research in the domain of prosocial decision-making it may be relevant to analyze what particular set of dispositional variables may influence these decisions and how they are interrelated. This seems particularly relevant for research in the context of environmental pollution that has, so far, revealed only very modest correlations between single personality traits and environmental behaviors (cf. Stern, 1992).

A fourth important finding of the present work is that, in evaluating several kinds of interventions to decrease car use in the commuting situation, individuals made a classification between, on the one hand, solutions that would limit the freedom to commute by car, in either a more physical (e.g., reducing parking places), monetary (e.g., no reimbursement of travel costs), or psychological sense (e.g., appointing transport coordinator per company unit), and, on the other hand, solutions that would preserve the decisional freedom of commuters (e.g., extension of public transportation facilities, educational campaigns). This interpretation was corroborated by the finding that in judging these two classes of solutions, commuters greatly differed in their evaluation of the individual freedom associated with these changes. Moreover, evidence was obtained that, although people strongly disapproved of maintaining the commuting situation as it was, freedomrestricting solutions were much less approved of than freedom-preserving solutions.

These preliminary results are important for several reasons. First, they indicate that the theoretical distinction between structural and nonstructural or "individual" solutions to social dilemmas as suggested by various social dilemma researchers (e.g., Komorita \& Parks, 1994; Messick \& Brewer, 1983; Yamagishi, 1986) may be less useful to describe how people actually perceive these solutions in the real world. It seems more appropriate to categorize social dilemma solutions to the extent that they affect the decisional freedom of people, with, on the one hand, 
solutions that eliminate the freedom to act completely (i.e., installment of superordinate authority governing collective good), and, on the other hand, solutions that leave people with complete decisional freedom (i.e., providing information and alternatives). This classification tends to parallel the distinction made in early motivational (and recent marketing) theories between "push" (i.e., moving away from actual behaviors) and "pull" factors (i.e., moving toward alternative behaviors) that are relevant to understanding behavioral change (cf. Weiner, 1972). Second and related, these findings suggest that the approval of various solutions to realworld social dilemmas may strongly depend on the perceived personal control over the decision-making process. Attempts to restrict the individual choice pattern may receive very negative responses of the public, because they may be seen as threats to their personal autonomy and self-determination (cf. Samuelson, 1993). Perhaps, this is particularly true for situations where people are forced to engage in behaviors that are difficult to perform (e.g., carpooling; Van Vugt et al., 1995).

A fifth finding concerned the idea that various evaluative processes may shape the approval of solutions to the commuting situation (i.e., to what extent are they effective, and preserve self-interest, collective interest, and individual freedom?), and that there may be individual differences underlying the importance of these attributes. Intriguingly, it was found that people with distinct social value orientations differed in their evaluations of solutions on the dimension of collective interest, whereas for trust differences were found on the dimension of self-interest. That pro-social and pro-self commuters differed in their importance ratings of collective interest, yet not in their importance ratings of self-interest is understandable from a model of social value orientations suggesting that cooperators, individualists, and competitors assign equal weights to self, but that cooperators assign greater weights to others' outcomes than both individualists and competitors (Wyer, 1969). Additionally, the finding that, relative to high-trusters, low-trusters assigned greater importance to self-interest, but equal importance to collective interest may be explained by the fact that one of the central facets of the trust concept is the fear of being exploited by others (cf. Yamagishi, 1986). Thus, while people with different trust levels may assign equal value to the collective well-being, low-trusters may still pursue their self-interest because of a greater fear of being "exploited" by others. More generally, these findings are important because they provide some of the first evidence that interpersonal dispositions may not only be relevant to understanding individual choice patterns in social dilemmas (e.g., Kramer et al., 1986; Liebrand et al., 1986), but also how people evaluate different kinds of solutions to social dilemmas (for an exception, see Samuelson, 1993). From a practical view point, this seems particularly relevant because the success of many pro-environmental regulations and devices may greatly depend on how the public perceives and evaluates these new arrangements (cf. Stern, 1992).

Nevertheless, although no formal hypotheses were tested, we should note that the impact of interpersonal dispositions on the approvals of several types of change were less straightforward, and differences were mainly obtained for trust. That low- 
trusting commuters exhibited a weaker preference than high-trusting commuters for freedom-restricting changes in the commuting situation is perhaps related to a greater pessimism about the effectiveness of solutions. Given the scale of the problems commuters are faced with (i.e., the pollution and traffic congestion), and their expectation that only few commuters will voluntarily cooperate, low-trusters may have doubted the success of pursuits to get people to leave their cars (low "collective efficacy"; for similar reasoning, see Yamagishi, 1992). Consistent with this explanation, the results of the regression analyses revealed that effectiveness was a stronger predictor of the approval of freedom-restricting change for low- than for high-trusters.

Some unanticipated findings also deserve brief attention. First, in the current study no evidence was obtained that pro-social commuters, and particularly those with high trust levels, would be more sensitive to information about the strong environmental cffects of excessive car use. A plausible explanation for this finding would be that the provision of details about the environmental damage produced by cars may have created a strong norm to cooperate, and this may have evaporated differences in social value orientations and trust (cf. Snyder \& Ickes, 1985). An alternative interpretation, namely that pro-social commuters may have doubted the credibility of the pollution information, in particular, information that cars were only mildly polluting the environment, seems to be less valid given the fact that these scenarios were judged to be quite realistic in all conditions.

A second surprising result was that, contrary to our prediction, trust had a negative influence on commuting decisions of pro-self individuals, with low-trusting pro-self commuters exhibiting greater public transportation preferences than hightrusting pro-self commuters. Why may this be? A first explanation would be that pro-self commuters shift to cooperation when their ultimate self-interest is in danger. That is, commuters who are generally concerned with their own outcomes and expect that most others will be like them (i.e., low-trusters), may fear to be faced, sooner or later, with an environment disaster resulting from massive car use. Thus, in order to avoid a situation in which all commuters are worse off, they may decide that acting cooperatively is perhaps more wise. Conversely, high-trusting pro-selfs may reason that other people will preserve the collective interest of a clean environment, and may decide that, in this case, their polluting act will be compensated by many non-polluting others. Alternatively, the differential preferences among high and low-trusting pro-self commuters may also be instigated by their immediate self-interest. Given their primary focus on issues of travel convenience and efficiency, pro-self commuters may choose strategically for the travel option that they expect most others will not choose. Accordingly, foreseeing that most people will commute by car (i.e., low-trusting individuals) it may be more attractive to commute by public transportation so as to avoid traffic congestion. Conversely, when they anticipate most others to commute by public transportation (i.e., high-trusting) it is more attractive to take the car because the trains are crowded and the roads empty. This argument is consistent with an earlier study 
(Van Vugt et al., 1995) revealing that pro-self commuters predominantly view the commuting situation as an accessibility or congestion problem with the underlying structure of an N-person Chicken Dilemma.

A third surprising finding was that preferences for public transportation were enhanced by providing information about the serious environmental and congestion conditions in the commuting situation separately, but there was no surplus effect when both problems were salient. In a similar vein, when both environmental and congestion problems were expected to be severe, people exhibited much weaker preference for freedom-restricting interventions, relative to freedom-preserving interventions. These findings suggest that people may be more willing to cooperate or accept cooperation-enhancing solutions when they are focused on one particular problem that needs to be solved (i.e., environmental or accessibility problem). If issues get too complicated it may be that people loose faith in the solubility of the problem and the possible cooperation of other people, and may therefore ignore relevant information. Of course, this interpretation is speculative and needs to be addressed in future research.

\section{Limitations, implications, and suggestions for future research}

Before closing, we wish to outline some weaknesses of the current work. A first concern of the present work is the fact that our sample consisted predominantly of pro-social individuals $(68 \%)$, which may have colored some of our findings a bit more positively (e.g., higher overall public transportation preference). While this percentage is not uncommon in research on social value orientations (e.g., Parks, 1994; Van Lange \& Liebrand, 1991), it is good to realize that a form of selection bias may have occurred, because pro-socials are perhaps more willing to participate as subjects in experimental research (cf. McClintock \& Allison, 1989). A second potential limitation concerns the hypothetical nature of the commuting situation, which may form a threat to the external validity of the study by not ruling out tendencies of self-presentation and self-enhancement in commuters' responses. Although we agree that these effects may account for the high overall preference for public transportation and the main effect of environmental pollution (i.e., a socially desirable attribute) these tendencies seem less likely to explain the combined effects of social value, trust, pollution and congestion. Moreover, while the overall weak approval of maintaining the commuting situation may be influenced by social desirability, this is clearly not a valid explanation for the strong disapproval of interventions affecting the immediate self-interest of commuting by car.

Several lines of research are suggested by the current work. First, and most importantly, we believe that the present preliminary work should be followed by studies examining the relation between interpersonal dispositions, environmental decisions and preferences for pro-environmental regulations and measurements with a stronger emphasis on actual behaviors and interventions. Second, additional research should be focused on developing a more comprehensive typology of 
different types of solutions to real world social dilemmas. The current work has identified some of the perceptual dimensions that people use in evaluating and categorizing different kinds of changes, and these importantly predicted the attractiveness of these changes. Nevertheless, the decision for these particular dimensions, but, more importantly, for the specific interventions may have been somewhat arbitrary and idiosyncratic (i.e., related to the domain of reducing car use). In this regard, it is also interesting to note that some important progress has been made in developing theories about preferences for and classifications of institutional changes in other types of real world social dilemmas, such as agriculture, fishery, and water conservation (e.g., Ostrom, 1990).

A practical implication of the current work is that it offers some useful insights in why previous educational campaigns stressing the environment may not have been terribly effective in changing transportation patterns (e.g., Baerwald, 1985; Kostyniuk, 1982). That is, people may only respond to these campaigns when they simultaneously strengthen the trust that a sufficient number of other people are willing to give up commuting by car. This may be accomplished by providing people with positive but realistic information about the number of commuters (e.g., in their company or living area) that commute by public transportation or are prepared to do so. However, policy makers should realize that such messages may only be effective in changing the commuter behaviors of individuals with pro-social orientations, whereas they may even be counterproductive for people with pro-self orientations (i.e., they might consider to commute by car when many are expected to commute by public transportation). Perhaps, the latter individuals may be more likely to behave in a pro-environmental fashion when the personal benefits of commuting by public transportation are stressed (e.g., an efficient and comfortable trip). Thus, future interventions should be aimed at bolstering the individual trust in other people's willingness to contribute to the environment while, at the same time, increasing the quality of public transportation (cf. "intervention mix"; Stern, 1992). 



\section{Chapter 6 \\ Structural solutions in the commuting situation: A field experiment on the first carpool lane in Europe ${ }^{1}$}

"The puzzle facing commons [i.e., social dilemma] researchers in the behavioral sciences can be phrased as follows: If technological solutions are often unworkable because of their inherent insufficiencies, or because consumers don't like to use them, if changes in morality are difficult to create, ... and if egalitarian principles and free choice are to be preserved, how are scarce resources to be saved over extended periods to the satisfaction of consumers?"

- Edney (1980, p. 133)

\subsection{Introduction}

\section{Main research questions}

One of the most challenging tasks societies and larger groups face concerns the management of social dilemmas, situations in which individual and collective interests conflict (Dawes, 1980; Komorita \& Parks, 1994; Messick \& Brewer, 1983). Many social dilemmas stem from the fact that a variety of behaviors are tempting to the individual, but at the same time are potentially detrimental to the well-being of the collective as a whole. For example, the decision to commute alone (i.e., the presumed noncooperative choice) instead of by carpool -- riding in a car with other people -- serves the individual's interest in that it is generally quicker and more flexible, whereas carpooling (i.e., the presumed cooperative choice) serves the collective interest because it helps minimize or overcome problems related to environmental pollution and traffic congestion. To reduce the harmful effects of excessive car use, the Dutch government recently implemented a carpool priority lane -- the first in Europe -- as a structural solution to this critical social dilemma.

What might be the psychological consequences of the implementation of the carpool priority lane? How does this intervention affect beliefs, evaluations, and efficacy judgments relevant to solo driving versus carpooling? And, to what extent are these constructs predictive of preferences and intentions regarding carpooling? At present, answers to such questions are indirect at best. Granted, there have been some studies (for the most part conducted in the U.S.) relevant to structural

\footnotetext{
'This chapter is based upon:

Van Vugt, M., Van Lange, P. A. M., Meertens, R. M., \& Joireman, J. A. (1995). Why structural solutions to social dilemmas may fail: A field experiment on the first carpool lane in Europe (under review).
} 
interventions in real-life social dilemmas, including energy conservation, recycling, as well as carpooling (for overviews, see Geller, Winett, \& Everett, 1982; Samuelson, 1990; Stern, 1992; Stern \& Aronson, 1984). However, these studies have been primarily concerned with one type of incentive (i.e., monetary rewards) as a means of promoting pro-environmental behavior, and have devoted little attention to the psychological processes underlying an individual's reactions to structural interventions (cf. Stern, 1992).

The major purpose of the current research is twofold. First and most importantly, we examine the impact of the carpool lane on attitudes and preferences relevant to commuting alone or by carpool. The second purpose is to explore the roles of attitudes, social norms, and efficacy in determining intentions to carpool before and after implementation of the carpool lane. To examine these issues, a field experiment was conducted in which we administered a survey to commuters at two different locations (i.e., along the highway where the carpool lane was established and along a comparable highway in terms of congestion which did not provide a carpool lane), and at two different times (i.e., approximately one month prior to and one month after the opening of the carpool lane).

\section{Approaches to promote carpooling: A social dilemma analysis}

The decision to commute alone or by carpool can be framed as a social dilemma, formally defined as an interdependent situation in which: (1) Each individual receives greater outcomes by making a noncooperative choice (i.e., solo driving) than by making a cooperative choice (i.e., carpooling) irrespective of the choices of others, yet (2) each individual is better off if all make a cooperative rather than a noncooperative choice (cf. Dawes, 1980; Messick \& Brewer, 1983). These social dilemma properties have been asserted to characterize many large-scale problems, including overpopulation, the functioning of labor unions, and depletion of natural resources (cf. Komorita \& Parks, 1994; Liebrand, Messick, \& Wilke, 1992).

Theorists of social dilemmas have distinguished between two broad categories of strategies for solving social dilemmas (cf. Messick \& Brewer, 1983; Rusbult \& Van Lange, in press; Samuelson, Messick, Rutte, \& Wilke, 1984; Yamagishi, 1986). A first category may be referred to as the individualpsychological approach, which includes interventions aimed at influencing individuals' attitudes and beliefs that may guide cooperative and noncooperative behaviors. That is, this approach attempts to change the subjective interpretations of the situation, such as interventions designed to increase individuals' awareness of the harmful effects of car use on environmental pollution or to offer guidelines as to how one can contribute to a better environment (e.g., educational campaigns).

A second category may be referred to as the structural approach to solve social dilemmas. This approach focuses on interventions that alter the situation at hand by either limiting or eliminating the decisional freedom or changing the incentive patterns associated with the desirable and undesirable behaviors. Thus, this approach attempts to change the objective features of the situation. In the 
context of transportation, the individual freedom can be reduced or eliminated by developing formal rules (e.g., prohibition for cars to enter particular areas of cities) or by physically altering the environment (e.g., reducing parking places). Moreover, carpooling can be stimulated by providing selective rewards and punishments (e.g., subsidies and taxes). The provision of a carpool lane is an example of such a structural solution in that this intervention aims at enhancing the outcomes associated with carpooling through changing the objective features of the situation. That is, by building a lane exclusively for carpoolers, the option of carpooling is expected to become more attractive in terms of travel time as well as other outcomes related to avoiding traffic jams (e.g., reduction of stress).

Over the past two decades, research on social dilemmas has identified a variety of individual-psychological and structural factors that appear to be consistently related to cooperative choice behavior (for recent reviews, see Komorita \& Parks, 1994; Van Lange, Liebrand, Messick, \& Wilke, 1992). For example, individuals exhibit greater cooperation when they can collectively coordinate their actions (e.g., through verbal communication or behavioral actions), are more accountable for their decisions, experience a greater level of self-efficacy, expect more others to cooperate, feel more responsible for the collective well-being, receive rewards for cooperative behavior and punishments for noncooperative behavior, and when the group size is small (e.g., Dawes, McTavish, \& Shaklee, 1977; Jerdee \& Rosen, 1974; Kelley \& Grzelak, 1972; Kerr, 1989; Yamagishi, 1992). These findings highlight the idea that cooperative behavior is systematically associated with factors that influence both the subjective and objective characteristics of the social dilemma.

The current study attempts to extend and complement prior work on social dilemmas in at least three ways. First, the vast majority of prior social dilemma studies have concentrated on decision making in experimentally induced social dilemmas, using experimental games as decision tasks for groups consisting of two to nine individuals (for exceptions, see Erev, Bornstein, \& Galili, 1993; Kerr, 1989; Van Vugt, Meertens, \& Van Lange, 1995). Hence, it would be fruitful to examine whether the logic and knowledge derived from this research can be applied to largescale dilemmas existing in the real world (for similar reasoning, see Komorita \& Parks, 1994; Samuelson, 1990; Van Lange \& Messick, in press). Thus, the current work extends prior social dilemma research by focusing on a real-life social dilemma -- the decision to commute alone or by carpool.

Second, in recent years a growing number of studies have been published on structural changes in social dilemmas (e.g., Messick, Wilke, Brewer, Kramer, Zemke, \& Lui, 1983; Rutte \& Wilke, 1984, 1985; Samuelson, 1991, 1993; Samuelson, Messick, Rutte, \& Wilke, 1984; Yamagishi, 1986, 1988; Yamagishi \& Sato, 1986). The primary concern of these studies has been to examine the conditions under which individuals opt for various kinds of structural changes in the 
social dilemma (e.g., structural changes such as giving up own freedom of choice to a leader, contributing to the establishment or maintenance of a sanctioning system, or privatizing the common resource). However, this line of research has paid relatively little attention to the question of how individuals respond to structural changes in social dilemmas. Thus, the current study extends prior social dilemma research by examining the impact of a structural change -- the implementation of the carpool priority lane -- on individuals' judgments and preferences regarding carpooling versus driving alone.

Third, the current research seeks to extend prior research on social dilemmas by testing and extending the theories of reasoned action and planned behavior (Ajzen, 1987, 1991; Ajzen \& Fishbein, 1980) in the domain of a social dilemma. Accordingly, we examine the roles of attitudes, social norms, and perceived behavioral control or efficacy in determining commuter preferences for commuting alone versus by carpool. Furthermore, we wish to extend prior research by demonstrating the relevance of two distinct forms of efficacy -- self-efficacy and collective efficacy (cf. Bandura, 1986) -- in accounting for preferences in social dilemma situations.

\section{Psychological reactions to structural solutions of social dilemmas: self-justification}

How might individuals respond to a structural change in their commuting situation and how might the structural change affect their commuting behavior? Given that structural solutions, unlike individual-psychological solutions, focus on altering the situation itself, such solutions are generally believed to be more promising (e.g., Rusbult \& Van Lange, in press). Indeed, experimental studies of social dilemmas have revealed that individuals tend to appreciate structural solutions, particularly when many fail to exhibit cooperative behavior (e.g., Messick et al., 1983; Samuelson, 1993; Samuelson et al., 1984; Yamagishi, 1986). Moreover, changes in the monetary payoff structure are quite effective, in that the probability of cooperation tends to vary directly with the amount of reward associated with cooperative behavior (for recent reviews, see Komorita \& Parks, 1994; Van Lange et al., 1992). However, in the real world, structural solutions may not always be effective in that they may sometimes be experienced as drastic, infringing on individual freedom, inefficient, or unfair (cf. Samuelson, 1993).

We propose that the implementation of the carpool lane as a structural solution may also suffer from these and related undesirable side-effects. First, in real-world social dilemmas the cooperative option may not be as viable as the one in the laboratory. For example, there may be several constraints that make it hard for people to carpool (e.g., constraints arising from finding carpool partners, coordinating time schedules with potential carpool partners, needing the car for work). While these latter obstacles may vary from person to person, it seems plausible that a significant number of people realistically feel unable to carpool. 
Second, the benefits of carpooling due to the implementation of the carpool lane (i.e., avoiding congestion) do not necessarily make carpooling more attractive than the personally more convenient and flexible option of driving solo. Indeed, one may assume that individuals have developed the habit of driving alone because this option is associated with numerous personal benefits (e.g., comfort, flexibility), and a reduction in travel time provided by the carpool lane may not be a strong enough incentive to alter that habit (cf. Verplanken, Aarts, Knippenberg, \& Knippenberg, 1994). Thus, a fair number of people may to some extent be unwilling to carpool. The willingness to carpool may also remain low when people (realistically) believe that many others do not carpool (cf. Pruitt \& Kimmel, 1977; Yamagishi, 1986).

How might people respond psychologically to the implementation of the carpool lane if it is assumed that a significant number of people are either unwilling to carpool or think that they are unable to carpool? First, the implementation of the carpool lane benefits a relative small group of people -- approximately 10 percent of the commuters were carpoolers prior to implementation of the carpool lane. It is possible that such benefits may lead to feelings of relative deprivation (cf. Cook, Crosby \& Hennigan, 1977; Martin, 1981) among those who do not receive such benefits (i.e., the solo drivers). Moreover, these feelings may be further enhanced by unfavorable social comparisons arising from the fact that solo drivers -- while being stuck in traffic jams -- actually perceive each day that the group of carpoolers do not face congestion and are therefore "better off." It seems plausible that feelings of relative deprivation are especially pronounced among commuters who think they are largely unable to carpool.

Second, the implementation of the carpool lane obviously conveys, and to some extent emphasizes the notion that carpooling is not only more efficient in terms of travel time, but also more desirable from a collective point of view. Because there is a fair amount of consensus about the desirability of carpooling in light of current environmental problems (cf. Osinga, 1995), solo drivers may possibly experience some level of cognitive dissonance, an experienced tension between their actual behavior and their beliefs about that behavior (e.g., relative to carpooling driving solo is less fast, more polluting, and contributes more to traffic jams; cf. Festinger, 1957). Such dissonance may be resolved in two ways: (a) through a behavioral change, if possible (i.e., individuals may start to commute by carpool), and (b) through a reappraisal of the attributes linked to carpooling and driving alone (e.g., individuals may derogate the alternative of carpooling). Given that dissonance should only be experienced when individuals feel personally responsible for their choices (cf. Cooper \& Fazio, 1984; Wicklund \& Brehm, 1976), it seems plausible that such psychological tension is most pronounced among those who view carpooling as a viable option, but who are unwilling to carpool. 
The current work postulates that the psychological tension arising from feelings of relative deprivation or cognitive dissonance may be largely resolved by a process of self-justification, a psychological revaluation of the behavioral options or conditions so as to serve one's view of the chosen option or situation (cf. Aronson, 1988). Indeed, there is a fair amount of evidence indicating that those who experience high levels of relative deprivation attempt to reconsider the situation in terms of additional attributes that make their position look less bad in relation to others ("driving my car alone may be somewhat more costly, but unlike carpoolers I am flexible about when to leave home or work"; "dimensional comparison"; cf. Wood, 1989; Wood \& Taylor, 1991). Similarly, it is a common finding in dissonance research that those who experience high levels of cognitive dissonance engage in self-justification processes to reduce the tension between their cognitions and behavior (e.g., Cooper \& Fazio, 1984; Wicklund \& Brehm, 1976). As a directly relevant example, prior social dilemma research has revealed that those who are unwilling to make a cooperative choice tend to justify their noncooperative behavior by claiming that they did not at all expect others to cooperate (Messé \& Sivacek, 1979).

In sum, the general hypothesis underlying the current study is that commuters driving alone will engage in self-justification in order to reduce the tension -- which may arise from cognitive dissonance and/or feelings of relative deprivation -caused by the establishment of the carpool lane. This hypothesis will be tested in an experimental design which includes, first, a repeated measurement within a twomonth interval (i.e., one month prior to and after the opening of the carpool lane: Time 1 vs. Time 2) so as to examine possible changes in attitudes and preferences for carpooling. Second, data are obtained from solo drivers as well as from a number of carpoolers who will actually use the carpool lane during our research. Finally, a control group is added to the design, consisting of both solo drivers and carpoolers who commute on a similar route in terms of congestion, but one that does not provide a carpool lane. This quasi-experimental design will presumably provide a suitable framework for analyzing the set of specific hypotheses outlined below (cf. Cook \& Campbell, 1979).

\section{Overview of hypotheses}

Our general self-justification hypothesis leads to a set of specific predictions regarding changes in the psychological determinants of commuting alone versus by carpool, by which we mean (a) beliefs about the outcomes associated with commuting alone versus by carpool (e.g., flexibility, environmental well-being, travel costs), and (b) evaluations or importance ratings of these outcomes; moreover, shifts are also predicted in (c) the stated preferences for commuting alone or by carpool. First, it is predicted that solo drivers and carpoolers will view their own commuting option in more positive terms than their non-chosen option. That is, relative to carpoolers, solo drivers will hold more positive beliefs about the outcomes associated with commuting alone and less positive beliefs about the 
outcomes associated with commuting by carpool (Hypothesis Ia). Moreover, following the general self-justification hypothesis, we anticipate shifts in commuters' beliefs resulting from the establishment of the carpool lane. Specifically, Hypothesis $1 b$ predicts that solo drivers who are faced with the carpool lane (i.e., the experimental route) will develop more negative beliefs about carpooling from Time 1 to Time 2 than the other groups (i.e., solo drivers on the control route and carpoolers on both routes).

Additionally, we test a specific prediction concerning the belief about the relative travel time of carpooling. Because the carpool lane will increase the efficiency of carpooling, there should be a fair amount of consensus among commuters on the experimental route that carpooling has become more attractive in terms of travel time. Accordingly, we predict that commuters on the experimental route will perceive a decrease in the travel time of carpooling from Time 1 to Time 2 (Hypothesis 1c).

Second, further evidence in support of the self-justification hypothesis would be obtained if, indeed, solo drivers will assign greater importance to outcomes associated with their commuting choice than outcomes associated with the carpool alternative. Accordingly, Hypothesis $2 a$ predicts that relative to carpoolers, solodrivers will assign greater importance to attributes inherently linked to solo driving (e.g., flexibility, comfort) and lower importance to attributes inherently linked to carpooling (e.g., environmental well-being, low travel costs, sociability). More direct evidence for the self-justification hypothesis would be obtained if the general tendency among solo drivers to increase the importance of "solo-driving attributes" and to decrease the importance of "carpool attributes" from Time 1 to Time 2 is greater for solo drivers who are confronted with the carpool lane. Thus, we predict that, relative to the other commuter groups, solo drivers on the experimental route will increase the importance attached to attributes inherently linked to solo driving and decrease the importance of attributes inherently linked to carpooling (Hypothesis 2b).

Third, we propose that the expected self-justification of solo drivers on the experimental route will be accompanied by a similar shift in preferences for carpooling. Moreover, those who already carpool and experience the further benefits of carpooling (i.e., a reduction in travel time) are likely to exhibit even stronger preferences for carpooling. Accordingly, we predict that, overall, solo drivers will exhibit a lower preference for carpooling than carpoolers (Hypothesis $3 a$ ). More importantly, over time we expect solo drivers to exhibit a decreasing preference and carpoolers to exhibit an increasing preference for carpooling; moreover, differences between these groups should be more pronounced on the experimental route than on the control route (Hypothesis $3 b$ ). 


\section{The role of collective efficacy in social dilemmas}

The second exploratory purpose of the current research is to test a general model of the psychological determinants of carpooling, a model derived, in part, from traditional attitude-behavior models (e.g., theory of reasoned action; Ajzen \& Fishbein, 1980) and extensions of these models (e.g., theory of planned behavior; Ajzen, 1987, 1991). That is, the intention to carpool is assumed to be a function of (a) attitudes towards carpooling, containing both beliefs and evaluations about outcomes associated with carpooling; (b) social norms towards carpooling, which include the opinions of important referent persons about carpooling (e.g., partner, colleagues) as well as the motivation to comply with these opinions (cf. Fishbein \& Ajzen, 1975); and (c) perceived self-efficacy, or the perceived possibilities and limitations to carpool (cf. Bandura, 1986). While this model has received a fair amount of support in studies examining preferences, intentions, and behaviors in several behavioral domains, this model may be somewhat limited for describing behavior in social dilemma situations. Recall that in social dilemmas individual outcomes are largely determined by the actions of others (i.e., they are characterized by high levels of fate control; cf. Kelley \& Thibaut, 1978) as well as other factors that lie outside an individual's control (e.g., the scale and seriousness of the dilemma); therefore, such situations require effective management at collective rather than individual levels. Hence, we propose that commuters' preferences, intentions, and behaviors are also influenced by perceptions of collective efficacy, the belief that "they can solve their problems and improve their lives through concerted effort" (Bandura, 1986; p. 449). Although it has been suggested that efficacy may be an important determinant of cooperation (e.g., Messick, 1973; Stroebe \& Frey, 1982), there is only very limited empirical work studying the role of efficacy in social dilemmas (for exceptions, see Kerr, 1989, 1992). Thus, the current research examines an extended model of "planned behavior," advancing the hypothesis that, in accounting for the intention to carpool, perceived collective efficacy will make a unique contribution independent of attitudes, social norms, and perceptions of self-efficacy (Hypothesis 4).

\subsection{Method}

\section{Participants and design}

Six hundred questionnaires were distributed among car commuters during the morning rush-hour traffic at gas stations along two major highways in the Netherlands. Of the initial sample of 600 participants, 267 completed the first questionnaire, yielding a response rate of $44.5 \%$. One hundred ninety-two of them also returned the second questionnaire (32.0\% of the initial sample), 169 males and 22 females (one participant failed to indicate gender), with an average age of 37 years and one month. All of them commuted by car on a daily or regular basis, with an average travel time of 60 minutes. The quasi-experimental design was a 2 
(Route: Control Route vs. Experimental Route; $N$ 's $=86$ vs. 86 ) x 2 (Commuter Type: Solo Driver vs. Carpooler; $N$ 's $=172$ vs. 20) x 2 (Time of Measurement: Time 1 vs. Time 2), the latter variable being a within-subject factor. The composition of these different route and commuter type samples was more or less similar regarding, age, gender, and attrition rate.

The main dependent variables were (1) beliefs and importance ratings associated with carpooling versus solo driving, (2) perceptions of self- and collective efficacy, and (3) preferences for carpooling.

\section{Procedure}

Commuters received the first questionnaire while stopping at a gas station during the morning peak-hour traffic between 7:00-10:00 a.m. First, they were asked whether they were on their way to work. If so, we asked them if they wanted to participate in a study regarding transportation decisions in commuting situations. Consequently, participants received an envelope containing the questionnaire which they could complete either at home or at work. Those who returned the first questionnaire (including their return address) received an almost identical questionnaire by mail about two months after the pre-test. Upon completion of both phases of the research, the remaining participants were debriefed; moreover, they received small gifts for their participation (i.e., a marker and map containing carpool parking places in the Netherlands). 
The carpool lane. The carpool lane, which was opened on October 27 1993, was built in the central reserve of one of the most congested highways in the Netherlands, known as the Al, between the cities of Amersfoort and Amsterdam (see Figure 8). The lane itself had a length of approximately six kilometers (about four miles), and was separated from the other lanes by means of a concrete wall with the size of approximately 0.5 meters. Accordingly, while the carpool lane was in clear sight of traffic on the other driving lanes, the regular motorized traffic could not switch to the carpool lane along the four miles' route. It was expected that this would diminish possible misuse of the carpool lane by noncarpoolers, which seems to be an important prerequisite for the success of these lanes (Geller et al., 1982).

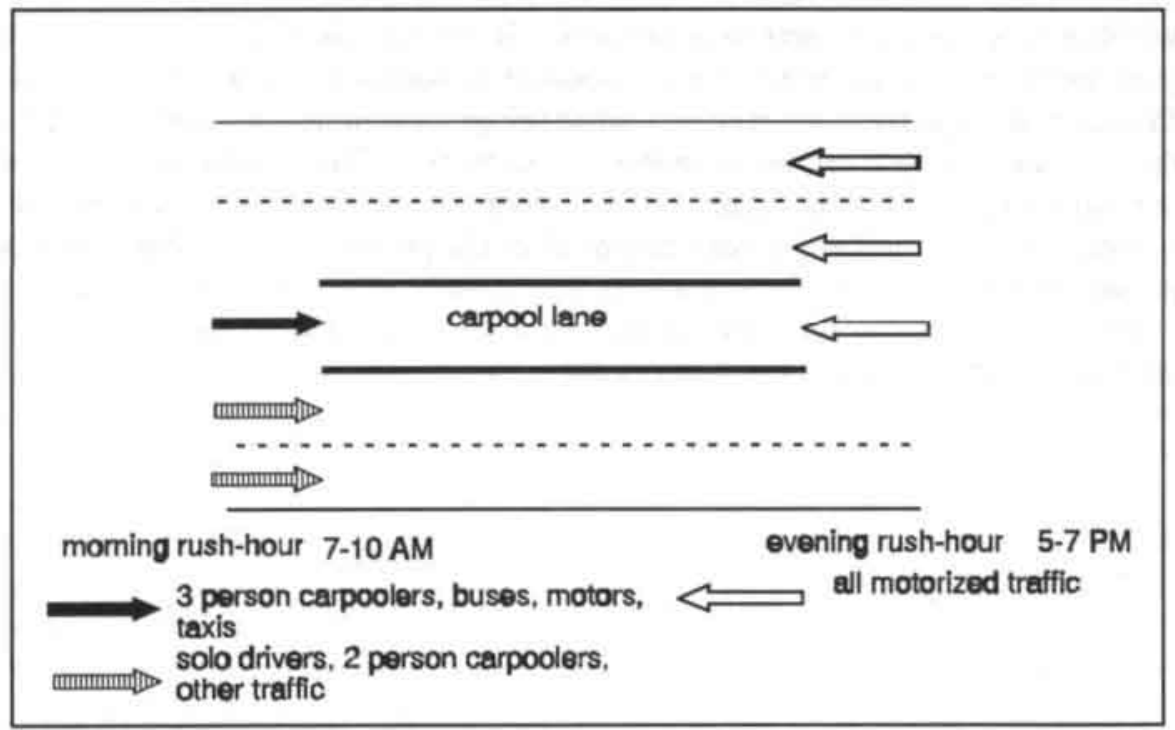

Figure 7. Graphical representation of the carpool lane

The carpool lane had two different functions. In the morning rush-hour (between 7:00 and 10:00 AM) the carpool lane could be used only by particular traffic in the direction of Amsterdam, such as cars containing at least three passengers (i.e., carpoolers), buses, taxis, and motorcycles. While being closed during the day, the carpool lane was opened for all motorized traffic leaving Amsterdam in the evening rush-hour (between 5:00 and 7:00 PM). Just prior to the opening of the lane, several travel time tests were performed by order of the Dutch Ministry of Traffic and Waterways, indicating that, compared to driving on the 
regular lanes, the carpool lane provided at least a twenty-minute travel time advantage.

The selection of routes. Half of the questionnaires $(N=300)$ were distributed at a gas station along the highway where the carpool priority lane was being built (Experimental Route). The control group also consisted of 300 commuters, who were recruited at a gas station along the highway known as the A2 (between the cities of Den Bosch and Utrecht) -- a route which is highly comparable to the experimental route in terms of number of cars and daily traffic congestion. This group was added to the design in anticipation of the media publicity accompanying the opening of the carpool priority lane, which could affect the actual impact of the carpool lane on commuters' attitudes and preferences. The distance between these gas stations was approximately 150 kilometers (about 94 miles), which made it virtually impossible that participants would commute to work along both routes. After the first measurement the response percentages for the control and experimental route were $43.7 \%$ and $45.3 \%$, respectively; whereas after the second measurement, the response percentages for both groups were $32.0 \%$ of the original of sample of 600 commuters.

Timing of measurements and commuter type. The Time 1 questionnaire was distributed at gas stations approximately one month before the opening date of the carpool lane. The almost identical Time 2 questionnaire was sent by mail to the participating commuters approximately one month after opening of the carpool lane. Questionnaires were allocated to both commuters driving alone and to carpoolers. The ultimate sample consisted of 172 solo drivers $(89.0 \%)$, and 20 carpoolers $(11.0 \%)$-- commuting by carpool with either one, two or more people. Because the carpool lane was exclusively reserved for cars containing at least three commuters, we removed two-person carpoolers on the experimental route from our analyses ( $N$ $=3$ ). For the control route we combined the two- and multi-person carpoolers to form one group of carpoolers.

\section{Dependent measures}

The questionnaire consisted of five parts. The first part included several biographical questions, including age, gender, travel mode, and estimated travel time; some of these questions were excluded from the Time 2 questionnaire. Moreover, at the first measurement the individuals' social value orientations were assessed by means of the three-choice Decomposed Games method (see Appendix II). Of 192 commuters 162 could be classified and among them were 99 cooperators $(61 \%)$ or "pro-socials, 54 individualists $(33 \%)$, and 9 competitors (6\%) - together referred to as pro-selfs (cf. Van Vugt et al., 1995). However, because preliminary analyses revealed no differences for social value orientations on the major dependent variables (i.e., carpool preferences, beliefs and evaluations regarding carpooling) this factor was further excluded from the research. 
The second part contained a list of nine travel attributes. The list was carefully constructed on the basis of interviews with commuters and prior travel mode research indicating that these were the main concerns in commuters' decisions for solo driving versus carpooling (e.g., Bronner, 1982; Flannelly \& McLeod, 1989; Norman, 1977; Owens, 1981). Some of these were assumed to be more strongly linked to solo driving (i.e., flexibility, comfort, short travel time), others to carpooling (i.e., low travel costs, environmental well-being, and sociability) ${ }^{2}$, whereas the rest were not supposed to be unequivocally related to either one of these options (i.e., relaxation, reliable travel time, safety). Participants were asked to indicate (a) to what extent they believed each of these travel attributes to be descriptive of driving solo or carpooling $(-3=$ more descriptive of driving solo, $0=$ equally descriptive, $+3=$ more descriptive of carpooling), and (b) how important they considered each of these travel attributes for their commuting decision $(1=$ very unimportant, $7=$ very important for my commuting decision). We performed reliability measurements on the list of the nine Travel Beliefs and Importance Ratings for Time 1 and Time 2, separately. These analyses revealed acceptable Cronbach's alphas of, respectively, .74 and .71 , for Time 1 and .73 and .70 for Time 2.

Third, a list of referent persons and groups (e.g., partner, colleagues, employer) was presented to commuters, and they were asked to rate (a) the attitudes of each of these referent persons toward carpooling $(-3=$ very much opposed, $+3=$ very much in favor), and (b) how much they complied with each of these opinions ( $1=$ not at all, $7=$ very strongly). The first group of variables can be referred to as normative beliefs, and the second as motivations to comply (cf. Fishbein \& Ajzen, 1975). Reliability analyses performed on the scales measuring all normative beliefs and motivations to comply, separately, yielded respective alphas of .73 and .83 for Time 1 and .74 and .85 for Time 2 .

Fourth, the questionnaire contained one general item concerning the perceived self-efficacy to carpool: "Would it be possible for you to commute by carpool in your working situation? $(1=$ not possible at all, $7=$ very much possible)." Moreover, two questions addressed the perceived collective efficacy to carpool: "Do you think that (a) a carpool priority lane, and (b) in general, the attempts of the Netherlands' government to stimulate commuters to carpool will be effective?" ( $1=$ very ineffective, 7 = very effective)." The correlation between these collective efficacy judgments was moderate $(r=.40, p<.01)$.

Finally, commuters stated their own preferences for driving solo or carpooling $(1=$ very strong preference for solo driving, $4=$ indifferent, $7=$ very strong preference for carpooling), as well as their intentions to carpool in the near future $(1=$ very weak intention, $7=$ very strong intention, with $8=I$ carpool

2 In the Dutch questionnaire this latter term was phrased as "gezelligheid"; however, there seems to be no equivalent of this word in English language. Perhaps, the closest translation would be "sociability." 
already [for carpoolers]). The correlation between preference and intention was quite strong $(r=.67, p<.01)$.

\subsection{Results}

\section{Changes in beliefs about carpooling versus solo driving:}

Tests of hypotheses 1a, 1b, and 1c

All nine beliefs relevant to carpooling versus driving solo were analyzed in a MANOVA using a 2 (Route) $\times 2$ (Commuter Type) $\times 2$ (Time) design, the latter variable being a within-subject factor. For these and all subsequent statistical tests an alpha level of .05 was used. At the multivariate level, this analysis revealed only a significant main effect for Commuter Type, $F(9,178)=2.34, p<.02$. Table 10 presents the mean values and standard deviations for the nine beliefs, ordered from being most descriptive of carpooling (environmental well-being) to driving solo (flexibility); it also shows the F- and p-values relevant to the Commuter Type main effect. As can be seen in this table, except for the two most extremely rated attributes - environmental well-being and flexibility -- there was no consensus between solo drivers and carpoolers regarding the beliefs about the commuter options (i.e., significant or marginally significant differences between the groups). Consistent with Hypothesis 1a, solo drivers considered attributes inherently linked to carpooling (i.e., low travel costs, sociability) less descriptive of carpooling than did carpoolers. Moreover, solo drivers found typical "solo driving" attributes (i.e., comfort, low and reliable travel time) to be more descriptive of solo driving than did carpoolers. Differences were also obtained for safety and relaxation -- as can be seen in this table, these attributes were not unequivocally related to a particular commuting option (i.e., ratings were negative for solo drivers and positive for carpoolers). Interestingly, this table also reveals that a fair amount of consensus existed with respect to the link between environmental well-being and carpooling, and -- to a lesser extent -- the link between flexibility and driving solo (i.e., no significant differences between solo drivers and carpoolers). 
Table 10

Average Beliefs about Travel Attributes Associated with Commuting Alone versus t Carpool as a Function of Commuter Type

\section{Commuter type}

Solo driver Carpooler Average $F(1,186) p$

Travel attribute

$\begin{array}{lllllll}M & S D & M & S D & M & S D\end{array}$

1. Environmental

well-being

2. Low travel costs

3. Sociability

4. Relaxation

5. Safety

6. Comfort

7. Low travel time

8. Reliable travel time

9. Flexibility
$2.41 * \quad 1.30$

$2.03 * \quad 1.68$

$0.46 \quad 1.83$

$-0.55$

1.91

$-0.95 *$

1.70

$-1.54 *$

1.61

$-1.65^{*}$

1.27

$-1.98^{*}$

1.55

$-2.57 *$

$2.39^{*}$
$2.62^{*}$
$1.95^{*}$
1.12
0.48
-0.30
-0.83
$-1.38^{*}$
$-2.06^{*}$

1.38

0.88

$2.41 *$

1.31

$.16 \quad .69$

2.08* 1.64

$3.64 \quad .06$

1.46

0.59 *

1.85

11.07

$2.13-0.41$

1.98

12.73

$2.13-0.82 *$

1.78

11.69

$1.84-1.43 *$

1.66

9.92

1.20

$4.60 \quad .03$

$1.01-1.57 *$

$2.00 \quad-1.93 * 1.60$

3.32

.07

$1.80 \quad .18$

Note. The judgment scale varies from -3 (= attribute is more descriptive of solo driving through +3 (= attribute is more descriptive of carpooling); attributes are rank ordered $x$ the basis of the average score, so that the first (environmental well-being) is consideri most typical of carpooling and the last (flexibility) of solo driving; means with an asteris differ significantly from zero, the midpoint of the response scale $(p<.05)$.

According to Hypothesis $1 \mathrm{~b}$, particularly solo drivers on the experimental route should be more negative about carpooling at Time 2 than Time 1 . However, the predicted three-way interaction of Route, Commuter Type and Time did not emerge, $F(9,178)=1.15, p=.33$, and none of the univariate effects were significant. Thus, no evidence for self-justification among solo drivers was found on the beliefs regarding carpooling.

Hypothesis 1c predicted that after the opening of the lane commuters on the experimental route would be more positive about the travel time of carpooling. At the univariate level, we found only a main effect for Time on the belief regarding travel time, $F(1,186)=3.86, p<.05$, revealing that carpooling was perceived to be 
faster after the implementation of the lane (Time 1 vs. Time $2:$ M's $=-1.67$ vs. $1.48, S D$ 's $=1.19$ and 1.03); however, the negative mean at Time 2 denotes that solo driving was still considered to be the faster option. Interestingly, contrary to Hypothesis 1c, this effect was not further influenced by Route, $F(1,186)<1$, suggesting that commuters on the control route also believed that carpooling had become quicker after the establishment of the carpool lane. Additional support for Hypothesis 1c would be obtained by examining the actual travel times as reported by commuters prior to and after the opening of the carpool lane. This analysis yielded, first, a main effect for Route, $F(1,185)=8.35, p<.001$, revealing that the average travel time reported on the Experimental Route was much shorter $(M=$ 48.66, $S D=21.41)$ than on the Control Route $(M=66.12, S D=36.75)$. Furthermore, a main effect for Time emerged, $F(1,185)=13.53, p<.001$, indicating that the travel time across the commuter groups decreased from Time $1(M=60.93$, $S D=33.73)$ to Time $2(M=54.31, S D=29.33)$. However, relevant to Hypothesis 1c a marginal significant three-way interaction of Route, Commuter Type, and Time was found, $F(1,185)=3.71, p<.06$, suggesting that the decline in travel time was not equal for all groups. Indeed, the means indicated that Carpoolers on the Experimental Route reported a substantial -- but, due to the low number of carpoolers, not statistically significant -- decrease in average time (Time 1 vs. Time 2: $M^{\prime} \mathrm{s}=63.33$ vs. 36.67 minutes, $S D^{\prime} \mathrm{s}=48.65$ and 18.87$), t(5)=1.08, p=.33$. In contrast, the reported travel time of Solo Drivers on the Experimental Route remained almost identical (Time 1 vs. Time $2: M^{\prime} \mathrm{s}=49.16$ vs. 47.97 minutes, $S D$ 's $=19.10$ and 21.26$), t(85)<1^{3}$. Thus, there is some additional evidence in support of Hypothesis 1c in that the carpool lane had a positive impact on the perceived travel time of carpoolers versus solo drivers.

\section{Changes in importance ratings of carpooling versus solo driving: Tests of hypotheses $2 \mathrm{a}$ and $2 \mathrm{~b}$}

Importance ratings of the nine travel attributes were analyzed in a 2 (Route) $\times 2$ (Commuter Type) x 2 (Time) MANOVA, the latter being a within-subject factor. The multivariate analysis on these ratings yielded two significant main effects, as well as a significant two-way and three-way interaction. Accordingly, in the following paragraphs, we will focus on the results of nine $2 \times 2 \times 2$ ANOVAs (i.e., the univariate effects) to interpret the above effects.

${ }^{3}$ On the Control Route both Solo drivers and Carpoolers reported a decrease in average travel time between Time $1\left(M^{\prime} s=69.92\right.$ and $81.36, S D^{\prime} s=39.58$ and 39.40 , respectively) and Time 2 $(M ' s=59.76$ and $70.91, S D$ 's $=34.66$ and 25.47 , respectively), which may have been caused by physical modifications of the route in between the research phases (e.g., completion of road construction). 
Hypothesis 2a predicted that solo drivers, relative to carpoolers, would assign greater importance to attributes inherently linked to solo driving and less importance to attributes inherently linked to carpooling. Consistent with this hypothesis, we observed a multivariate main effect for Commuter Type, $F(9,178)=3.35, p<.001$. Univariate effects were found on five attributes, of which some were strongly linked to solo driving (i.e., flexibility) or carpooling (i.e., low travel costs, sociability and environmental well-being; see Table 10). The means, F- and p-values associated with the Commuter Type main effect (displayed in Table 11) indicate that compared to Carpoolers, Solo Drivers found typical the typical "solo driving attribute" to be more important and the typical "carpool attributes" to be less important (i.e., significant differences between the ratings of these groups).

\section{Table 11}

Average Importance Ratings of Travel Attributes Associated with Commuting Alone versus by Carpool as a Function of Commuter Type

\section{Commuter type}

Solo driver Carpooler Average $F(1,186) p<$

Travel attribute

$\begin{array}{llllll}M & S D & M & S D & M & S D\end{array}$

1. Environmental well-being $(6)$

2. Low travel costs(9)

3. Sociability $(8)$

4. Relaxation(7)

5. Safety(5)

6. Comfort(3)

7. Low travel time(4)

8. Reliable travel time(2)

9. Flexibility(1)

\section{$\begin{array}{ll}4.31 & 1.70\end{array}$}

2.82

3.21

4.17

4.67

4.94

4.81

5.13

5.64

\subsection{0}

1.95

1.96

2.29

1.89

2.24

1.94

2.01

\subsection{5}

4.38

1.72

4.70

2.06

4.41

1.94

4.56

2.04

5.38

1.91

4.21

1.83

4.74

2.07

4.94

4.88

\subsection{9}

1.82

2.96

3.35

4.21

4.73

4.88

4.81

5.11

1.72

9.69

.01

2.14

8.76

.01

$\begin{array}{ll}1.99 & 10.07\end{array}$

.01

1.96

.04

.85

2.27

1.07

.31

1.89

6.45

.02

2.22

.10

.76

1.93

.48

.50

$2.00 \quad 5.62$

.02

Note. The judgment scale varies from 1 (= attribute is very unimportant) through 7 (= attribute is very important); attributes are rank ordered on the basis of the average belief score, so that the first (environmental well-being) is considered most typical of commuting by carpool and the last (flexibility) of commuting alone; the numbers in between parentheses refer to the rankings in terms of perceived importance, so that flexibility (1) is considered to be most and low travel costs (9) to be least important. 
Hypothesis $2 \mathrm{~b}$ predicted that, relative to other commuters, solo drivers on the experimental route would justify their choices by increasing the importance of attributes linked to solo driving and decreasing the importance of attributes linked to carpooling. In support of this prediction, a significant interaction of Route, Commuter Type, and Time was obtained, $F(9,178)=2.99, p<.005$, which qualified a lower-order interaction of Route and Time, $F(9,178)=2.95, p<.005$. Univariate significant effects for this three-way interaction were obtained on flexibility, $F(1,186)=3.94, p<.05$, low travel costs, $F(1,186)=4.35, p<.04$, and safety, $F(1,186)=4.91, p<.03$. Table 12 presents the $\mathrm{F}$ - and $\mathrm{p}$-values associated with the univariate results of the Route by Commuter Type by Time interaction, and the mean differences in importance ratings for each subgroup in the analysis. Consistent with Hypothesis $2 \mathrm{~b}$, Solo Drivers on the Experimental Route increased the importance of flexibility (an attribute consensually linked to driving solo) after the implementation of the carpool lane $(M$ difference $=+0.62), F(1,85)=6.33, p$ $<.02$. In addition, Experimental Solo Drivers decreased the importance of low travel costs $(M$ difference $=-0.76), F(1,85)=6.94, p<.01-$ the attribute most strongly linked to carpooling. Unexpectedly, shifts in evaluations were also observed among the group carpoolers. As opposed to Solo Drivers, Carpoolers on the Experimental Route assigned less importance to flexibility $(M$ difference = 1.33), $F(1,5)=2.29, p<.20$, and greater importance to safety $(M$ difference $=$ $+2.50), F(1,5)=5.28, p<.08-$ however, due to the small number of carpoolers, these changes failed to reach acceptable levels of significance.

In sum, these results are consistent with the idea that solo drivers tend to engage in self-justification activities when confronted with the carpool lane. Although the predicted effects were found on two attributes, both of these attributes were consensually and strongly linked to either solo driving (flexibility) or carpooling (low travel costs; see Table 10). Additionally, the unanticipated changes in the evaluations of carpoolers indicate that they too may have engaged in a process of self-justification (we will address this in the discussion) . $^{4}$

${ }^{4}$ We also performed an analysis using as input the products of the beliefs and evaluations per attribute (i.e., attitudes). This analysis revealed only a significant multivariate main effect for Commuter Type, $F(9,178)=3.86, p<.001$. The mean attitude ratings demonstrated that Solo drivers held more negative attitudes toward carpooling than did Carpoolers, which is consistent with the findings on beliefs and evaluations. 
Table 12

Changes in Importance Ratings of Travel Attributes Between Time 1 and Time 2 as a Function Route and Commuter Type

Experimental route Control route

Travel attribute

Solo Carpool

Solo

Carpool Average $F(1,186)$ p

1. Environmental

\section{well-being $(6)$}

2. Low travel $\operatorname{costs}(9)$

3. Sociability $(8)$

4. Relaxation(7)

5. Safety(5)

6. Comfort(3)

7. Low travel time(4)

8. Reliable travel time(2)

9. Flexibility(1)

\section{$-0.09$}

$+0.34$

$+0.33$

$+0.17$

$-0.50$

$+2.50$

$+0.83$

$+0.17$

$+0.50$

$-1.33$
$-0.02$

$-0.27$

$-0.32$

$-0.07$

$-0.03$

$+0.24$

$+0.36$

$-0.24$

$+1.10$

$-0.10$

$+0.27$

$+0.01$
$-0.36$

$+1.00$

$-0.27$

$+0.37$

$-0.18$

$-0.37$
4.41

2.96

3.35

4.21

4.73

4.88

4.81

5.11

.51

4.35

.13

.95

4.91

.14

.73

5.58

Note. The original judgment scale varies from 1 (= very unimportant) to 7 (= very important); positive sign indicates an increase and a negative sign a decrease in perceived importance betwe Time 1 and Time 2; attributes are rank ordered on the basis of the average belief score; 4 numbers in between parentheses refer to the rankings in terms of perceived importance.

\section{Changes in preferences for carpooling:}

Tests of hypotheses $3 \mathbf{a}$ and $\mathbf{3 b}$

To test Hypothesis $3 \mathrm{a}$ and $3 \mathrm{~b}$, which parallel our earlier predictions for beliefs (i.e., Hypotheses $1 \mathrm{a}$ and $1 \mathrm{~b}$ ) and importance ratings (i.e., Hypotheses $2 \mathrm{a}$ and $2 \mathrm{~b}$ ), we submitted commuters' preferences (very strong preference for $1=$ driving solo, $7=$ carpooling) to a 2 (Route) $\times 2$ (Commuter Type) $\times 2$ (Time) ANOVA, the latter independent variable being a within-subject factor. Consistent with Hypothesis $3 \mathrm{a}$, this analysis revealed a strong main effect for Commuter Type, $F(1,186)=33.62, p$ $<.001$, indicating that Carpoolers exhibited a stronger preference for carpooling $(M$ $=4.54, S D=2.16)$ than Solo Drivers $(M=2.49, \mathrm{SD}=1.57)$.

Hypothesis $3 \mathrm{~b}$ predicted that solo drivers would exhibit a weaker, and carpoolers a stronger preference for carpooling, and that these differences would be 
more pronounced for commuters on the experimental route. Support for Hypothesis $3 \mathrm{~b}$ would be revealed by a significant interaction of Route, Commuter Type, and Time. The analysis revealed, indeed, the predicted three-way interaction, $F(1,186)$ $=4.15, p<.05$. To examine this interaction more closely, we performed several additional analyses. First, we performed two 2 (Commuter Type) $\times 2$ (Time) ANOVAs for the two Routes separately, so as to examine the shifts in preference between the distinct commuter groups. For the Experimental Route, a main effect was found for Commuter Type, $F(1,90)=14.72, p<.001$, which was qualified by a Commuter Type $x$ Time interaction, $F(1,90)=9.14, p<.001$. The associated means (displayed in Table 13) show that Solo Drivers exhibited a decrease in carpool preferences between Time $1(M=2.91)$ and Time $2(M=2.31)$, whereas Carpoolers exhibited an increase in carpool preferences $\left(M^{\prime} \mathrm{s}=4.25\right.$ vs. 5.83$)$, however the latter difference was not statistically significant. In addition, for the Control Route, a significant main effect was observed for Commuter Type, $F(1,95)$ $=20.30, p<.001$, with Solo Drivers $(M=2.36)$ displaying a weaker preference for carpooling than Carpoolers $(M=4.27)$; however, this was not qualified by a significant two-way interaction of Commuter Type and Time, $F(1,95)<1$.

Another way to look at this three-way interaction is to compare the preferences for Time 1 and Time 2 separately, so as to examine whether the differential preference of carpoolers and solo drivers increased more strongly on the experimental than on the control route (as was predicted in the second part of Hypothesis 3b). Accordingly, two 2 (Route) x 2 (Commuter Type) ANOVAs were conducted for Time 1 and Time 2, separately. At Time 1, the main effect for Commuter Type, $F(1,186)=10.81, p<.001$, was not qualified by an interaction effect of Route and Commuter Type, $F(1,186)<1$. Thus, as shown in Table 13, the relative difference between Carpoolers and Solo Drivers was similar for Experimental $(M$ difference $=1.34)$ and Control Route $(M$ difference $=1.68)$. However, at Time 2 an interaction of Route and Commuter Type emerged, $F(1,186)$ $=4.10, p<.05$, qualifying a main effect for Commuter Type, $F(1,186)=50.89, p$ $<.001$. The associated means indicate that Time 2 differences between Carpoolers and Solo Drivers were more pronounced on the Experimental $(M$ difference $=3.52)$ than on the Control Route ( $M$ difference $=2.14$ ).

Taken together, these analyses reveal that solo drivers showed a decrease and carpoolers an increase in carpool preference between the measurement times. Moreover, these changes in carpool preferences were more pronounced on the route providing the carpool lane than on the control route. Thus, these results are congruent with the prediction of self-justification among solo drivers on the experimental route (Hypothesis $3 \mathrm{~b}$ ) and parallel the prior effects on importance ratings (Hypothesis $2 b$ ). 
Table 13

Preferences for Carpooling as a Function of Route, Commuter Type, and Time

Time 1

Time 2

Route

$M$

$S D$

$M$

$S D$

Experimental route

Solo driver

$2.91^{\mathrm{a}}$

1.82

$2.31^{\mathrm{b}}$

1.58

Carpooler

$4.25^{\mathrm{c}}$

2.47

$5.83^{\mathrm{c}}$

1.75

Mean difference (C-S)

$1.34^{1}$

$3.52^{2}$

Control route

$\begin{array}{lllll}\text { Solo driver } & 2.59^{\mathrm{a}} & 1.57 & 2.13^{\mathrm{b}} & 1.17 \\ \text { Carpooler } & 4.27^{\mathrm{c}} & 1.99 & 4.27^{\mathrm{c}} & 2.32\end{array}$

Mean difference (C-S)

Note. The judgment scale varies from 1 (= strong preference for solo driving) to 7 (= strong preference for carpooling), where 4 stands for indifferent; means and mean differences with a distinct superscript differ significantly, $p<.05$.

In addition to the preferences for carpooling, we examined commuters' intentions to carpool in the near future, and their actual behavior. For intentions, commuters who already carpooled were excluded from the sample, and so intentions were analyzed in a 2 (Route) $\times 2$ (Time) ANOVA, the second factor being withinsubject. This analysis yielded a marginally significant main effect for Time, $F(1,170)=2.94, p<.09$, revealing that Solo Drivers displayed a weaker intention to commute by carpool between Time $1(M=2.55, S D=1.64)$ and Time $2(M=2.36$, $\mathrm{SD}=1.58$ ). The effect for Time was not further influenced by Route, indicating that solo drivers on the control route also developed a weaker intention to carpool between Time 1 and Time 2. Finally, we examined possible changes in the actual behavior of commuters during the length of our study (i.e., approximately two months). Given the relatively short time interval between Time 1 and Time 2, it was rather unlikely to find substantial behavioral change. Indeed, in our sample none of the solo drivers changed to carpooling and none of the carpoolers changed to driving solo. 


\section{Changes in perceived self-efficacy and collective efficacy}

In the introduction, we assumed that there could be various kinds of obstacles preventing commuters from carpooling (perceived self-efficacy and collective efficacy; cf. Bandura, 1986), and that these perceptions would influence commuter preferences. Accordingly, we first analyzed the perceived self-efficacy to commute by carpool in a 2 (Route) $\times 2$ (Commuter Type) $\times 2$ (Time) ANOVA, the latter being a within-subject factor. A significant main effect for Commuter Type was found on the question: "Would it be possible for you to carpool in your commuting situation?" $(1=$ not possible at all, $7=$ very much possible), $F(1,186)=45.62, p$ $<.001$. Compared to Carpoolers $(M=4.68, S D=2.63)$, Solo Drivers considered carpooling highly infeasible $(M=2.03, S D=1.54)$. No effects were found as a function of Time, indicating that the implementation of the carpool lane did not change the perceived self-efficacy to carpool, neither for carpoolers nor solo drivers.

Second, commuters' perceptions of the collective efficacy to carpool were determined by analyzing their ratings of the questions: "Do you think that (a) a carpool priority lane, and (b) in general, the efforts of the Dutch government will be effective in stimulating commuters to carpool?" $(1=$ very ineffective, $7=$ very effective). A multivariate analysis including the full factorial design yielded a significant Time effect, $F(2,181)=3.05, p<.05$. Univariate tests revealed that commuters perceived a carpool priority lane to be less effective at Time 2 ( $M=$ $3.76, S D=2.03)$ than at Time $1(M=4.33, S D=2.21), F(1,186)=3.26, p<.08$. Commuters also judged the governmental activities to be less effective at Time 2 $(M=3.42, S D=1.78)$ than at Time $1(M=3.86, S D=1.76), F(1,186)=3.83, p$ $<.05$. These effects were not further influenced by Commuter Type or Route. Thus, across all groups there is an apparent decline in the perceived ability of society to handle massive car use by stimulating people to carpool. 


\section{Predicting intentions to carpool: Test of hypothesis 4}

Hypothesis 4 predicted that perceptions of collective efficacy would make a unique, independent contribution to predicting intention to carpool, in addition to a model including attitudes, social norms, self-efficacy (i.e., factors that have been established in prior research on behavioral decision making; cf. Ajzen, 1991) $)^{5}$. To test this hypothesis, we performed regression analyses for Time 1 and Time 2 separately, in which intention to carpool was regressed, first, onto attitudes, social norms, and perceptions of self-efficacy, variables that were entered in the equation as a block. Thereafter, collective efficacy was entered in the equation to see whether it would significantly increase the totally explained variance. For attitude, the products of the belief and importance ratings per attribute were averaged, and this score served as input for the regression analyses; similarly, for social norm we used the average of the products of normative beliefs and motivations to comply (for a similar procedure, see Ajzen \& Fishbein, 1980); finally, the collective efficacy score was created by averaging the ratings on the two items tapping this construct.

As a first step, zero-order correlations were calculated between the model variables at the two time measurements. As can be seen in Table 14, all variables correlated positively with intention to carpool both at Time 1 and Time 2 . However, Time 2 showed greater variations in the relative size of these correlations ( $r$ 's between .23 and .47 , all $r$ 's, $p<.01$ ) than Time 1 ( $r$ 's between .31 and .38 , all $r$ 's, $p<.01$ ), suggesting that constructs may have changed in importance for predicting intention from Time 1 to Time 2. Interestingly, inspection of the table also reveals that the two forms of efficacy -- self-efficacy and collective efficacy -did not correlate significantly (Time 1 and Time 2 : both $r$ 's $=.12$, n.s.). Thus, consistent with our prior reasoning, they presumably tap different levels of efficacy. Finally, this table indicates that collective efficacy correlated with other behavioral determinants and most strongly with the attitude toward carpooling (Time 1 and Time 2: $r$ 's $=.31$ and $.27, p<.01)$.

${ }^{5}$ Although there were no a priori expectations about specific changes in social norms toward carpooling, these variables were also subjected to multivariate analyses. Accordingly, two 2 (Route) $\times 2$ (Commuter Type) $\times 2$ (Time of Measurement) MANOVAs, the latter being a withinsubject factor, were performed for normative beliefs and motivations to comply, separately. First, for normative beliefs $(-3=$ strongly opposed vs. $+3=$ strongly in favor of carpooling $)$ this analysis revealed only a multivariate main effect for Commuter Type, $F(5,182)=4.43, p<.001$. It was found that, relative to Carpoolers, Solo drivers considered all referent persons to be more opposed toward carpooling: partner $(M ' s=-1.08$ vs, $0.42, S D ' s=1.63$ and 1.90$), F(1,186)=16.44, p$ $<.001$, colleagues $\left(M{ }^{\prime} s=-1.48\right.$ vs. $-0.59, S D ' s=1.45$ and 1.92$), F(1,186)=4.25, p<.05$, friends $\left(M^{\prime} s=-1.33\right.$ vs. $-0.62, S D^{\prime} s=1.47$ and 1.54$), \bar{F}(1,186)=4.63, p<.05$, the company $\left(M^{\prime} s=-1.27\right.$ vs. $0.18, S D$ 's $=1.79$ and 2.41$), F(1,186)=7.44, p<.01$, and the Dutch government $(M ' s=1.71$ vs. $2.38, S D^{\prime} \mathrm{s}=1.69$ and 1.06$), F(1,186)=3.91, p<05$. Second, the analysis on motivations to comply $(1=$ not at all vs. $7=$ very strongly $)$ yielded two multivariate main effects, for Commuter Type, $F(5,182)=2.60, p<.05$, and Route, $F(5,182)=2.34, p<.05$, which were qualified by a significant interaction effect of Commuter Type and Route, $F(5,182)=2.46, p<.05$. However, no significant univariate effects emerged that determined this multivariate result.

The results on normative beliefs are reminiscent of a common finding that people tend to overestimate the magnitude of social support for their opinions ("false consensus"". cf. Goethals, Allison, \& Frost, 1979; Ross, Greene, \& House; 1977), which is perhaps the result of a process of self-justification (cf. Marks \& Miller, 1987). 
Table 14

Zero Order Correlations between Model Variables for Time 1 and Time 2

Variable

$12 \quad 3$

34

56

7

8

$9 \quad 10$

Time 1

1. Attitude

$\begin{array}{llllllllll}\ldots & .54 * * & .30^{* *} & .31^{* *} & .33^{* *} & .71 * * & .34 * * & .28^{* *} & .15^{*} & .37^{* *} \\ \ldots & .40^{* *} & .20^{* *} & .36^{* *} & .45^{* *} & .70^{* *} & .33^{* *} & .14 & .45^{* *} \\ & \ldots & .12 & .38^{* *} & .37^{* *} & .36^{* *} & .73^{* *} & .14 & .41^{* *} \\ & & \ldots & .31^{* *} & .32^{* *} & .10 & .10 & .47^{* *} & .24 * * \\ & & & \ldots & \ldots & .28 * * & .21 * * & .48^{* *} & .07 & .58^{* *}\end{array}$

2. Social norm

3. Self-efficacy

4. Collective efficacy

5. Intention

Time 2

6. Attitude

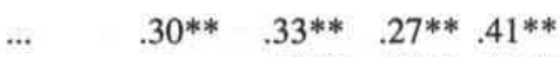

7. Social norm

8. Self-efficacy

9. Collective efficacy

10. Intention

Note. ${ }^{*} p<.05 ;{ }^{* *} p<.01$.

Second, the regression analyses revealed that at Time 1 the three variables that were entered in the regression equation in one block (i.e., attitude, social norm, and efficacy) significantly predicted the carpool intention, $F(3,237)=24.94, p<.001$, together accounting for $23 \%$ of the variance. Self-efficacy had the greatest relative weight in predicting intention (beta $=.30$ ), followed by attitude (beta $=.20$ ), and social norm ( beta $=.17$ ). Most importantly, when collective efficacy was added as a predictor (beta $=.18$ ), the total variance accounted for significantly improved, from $23 \%$ to $27 \%, F$ change $(4,236)=9.06, p<.001$.

Yet, a somewhat different pattern of results emerged at Time 2 . When the three traditional predictors were entered simultaneously, they accounted for $40 \%$ of the variance in carpool intention, $F(3,182)=42.67, p<.001$. Again, self-efficacy had the greatest relative weight $($ beta $=.35)$, followed by social norm $($ beta $=.29$ ) and attitude (beta $=.28$ ). However, inconsistent with Hypothesis 4, collective efficacy did not significantly explain carpool intention above and beyond these factors, $F$ change $(4,181)<1$. 
In sum, these analyses revealed that, in partial support of Hypothesis 4, collective efficacy contributed to predicting intention to carpool, but only at Time 1 . Thus, a stronger intention to carpool was associated with a greater expectancy that society would be able to decrease massive car use and promote carpooling. However, at Time 2 collective efficacy was not significantly related to carpool intentions, over and above the other three variables. Finally, both regression analyses revealed that perceived self-efficacy seemed to be the best predictor across the two research phases. All in all, these analyses suggest that carpool intentions are partly shaped by social-psychological factors, such as attitudes, social norms, and self-efficacy, but also to some extent by the perception of collective efficacy, a largely unexplored factor in well-established attitude-behavior models.

\subsection{Discussion}

\section{Main conclusions}

The current chapter evaluated a structural solution to a real-life social dilemma by examining the effects of a carpool priority lane on judgments and preferences relevant to the decision to commute alone (i.e., the presumed noncooperative option) or by carpool (i.e., the presumed cooperative option). In general, our findings demonstrate that this intervention -- the first of its kind in Europe -- was not successful. Although solo drivers changed their belief regarding the efficiency of carpooling (i.e., carpooling was considered to be somewhat faster after the implementation of the carpool lane), they also tended to upgrade the importance of an attribute consensually linked to driving alone, and downgrade the importance of an attribute consensually linked to carpooling. Moreover, solo drivers' preferences for and intentions to carpool tended to decline rather than to increase following the establishment of the carpool lane. Below, we will discuss several psychological mechanisms that may underlie these changes, as well as the strengths and limitations of the current findings.

The major purpose of the current work was to examine the impact of the implementation of a carpool lane on judgments and preferences relevant to carpooling. The general hypothesis was advanced that solo-driving commuters, when confronted with the carpool lane, would engage in a process of selfjustification to reduce the tension arising from feelings of relative deprivation and/or cognitive dissonance. First, and in support of Hypothesis 1a, it was found that solo drivers held more positive beliefs about solo driving and negative beliefs about carpooling than did carpoolers. For example, solo drivers found commuting alone more comfortable, reliable, and efficient, whereas carpoolers found carpooling less expensive, and more sociable.

Second, contrary to Hypothesis $1 \mathrm{~b}$, there was no evidence that solo drivers exaggerated these judgments after the carpool lane had been established; thus, no 
support was found for the self-justification hypothesis on the beliefs regarding commuting alone versus by carpool. Third, and in partial support of Hypothesis 1c, we observed a fair amount of consensus among commuters that carpooling had become more attractive in terms of travel time, delineating that solo drivers as well as carpoolers recognized the increased efficiency of carpooling. These observations were consistent with the reported actual change in travel time of carpoolers (i.e., according to carpoolers, their commuting time was reduced considerably after the implementation of the carpool lane). Thus, we may conclude that in and of itself, the carpool lane intervention was successful in making carpooling more viable in terms of travel time.

Consistent with Hypotheses $2 \mathrm{a}$ and $2 \mathrm{~b}$, there were pronounced differences between solo drivers and carpoolers in the importance they assigned to attributes linked to either commuting alone or by carpool, and the implementation of the carpool lane tended to strengthen such differences. Commuters driving alone assigned greater importance than carpoolers to a travel attribute strongly linked to commuting alone (flexibility), and less importance to attributes strongly linked to carpooling (low travel costs, sociability, and environmental well-being). More importantly, in support of Hypothesis $2 b$, some of these effects were more pronounced after the implementation of the carpool lane. That is, when faced with the carpool lane solo drivers clearly increased the importance of flexibility, which all commuters judged to be the most prototypic attribute of solo driving; also, they decreased the importance of low travel costs -- one of the most exemplary attributes of carpooling. Finally, again in support of the self-justification hypothesis, solo drivers showed a decrease in their preference for carpooling, and differences in carpool preferences between solo drivers and carpoolers became more pronounced on the route providing the carpool lane (evidence in support of Hypotheses 3a and $3 \mathrm{~b})$. These findings extend and complement prior research on self-justification by providing evidence for this self-serving mechanism in the context of a social dilemma -- a situation in which people often feel the need to justify the pursuit of their self-interest at the cost of the collective (i.e., to continue driving alone despite the negative effects on the levels of congestion and environmental pollution; cf. Messé \& Sivacek, 1979).

It seems appropriate to further discuss the strength and nature of the selfjustification findings. First, evidence in support of self-justification among solo drivers was more pronounced on the importance ratings than on the beliefs relevant to commuting alone or by carpool. A plausible explanation for this discrepancy is provided by the notion that people are generally motivated to view themselves and their situation positively, but only to the extent that reality permits them to do so. Indeed, prior research has shown that self-serving biases are constrained by the specificity and objectivity of the dimensions on which these judgments are made (cf. Dunning, Meyerowitz, \& Holzberg, 1989; Goethals, Messick \& Allison, 1991: 
Van Lange, 1991). Given that beliefs are more verifiable and more constrained by reality than importance ratings, it is understandable that self-justification effects primarily occurred through changes in the importance assigned to travel attributes rather than changes in beliefs about those attributes. Nevertheless, we did obtain some evidence that commuters may also have been somewhat biased in their beliefs about their commuting option and situation. The finding that both solo drivers and carpoolers held more positive beliefs about a variety of attributes associated with their own commuting choice (i.e., relative to carpoolers, solo drivers found their own option quicker, more comfortable, and less expensive) indicates that commuters tend to systematically overestimate the virtues of their own commuting option and underestimate the virtues of others, a finding consistent with the results of prior travel mode research (e.g., Golob, Horowitz, \& Wachs, 1979). However, in support of our argument that self-serving judgments may be reality-constrained, it was found that commuters did not display these biases on beliefs consensually and strongly related to either carpooling (i.e., environmental well-being) or solo driving (i.e., flexibility).

A second finding deserving brief attention is that self-justification effects among solo drivers were obtained for only a subset of travel attributes. For example, solo drivers did not upgrade the importance of a reliable travel time -which was viewed as an advantage of driving alone -- or downgrade the importance of sociability. A possible interpretation of this result may be that in the service of self-justification it is sufficient to display biases along a few dimensions, provided that they are consensually linked to either one of the behavioral options ("selfrelevant dimensions"; cf. Tesser \& Campbell, 1982). Thus, this may explain why effects were found for the attributes flexibility and low travel costs, about which a fair amount of consensus existed that these were linked to, respectively, solo driving and carpooling. Moreover, in order to maintain a positive self-image it may not be opportune to downgrade the importance of a highly socially desirable attribute, such as environmental well-being (cf. Steele, 1988; Wood, 1989).

Third, it was assumed that only commuters driving alone would feel the need to justify their behavior. However, our findings suggest that carpoolers may have engaged in self-justification processes as well. When confronted with the carpool priority lane, carpoolers tended to decrease the importance of flexibility and increase the importance of travel safety -- an attribute they perceived to be linked to carpooling, because presumably driving on the carpool lane was less risky than driving on the heavily congested regular lanes. Why may this be? One post-hoc interpretation would be that carpoolers are a minority who engage in behavior that is somewhat uncommon and conflicting with attitudes and behaviors of the vast majority which, perhaps, have become increasingly critical of the carpool lane. In light of such majority pressures, it is understandable that carpoolers feel the need to display strong commitment to their commuting decision (cf. Moscovici, 1976), and that they engage in self-justification. Alternatively, it is possible that carpoolers feel somewhat overcompensated for a behavior they already perform (cf. 
overjustification effect; Deci \& Ryan, 1985; Lepper \& Greene, 1979), and therefore attempt to rationalize carpooling in other ways as well. Needless to say, both accounts are highly speculative and remain to be examined in future research.

Fourth, to our surprise the predicted decline in carpool preference and intention among experimental solo drivers was also found for solo drivers on the control route. A plausible explanation for this finding may be that commuters driving alone on the control route have been exposed to various media reports stating that the carpool lane attracted fewer people than expected. Accordingly, they may have reasoned that if people would not even start carpooling under more favorable circumstances (i.e., the presence of a carpool priority lane) then it may not at all be viable in their own situation ("vicarious learning"; cf. Bandura, 1986).

Fifth, we should address the origin of the self-justification effects in experimental solo drivers. In the introduction we offered two complementary explanations, based on distinct psychological processes that may have been set in motion by the implementation of the carpool lane, including (a) relative deprivation, emanating from the perceived inequity between their outcomes and those of carpoolers, and (b) cognitive dissonance, emanating from the tension between the beliefs about carpooling and their actual behavior. It was assumed that feelings of deprivation would be paramount among people who were not able to carpool and feelings of dissonance among those for whom carpooling was a viable option. Which of these processes was more prominent in the current study? To begin with, the rather low self-efficacy ratings (i.e., an average of 2 on a seven-point scale) suggest the validity of a relative deprivation interpretation. Also, the outcomes of the regression analyses indicated that self-efficacy was the strongest predictor of the intention to carpool, and seemed to be even stronger after the implementation of the carpool lane. Indeed, various obstacles may exist that lower perceptions of selfefficacy (e.g., finding carpool partners, coordinating time schedules). Furthermore, feelings of deprivation may have been further enhanced by the belief that, instead of a carpool lane benefiting a small minority of commuters, there could have been an extra regular lane which would have diminished the congestion problems considerably ("counterfactual thinking"; cf. Kahneman \& Miller, 1986). Finally, more illustrative evidence for a deprivation interpretation is provided by a list of incidents that took place shortly after the lane had been opened, showing expressions of reactance (cf. Brehm \& Brehm, 1981; e.g., people drove purposely alone on the lane, and some of them placed mannequins in their cars). Although the evidence for a deprivation interpretation seems compelling, this may not entirely account for the obtained effects. It may well be that the low perceived efficacy judgments themselves have been distorted by a process of self-justification (e.g., to deny personal responsibility for the problems related to car use; cf. Heider, 1958).

The second purpose of the current study was to explore a social-psychological model of the intention to carpool. In partial support of Hypothesis 4, collective 
efficacy perceptions (i.e., the belief that society would be able to encourage commuters to carpool) made a significant contribution to predicting carpool intentions of solo drivers over and above the well-established factors of attitudes, social norms, and self-efficacy (Ajzen, 1987). The finding that collective efficacy only predicted Time 1 but not Time 2 intentions may be attributable to the fact that between these measurements solo drivers became increasingly and unequivocally pessimistic about the chances to promote carpooling (i.e., the ratings on items related to collective efficacy were quite low). Indeed, after the opening of the lane solo drivers perceived almost every day that the number of people using the carpool lane was much lower than expected, and so commuters became perhaps more convinced in their opinion about the lack of effectiveness of carpool enhancing strategies.

These preliminary findings suggest that collective efficacy judgments may play a role in the willingness to cooperate in a real-life social dilemma, and they are consistent with prior laboratory research on efficacy in social dilemmas. Within the framework of a public good dilemma, for example, Kerr (1992) obtained evidence that the perception of collective efficacy (i.e., the perceived possibilities of attaining the public good as a group) decreases as group size increases even when the objective efficacy remains the same. Based on these findings, he suggested that "If there is an illusion of greater efficacy in small groups, then there may be ways of redefining or reframing large-group social dilemmas in terms of smaller groups" (p. 310). From this perspective, pro-environmental behaviors such as carpooling may be enhanced by redefining the problem of environmental pollution into smaller scale problems (e.g., initiating environmental projects in local communities and organizations). This may promote perceptions of collective efficacy which, in turn, may enhance cooperation in this real-life social dilemma.

\section{Strengths, limitations, and implications of the present study}

Before closing, we wish to outline some of the strengths and limitations of the current work in which we attempted to provide a new perspective on the effectiveness of structural solutions to social dilemmas. A first limitation of the current work is that we did not directly examine the mechanisms underlying selfjustification (i.e., the unpleasant states arising from relative deprivation and cognitive dissonance); thus, the current findings do not allow us to draw firm conclusions about the origin of the self-justification effects. However, as indicated in previous work (for reviews, see Cooper \& Fazio, 1984; Martin, 1981), it is exceedingly difficult to reliably measure such feelings or states; hence, tension arising from dissonance and relative deprivation is usually inferred from people's attitudes and behaviors. The other limitations are related to the experimental design that was used to test the self-justification hypotheses. One potential confinement concerns the timing of measurements. Because the first measurement was conducted just one month prior to the opening of the carpool priority lane, it is conceivable that our Time 1 ratings may have been affected by expectations about 
the would-be commuting situation; thus, it would have been more desirable if the Time 1 measurement had been conducted a more substantial period before the opening of the carpool lane. Another limitation of the present work is that the sample of commuters consisted for the most part of solo drivers and for only a small part of carpoolers. Notwithstanding the fact that the current sample reflected the actual proportions of these groups in the commuting population, and that our hypotheses were mainly focused on the reactions of solo drivers, the strength of our findings might have been enhanced by increasing the number of carpoolers.

Despite these limitations, this research makes several novel contributions to our knowledge and understanding of structural solutions to real-life social dilemmas. First, it provides some of the first evidence on how people may respond to a structural change in a social dilemma existing in the real world. This is particularly important in light of Stern's (1992) comprehensive review in which he emphasizes the importance of psychological research concerning the effects of environmental regulations and laws. Second and related, contrary to the widely shared optimism among social dilemma theorists about the impact of structural solutions (e.g., Messick \& Brewer, 1983; Yamagishi, 1986), the current findings indicate that not all structural solutions may be effective in eliciting cooperative behavior. When these interventions are not strong enough or the desired behavior is difficult to perform, the consequences may, in fact, be detrimental due to a process of selfjustification. The validity of this conclusion was clearly demonstrated in the case of the carpool lane and its aftermath. That is, the Dutch government closed the carpool priority lane less than a year after the opening, and this was due to (a) lack of interest and (b) enduring resistance on the part of commuters (i.e., people successfully fought in court the legitimacy of the lane from which in their opinion so many citizens were excluded). A third novelty of the current research is that it has identified and supported the role of a largely unexplored factor -- collective efficacy -- in determining people's willingness to engage in environment-preserving behaviors.

Although we do not wish to engage in a process of self-justification ourselves, we believe that experimentation with the carpool priority lane has taught us the following, important lessons. First, prior to implementing structural measures whereby the majority is refrained from any benefits, it seems important to know more about the number of people who believe they are capable of performing the collectively-desired action so as to anticipate feelings of relative deprivation among a large group of individuals. Second, a thorough understanding of why individuals are unwilling to carpool (e.g., comfort and flexibility of solo driving) seems important before undertaking drastic structural measures because solo-drivers might use exactly those dimensions for justifying their travel mode choice. Perhaps, the effectiveness of structural solutions may be improved by following a more decentralized approach, so that these interventions are accompanied by initiatives of 
local governments, businesses, and organizations that presumably are in a better position to find solutions compatible with the possibilities and motivations of commuters. That is, for those who are unable to carpool these local institutions could focus on removing important individual obstacles (e.g., matching commuters in the same neighborhoods, coordinating work schedules). Moreover, those unwilling to carpool may be persuaded by providing them with multiple benefits of carpooling at the same time (e.g., better parking places in combination with financial arrangements) so that they can no longer justify their behavior. 


\section{Summary}

It is widely assumed that the automobile is among one of the greatest technological devices of mankind, because it provides people with a highly efficient, reliable, and convenient travel mode. Yet, despite these attractive qualities, car use is also responsible for some major societal problems, most notably environmental pollution and traffic congestion. Indeed, in many ways modern society would be better off if fewer people would take their car and more people would carpool or make use of public transportation. This situation, which contains a conflict of interests between the individual and society at large, can be framed as a social dilemma (Dawes, 1980).

This dissertation advances a social dilemma approach to analyze decisions to commute by car versus public transportation or carpooling (i.e., commuting traffic is presumed to be the main cause of congestion and environmental problems). Based on interdependence theory (Kelley \& Thibaut, 1978) and the extant social dilemma literature, it is assumed that the individual decision to commute by car versus public transportation (or carpool) is not only shaped by the immediate, self-interested concerns of the individual, which are likely to lead to a preference for the car, but also by the broader motives and concerns of individuals in the decision situation (i.e., pro-social and pro-environmental considerations). The process whereby people tend to respond to the broader implications of their behavior is referred to as transformation of motivation, and this process may be instigated by various (inter)personal factors. On the basis of the above assumption, five experiments were conducted -- utilizing different research paradigms including a laboratory and field-study -- which are reported in greater detail in Chapters 2 to 6.

Chapter 1 provides a general overview of the dissertation. First, it describes the problems modern society faces as a consequence of excessive automobile use. Thereafter, the theoretical foundations of the dissertation are discussed, advancing the social dilemma approach as complementary to traditional models (i.e., attitude and reinforcement model) in studying and modifying transportation patterns. The third part briefly discusses the historical roots of the social dilemma approach, that is, social dilemma research and interdependence theory. In the next section, the social dilemma approach is applied to the decision situation of commuters by explaining how commuters may transform the decision situation depending on the salience of their self-interested or pro-social concerns. Thereafter, the main research goals and findings are summarized. The overview concludes with a general discussion of the dissertation research, including some important conclusions, theoretical and practical implications.

In Chapters 2 and 3 the first and second experiment are described. Their main objectives were to examine how commuters might transform the commuting situation differently on the basis of their personal habits and motives. In the first 
experiment (described in Chapter 2) a sample of commuters -- all daily car users -and students -- traveling primarily by public transportation -- were asked to make a decision either to commute by car or public transportation in a standard commuting situation. Both groups received (manipulated) information about the expected decisions of a majority of other commuters, and the environmental and congestion consequences of their decisions. Following interdependence theory, it was assumed that the individual decision would be shaped by the perceived interdependence structure underlying the commuting situation, which would presumably vary with the personal dependence on either car or public transportation. Indeed, it was found that commuters (being strongly dependent on cars) viewed the situation more as an accessibility problem, exhibiting a greater preference for commuting by public transportation when they expected a majority to commute by car -- so as to avoid heavy traffic congestion on their route. This interpretation reflects the interdependence structure of an N-person Chicken Dilemma. In contrast, students (being not very dependent on cars) viewed the situation primarily as an environmental problem, exhibiting a greater public transportation preference when they expected a majority to also commute by public transportation, so as to minimize the levels of environmental pollution. This interpretation reflects the structure of an $\mathrm{N}$-person Prisoner's Dilemma.

Using a procedure and manipulations similar to those employed in the previous experiment, the second experiment (described in Chapter 3) examined the role of social value orientations, an interpersonal disposition determining the way people evaluate outcomes for themselves and others in interdependent settings (Messick \& McClintock, 1968). The main finding was that people with pro-self orientations -- who tend to view interdependent situations predominantly in terms of their self-interest -- transformed the situation into an accessibility problem, exhibiting a greater preference for the commuting option that fewer others were expected to take, so as to avoid traffic jams or crowded trains. In contrast, people with pro-social orientations -- who tend to primarily view such situations in terms of the collective interest -- transformed the situation into an environmental problem, exhibiting a greater public transportation preference when many others were expected to also choose for public transportation, and the pollution would be minimal. Thus, experiments 1 and 2 show that individuals perceived and responded to the same commuting situation in very different ways, and these differential construals were based on a concern with either their immediate self-interest (i.e., to travel in an efficient way) or a concern with the long-term, collective interest (i.e., to travel in an environment-preserving manner).

In Chapter 4 the third study is reported, which further investigated the role of self-interested and pro-social considerations in shaping decisions to commute by car or public transportation. Consistent with the prediction, the major finding was that public transportation preferences are enhanced not only by a more favorable travel time (relative to the car), but also by a more or equally reliable travel time. Another interesting finding was that public transportation was preferred above the 
car most clearly, when the two barriers to use public transportation (more efficient and more reliable travel time by car) were removed simultaneously. This supports the idea that commuters are using a multiplicative instead of an additive decision rule in determining their choice. Finally, it was found that commuting preferences were related to individual differences in social value orientations, which again demonstrates the importance of personality variables in explaining environmentallyrelevant decisions.

The fourth study (described in Chapter 5) extended prior studies in two important ways. First, the research addressed the simultaneous impact of two interpersonal dispositions, (a) social value orientations, and (b) trust (Yamagishi, 1986) on decisions to commute by car or public transportation. Consistent with the goal/expectation hypothesis (Pruitt \& Kimmel, 1977), our findings revealed that public transportation preferences were most pronounced when people had both prosocial value orientations and high expectations about others' willingness to cooperate. Second, following a social dilemma approach, it is argued that systematic cooperation in large-scale social dilemmas, such as environmental pollution, could only be promoted by altering the interdependence structure of the decision situation (e.g., through providing rewards for public transportation use or imposing restrictions for car use). Accordingly, in an exploratory vein of the fourth study we examined how people would evaluate and classify various structural solutions to the commuting situation. It was found that the evaluation of these solutions systematically varied with differences in social value orientations and trust. That is, relative to pro-self commuters, pro-social commuters were more concerned with how these solutions would affect the collective interest; moreover, low-trusters were more strongly concerned than high-trusters in how these solutions would affect their self-interest. Finally, findings revealed that commuters generally disapproved of structural solutions, and particularly the ones that would limit their freedom to move (e.g., reduction of parking space or obligation to take public transportation to the company).

The final chapter (Chapter 6) of this dissertation further addressed the impact of structural solutions in solving real-life social dilemmas, by reporting a field experiment on a real-life structural solution -- the implementation of a carpool lane in the Netherlands. Consistent with predictions, it was found that this solution not only enhanced the belief that carpooling had become more efficient, but also evoked a process of self-justification among solo drivers who drove on the route where the lane was established. That is, after the implementation of the carpool lane solo drivers downgraded the importance of attributes linked to carpooling (i.e., low travel costs), while upgrading the importance of attributes linked to solo driving (i.e., flexibility). Moreover, compared to carpoolers -- who became increasingly positive about carpooling - the carpool preference of solo drivers decreased substantially.

The research findings of the dissertation lead to the following conclusions and implications (see Chapter 1). First, as suggested by the social dilemma approach, the experiments showed that commuters indeed perceived and responded 
to the decision situation as if they were faced with a social dilemma. Second, consistent with interdependence theory (Kelley \& Thibaut, 1978), evidence was obtained that people interpreted the decision situation differently on the basis of their broader motives and concerns. The finding that some people perceived the commuting situation predominantly as an accessibility problem may explain why large numbers of people are generally unresponsive to campaigns accentuating the environmental consequences of car use. Perhaps more successful are campaigns stressing the personal benefits of commuting by public transportation or carpooling.

A third conclusion is that, in spite of a general optimism among social scientists about the effectiveness of structural solutions to social dilemmas, their implementation in the real-world may have important drawbacks, because people may not be able or very willing to exhibit the desired behavior. Accordingly, people may engage in ego-defensive processes, such as self-justification, in responding to these changes. Before implementing such solutions in transportation situations, one should therefore better investigate how many car drivers are actually capable of performing the desired behaviors, and what travel alternatives they consider to be most attractive. This may require a more decentralized approach, whereby the government stimulates companies and other local institutions to develop their own programs aimed at reducing individual car use.

Fourth, on the basis of our research findings we may conclude that cooperation in real-world social dilemmas, such as environmental pollution, may often be better understood by taking into account the simultaneous impact of several personality and situational variables. The strength of these person $\mathrm{x}$ person and person $\mathrm{x}$ situation interactions may account for the weak correlations between behaviors and single personality variables that have been generally obtained in environmental research. Thus, in studying pro-social behavior it seems useful to consider how several personality traits may influence the decision-making process of individuals, and how these traits may interact. From a practical viewpoint, in implementing environmental programs one might take into account how various activities will affect people with different personality types. 


\section{Samenvatting}

De auto wordt door velen gezien als één van de grotere technische uitvindingen van de afgelopen eeuwen, vanwege zijn efficiëntie, reiscomfort en flexibiliteit. Ondanks deze positieve eigenschappen is het autogebruik verantwoordelijk voor belangrijke maatschappelijke problemen, zoals milieuvervuiling en verkeersopstoppingen. De samenleving zou er in velerlei opzichten bij gebaat zijn wanneer minder mensen de auto zouden nemen en meer mensen zouden gaan carpoolen of met het openbaar vervoer zouden reizen. Een dergelijke situatie, waarin het eigenbelang en maatschappelijk belang zich niet met elkaar verdragen, wordt een sociaal dilemma genoemd (Dawes, 1980).

In dit proefschrift wordt met behulp van een sociaal dilemma benadering geanalyseerd hoe mensen komen tot een keuze voor de auto of het openbaar vervoer (carpoolen) in het woon-werkverkeer. Uitgaande van de interdependentietheorie (Kelley \& Thibaut, 1978) en de uitgebreide onderzoeksliteratuur over sociale dilemma's wordt aangenomen dat de vervoermiddelkeuze niet alleen bepaald wordt door het directe eigenbelang, die mensen veelal aanzet om met de auto naar het werk te gaan, maar ook door overwegingen van meer sociale en milieuvriendelijke aard. Het proces waarbij mensen hun aandacht richten op de brede implicaties van hun gedrag wordt ook wel transformatie van motivatie genoemd en kan worden ingegeven door allerlei (inter)persoonlijke kenmerken. Op basis van bovenstaande assumptie zijn vijf experimenten uitgevoerd, zowel in laboratorium- als in veldsituaties. Deze experimenten worden beschreven in de hoofdstukken 2 tot en met 6.

In Hoofdstuk 1 wordt een overzicht van het gehele proefschrift gegeven. Allereerst worden de maatschappelijke gevolgen van het massale autogebruik beschreven. Daarna wordt het theoretische uitgangspunt van de sociale dilemma benadering besproken en wordt deze gepresenteerd als aanvulling op meer traditionele benaderingen om vervoerskeuzes te onderzoeken en te beïnvloeden (attitude- en beloningsbenadering). Het derde deel beschrijft kort de grondslagen van de sociale dilemma benadering, te weten, interdependentie-theorie en de onderzoeksliteratuur op het gebied van sociale dilemma's. In de daaropvolgende secties wordt deze benadering toegepast op de beslissingssituatie van forensen en worden de belangrijkste doelen en bevindingen van het onderzoek besproken. Het overzichtshoofdstuk wordt afgesloten met een algemene discussie, waarin de belangrijkste conclusies op een rijtje worden gezet, aanbevelingen worden gedaan voor verder onderzoek en aangrijpingspunten worden geboden voor interventies om het autogebruik terug te dringen.

In het tweede en derde hoofdstuk worden experimenten 1 en 2 besproken. Deze hadden als voornaamste doel om aanwijzingen te vinden voor het transformatieproces dat aan de vervoerskeuze ten grondslag zou liggen. In het eerste experiment (beschreven in Hoofdstuk 2) werd een gesimuleerde woon-werk 
situatie voorgelegd aan een steekproef bestaande uit forensen (allen regelmatige autogebruikers) en een steekproef bestaande uit studenten (allen regelmatige OVreizigers). Gefingeerde informatie werd verstrekt over de verwachte keuzes van een meerderheid van andere forensen en de consequenties daarvan voor de milieuvervuiling en filevorming. Aangenomen werd dat de beslissing om met auto of trein te reizen in sterke mate zou worden bepaald door de waargenomen interdependentiestructuur, die waarschijnlijk zou samenhangen met hoe afhankelijk mensen zich voelen van auto of trein. Overeenkomstig de verwachtingen bleken forensen de situatie vooral als bereikbaarheidsprobleem te interpreteren (met een interdependentiestructuur die vergelijkbaar is met het $\mathrm{N}$-personen Chicken Dilemma) met een sterkere voorkeur voor de trein wanneer men verwachtte dat velen de auto zouden nemen. Daarentegen zagen studenten de situatie vooral als milieuprobleem (met een onderliggende structuur vergelijkbaar met die van een $\mathrm{N}$ personen Prisoner's Dilemma) en zij hadden een sterkere voorkeur voor de trein wanneer verwacht werd dat de meeste anderen ook de trein zouden nemen.

In een vergelijkbare onderzoeksopzet en met vergelijkbare manipulaties werd in het tweede experiment, dat beschreven staat in Hoofdstuk 3, de invloed onderzocht van sociale waarde-oriëntaties, een persoonseigenschap die bepaalt hoe mensen uitkomsten voor zichzelf en anderen evalueren (Messick \& McClintock, 1968). Als belangrijkste resultaat werd gevonden dat mensen met een "pro-sociale" instelling -- die interdependente situaties vooral beoordelen in het licht van het algemeen belang -- de situatie als milieuprobleem zagen en een sterkere voorkeur hadden voor de trein wanneer verwacht werd dat velen de trein zouden nemen. Daarentegen zagen mensen met een "pro-zelf" instelling de situatie vooral als een bereikbaarheidsprobleem, met een sterkere voorkeur voor de trein wanneer verwacht werd dat velen juist de auto zouden nemen. Op basis van beide experimenten kan worden geconcludeerd dat de vervoerskeuze van sommige mensen vooral door het directe eigenbelang wordt bepaald (d.w.z. een efficiënte reis), terwijl anderen ook oog hebben voor het algemeen belang van een schoon milieu.

In het vierde hoofdstuk wordt experiment 3 beschreven, waarin opnieuw de invloed van verschillende zelfzuchtige en pro-sociale motieven op de vervoerskeuze werd onderzocht. De belangrijkste bevinding was dat de voorkeur voor de trein niet alleen afhankelijk was van de absolute reistijd, maar ook van de reistijdbetrouwbaarheid vergeleken met de auto. Dit suggereert dat het openbaar vervoer zou kunnen worden gestimuleerd door de nadruk te leggen op hoe betrouwbaar deze vervoerswijze is in vergelijking met de auto. Verder werd gevonden dat het openbaar vervoer het meest werd geprefereerd wanneer tegelijkertijd twee nadelen van de trein werden opgeheven (d.w.z. een kortere en minstens zo betrouwbare reistijd als de auto). Derhalve kunnen we concluderen dat forensen kennelijk een multiplicatieve in plaats van additieve beslisregel hanteren bij het bepalen van hun vervoerskeuze. Ten slotte werd gevonden dat de keuze voor auto of trein samenhing met verschillen in sociale waarde-oriëntaties, hetgeen 
opnieuw de relevantie aantoont van persoonlijkheidskenmerken bij het voorspellen van milieurelevant gedrag.

Het vierde experiment, beschreven in Hoofdstuk 5, vormt in een tweetal opzichten een uitbreiding op de eerdere onderzoeken. Allereerst werd de gezamenlijke invloed onderzocht van twee persoonlijkheidskenmerken, te weten (a) sociale waarde oriëntaties, en (b) trust (Yamagishi, 1986). In overeenstemming met de doel/verwachtingen hypothese (Pruitt \& Kimmel, 1977) werd gevonden dat de sterkste voorkeur voor de trein bestond onder forensen, die zowel (a) een coöperatief doel hadden, alsmede (b) hoge verwachtingen over het coöperatieve gedrag van anderen. Op grond van een sociale dilemma benadering kan worden beargumenteerd dat, aangezien men vooral in grootschalige sociale dilemma's (zoals de milieuvervuiling) waarschijnlijk nogal pessimistisch is over de bereidwilligheid van anderen, systematische coöperatie alleen tot stand zou kunnen komen wanneer de structuur van het sociaal dilemma wordt veranderd (bijvoorbeeld door beloningen of restricties). Als tweede werd daarom bekeken hoe forensen verschillende structurele oplossingen voor sociale dilemma's evalueerden en aan welke daarvan ze de voorkeur gaven. De belangrijkste bevinding was dat forensen weinig geporteerd waren van dergelijke interventies, vooral niet wanneer ze de individuele keuzevrijheid zouden beperken (bijvoorbeeld, reductie van aantal parkeerplaatsen). Verder bleek de evaluatie van deze oplossingen samen te hangen met verschillen in sociale waarde oriëntaties en trust, waarbij pro-socialen (in vergelijking tot pro-zelvers) meer letten op de consequenties voor het algemeen belang en mensen met weinig vertrouwen in de coöperatie van anderen (in vergelijking met mensen die veel vertrouwen hadden) meer letten op de consequenties voor het eigenbelang.

In het afsluitende Hoofdstuk 6 wordt meer aandacht besteed aan de mogelijke effectiviteit van structurele oplossingen, en wel door middel van een veld-experiment naar een daadwerkelijke structurele verandering - de invoering van de carpoolstrook in Nederland. Gevonden werd dat deze verandering niet alleen de waargenomen efficiëntie van het carpoolen bevorderde, maar tevens leidde tot een proces van zelfrechtvaardiging onder alleenrijdende forensen die dagelijks op het betreffende traject reden. Zo begonnen zij na invoering van de strook meer waarde te hechten aan de flexibiliteit van het alleenrijden en juist minder aan de kosten van het alleenrijden. Bovendien nam hun voorkeur om te carpoolen af, terwijl die van carpoolers, die van de strook gebruik gingen maken, juist sterk toenam.

Bovenstaande bevindingen geven aanleiding tot de volgende conclusies en implicaties (zie Hoofdstuk 1). Allereerst lieten de experimenten zien dat forensen de beslissingssituatie inderdaad opvatten als een sociaal dilemma, een conflict tussen eigenbelang en algemeen belang. Ten tweede werden aanwijzingen gevonden dat forensen de beslissingssituatie op een verschillende wijze interpreteerden, namelijk vooral als milieu- of bereikbaarheidsprobleem. Met het oog op nieuwe pogingen het autogebruik terug te dringen is het van belang om rekening te houden met deze interpretaties. Zo zullen voorlichtingscampagnes die 
het belang van het milieu benadrukken waarschijnlijk weinig effect hebben op het gedrag van mensen die vooral oog hebben voor het directe eigenbelang. Deze laatste groep is wellicht te overtuigen met informatie die de persoonlijke voordelen om met de trein te reizen benadrukt (bijvoorbeeld, luxere en snellere treinen).

Ten derde kan worden geconstateerd dat, ondanks een zeker optimisme onder sociaal-wetenschappelijke onderzoekers over het effect van structurele veranderingen, deze negatieve reacties bij het publiek kunnen oproepen (bijvoorbeeld via zelfrechtvaardiging). Deze reacties komen wellicht voort uit het feit dat mensen soms niet in staat of niet bereid zijn om het gewenste gedrag te vertonen. Voordat een dergelijke structurele ingreep wordt ondernomen zou daarom moeten worden uitgezocht in hoeverre mensen in staat zijn hun vervoersgedrag te veranderen en welke alternatieven zij aantrekkelijk vinden. Dit pleit voor een meer decentrale benadering van de vervoersproblematiek, waarin de overheid bedrijven en andere instellingen stimuleert om zelf vervoersprogramma's te ontwikkelen, die zijn afgestemd op de wensen en behoeften van hun medewerkers.

Ten vierde toonden de onderzoeken aan dat coöperatief gedrag (d.w.z. met de trein reizen of carpoolen) vaak beter werd verklaard uit een combinatie van persoonlijkheidsfactoren en structurele kenmerken dan uit de optelsom van de onafhankelijke bijdragen van deze factoren. Dit zou wel eens een verklaring kunnen bieden voor het feit dat er in milieu-onderzoek vaak zwakke verbanden worden gevonden tussen één bepaalde persoonlijkheidsfactor en gedrag (Stern, 1992). Derhalve dienen onderzoekers bij het bestuderen van pro-sociaal gedrag aandacht te besteden aan mogelijke interacties tussen relevante persoonlijkheidseigenschappen. In meer praktisch opzicht dient men bij het implementeren van milieuprogramma's rekening te houden met het feit dat mensen op grond van verschillen in persoonlijkheidskenmerken anders op deze activiteiten zouden kunnen reageren. 


\section{References}

Abelson, R. P., \& Levi, A. (1985). Decision making and decision theory. In G. Lindzey \& E. Aronson (Eds.), Handbook of social psychology (pp. 231-309). New York: Random House.

Ajzen, I. (1987). Attitudes, traits, and actions: Dispositional prediction of behavior in personality and social psychology. In L. Berkowitz (Ed.), Advances in Experimental Social Psychology: Vol. 20 (pp. 1-63). San Diego, CA: Academic Press.

Ajzen I. (1991). The theory of planned behavior. Organizational Behavior and Human Decision Processes, 50, 179-211.

Ajzen I., \& Fishbein, M. (1980). Understanding attitudes and predicting social behavior. Englewood Cliffs, NJ: Prentice-Hall.

Aronson, E. (1988). The social animal. New York: W. H. Freeman and Company.

Averill, J. R. (1973). Personal control over aversive stimuli and its relationship to stress. Psychological Bulletin, 80, 286-303.

Baerwald, T. J. (1985). Commuter attitudes toward ridesharing. Environments, 17, 96-99.

Bandura, A. (1986). Social foundations of thought and action: Social cognitive theory. Englewood Cliffs, NJ: Prentice Hall.

Beggan, J. K., Messick, D. M., \& Allison, S. T. (1988). Social values and egocentric bias: Two tests of the might over morality hypothesis. Journal of Personality and Social Psychology, 55, 606-611.

Bem, D. J., \& Allen, A. (1974). On predicting some of the people some of the time: The search for cross-situational consistencies in behavior. Psychological Review, 81, 506-520.

Bem, D. J., \& Lord, C. G. (1979). Template matching: A proposal for probing the ecological validity of experimental settings in social psychology. Journal of Personality and Social Psychology, 37, 833-846.

Bornstein, G. (1992). The free-rider problem in intergroup conflicts over step-level and continuous public goods. Journal of Personality and Social Psychology, 62, 597-606.

Brann, P., \& Foddy M. (1987). Trust and the consumption of a deteriorating common resource. Journal of Conflict Resolution, 31, 615-630.

Brechner, K. C., \& Linder, D. E. (1981). A social trap analysis of energy distribution systems. In A. Baum \& J. Singer (Eds.), Advances in Environmental Psychology: Vol. 3 (pp. 27-51). Hillsdale, NJ: Lawrence Erlbaum Associates.

Brehm, S. S., \& Brehm, J. W. (1981). Psychological reactance: A theory of freedom and control. San Diego, CA: Academic Press. 
Bronner, A. E. (1982). Decision styles in transport mode choice. Journal of Economic Psychology, 2, 81-101.

Cavalini, P. M., Hendrickx, L., \& Rooijers, A. J. (1993). Differences among car user groups regarding $\mathrm{CO}_{2}$ emissions (Research Report 65). Groningen, the Netherlands: IVEM.

Central Bureau of Statistics (1991). De mobiliteit van de Nederlandse bevolking [The mobility of the Dutch population]. Heerlen, the Netherlands: Centraal Bureau voor de Statistiek.

Cook, T. D., \& Campbell, D. T. (1979). Quasi-experimentation: Design and analysis issues for field settings. Chicago, $\mathrm{IL}$ : Rand McNally.

Cook, T. D., Crosby, F., \& Hennigan, K. M. (1977). The construct validity of relative deprivation. In J. M. Suls \& R. L. Miller (Eds.), Social comparison processes (pp. 307-333). Washington DC: Hemisphere.

Cooper, J. (1976). Deception and role playing: On telling the good guys from the bad guys. American Psychologist, 31, 605-610.

Cooper, J., \& Fazio, R. H. (1984). A new look at dissonance theory. In L. Berkowitz (Ed.), Advances in Experimental Social Psychology: Vol. 17 (pp. 229266). San Diego, CA: Academic Press.

Costanzo, M., Archer, D., Aronson, E., \& Pettigrew, T. (1986). Energy conservation behavior: The difficult path from information to action. American Psychologist, 41, 521-528.

Dawes, R. M. (1980). Social dilemmas. Annual Review of Psychology, 31, 169-193.

Dawes, R. M. (1988). Rational choice in an uncertain world. New York: Harcourt Brace Jovanovich.

Dawes, R. M., McTavish, J., \& Shaklee, H. (1977). Behavior, communication and assumptions about other people's behavior in a common's dilemma situation. Journal of Personality and Social Psychology, 35, 1-11.

De Dreu, C. K. W., \& Van Lange, P. A. M. (in press). Impact of social value orientations on negotiator cognition and behavior. Personality and Social Psychology Bulletin.

Deci, E. L., \& Ryan, R. M. (1985). Intrinsic motivation and selfdetermination in human behavior. New York: Plenum Press.

Deutsch, M. (1958). Trust and suspicion. Journal of Conflict Resolution, 2, 265-279.

Diekmann, A. (1985). Volunteer's dilemma. Journal of Conflict Resolution, 29, 605-610.

Doosje, E. J., \& Siero, F. W. (1990). Houdingen en opvattingen van ANWBleden ten aanzien van de auto-milieu discussie [Attitudes and opinions of ANWBmembers about car-environment debate] (Research report). Groningen, the Netherlands: Groningen University.

Dunlap, R. E., \& Scarce, R. (1991). The polls-poll trends: Environmental problems and protection. Public Opinion Quarterly, 55, 713-734. 
Dunning, D., Meyerowitz, J. A., \& Holzberg, A. D. (1989). Ambiguity and self-evaluation: The role of idiosyncratic trait definitions in self-serving assessments of ability. Journal of Personality and Social Psychology, 57, 10821090.

Dutch Ministry of Traffic \& Waterways (1990). Second structural transportation program (Report). The Hague, the Netherlands: Ministry of Traffic \& Waterways.

Edney, J. J. (1980). The commons problem; alternative perspectives. American Psychologist, 35, 131-150.

Eisenberger, R., Kuhlman, D. M., \& Cotterell, N. (1992). Effects of social values, effort training, and goal structure on task persistence. Journal of Research in Personality, 26, 258-272.

Erev, I., Bornstein, G., \& Galili, R. (1993). Constructive intergroup competition as a solution to the free rider problem: A field experiment. Journal of Experimental Social Psychology, 29, 463-478.

Festinger, L. (1957). A theory of cognitive dissonance. Evanston, IL: Row, Peterson.

Fishbein, M., \& Ajzen, I. (1975). Belief, attitude, intention, and behavior: An introduction to theory and research. Reading, MA: Addison-Wesley.

Flannelly, K. J., \& McLeod, M. S. (1989). A multivariate analysis of socioeconomic and attitudinal factors predicting commuters' mode of travel. Bulletin of the Psychonomic Society, 27, 64-66.

Gardner, P. L. (1975). Scales and statistics. Review of Educational Research, 45, 43-57.

Geller, E. S., Winett, R. A., \& Everett, P. B. (1982). Preserving the environment: New strategies for behavior change. New York: Pergamon Press.

Goethals, G. R., Allison, S. J., \& Frost, M. (1979). Perceptions of the magnitude and diversity of social support. Journal of Experimental Social Psychology, 15, 570-581.

Goethals, G. R., Messick, D. M., \& Allison, S. T. (1991). The uniqueness bias: Studies of constructive social comparison. In J. M. Suls \& T. A. Wills (Eds.), Social comparison: Contemporary theory and research (pp. 149-176). Hillsdale, NJ: Lawrence Erlbaum and Associates.

Golob, T. F., Horowitz, A. D., \& Wachs, M. (1979). Attitude-behaviour relationships in travel-demand modelling. In D. A. Hensher \& P. R. Stopher (Eds.), Behavior travel modelling. London: Croom Helm.

Hamburger, H. (1979). Games as models of social phenomena. San Francisco: W. H. Freeman and company.

Hardin, G. (1968). The tragedy of the commons. Science, 162, 1243-1248.

Heider, F. (1958). The psychology of interpersonal relations. New York: Wiley.

Homans, G. C. (1961). Social behavior: Its elementary forms. New York: Harcourt Brace Jovanovich. 
Iedema, J., \& Poppe M. (1994). Effects of social value orientation on expecting and learning of others' orientations. European Journal of Social Psychology, 24, 565-579.

Insko, C. A., Schopler, J., Hoyle, R. H., Dardis, G. J., \& Graetz, K. A. (1990). Individual-group discontinuity as a function of fear and greed. Journal of Personality and Social Psychology, 58, 68-79.

Jerdee, T. H., \& Rosen, B. (1974). Effects of opportunity to communicate and visibility of individual decisions on behavior in the common interest. Journal of Applied Psychology, 59, 712-716.

Johnson, J. M. (1975). Doing field research. New York: Free Press.

Joireman, J. A., Van Lange, P. A. M., Kuhlman, D. M., Van Vugt, M., \& Shelley, G. P. (in press). An interdependence analysis of commuting decisions. European Journal of Social Psychology.

Jorgenson, D. O., \& Papciak, A. S. (1981). The effects of communication, resource feedback, and identifiability on behavior in a simulated commons. Journal of Experimental Social Psychology, 17, 373-385.

Kahneman, D., \& Miller, N. (1986). Norm theory: Comparing reality to its alternatives. Psychological Review, 93, 136-153.

Kahneman, D., \& Tversky, A. (1979). Prospect theory: An analysis of decisions under risk. Econometrica, 47, 263-291.

Kelley, H. H. (1984). The theoretical description of interdependence by means of transition lists. Journal of Personality and Social Psychology, 47, 956982.

Kelley, H. H., \& Grzelak, J. L. (1972). Conflict between individual and common interests in an n-person relationship. Journal of Personality and Social Psychology, 21, 190-197.

Kelley, H. H., \& Stahelski, A. J. (1970). Social interaction basis of cooperators' and competitors' beliefs about others. Journal of Personality and Social Psychology, 16, 66-91.

Kelley, H. H., \& Thibaut, J. W. (1978). Interpersonal relations: A theory of interdependence. New York: Wiley.

Kempton, W., Darley, J. M., \& Stern, P. C. (1992). Psychological research for the new energy problems: Strategies and opportunities. American Psychologist, 47, 1213-1223.

Kenrick, D. T., \& Funder D. C. (1988). Profiting from controversy: Lessons from the person-situation debate. American Psychologist, 43, 23-34.

Kerr, N. L. (1989). Illusions of efficacy: The effects of group size on perceived efficacy in social dilemmas. Journal of Experimental Social Psychology, $25,287-313$.

Kerr, N. L. (1992). Efficacy as a causal and moderating variable in social dilemmas. In W. B. G. Liebrand, D. M. Messick, \& H. A. M. Wilke (Eds.), Social dilemmas: Theoretical issues and research findings (pp. 59-80). Oxford: Pergamon Press. 
Kerr, N. L., \& Bruun, S. E. (1983). Dispensability of member effort and group motivation losses: Free-rider effects. Journal of Personality and Social Psychology, 44, 78-94.

Kessler, R. C., \& Greenberg, D. F. (1981). Linear panel analysis: Models of quantitative change. New York: Academic Press.

Kihlstrom, J. F. (1987). Introduction to the special issue: Integrating personality and social psychology. Journal of Personality and Social Psychology, $53,989-992$.

Klandermans, B. (1992). Persuasive communication: Measures to overcome real-life social dilemmas. In W. B. G. Liebrand, D. M. Messick, \& H. A. M. Wilke (Eds.), Social dilemmas: Theoretical issues and research findings (pp. 307-318). Oxford: Pergamon Press.

Knight, G. P., \& Dubro, A. F. (1984). Cooperative, competitive, and individualistic social values: An individualized regression and clustering approach. Journal of Personality and Social Psychology, 46, 98-105.

Knight, G. P., Johnson, L. G., Carlo, G., \& Eisenberg, N. (1994). A multiplicative model of the dispositional antecedents of a prosocial behavior: Predicting more of the people more of the time. Journal of Personality and Social Psychology, 66, 178-183.

Komorita, S. S., \& Parks, C. D. (1994). Social dilemmas. Dubuque, IA: Brown \& Benchmark.

Komorita, S. S., \& Parks, C. D. (1995). Interpersonal relations: Mixedmotive interaction. Annual Review of Psychology, 46, 183-207.

Komorita, S. S., Sweeney, J., \& Kravitz, D. A. (1980). Cooperative choice in the N-person dilemma situation. Journal of Personality and Social Psychology, $38,504-516$.

Kostyniuk, L. P. (1982). Demand analysis for ridesharing: State-of -the-art review. Transportation Research Record, 876, 17-26.

Kramer, R. M., \& Brewer, M. B. (1984). Effects of group identity on resource use in a simulated commons dilemma. Journal of Personality and Social Psychology, 46, 1044-1057.

Kramer, R., McClintock, C. G., \& Messick, D. M. (1986). Social values and cooperative response to a simulated resource conservation crisis. Journal of Personality, 54, 101-117.

Kropman, J., \& Katteler, H. (1993). De betekenis van de verplaatsingstijdfactor [The significance of the travel time factor]. Nijmegen, the Netherlands: ITS.

Kuhlman, D. M., Camac, C., \& Cunha, D. A. (1986). Individual differences in social value orientation. In H. Wilke, D. Messick, \& C. Rutte (Eds.), Experimental social dilemmas (pp. 151-176). New York: Verlag Peter Lang.

Kuhlman, D. M., \& Marshello, A. (1975). Individual differences in game motivation as moderators of preprogrammed strategy effects in prisoner's dilemma. Journal of Personality and Social Psychology, 32, 922-931. 
Latané, B., \& Wolf, S. (1981). The social impact of majorities and minorities. Psychological Review, 88, 438-453.

Lepper, M. R., \& Greene, D. (1979). The hidden costs of reward. New York: Lawrence Erlbaum.

Lewin, K. (1948). The background of conflict in marriage. In G. W. Lewin (Ed.), Resolving social conflicts: Selected papers on group dynamics (pp. 84-102). New York: Harper.

Liebrand, W. B. G. (1983). A classification of social dilemma games. Simulation and Games, 14, 123-138.

Liebrand, W. B. G. (1984). The effect of social motives, communication and group size on behaviour in an N-person multi-stage, mixed-motive game. European Journal of Social Psychology, 14, 239-264.

Liebrand, W. B. G. (1992). How to improve our understanding of group decision making with the help of artificial intelligence. Acta Psychologica, 80, 279295.

Liebrand, W. B. G., Messick, D. M., \& Wilke, H. A. M. (1992). Social dilemmas: Theoretical issues and research findings. Oxford: Pergamon Press.

Liebrand, W. B. G., \& Van Lange, P. A. M. (1989). Als het mij maar niets kost! De psychologie van sociale dilemma's [As long as it does not cost me anything! The psychology of social dilemmas]. Lisse, the Netherlands: Swets \& Zeitlinger.

Liebrand, W. B. G., \& Van Run, G. J. (1985). The effects of social motives across two cultures on behavior in social dilemmas. Journal of Experimental Social Psychology, 21, 86-102.

Liebrand, W. B. G., Wilke, H. A. M., Vogel, R., \& Wolters, F. J. M. (1986). Value orientation and conformity in three types of social dilemma games. Journal of Conflict Resolution, 30, 77-97.

Loos, A. L., \& Kropman, J. (1993). Reistijd cruciaal voor keuze vervoerwijze [Travel time crucial for travel mode choice]. Verkeerskunde, 5, 26-29.

Lowe, M. D. (1990). Alternatives to the automobile: Transport for livable cities. World Watch Paper 98, October.

Luce, R. D., \& Raiffa, H. (1957). Games and decisions: Introduction and critical survey. London: John Wiley and sons.

MacLean, D. (1983). A moral requirement for energy policies. In D. MacLean \& P. Brown (Eds.), Energy and the future (pp. 180-196). Towatta, NJ: Rowman \& Littlefield.

Mahmassani, H. S., \& Chang, G. (1985). Dynamic aspects of departure time choice behavior in a commuting system: Theoretical framework and experimental analysis. Transportation Research Record, 1037, 88-101.

Marks, G., \& Miller, N. (1987). Ten years of research on the falseconsensus effect: An empirical and theoretical review. Psychological Bulletin, 1, $72-90$. 
Martin, J. (1981). Relative deprivation: A theory of distributive injustice for an era of shrinking resources. Research in Organizational Behavior, 3, 53-107.

McClintock, C. G. (1972). Social motivation -- a set of propositions. Behavioral Science, 17, 438-454.

McClintock, C. G., \& Allison, S. T. (1989). Social value orientation and helping behavior. Journal of Applied Social Psychology, 19, 353-362.

McClintock, C. G., \& Liebrand, W. B. G. (1988). The role of interdependence structure, individual value orientation and other's strategy in social decision making: A transformational analysis. Journal of Personality and Social Psychology, 55, 396-409.

McGuire, W. J. (1985). Attitudes and attitude change. In G. Lindzey \& E. Aronson (Eds.), Handbook of social psychology (pp. 233-346). New York: Random House.

McLuhan, M. (1964). Understanding media: The extensions of man. Chicago: McGraw-Hill.

McNemar, Q. (1969). Psychological statistics. New York: Wiley.

Messé, L. A., \& Sivacek, J. M. (1979). Predictions of others' responses in a mixed-motive game: Self-justification or false consensus? Journal of Personality and Social Psychology, 37, 602-607.

Messick, D. M. (1973). To join or not to join: An approach to the unionization decision. Organizational Behavior and Human Performance, 10, 145156.

Messick, D. M., Allison, S. T., \& Samuelson C. D. (1988). Framing and communication effects on group members' responses to environmental and social uncertainty. In S. Maital (Ed.), Applied behavioral economics: Vol. 2 (pp. 677. 700). Brighton: Wheatsheaf Books.

Messick, D. M., \& Brewer, M. B. (1983). Solving social dilemmas: A review. In L. Wheeler \& P. Shaver (Eds.), Review of Personality and Social Psychology: Vol 4. (pp. 11-44). Beverly Hills, CA: Sage.

Messick, D. M., \& Liebrand, W. B. G. (1995). Individual heuristics and dynamics of cooperation in large groups. Psychological Review, 102, 131-145.

Messick, D. M., \& McClintock, C. G. (1968). Motivational basis of choice in experimental games. Journal of Experimental Social Psychology, 4, 1-25.

Messick, D. M., Wilke, H. A. M., Brewer, M. B., Kramer, R. M., Zemke, P. E., \& Lui, L. (1983). Individual adaptations and structural change as solutions to social dilemmas. Journal of Personality and Social Psychology, 44, 294-309.

Mischel, W. (1968). Personality and assessment. New York: Wiley.

Moscovici, S. (1976). Social influence and social change. London: Academic Press.

Nemeth, C. (1972). A critical analysis of research utilizing the prisoner's dilemma paradigm for the study of bargaining. In L. Berkowitz (Ed.), Advances in Experimental Social Psychology: Vol. 6 (pp. 203-234). San Diego, CA: Academic Press. 
Newman, P., \& Kenworthy, J. (1989). Cities and automobile dependence: An international sourcebook. Gower, England: Aldershot.

Norman, K. L. (1977). Attributes in bus transportation: Importance depends on trip purpose. Journal of Applied Psychology, 62, 164-170.

Olson, M. (1965). The logic of collective action: Public goods and the theory of groups. Cambridge, MA: Harvard University Press.

Orbell, J. M., \& Dawes, R. M. (1981). Social dilemmas. In G. Stephenson, G. \& J. H. Davis (Eds.), Progress in Applied Social Psychology: Vol. 1 (pp. 3766). Chicester: Wiley.

Orbell, J. M., \& Wilson, L. A. (1978). Institutional solutions to the N-person prisoner's dilemma. American Political Science Review, 72, 411-421.

Osinga, F. (1995). Wat vindt de Nederlander van carpoolen? [How do the Dutch feel about carpooling?]. Unpublished manuscript. Groningen, the Netherlands: Institute of Traffic Safety.

Ostrom, E. (1990). Governing the commons: The evolution of institutions for collective action. New York: Cambridge University Press.

Owens, D. D. (1981). Ridesharing programs: Governmental responses to urban transportation problems. Environment and Behavior, 13, 311-330.

Parks, C. D. (1994). The predictive ability of social values in resource dilemmas and public goods games. Personality and Social Psychology Bulletin, 20, 431-438.

Platow, M. J. (1992). A note on the social desirability of pro-social choices in decomposed games. Unpublished manuscript, University of Otago, New Zealand.

Platow, M. J., McClintock, C. G., \& Liebrand, W. B. G. (1990). Predicting intergroup fairness and ingroup bias in the minimal group paradigm. European Journal of Social Psychology, 20, 221-239.

Platt, J. (1973). Social traps. American Psychologist, 28, 641-651.

Pruitt, D. G., \& Kimmel, M. (1977). Twenty years of experimental gaming: Critique, synthesis, and suggestions for the future. Annual Review of Psychology, $28,363-392$.

Roberts, D. F., \& Maccoby, N. (1985). Effects of mass communication. In G. Lindzey \& E. Aronson (Eds.), Handbook of social psychology (pp. 539-598). New York: Random House.

Ross, L., Greene, D., \& House, P. The "false consensus" effect: An egocentric bias in social perception and attribution processes. Journal of Experimental Social Psychology, 13, 279-301.

Ruiter, R. A. C., Van Vugt, M., Meertens, R. M., \& Van Lange, P. A. M. (1995). Egoïsten en idealisten in het woon-werk verkeer: de invloed van sociale waarde oriëntaties op de vervoerskeuze in een realistisch sociaal dilemma [Egotists and idealists in commuter traffic: The role of social value orientations in a realistic social dilemma]. In F. Siero, E. Van Schie, D. Daamen, \& A. Pruyn (Eds.), Sociale psychology en haar toepassingen: Vol. 9 (pp. 97-110). Delft, the Netherlands: Eburon. 
Rusbult, C. E., \& Van Lange, P. A. M. (in press). Interdependence processes. In T. Higgins \& A. Kruglanski (Eds.), Social psychology: Handbook of basic principles. Guilford Press.

Rutte, C. G. (1990). Solving organizational social dilemmas. Social Behaviour, 5, 285-294.

Rutte, C. G., \& Wilke, H. A. M. (1984). Social dilemmas and leadership. European Journal of Social Psychology, 14, 294-309.

Rutte, C. G., \& Wilke, H. A. M. (1985). Preference for decision structures in a social dilemma situation. European Journal of Social Psychology, 15, 367-370.

Samuelson, C. D. (1990). Energy conservation: A social dilemma approach. Social Behaviour, 5, 207-230.

Samuelson, C. D. (1991). Perceived task difficulty, causal attributions, and preferences for structural change in resource dilemmas. Personality and Social Psychology Bulletin, 17, 181-187.

Samuelson, C. D. (1993). A multivariate evaluation approach to structural change in resource dilemmas. Organizational Behavior and Human Decision Processes, 55, 298-324.

Samuelson, C. D., \& Messick, D. M. (1986). Inequities in access to and use of shared resources in social dilemmas. Journal of Personality and Social Psychology, 51, 960-967.

Samuelson, C. D., \& Messick, D. M. (in press). When do people want to change the rules for allocating shared resources? In D. Schroeder (Ed.), Social dilemmas. New York: Praeger.

Samuelson, C. D., Messick, D. M., Rutte, C. G., \& Wilke, H. A. M. (1984). Individual and structural solutions to resource dilemmas in two cultures. Journal of Personality and Social Psychology, 47, 94-104.

Sattler, D. N., \& Kerr, N. L. (1991). Might versus morality explored: Motivational and cognitive bases for social motives. Journal of Personality and Social Psychology, 60, 756-765.

Schaeffer, M. H., Street, S. W., Singer, J. E., \& Baum, A. (1988). Effects of control on the stress reactions of commuters. Journal of Applied Social Psychology, 18, 944-957.

Schroeder, D. A., Jensen, T. D., Reed, A. J., Sullivan, D. D., \& Schwab, M. (1983). The actions of others as determinants of behavior in social trap situations. Journal of Personality and Social Psychology, 19, 522-539.

Schulz, U., Albers, W., \& Mueller, U. (1994). Social dilemmas and cooperation. Berlin: Springer-Verlag.

Schwartz, S. H. (1977). Normative influences on altruism. In L. Berkowitz (Ed.), Advances in Experimental Social Psychology: Vol. 10 (pp. 221-279). San Diego, CA: Academic Press.

Skinner, B. F. (1953). Science and human behavior. New York: Macmillan. 
Snyder, M. (1993). Basic research and practical problems: The promise of a "functional" personality and social psychology. Personality and Social Psychology Bulletin, 19, 251-264.

Snyder, M., \& Ickes, W. (1985). Personality and social behavior. In G. Lindzey \& E. Aronson (Eds.), Handbook of social psychology (pp. 883-947). New York: Random House.

Steele, C. M. (1988). The psychology of self-affirmation: Sustaining the integrity of the self. In L. Berkowitz (Ed.), Advances in Experimental Social Psychology: Vol. 21 (pp. 261-302). San Diego, CA: Academic Press.

Stern, P. C. (1976). Effects of incentives and education on resource conservation decisions in a simulated commons dilemma. Journal of Personality and Social Psychology, 34, 1285-1292.

Stern, P. C. (1992). Psychological dimensions of global environmental change. Annual Review of Psychology, 43, 269-302.

Stern, P. C., \& Aronson, E. (1984). Energy conservation: The human decision. New York: W. H. Freeman and Company.

Stern, P. C., Dietz, T., \& Kalof, L. (1993). Value orientations, gender, and environmental concern. Environment and Behavior, 25, 322-348.

Stokols, D., Novaco, R. W., Stokols, J., \& Campbell, J. (1978). Traffic congestion, Type A behavior, and stress. Journal of Applied Psychology, 63, 467480 .

Stroebe, W., \& Frey, B. S. (1982). Self-interest and collective action: The economics and psychology of public goods. British Journal of Social Psychology, $21,121-137$.

Suleiman, R., \& Rapoport, A. (1989). Environmental and social uncertainty in single-trial resource dilemmas. Acta Psychologica, 68, 99-112.

Swap, C. W., \& Rubin, J. Z. (1983). Measurement of interpersonal orientation. Journal of Personality and Social Psychology, 44, 208-219.

Tesser, A., \& Campbell, J. (1982). Self-evaluation maintenance and the perception of friends and strangers. Journal of Personality, 50, 261-279.

Thibaut, J. W., \& Kelley, H. H. (1959). The social psychology of groups. New York: Wiley.

Van Assema, P. T. (1993). The development, implementation, and evaluation of a community health project. Unpublished dissertation, University of Limburg, the Netherlands.

Van Dijk, E., \& Wilke, H. A. M. (1993). Differential interests, equity, and public good provision. Journal of Experimental Social Psychology, 29, 1-16.

Van Dijk, E., \& Wilke, H. A. M. (1995). Coordination rules in asymmetric social dilemmas: A comparison between public good dilemmas and resource dilemmas. Journal of Experimental Social Psychology, 31, 1-27.

Van Knippenberg, C., \& Van Knippenberg, A. (1986). Measurement of arrival times; a discussion of Mahmassani et al., 1985. Transportation Research Record, 1085, 47-49. 
Van Lange, P. A. M. (1991). Being better but not smarter than others: The Muhammad Ali effect at work in interpersonal situations. Personality and Social Psychology Bulletin, 17, 690-694.

Van Lange, P. A. M. (1992). Confidence in expectations: A test of the triangle hypothesis. European Journal of Personality, 6, 371-379.

Van Lange, P. A. M. (1995). Mobiliteit vanuit een sociaal dilemma perspectief: barrières en aambevelingen [Mobility from a social dilemma perspective: obstacles and suggestions]. Report for Dutch Ministry of Traffic and Waterways.

Van Lange, P. A. M., \& Agnew, C. R. (1995). How does social value orientation affect willingness to sacrifice in ongoing close relationships? Unpublished manuscript, Free University, Amsterdam.

Van Lange, P. A. M., \& Kuhlman, D. M. (1994). Social value orientations and impressions of partner's honesty and intelligence: A test of the might versus morality effect. Journal of Personality and Social Psychology, 67, 126-141.

Van Lange, P. A. M., \& Liebrand, W. B. G. (1991). Social value orientation and intelligence: A test of the Goal-Prescribes-Rationality Principle. European Journal of Social Psychology, 21, 273-292.

Van Lange, P. A. M., Liebrand, W. B. G., \& Kuhlman, D. M. (1990). Causal attribution of choice behavior in three $\mathrm{N}$-person prisoner's dilemmas. Journal of Experimental Social Psychology, 26, 34-48.

Van Lange, P. A. M., Liebrand, W. B. G., Messick, D. M., \& Wilke, H. A. M. (1992). Introduction and literature review. In W. B. G. Liebrand, D. M. Messick, \& H. A. M. Wilke (Eds.), Social dilemmas: Theoretical issues and research findings (pp. 3-28). Oxford: Pergamon Press.

Van Lange, P. A. M., \& Messick, D. M. (in press). Psychological processes underlying cooperation in social dilemmas. Praxiology: Annual review of practical philosophy and methodology.

Van Lange, P. A. M., Van Vugt, M., \& Van Veenendaal, A. F. M. (in press). Eigen gemak versus ons milieu: Mobiliteit als sociaal dilemma [Own convenience versus our environment: Mobility as social dilemma]. In C. Vlek, T. Rooijers, \& B. Verplanken (Eds.), Mobility and Transport.

Van Vugt, M., Meertens, R. M., \& Van Lange, P. A. M. (1993). De keuze voor de auto of het openbaar vervoer? Een interdependentie-theoretische benadering [Choosing between car or public transportation? An interdependence theoretical approach]. In B. Verplanken, P. Van Lange, R. Meertens, \& F. Siero (Eds.), Sociale psychologie en haar toepassingen: Vol. 7 (pp. 195-206). Delft, the Netherlands: Eburon.

Van Vugt, M., Meertens, R. M., \& Van Lange, P. A. M. (1994). Commuting by car or by public transportation: An interdependence theoretical analysis. In U. Schulz, W. Albers, \& U. Mueller (Eds.), Social dilemmas and cooperation (pp. 291-309). Berlin: Springer-Verlag. 
Van Vugt, M., Meertens, R. M., \& Van Lange, P. A. M. (1995). Car versus public transportation? The role of social value orientations in a real-life social dilemma. Journal of Applied Social Psychology, 25, 258-278.

Van Vugt, M., \& Samuelson, C. D. (1995). Social value orientations and social desirability. Unpublished manuscript, University of Limburg, the Netherlands.

Van Vugt, M., Van Lange, P. A. M., \& Meertens, R. M. (in press). Commuting by car or public transportation? A social dilemma analysis of travel mode judgements. European Journal of Social Psychology.

Van Vugt, M., Van Lange, P. A. M., \& Meertens, R. M., \& Van Breukelen, G. (1994). We willen de auto wel laten staan, mits... De sociaal-psychologische aspecten van de vervoerskeuzes van forensen [We certainly wish to abondon car use, provided that.... The social-psychological aspects of commuters' decisions]. In P. Van Lange, F. Siero, B. Verplanken, en E. Van Schie (Eds.), Sociale psychologie en haar toepassingen: Vol. 8 (pp. 201-212). Delft, the Netherlands: Eburon.

Van Vugt, M., Van Lange, P. A. M., Meertens, R. M., \& Joireman, J. A. (1995). Why structural solutions to social dilemmas may fail: A field experiment on the first carpool lane in Europe. Manuscript submitted for publication.

Verplanken, B., Aarts, H., Knippenberg, A. van, \& Knippenberg, C. van (1994). Attitude versus general habit: Antecedents of travel mode choice. Journal of Applied Social Psychology, 24, 285-300.

Vlek, C. A. J., \& Keren, G. (1992). Behavioral decision theory and environmental risk management: Assessment and resolution of four "survival" dilemmas. Acta Psychologica, 80, 249-278.

Vlek, C. A. J., \& Michon, J. A. (1992). Why we should and how we could decrease the use of motor vehicles in the near future. Journal of the International Association of Traffic and Safety Sciences, 15, 82-93.

Von Neumann, J., \& Morgenstern, O. (1947). Theory of games and economic behavior. Princeton, NJ: Princeton University Press.

Weenig, W. H., Schmidt, T., \& Midden, C. J. H. (1990). Social dimensions of neighborhoods and the effectiveness of information programs. Environment and Behavior, 22, 27-54.

Weiner, B. (1972). Theories of motivation: From mechanism to cognition. Chicago, IL: Rand McNally.

Weiner, B. (1980). A cognitive (attribution)-emotion-action model of motivated behavior: An analysis of judgments of help-giving. Journal of Personality and Social Psychology, 39, 186-200.

Wicklund, R. A., \& Brehm, J. W. (1976). Perspectives on cognitive dissonance. Hillsdale, $\mathrm{NJ}$ : Lawrence Erlbaum and Associates. 
Wit, A. P., \& Wilke, H. A. M. (1995). Omgevings- en sociale onzekerheid in sociale dilemma's [Environmental and social uncertainty in social dilemmas]. In N. De Vries, C. De Dreu, N. Ellemers, \& R. Vonk (Eds.), Fundamentele sociale psychologie: Vol. 9 (pp. 137-151). Tilburg, the Netherlands: Tilburg University press.

Wit, A. P., Wilke, H. A. M., \& Oppewal, H. (1992). Fairness in asymmetric social dilemmas. In W. B. G. Liebrand, D. M. Messick, \& H. A. M. Wilke (Eds.), Social dilemmas: Theoretical issues and research findings (pp. 183-197). Oxford: Pergamon Press.

Wood, J. V. (1989). Theory and research concerning social comparisons of personal attributes. Psychological Bulletin, 106, 231-248.

Wood, J. V., \& Taylor, K. L. (1991). Serving self-relevant goals through social comparison. In J. M. Suls \& T. A. Wills (Eds.), Social comparison: Contemporary theory and research (pp. 23-49). Hillsdale, NJ: Erlbaum.

Wyer, R. S. (1969). Prediction of behavior in two-person games. Journal of Personality and Social Psychology, 13, 222-238.

Yamagishi, T. (1986). The structural goal/expectation theory of cooperation in social dilemmas. In E. Lawler (Ed.), Advances in Group Processes, 3, 51-87.

Yamagishi, T. (1988). The provision of a sanctioning system in the United States and Japan. Social Psychology Quarterly, 51, 264-270.

Yamagishi, T. (1992). Group size and the provision of a sanctioning system in a social dilemma. In W. B. G. Liebrand, D. M. Messick, \& H. A. M. Wilke (Eds.), Social dilemmas: Theoretical issues and research findings (pp. 267-287). Oxford: Pergamon Press.

Yamagishi, T., \& Sato, K. (1986). Motivational bases of the public goods problem. Journal of Personality and Social Psychology, 50, 67-73. 



\section{Appendices}




\section{Appendix I \\ Description of commuting situation}

Please note that the original transcript is in Dutch, and that this version was used in Experiment 3 (see Chapter 4), with pollution and travel time being between-subjects factors (i.e., each research participant received information about one of the congestion and pollution conditions), and variability a within-subject factor (i.e., each participant received information about all variability conditions). The descriptions that were used in Experiments 1, 2, and 4 were quite similar (for specific details, see Chapters 2, 3, and 5, respectively).

\section{Introduction}

Imagine that, within ten years from now, you find yourself in the following commuting situation. You are living in a suburb of a middle-sized city in the Netherlands. The company you are working for is located 40 kilometers from your house. This distance can be covered by taking your car or public transportation. There is a train station within a three-minute walk of your house. From there the train takes you to a station located within a two-minute walk of the company. Alternatively, near your home is the onramp to the highway that leads directly to your work. Every working day you commute to work, and every day you have to make a decision whether to commute by car or public transportation. All other employees of the company face the same decision situation, and use the same route either by car or train. They also have to decide between commuting by car or public transportation. Your decision, as well as those of other commuters, have consequences for both the travel time and level of environmental pollution.

\section{Pollution}

Within ten years from now the environment will be in a very bad condition. At that time, scientists have determined that the hole in the ozone layer has grown, and that the earth temperature has risen due to the greenhouse effect. Moreover, in many places around the world there is serious smog pollution and acid rain, which contribute to the extinction of the forests, and may possibly form a threat to public health.

\section{Small Impact-condition}

Private car use is hardly responsible for the environmental problems. The use of catalytic converters for cars and other environment-preserving measures have substantially reduced the negative impact of cars on the environment. Also, public transportation has hardly any impact on the level of environmental pollution.

\section{Large Impact-condition}

Private car use is one of the main polluters of the environment. Despite the introduction of catalytic converters for the car and other environment preserving measures our environment is still severely affected by cars. In contrast, public transportation has hardly any impact on the level of environmental pollution. 


\section{Travel Time}

The average travel times associated with commuting by car or public transportation differ.

\section{Time by Public Transportation Longer-condition}

It always takes you longer to commute by public transportation than by car. On average, the travel time by public transportation will be 60 minutes (including a three and two minute walk), whereas by car it will be 40 minutes.

\section{Time by Public Transportation Shorter-condition}

It always takes you less time to commute by public transportation than by car. On average, the travel time by public transportation will be 40 minutes (including a three and two minute walk), whereas by car it will be 60 minutes.

\section{Travel Time Variability}

Public Transportation Smaller Variability-condition (i.e., when travel time by public transportation is shorter)

Public transportation offers quite a stable travel time. When commuting by public transportation your travel time will vary between 38 and 42 minutes. In contrast, the travel time by car is quite unstable, varying between 44 and 76 minutes. That means that on one day it may take you 60 minutes to go to work by car, another day perhaps 44 minutes, whereas another day it may take 76 minutes. The precise travel times by car or public transportation are dependent on a great variety of factors. In practice, it is very hard to predict exactly how long it will take to get to work. Nevertheless, it has been consistently found that the variability in travel time commuting by public transportation is much smaller than by car.

\section{Public Transportation Greater Variability-condition}

The car provides quite a stable travel time. When commuting by car your travel time will vary between 58 and 62 minutes. In contrast, the travel time by public transportation is quite unstable, varying between 24 and 56 minutes. That means that on one day it may take you 40 minutes to go to work by public transportation, another day perhaps 24 minutes, whereas another day it may take 56 minutes. The precise travel times by car or public transportation are dependent on a great variety of factors. In practice, it is very hard to predict exactly how long it will take to get to work. Nevertheless, it has been consistently found that the variability in travel time commuting by public transportation is much greater than by car.

\section{Public Transportation Equal Variability-condition}

Commuting by car and public transportation the travel times may vary somewhat. When commuting by car your travel time will vary between 51 and 69 minutes. The travel time by public transportation may also vary somewhat, between 31 and 49 minutes. The precise travel times by car or public transportation are dependent on a great variety of factors. In practice, it is very hard to predict exactly how long it will take to get to work. Nevertheless, it has been consistently found that the variability in travel time commuting by public transportation or by car is quite similar. 
To summarize:

(a) In contrast to public transportation, cars mildly/severely pollute the environment;

(b) The travel time by public transportation is longer (60 minutes)/shorter (40 minutes) than by car (40 minutes/ 60 minutes);

(c) The variability in travel time by public transportation is much smaller (38-42 minutes)/greater (24-56 minutes)/equal (31-49 minutes) relative to car (44-76 minutes/38-42 minutes/51-69 minutes).

It is a weekday morning. At about 8:30 AM you want to arrive at work. Please decide whether you want to commute by car or public transportation. 


\section{Appendix II \\ Measurement of social value orientation \\ by three-choice decomposed games method}

Please note that there are several different versions of this measurement, which vary in terms of (a) whether the outcomes are defined in points or money, and (b) whether they emphasize or de-emphasize interdependence between the focal person and other person. In the current research we used the low interdependence-version, and the outcomes were depicted in money. More generally, it should be noted that the measurement was administered before research participants got any specific instructions regarding the research content and commuting situation. In most of our experiments the task was introduced rather vaguely, as a "decision task involving sums of money" (see Chapters 4,5 , and 6).

\section{Introduction}

Imagine that you have to choose between a series of monetary outcomes for yourself and someone else, referred to as Other. You will never knowingly meet this person, or will s/he ever knowingly meet you. Your choices determine the amount of money you receive and the amount of money the other person receives. At the same time the other person will also make choices in this task. Accordingly, his or her choices also determine the amount of money you receive and the amount of money he or she receives. Below we provide an example of the choice options:

\section{Example:}

You get

Other gets

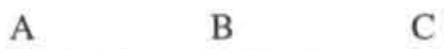

$\begin{array}{lll}5,00 \mathrm{Dfl} & 5,00 \mathrm{Dfl} & 5,50 \mathrm{Dfl} \\ 1,00 \mathrm{Dfl} & 5,00 \mathrm{Dfl} & 3,00 \mathrm{Dfl}\end{array}$

In this example, if you choose A you would receive 5 Dutch florins and the Other would receive $1 \mathrm{Dfl}$; if you choose $B$, you and the Other would both receive $5 \mathrm{Dfl}$; and, if you choose C, you would receive 5,50 Dfl and the Other 3,00 Dfl. So, your decision affects the outcomes of yourself and the Other. Similarly, Other's decision influences his or her own outcomes and those of you.

In total, you are asked to make nine decisions. Please keep in mind that there are no right or wrong answers. Choose the option that you prefer most. 
(1)

You get

Other gets

(2)

You get

Other gets

(3)

You get

Other gets

(4)

You get

Other gets

(5)

You get

Other gets

(6)

You get

Other gets

(7)

You get

Other gets

(8)

You get

Other gets

(9)

You get

Other gets
A B $\quad$ C

$4,80 \mathrm{Dfl} \quad 5,40 \mathrm{Dfl} \quad 4,80 \mathrm{Dfl}$

0,80 Dfl 2,80 Dfl $\quad 4,80$ Dfl

A $\quad$ B $\quad$ C

$5,60 \mathrm{Dfl} \quad 5,00 \mathrm{Dfl} \quad 5,00 \mathrm{Dfl}$

$3,00 \mathrm{Dfl} \quad 5,00 \mathrm{Dfl} \quad 1,00 \mathrm{Dfl}$

A $\quad$ B $\quad$ C

$5,20 \mathrm{Dfl} \quad 5,20 \mathrm{Dfl} \quad 5,80 \mathrm{Dfl}$

$5,20 \mathrm{Dfl} \quad 1,20 \mathrm{Dfl} \quad 3,20 \mathrm{Dfl}$

A $\quad$ B $\quad$ C

$5,00 \mathrm{Dfl} \quad 5,60 \mathrm{Dfl} \quad 4,90 \mathrm{Dfl}$

1,00 Dfl 3,00 Dfl 4,90 Dfl

A $\quad$ B $\quad$ C

$5,60 \mathrm{Dfl} \quad 5,00 \mathrm{Dfl} \quad 4,90 \mathrm{Dfl}$

$3,00 \mathrm{Dfl} \quad 5,00 \mathrm{Dfl} \quad 0,90 \mathrm{Dfl}$

A $\quad$ B $\quad$ C

$5,00 \mathrm{Dfl} \quad 5,00 \mathrm{Dfl} \quad 5,70 \mathrm{Dfl}$

$5,00 \mathrm{Dfl} \quad 1,00 \mathrm{Dfl} \quad 3,00 \mathrm{Dfl}$

A $\quad$ B $\quad$ C

$5,10 \mathrm{Dfl} \quad 5,60 \mathrm{Dfl} \quad 5,10 \mathrm{Dfl}$

$5,10 \mathrm{Dfl} \quad 3,00 \mathrm{Dfl} \quad 1,10 \mathrm{Dfl}$

A $\quad$ B $\quad$ C

$5,50 \mathrm{Dfl} \quad 5,00 \mathrm{Dfl} \quad 5,00 \mathrm{Dfl}$

$3,00 \mathrm{Dfl} \quad 1,00 \mathrm{Dfl} \quad 5,00 \mathrm{Dfl}$

A B C

$4,80 \mathrm{Dfl} \quad 4,90 \mathrm{Dfl} \quad 5,40 \mathrm{Dfl}$

$1,00 \mathrm{Dfl} \quad 4,90 \mathrm{Dfl} \quad 3,00 \mathrm{Dfl}$

Note (not for participants).

The coding of the choices is as follows: pro-social orientation: 1C $2 \mathrm{~B} 3 \mathrm{~A} 4 \mathrm{C} 5 \mathrm{~B}$ $6 \mathrm{~A} 7 \mathrm{~A} 8 \mathrm{C}$ 9B; individualistic orientation: 1B $2 \mathrm{~A} 3 \mathrm{C} 4 \mathrm{~B} 5 \mathrm{~A} \quad 6 \mathrm{C} 7 \mathrm{~B} 8 \mathrm{~A} 9 \mathrm{C}$; competitive orientation: 1 A 2 C 3B 4A 5C 6B 7C 8 B 9A). People are classified if at least six out of nine decisions is consistent with either one of these orientations. 


\section{Curriculum Vitae}

Mark van Vugt werd geboren in Amsterdam op 9 mei 1967. Na zijn middelbare schoolperiode in Hengelo, Overijssel (Bataafse kamp; Gymnasium alfa) ging hij in 1986 psychologie studeren aan de Rijksuniversiteit Groningen. In 1991 studeerde hij af in de Sociale Psychologie en Organisatiepsychologie. Daarna werkte hij van september 1991 tot september 1995 als assistent-in-opleiding bij de vakgroep Gezondheidsvoorlichting van de Rijksuniversiteit Limburg. In die periode schreef hij zijn proefschrift over sociale dilemmas en vervoermiddelkeuzes. Vanaf oktober 1995 is hij werkzaam als universitair docent bij de vakgroep Psychologie van de Universiteit van Southampton, Verenigd Koninkrijk.

Mark Van Vugt was born in Amsterdam, the Netherlands, on May 9 1967. After finishing high school in Hengelo (Bataafse kamp; Gymnasium alpha), he studied psychology at the University of Groningen in the period 1986-1991, where he graduated in Social and Organizational Psychology. From September 1991 until September 1995 he worked on his $\mathrm{PhD}$ project concerning social dilemmas and transportation decisions at the Department of Health Education. University of Limburg. From October 1995 he is working as a lecturer in the Department of Psychology at the University of Southampton, United Kingdom. 